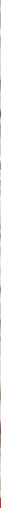

\title{
IntechOpen
}

\section{Forest Degradation Around the World}

Edited by Mohd Nazip Suratman, Zulkiflee Abd Latif, Gabriel De Oliveira, Nathaniel Brunsell, Yosio Shimabukuro and Carlos Antonio Costa Dos Santos
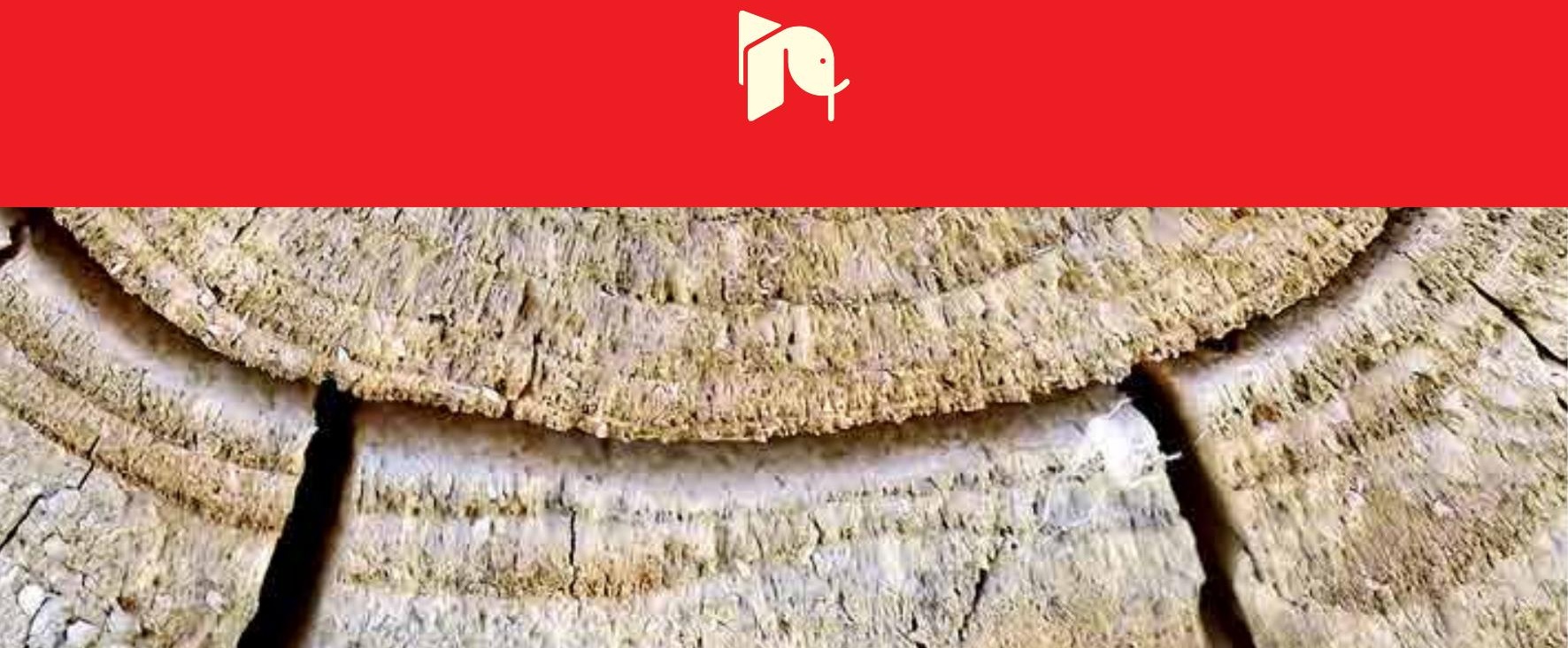



\section{Forest Degradation Around the World}

Edited by Mohd Nazip Suratman, Zulkiflee Abd Latif, Gabriel De Oliveira, Nathaniel

Brunsell, Yosio Shimabukuro and Carlos

Antonio Costa Dos Santos 

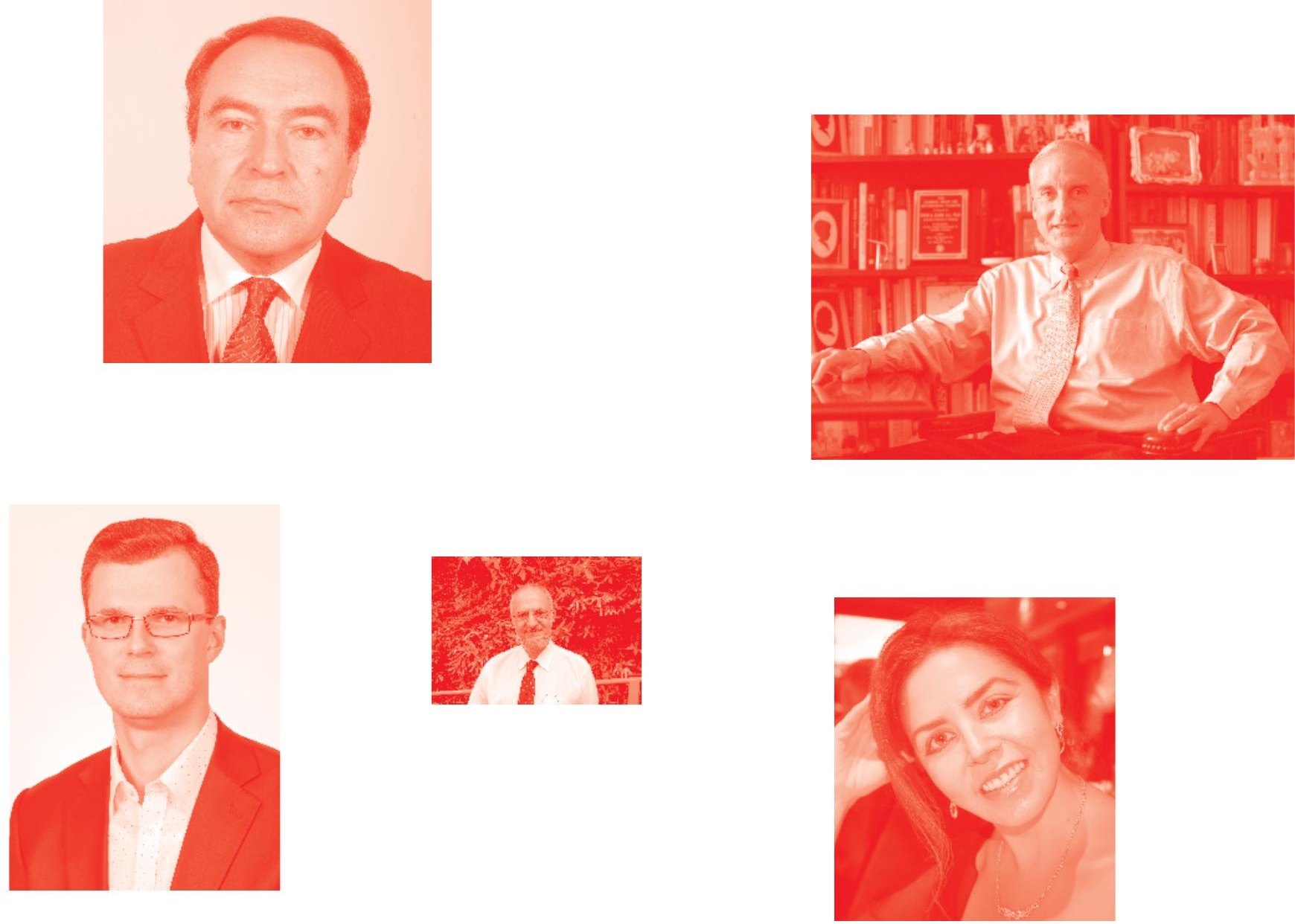

Supporting open minds since 2005
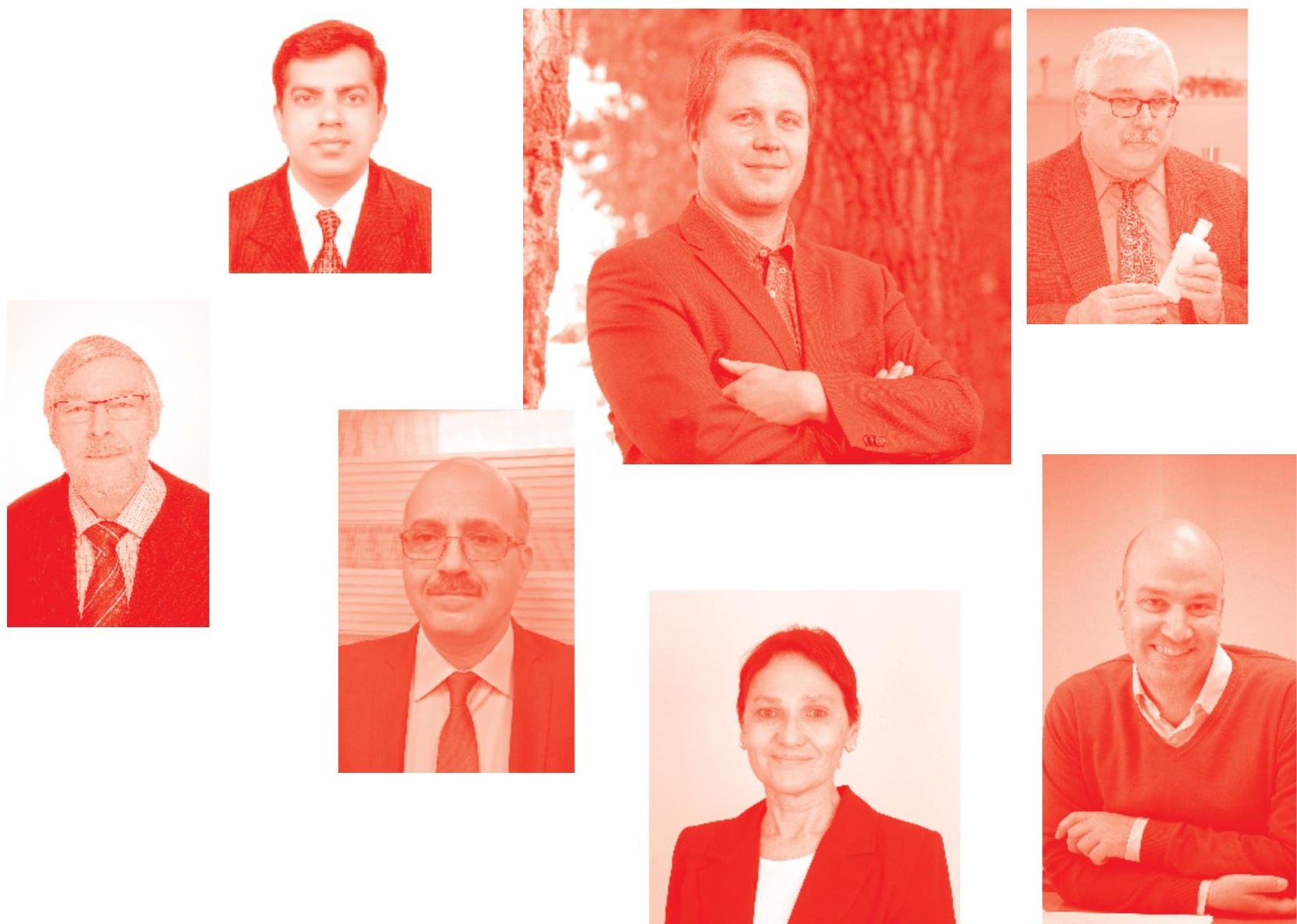
Forest Degradation Around the World

http: //dx. doi.org/10.5772/intechopen. 77433

Edited by Mohd Nazip Suratman, Zulkiflee Abd Latif, Gabriel De Oliveira, Nathaniel Brunsell, Yosio Shimabukuro and Carlos Antonio Costa Dos Santos

\section{Contributors}

Eduarda Silveira, Fausto Weimar Acerbi Junior, Marcela De Castro Nunes Santos Terra, Ahm Reza, Md. Kamrul Hasan, Edersson Cabrera, Alvaro Duque, Rima Kumari, Ayan Banerjee, Purabi Saikia, Amit Kumar, Mohammed Latif Khan, Rahul Kumar, Chang Seok Lee, Bong Soon Lim, A Reum Kim, Songhie Jung, Chi Hong Lim, Hansol Lee, Amadou K. Dit Amobo Waïgalo, MOHD NAZIP SURATMAN, Gabriel De Oliveira

( ) The Editor(s) and the Author(s) 2020

The rights of the editor(s) and the author(s) have been asserted in accordance with the Copyright, Designs and Patents Act 1988. All rights to the book as a whole are reserved by INTECHOPEN LIMITED . The book as a whole (compilation) cannot be reproduced, distributed or used for commercial or non-commercial purposes without INTECHOPEN LIMITED's written permission. Enquiries concerning the use of the book should be directed to INTECHOPEN LIMITED rights and permissions department (permissions@intechopen.com).

Violations are liable to prosecution under the governing Copyright Law .

\section{(cc) BY}

Individual chapters of this publication are distributed under the terms of the Creative Commons Attribution 3. 0 Unported License which permits commercial use, distribution and reproduction of the individual chapters, provided the original author(s) and source publication are appropriately acknowledged. If so indicated, certain images may not be included under the Creative Commons license. In such cases users will need to obtain permission from the license holder to reproduce the material. More details and guidelines concerning content reuse and adaptation can be found at http : //www . intechopen . com/copyright-policy . html .

\section{Notice}

Statements and opinions expressed in the chapters are these of the individual contributors and not necessarily those of the editors or publisher. No responsibility is accepted for the accuracy of information contained in the published chapters. The publisher assumes no responsibility for any damage or injury to persons or property arising out of the use of any materials, instructions, methods or ideas contained in the book.

First published in London, United Kingdom, 2020 by IntechOpen

IntechOpen is the global imprint of INTECHOPEN LIMITED, registered in England and Wales, registration number: 11086078,7 th floor, 10 Lower Thames Street, London,

EC3R 6AF, United Kingdom

Printed in Croatia

British Library Cataloguing-in-Publication Data

A catalogue record for this book is available from the British Library

Additional hard and PDF copies can be obtained from orders@intechopen.com

Forest Degradation Around the World

Edited by Mohd Nazip Suratman, Zulkiflee Abd Latif, Gabriel De Oliveira, Nathaniel Brunsell, Yosio

Shimabukuro and Carlos Antonio Costa Dos Santos

p. $\mathrm{cm}$.

Print ISBN 978-1-78923-833-4

Online ISBN 978-1-78923-834-1

eBook (PDF) ISBN 978-1-83880-315-5 


\section{We are IntechOpen, \\ the world's leading publisher of Open Access books}

\section{Built by scientists, for scientists}

\section{$4,600+$}

Open access books available

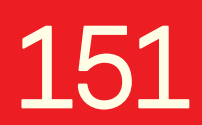

Countries delivered to

\section{$120,000+$}

International authors and editors

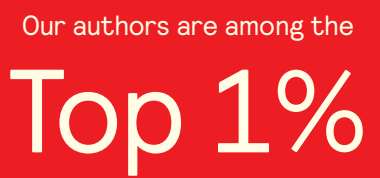

most cited scientists

Contributors from top 500 universities
$135 \mathrm{M}+$

Downloads
$12.2 \%$

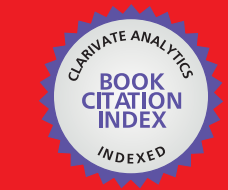

WEB OF SCIENCE ${ }^{\text {M }}$

Selection of our books indexed in the Book Citation Index in Web of Science ${ }^{\mathrm{TM}}$ Core Collection (BKCI)

\section{Interested in publishing with us? \\ Contact book.department@intechopen.com}

Numbers displayed above are based on latest data collected.

For more information visit www.intechopen.com 



\section{Meet the editors}

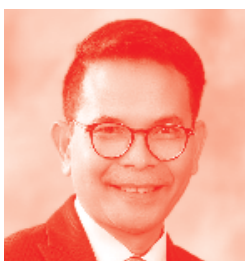

Mohd Nazip Suratman is a Professor of forestry and the Head of the Centre for Biodiversity and Sustainable Development, Universiti Teknologi MARA (UiTM), Malaysia. He holds a B Sc (Forestry) degree from the Universiti Putra Malaysia (UPM) and an MSc degree from the University of Nebraska-Lincoln (UNL), USA. He obtained his PhD degree from the University of British Columbia (UBC), Canada, and specialised in forest resources management. Currently, much of his research work is focused on forest modelling, applied remote sensing and biodiversity. Throughout his academic career, he has attained many national and international research grants and carried out a number of research projects that led to publications in leading journals, books and chapters in books. He is currently the Deputy Vice-Chancellor for Research and Innovation of Universti Teknologi MARA (UiTM), Malaysia. Contact: nazip@uitm.edu.my.

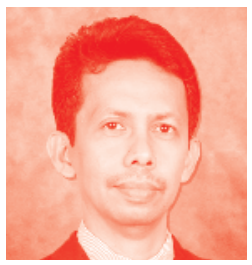

Zulkiflee Abd Latif is a Professor of geomatics (remote sensing \& GIS) and the Head of Applied Remote Sensing and Geospatial Research Group, Universiti Teknologi MARA (UiTM), Malaysia. He holds a Bachelor of Geomatics degree from the University of Melbourne, Australia and MSc degree of remote sensing \& GIS from the Universiti Putra Malaysia (UPM). He obtained his PhD from Lancaster University, United Kingdom (UK), and specialised in forestry remote sensing. He specialises in remote sensing, GIS and soft computing techniques in forestry, natural hazard, health and environmental problems. He has more than 20 years of teaching, research and industrial experience and has published over 100 research articles in high impact journals, proceedings, chapters in book and a book. Currently, he is the Fellow of Royal Institute of Surveyors, Malaysia (RISM). Contact: zulki721@uitm.edu.my.

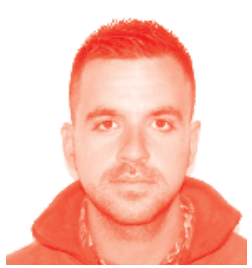

Dr Gabriel de Oliveira has a background in geography from the Federal University of Rio Grande do Sul (UFRGS) (Brazil) with an $\mathrm{MSc}$ and $\mathrm{PhD}$ in remote sensing from the National Institute for Space Research (INPE) (Brazil). He is currently a Postdoctoral Researcher and Lecturer in the Department of Geography and Atmospheric Science at the University of Kansas (USA). His main research interests are: biosphere-atmosphere interactions, spatial-temporal analysis, eddy covariance, remote sensing, terrestrial ecosystems, land use/land cover changes, grasslands, perennial agroecosystems, tropical forests and the Amazon region. 


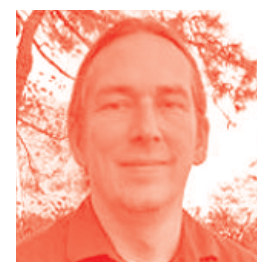

Dr Nathaniel A. Brunsell has a background in earth and planetary sciences from the University of New Mexico (USA) with a PhD in biometeorology from Utah State University (USA). Dr Brunsell is a Professor in the Department of Geography and Atmospheric Science at the University of Kansas. He is a biometeorologist by training with extensive experience in land-atmosphere interactions, the impacts of land use/land cover change on water and carbon cycling and the role of spatial and temporal heterogeneity on influencing these exchange processes.

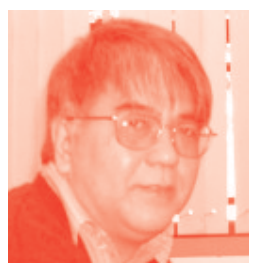

Dr Yosio E. Shimabukuro has a background in forest engineering from the Federal University of Rio de Janeiro (Brazil) with a $\mathrm{PhD}$ in forest sciences/remote sensing from Colorado State University (USA). He is currently a Senior Scientist at the National Institute for Space Research (INPE) (Brazil). His main research interests are: linear mixing model, Landsat images, shade fraction image, reforested areas, mathematical modelling and the carbon balance in Amazon forests.

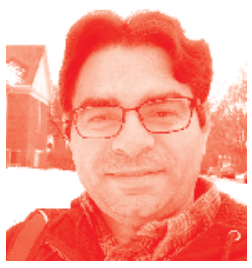

Dr Carlos A. C. dos Santos has a background in physics from the Paraiba State University (UEPB) (Brazil) with an MSc and PhD in meteorology from the Federal University of Campina Grande (UFCG) (Brazil) in partnership with the Utah State University (USA). He is an Associate Professor at Department of Atmospheric Sciences, UFCG, Brazil. His research fields are: land-atmosphere interactions, climatology, micrometeorology, radiation and application of remote sensing algorithms in agricultural and forest areas. 


\section{Contents}

Preface

Section 1

Deforestation Around the World

Chapter 1

Introductory Chapter: Managing World's Forests for Sustainable

Development

by Mohd Nazip Suratman and Zulkiflee Abd Latif

Chapter 2

Forest Biodiversity and Deforestation in Bangladesh: The Latest Update by Ahm Ali Reza and Md. Kamrul Hasan

Chapter 3

Colombian Forest Monitoring System: Assessing Deforestation in an

Environmental Complex Country

by Edersson Cabrera, Gustavo Galindo, Jose González, Lina Vergara,

Cristhian Forero, Alexander Cubillos, Javier Espejo, Juan Rubiano,

Xavier Corredor, Leonardo Hurtado, Diana Vargas and Alvaro Duque

Chapter 4

Deforestation in India: Consequences and Sustainable Solutions by Rima Kumari, Ayan Banerjee, Rahul Kumar, Amit Kumar, Purabi Saikia and Mohammed Latif Khan

Chapter 5

Forest Decline Under Progress in the Urban Forest of Seoul, Central Korea by Chang Seok Lee, Songhie Jung, Bong Soon Lim, A Reum Kim, Chi Hong Lim and Hansol Lee

\section{Section 2}

Forest Degradation and its Issues in the Tropics

Chapter 6

Prologue: Sustainable Development, Economic Growth and the Fate of Tropical Forests

by Gabriel de Oliveira, Nathaniel A. Brunsell, Yosio E. Shimabukuro and Carlos A.C. dos Santos 
Estimating Aboveground Biomass Loss from Deforestation in the Savanna and Semi-arid Biomes of Brazil between 2007 and 2017

by Eduarda Martiniano de Oliveira Silveira, Marcela Castro Nunes Santos Terra, Fausto Weimar Acerbi-Júnior and José Roberto Soares Scolforo

Chapter 8

Economic Impacts of the Anthropic Effects of the Deforestation on the Rural Populations of Mali

by Amadou K. dit Amobo Wä̈galo 


\section{Preface}

Forests are crucial to the well-being of humanity. They provide foundations for life on Earth through ecological functions, by regulating the climate and water resources, and by serving as habitats for plants and animals. Forests also provide a wide range of essential resources such as wood, food and medicines; in addition to providing opportunities for recreation, spiritual renewal and other activities. Nowadays, forests are under pressure from expanding human populations, which frequently leads to the conversion of forests into unsustainable forms of land use. When forests are lost or severely damaged, their capacity to function as regulators of the environment is also lost, increasing flood and erosion hazards, reducing soil fertility, and contributing to the loss of plant and animal life. The importance of forests in influencing global climate due to their role in the carbon cycle is increasingly recognized. Deforestation has dramatically affected the human populations living in or dependent on the forests. Despite global consequences, deforestation presents at local and regional levels.

We are delighted to write the preface for the second book published by IntechOpen entitled Deforestation around the World. The first book National Park: Management and Conservation edited by M. N. Suratman was well received and has been through several printings. Now two years later, we have carefully edited a book that contains eight chapters that reflect negative impacts of deforestation on the planet's atmosphere. Each chapter contains evidence-based background information and identifies regions at risk for catastrophic deforestation. Chapter 1 sets the scene of the book by elaborating on the crucial roles of forest, and the current extent of forest degradation around the world. Specifically, this chapter provides an overview of the complexity of Malaysia's tropical rainforests in terms of their current extent and formation and the threats to biodiversity. The chapter concludes that sustainable forest management can be achieved by strengthening governments' efforts at all levels for the full implementation of the National Forestry Policy, especially through increased allocations of human and technical resources and financial aid. The second chapter discusses the continuous threats to major vertebrate animals in Bangladesh due to deforestation and degradation of habitat caused by various anthropogenic activities. The third chapter presents the SMByC, a system that integrates tools for the pre-processing and semi-automated processing of satellite imagery to detect and quantify the loss of forest cover by deforestation in Colombia. Chapter 4 highlights the main reasons for the reduction in forest cover in India, which include shifting cultivation, rotational felling, other biotic pressures and diversion of forest lands for developmental activities. Forest decline under progress in the urban forest in Seoul, Korea is discussed in Chapter 5. After the prologue, the seventh chapter addresses the loss of above-ground biomass across savanna and semi-arid woodland in the state of Minas Gerais, southeast of Brazil, which encompasses landscape variations ranging from savanna and Atlantic forest to semiarid woodlands. Lastly, the eighth chapter discusses deforestation issues around the rural areas of Mali, which mainly occur due to the demand for firewood as a result of population growth. 
It is our hope and expectation that this book will provide a resource for all readers and stakeholders on the need for effective management of the world's forest for sustainable development.

Mohd Nazip Suratman and Zulkiflee Abd Latif Universiti Teknologi MARA, Malaysia

Gabriel de Oliveira and Nathaniel Brunsell

University of Kansas, USA

Yosio Shimabukuro

National Institute for Space Research (INPE),

Brazil

Carlos Antonio Costa Dos Santos

Federal University of Campina Grande,

UFCG,

Brazil 
Section 1

\section{Deforestation Around the World}





\title{
Introductory Chapter: Managing World's Forests for Sustainable Development
}

\author{
Mohd Nazip Suratman and Zulkiflee Abd Latif
}

\section{Introduction}

Forests are important biological resources as they provide habitat for many of the world's species [1]. Forests also provide timber and non-timber forest products such as bamboo and rattan and food ranging from fruits, mushrooms, honey, and a wide variety of traditional medicines that are critical for human survival [2]. Furthermore, they are key component of many species' habitats, providing nourishment, shelter, and structural features needed for communication, surveillance, and other activities [3]. They also provide significant ecosystem services in terms of nutrients, water cycling, prevention of erosion, sequestration of carbon as well as performing of range of other physical and biological functions. Forests are the main filters in the earth since there are many pollutions from human activities such as industry and motor transportation are disposed, i.e., carbon dioxide $\left(\mathrm{CO}_{2}\right)$, water $\left(\mathrm{H}_{2} \mathrm{O}\right)$, nitrogen $(\mathrm{N})$, nitrogen dioxide $\left(\mathrm{NO}_{2}\right)$, and sulfur dioxide $\left(\mathrm{SO}_{2}\right)$ (National Research Council U.S., 1972). These pollutants can be filtered by plants for its life cycle, thereby reducing pollution at the atmosphere, although $\mathrm{CO}_{2}$ and $\mathrm{H}_{2} \mathrm{O}$ become main material for their photosynthesis [4]. Results from photosynthesis of plants are the main energy resources for all animal life including human. It is a substantial ecosystem service in terms of providing nutrients, water recycling, prevention of erosion, and carbon storage in the terrestrial ecosystem as well as sequestering $\mathrm{CO}_{2}$ in the atmosphere [5-8].

\section{Forest degradation around the world}

The growth in human population has forced mankind to explore existing resources, including forest for multiple purposes [9], for instance, logging of timber for wood-based industries, agricultural activities, urban areas, road, and mining. All these practices are done at different stages of forest growth which give significant impacts on the stand structure, composition, and other components of the forest and will consequently reduce forest productivity and their ecosystem functions [10]. During early civilizations, forest occupied about half of the earth's surface. However, it has, at the moment, reduced into less than one-third of the total earth's surface. The significant reduction of the forest areas requires appropriate planning and management for the conservation [8], especially forest in the tropical and subtropical areas in the developing nations. Today, the degradation of the forest due to anthropogenic activities and natural disturbances is significantly reducing total forest areas in the world. Originally, tropical forest covered about 1.5-1.8 billion ha 
of the land surface $[6,11]$. Unfortunately, one-third of these original forests have been lost because of deforestation, resulting into large degraded areas. To date, the degraded areas are common in many countries, most of which are converted into other land uses, although some of them will regenerate into secondary forests [12]. Currently, the secondary forest can be found in all areas in the world and it is estimated to reach about $64 \%$ of the total world forest [13].

The decrease of world's forest is caused by many activities such as clearing to open land for agriculture, roads, settlement, logging for timber, and cutting for fuel. Indirectly, forest is succumbing to the effect of environmental pollution and further threat by climatic change. Together, these causes have been responsible for decimating many of the world's forest, and they threaten to significantly degrade those that remain. Moreover, the burning of trees, shrubs, and other vegetation during land clearing and after logging further contributes to environmental deterioration [14].

\section{The role of natural regeneration}

Sapling regeneration is important to restore forest formation after disturbance, balancing the loss of primary forest and as a main sequester of $\mathrm{CO}_{2}$. Their radial growth characteristics are the main performer of canopy closure, and it can be used to identify the canopy formation in the secondary forest after disturbances. Moreover, the canopy closure can be used to predict the vertical structure in the future; therefore, it will explain the pressure that will be given by dominant species in the later succession.

The continuing loss of primary tropical forest has made the secondary forest to be increasingly important for maintaining the ecology across the large forested landscapes [15]. The regeneration in the tropical secondary forest is strongly influenced by disturbances that resulted from natural tree fall in primary forest $[15,16]$. Regeneration is widely recognized as being a key process in determining the structure and dynamism of tropical secondary forest [17]. For instance, the logging of mature trees can reduce seed resource in the forest [9]. Nevertheless, it may increase the light intensity, which reaches the forest floor and will stimulate the seeds' germination and growth of saplings. The ability of regeneration in the degraded areas is determined by the success of the seedlings and saplings to grow [18].

The success of forest regeneration in terms of its distribution and diversity can be used as parameters to understand the level of forest succession and to figure out the population dynamic condition in the areas that have been controlled [18]. A lot of efforts have been made to study forest regeneration to provide information on ecological condition [18-20]; however, the data which have been collected cannot solve the same problem in different areas in the world. This is because every area in the world has different conditions which make it possible to create the different microclimate after fragmentation, and then influence the recovery process. The change of microclimate because of forest fragmentation will influence the plant species survival. Therefore, only species that can adapt to the environmental change will survive as different species have different capabilities to response to the ecological pressure. Furthermore, there are crucial chemical elements in the soil that have been recognized for growth of all plants [21], and the loss one of these elements will influence the plant growth, especially macronutrient. Besides the chemical elements, forest regeneration is influenced by light intensity which reaches under the canopy. The increasing of light intensity which reaches under the canopy will 
stimulate the amount of photosynthesis that directly accelerates regeneration for the light demanding plant [12].

\section{Carbon sequestration in forests}

Rapid development of industrial technologies in the world has contributed to the increment of greenhouse gases. The increase of greenhouse gases, such as $\mathrm{CO}_{2}$ in the atmospheres, has led to global warming phenomenon. Nowadays, rise of global temperatures has constituted a challenge to the mankind. The increment of $\mathrm{CO}_{2}$ today is estimated to be 1.3-1.9 $\mathrm{ppm} \mathrm{year}^{-1}$ [22]. According to [23], from the analysis recorded in Malaysia, the average of temperatures has increased by $1.1^{\circ} \mathrm{C}$ within 50 years, which is consistent with the trend on global warming.

In reality, trees have important function in the carbon sequestration process [24-26]. In this case, the conservation of plant resources in a sustainable manner is the best solution. Forests play important roles in the $\mathrm{CO}_{2}$ sequestration process. Trees in the forests are important in order to perform the canopy closure in the forest and then influence the other species. Several studies have shown that the light intensity in the understory affects the growth and crown morphology of several tree species $[17,21,27]$ and soil properties at allocation of plant biomass [28-31]. Additionally, the effect of soil properties and light intensity has been known to correlate with growth rate, and distribution pattern as well as species composition. In reality, each species has different capability to respond to their environmental factors.

In the tropical rainforests, nutrient cycling is probably one of the most significant ecological processes [32]. Similarly, according to Hamzah et al. [33], tropical rainforests are recognized as the richest ecosystems in the world in terms of structures, species diversity, and ability to maintain the global climate change by reducing the accumulation of greenhouse gases. According to Sands [34], tropical rainforests contain $70 \%$ of the world's plants and animals, $70 \%$ of the world's vascular plants, $30 \%$ of all birds, and more than $90 \%$ of all the invertebrates. There can be more than 200 tree species per hectare in tropical rainforest.

\section{Tropical rainforests: Malaysia's perspective}

The tropical rainforest in Malaysia is one of the most diverse, complex, and productive terrestrial ecosystems in the world. The climate of Malaysia is typically humid tropical and is characterized by year-round high temperatures and seasonal heavy rain. As a result of these climatic conditions, the predominant natural vegetation is tropical rain forest whereby the main forest types being lowland then hill dipterocarp forest, peat swamp forest, freshwater swamp forest, and mangrove forest [35]. Malaysia has a total land area of 32.86 million ha. Of the total land area, 20.46 million ha are forest areas in which Peninsular Malaysia, Sarawak, and Sabah cover 28,45 , and $27 \%$ of the total forest areas, respectively [13]. It was estimated that Malaysia forests in Peninsular and Borneo are about 2830 and 9000-15,000 tree species, respectively $[36,37]$.

\subsection{Species composition}

Malaysian tropical rainforest is a productive forest which consists of various valuable timbers from the family of dipterocarpaceae and non-dipterocarpaceae. The name "dipterocarp" comes from the Greek for "two-winged seed." The 
dipterocarp species are from the family dipterocarpaceae and are the giants of the South-East Asian forests as well as the dominant family in them. Dipterocarp trees dominate forests in Borneo, Sumatra, Java, Peninsular Malaysia, and the wet parts of Philippines. The largest genera are Shorea (196 species), Hopea (104 species), Dipterocarpus (70 species), and Vatica (65 species). Other common genera namely Dryobalanops, Neobalanocarpus, Parashorea, Cotylelobium, and Anisoptera are also important part of tree communities of tropical rainforests. It is common to find 25 or more species of Shorea, and six or more species of the other three genera in the forest of Peninsular Malaysia, Borneo, and Sumatra. Dipterocarp trees have excellent timber qualities, and they are marketed internationally as plywood and as sawn timber [38].

Non-dipterocarps consist of 427 species from 201 genera and 50 families of nondipterocarps. Examples of important non-dipterocarp families are Leguminosae, Myristicaceae, Euphorbiaceae, Burseraceae, Sapotaceae, and Apocynaceae. Unlike dipterocarp species, generally non-dipterocarp timbers are less durable than the dipterocarp. However, according to Schulte [39], the non-dipterocarp species also play an important role within the tropical rainforest. They either form the major components of the understory layer (i.e., Annonaceae, Euphorbiaceae, Lauraceae, Meliaceae, Myristicaceae, and Rubiaceae) or they have the commercial use, frequently only locally as fruit trees (i.e., Moraceae, Anacardiaceae, Bombacaceae, Euphorbiaceae, Guttiferae, Lauraceae, Mimosaceae, Polygalaceae, and Sapindaceae).

\subsection{Tropical rainforest formation}

The main forest types in Malaysia are formed from three types of formation, that is, climatic, edaphic, and biotic climax. Figure 1 shows five forest zones are developed from climatic climax formations are lowland dipterocarp forest (0-300 m above sea level [a.s.l.]), hill dipterocarp forest (300-800 m a.s.l.), upper hill dipterocarp forest (800-1100 m a.s.l.), oak-laurel forest (1100-1600 m a.s.l.), and montane ericaceous forest (above $1600 \mathrm{~m}$ a.s.l.) (Symington, 2004). These forests are characterized by species composition. The first three forest types are mostly dominated by trees from the dipterocarpaceae family; hence, they are termed as

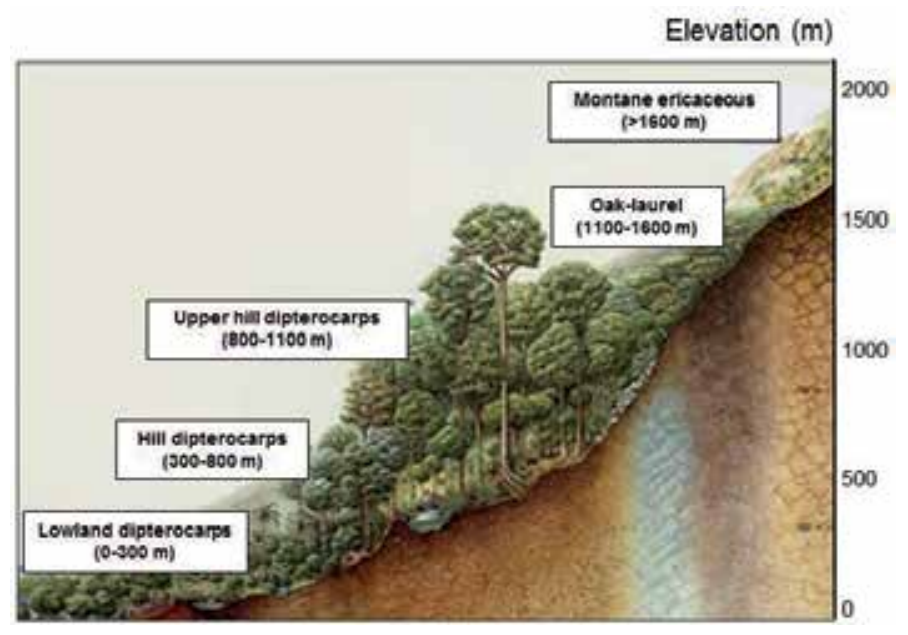

Figure 1.

Altitudinal profile of forest zones developed from climatic climax formation in Malaysia (modified from Symington [40]). 
dipterocarp forests. Montane ericaceous and oak-laurel are characterized by an abundance of trees from Fagaceae-Lauraceae and Ericaceae families, respectively [41]. They can be distinguished by a number of structural characters which include the size of canopy height, canopy layer, leaves, and the presence of vascular and non-vascular epiphytes and climbers. The montane forest also differs from lowland in having fewer and smaller emergent trees, flattish canopy surfaces, gnarled limbs, and denser sub-crowns [42]. The montane ericaceous and oak-laurel forests are moist and are characterized by a thick layer of mosses and bryophytes.

There are seven forest types that were developed based on edaphic climax formations [40]. The edaphic refers to ecological climax resulting from soil factors which are commonly persisting through cycles of climatic and physiographic change. These forests include mangrove swamp, peat swamp, freshwater swamp, beach, riparian, heath, and limestone. Mangroves occur on estuarine mud below the tide mark mainly concentrated in the west of Peninsular Malaysia [24]. Main genera of mangroves include Rhizophora, Sonneratia, Avicennia, Bruguiera, Ceriops, and Lumnitzera.

Beach forests form narrow strips of woodland, sandy, or gravel beaches along the seacoast, above the level of all but the highest tides. Calophyllum inophyllum (Bintangor laut), Syzygium grande (Kelat jambu laut), and Casuarina equisetifolia (Ru pantai) are the main common trees dominated the beach forests. Dipterocarpaceae species such as Shorea siamensis (Temak batu) has been recorded to occur in the beach forests of Pulau Rebana located at off the coast of Perlis [40].

Peat swamp forest developed on un-decomposed and partly decomposed organic matter. Over time, these create thick layers of acidic peaty soils. Most of the species are different from dry land. Dipterocarps are important components in peat swamp forests such as S. albida (Meranti merah), S. uliginosa (Meranti bakau), S. teysmanniana (Meranti bunga), S. platycarpa (Meranti paya), and $A$. marginata (Mersawa paya). Non-dipterocarpaceae species include Tetramerista glabra (Punah), Gonystylus bancanus (Ramin melawis), and Koompassia malaccensis (Kempas).

Riparian forests are narrow strips of vegetation in adjacent to a body of water such as a river, stream, and lake [43]. The zones of riparian forest are determined by the incidence of tidal influence, width of stream, rate of flow, and altitude. The most abundant Dipterocarpaceae is D. oblongifolius (Keruing neram). The best known non-dipterocarpaceae include Saraca thaipingensis (Gapis), Pometia pinnata (Kasai daun besar), Tristaniopsis whiteana (Pelawan), and Dysoxylum angustifolium (Maris).

Freshwater swamp forests occur in flat land, which is inundated with freshwater, either permanently or seasonally. The forests contain many of the endangered species such as D. semivestitus (Keruing padi), S. hemsleyana (Cengal pasir daun besar), V. flavida (Resak padi), H. apiculata (Giam melukut), and S. macrantha (Meranti kepong hantu) as discovered at Hutan Simpan Parit, Perak [44]. Commonly found non-dipterocarps include Alstonia spatulata (Pulai basung), Fagraea crenulata (Malabera), and Lagerstroemia spp. (Bungor).

Heath forests are moist forest in areas with acidic and sandy soils that are extremely nutrient poor. The forests developed on pale, light-textured, and acidic sandy soils. The forests are known in Borneo as Kerangas-an Iban language means land too poor for rice growing once cleared. S. glauca (Damar laut daun kecil) occurs gregariously, other dipterocarps are H. semicuneata (Sama rupa cengal) and Vatica odorata (Resak kesat).

The association of man has resulted in destruction or interference of forests that produce a type of vegetation that is in equilibrium with the prevailing biotic factors. For example, lowland dipterocarp forests were converted into very different type of 
forests due to cutting, firing, grazing, or intermittent cultivation. The forests mainly contain a mixture of Schima wallichiana (Medatang gatal) and Oxytenanthera nigrociliata (bamboo), which also includes forest remnants in the form of secondary forests in all stages of development from open grassland to scrub. Some common dipterocarps found this type of forests are S. roxburghii (Meranti temak nipis), Anisoptera spp. (Mersawa), and V. cinerea (Resak laut).

Ecologically, Gelam swamp forests are related to the peat swamp forests but their floristic composition is almost entirely different. Many of secondary species exist, namely, Macaranga maingayi (Mahang) and Stenochlaena palustris (Akar paku). Fire has prevented the development of peat swamp complex and promoted predominance of the fire-resistant gelam-Melaleuca cajuputi. No dipterocarps occur in gelam freshwater swamp forest.

\section{The need for sustainably managed forests}

Sustainable forest management is high on both political and scientific agendas of many countries and at a global level, with much recent attention being focused on the tropical rainforest. Forest is the most biologically deserved terrestrial ecosystems within which trees are central to the habitat and environmental of other plant and animal species. Knowledge of the biology of tree flora is therefore critical in providing a sound scientific basis to the management and conservation of the world's forest resource. By its very nature, biodiversity and its conservation are complex and multi-faceted. With respect to forest, biodiversity may be viewed at the level of the forest community and constituent population of species.

The emphasis on conservation often has one dimension, traditionally focused on the establishment of national park for the protection of fauna or particular ecosystems with little regard for hierarchy of organization and the spatial and temporal dynamic of biological processes [40]. Deforestation continues to keep forest stand, and sustainable management of forest ecosystems for the future has become a global environmental imperative. Within this, effective management of forest genetic resources is a key element in the future forest conservation.

\section{Biodiversity of forest}

Biodiversity is referred to as the variety of plants, animals, and microorganisms that exist, the genes they contain, and the ecosystems they live in. The diversity of life that a tree can support is incredible. A single tree in the tropical rainforest can house up to 2000 different species of insects, birds, amphibians, reptiles, mammals, fungi, mosses, and epiphytic plants. Trees are an important component of biodiversity. The tropical rain forests are blessed with abundant biodiversity and are known to have more species per unit area than temperate areas and biodiversity decreases with increasing altitudes [41]. Tropical rain forests contain the mixture of species as compared with temperate forests which tend to be dominated by one species.

The status of biodiversity tropical rainforest as elsewhere has always been dynamic. Over millions of years, under natural conditions, some species have increased in variety or numbers and others have been reduced or lost. Some people wonder why we should be worried about conserving biodiversity now, in particular, when the world has gone on more or less as it is for so long. But natural habitats everywhere are being destroyed as never before and as habitats are lost, we are also losing various types of plants and animals. No one would have thought, even a few years ago, that some members from the family dipterocarpaceae in Malaysia could 
be endangered, but now it is. With the rapid land use and cover changes, there are concerns that anthropogenic changes to environment are leading to too many of forest species being lost and biodiversity becoming seriously depleted.

Biodiversity is important because it helps to keep the environment in a natural balance. An ecosystem which is species rich is more resilient and adaptable to external stress than the one in which the range of species is limited. In a system where species are limited, the loss or temporary reduction of any one could disrupt a complex food chain with serious effects on other species in that same system.

Biodiversity is the key issue to natural conservation, and plant diversity is one of the important components of the biological diversity [45-47]. The diversity of tree species is fundamental to total forest biodiversity. The central biodiversity in the world are tropical and subtropical forest [42]. Central and western Amazonia Tropical rain forests have been considered as the two central mega-diversity areas in the world [48, 49], and the other tropical rain forests could be found in central Africa, west Africa, Madagascar, and Indo-Malaysian area [50, 51].

\section{Conclusions and recommendation}

Any initiatives involved in sustainable forest management and conservation are essential to human well-being. Therefore, to ensure a successful conservation effort, an understanding on the significance roles of forests among general public is extremely important. Promoting and raising awareness to the public toward forest resource management are crucial for the general public to be aware on their importance, roles, and threats. Understanding their intrinsic values and variability within and among living organisms and the systems they inhabit is critical to the survival of the planet, species, and mankind. In order to spread the message, the use of social media can be an effective way to disseminate the information far and wide. Another way to communicate various aspects of forest (i.e., species of flora and fauna, genetic, ecosystem, and environmental diversity), a street mural can be constructed in a public space as an approach of communicating to raise awareness to a public audience. Recognizing the importance of forest management and conservation is necessary toward achieving sustainable development in terms of contribution to species conservation, provision of water supply, food security, and poverty alleviation. These can be incorporated into education curriculum beginning from the primary level. Providing capacity building to the teachers on sustainable forest management will enhance the effectiveness of teaching and learning.

Strengthening governments' efforts at all levels for the full implementation of the National Forestry Policy, especially through increased allocations of human and technical resources and financial could contribute toward the success of sustainable forest management strategy. Coordination efforts among all agencies responsible in the development of policy, planning, and natural resources management are important to ensure the ecosystem approaches and objectives of forest conservation can be incorporated in sectors such as forest management, agriculture, transportation, and water management. These coordinate efforts can reduce the significant loss of forest resources in both terrestrial and aquatic ecosystems.

Establishment of protected areas is extremely important in particular for endangered species and sensitive habitats. The current terrestrial protected areas in Peninsular Malaysia of 1.8 million ha are not sufficient for the implementation of full range conservation biodiversity efforts. More protected areas should be established to increase more habitats for rare and threatened species and sensitive habitats. In addition, Malaysia should establish uniform national protected areas system operating in the country. Currently, the protected areas are managed by 
different networks and governed by different laws with varying degrees of protection status. Protected areas need to be better located and effectively managed to deal with problems of such as illegal logging, human settlements, unsustainable tourism, encroachment, and challenges in climate change.

The setting up of natural history museum (government- or privately-run) can contribute to demonstrate and educate about the importance of forest management and conservation. In addition, besides raising a greater awareness, the collection of specimens can be used for research and education by the students, communities, and relevant stakeholders. The museum can be used not only as a significant repository for specimens of the threatened animal and plant populations but also serves as a primary source of information about historical aspects of biodiversity at the national, regional, and global levels.

\section{Author details}

Mohd Nazip Suratman ${ }^{1 *}$ and Zulkiflee Abd Latif ${ }^{2}$

1 Faculty of Applied Sciences, Universiti Teknologi MARA (UiTM), Shah Alam, Malaysia

2 Faculty of Architecture, Planning and Surveying, Universiti Teknologi MARA (UiTM), Shah Alam, Malaysia

*Address all correspondence to: nazip@uitm.edu.my

\section{IntechOpen}

(C) 2020 The Author(s). Licensee IntechOpen. This chapter is distributed under the terms of the Creative Commons Attribution License (http://creativecommons.org/licenses/ by/3.0), which permits unrestricted use, distribution, and reproduction in any medium, provided the original work is properly cited. (cc) BY 


\section{References}

[1] Mackey B. Wildlife, Fire and Future Climate: A Forest Ecosystems Analysis. Melbourne: CSIRO Publishing; 2002. $188 \mathrm{p}$

[2] Young A, Boshier D, Boyle T. Forest Conservation Genetics: Principles and Practice. Melbourne: CRISO Publishing; 2000

[3] Lowet CH, Wirt EB, Rosen PC. Vegetation Structure and Diversity in Natural Communities at Organ Pipe Cactus National Monument. Tucson: University of Arizona Press; 1994

[4] Salisbury FB, Ross CW. Plant Physiology. 4th ed. Belmont: Wadswoth Publishing Company; 1992. 682 p

[5] Montagnini F, Nair PKR. Carbon sequestration: An underexploited environmental benefit of agroforestry systems. Agroforestry Systems. 2004;61-62:281-295

[6] Ahrends A, Burgess ND, Milledge SAH, Bulling MT, Fisher B, Smart JCR, et al. Predictable waves of sequential forest degradation and biodiversity loss spreading from an African city. Proceedings of the National Academy of Sciences of the United States of America. 2010;107(33):14556-14561

[7] Kenzo T, Ichie T, Hattori D, Kendawang JJ. Change in aboveand belowground biomass in early successional tropical secondary forests after shifting cultivation in Sarawak, Malaysia. Forest Ecology and Management. 2010;260:875-882

[8] Leroux SJ, Krawchuk MG, Schmiegelow F, Cumming SG, Lisgo K, Anderson LG, et al. Global protected areas and UICN designation: Do the categories match the conditions. Biological Conservation. 2010;143:609-616
[9] Gardingen PRV, Clearwater MJ, Nifinluri T, Effendi R, Rusmantoro W, Noor M, et al. Impact of logging on the regeneration of lowland dipterocarp forest in Indonesia. Commonwealth Forest Review. 1998;77:71-82

[10] Hardiwinoto S, Pudyatmoko S, Sabarnurdin S. Tingkat ketahanan dan proses regenerasi vegetasi setelah letusan gunung merapi. Manusia dan Lingkungan. 1998;15:47-59

[11] Appiah M. Changes in plant species composition within a planted forest in a deciduous agroecosystem in Ghana. Agroforestry Systems. 2011;85(1):57-74

[12] Amlin G. Characteristics of sapling compositions and soil nutrients in logged-over forest at Krau Wildlife Reserve, Pahang [M. Sc. thesis]. Universiti Teknologi MARA; 2014. 120p (unpublished)

[13] Food and Agriculture Organization of the United Nations (FAO). Global Forest Resources Assessment (Main Report). Rome: FAO; 2010

[14] National Research Council (U.S.). Physics Survey Committee on Managing Global Genetic Resource: Agricultural Imperatives. Forest Trees. Washington DC: National Academy Science; 1991

[15] Siminski A, Alfredo CF, Raymond PG, Ademir RR, Maur'icio SR. Secondary forest succession in themata atlantica, Brazil: Floristic and phytosociological trends. Ecology. 2011;2011:1-9

[16] Johnston JM, Crossley JRDA. Forest ecosystem recovery in the southeast US: Soil ecology as an essential component of ecosystem management. Forest Ecology and Management. 2002;155:187-203 
[17] D’Oliveira MVN, Ribas LA. Forest regeneration in artificial gaps twelve years after canopy opening in acre state western Amazonia. Forest Ecology and Management. 2011;261:1722-1731

[18] Carter WK, Fredericksen TS. Tree seedling and sapling density and deer browsing incidence on recently logged and mature non-industrial private forestlands in Virginia, USA. Forest Ecology and Management. 2007;242:671-677

[19] Finzi AC, Canham CD. Sapling growth in response to light and nitrogen availability in a southern New England forest. Forest Ecology and Management. 2000;131(1):153-165

[20] Duchesneau R, Lesage I, Messier C, Morin H. Effect of light and intraspecific competition and growth and crown morphology of two size classes of understory balsam fir saplings. Forest Regeneration and Management. 2001;140:215-225

[21] Mengel K, Kirkby EA, Konsergaten H, Appel T. Principles of Plant Nutrition. 5th ed. Dordrecht: Kluwer Academic Publishers; 2001

[22] Intergovernmental Panel Climate Change (IPCC). Atmospheric carbon dioxide concentration. 2009. Available from: http://www.ipcc.ch/ [Accessed November 18, 2015]

[23] Natural Resources and Environment (NRE). Jumlah kes pembalakan haram yang dilaporkan sejak tahun 2006 hingga 2008 mengikut negeri. 2010. Available from: http://www.nre.gov. my/Parlimen/archive/2010/05/19/ jumlah-kes-pembalakan-aram-yangdilaporkan-sejak-tahun-2006-sehinnga2008-mengikut-negeri-1.aspx [Accessed November 14, 2011]

[24] Suratman MN. Carbon sequestration potential of mangroves in Southeast
Asia. In: Bravo F, Jandl R, LeMay V, von Gadow K, editors. Managing Forest Ecosystems: The Challenge of Climate Change, Berlin: Springer; 2008. pp. 297-315

[25] Mohd Zaki NA, Latif ZA, Suratman MN, Zainal MZ. Modelling the carbon stocks estimation of the tropical lowland dipterocarp forest using LiDAR and remotely sensed data. ISPRS Annals of Photogrammetry, Remote Sensing and Spatial Information Sciences. 2016;III-7:187-194

[26] Mohd Zaki NA, Latif ZA, Suratman MN. Modelling aboveground live trees biomass and carbon stock estimation of tropical lowland dipterocarp forest: Integration of fieldbased and remotely sensed estimates. International Journal of Remote Sensing. 2018;39(8):2312-2340

[27] Latif ZA, Blackburn GA. The effects of gap size on some microclimate variables during late summer and autumn in a temperate broadleaved deciduous forest. International Journal of Biometeorology. 2010;54(2):119-129

[28] Castilho CVD, Magnusson WE, Araujo RNOD, Luizao RCC, Luizao FJ, Lima AP, et al. Variation in aboveground tree live biomass in a central Amazonia Forest. Effect of Soil and Topography. 2006;234:85-96

[29] Nogueira EM, Fearnside PM, Nelson BW, Barbosa RI, Keizer EWH. Estimate of forest biomass in the Brazilian amazon: New allometric equations and adjustment to biomass from wood-volume inventories. Forest Ecology and Management. 2008;256:853-867

[30] Kenzo T, Ichie T, Hattori D, Kendawang JJ. Change in aboveand belowground biomass in early successional tropical secondary forests after shifting cultivation in 
Sarawak, Malayisa. Forest Ecology and Management. 2010;260:875-882

[31] Niiyama K, Kajimoto T, Matsuura Y, Yamashita T, Matsuo N, Yashiro Y, et al. Estimation of roots biomass based on excavation of individual root systems in primary dipterocarp forest in Pasoh forest reserve, Peninsular Malaysia. Journal of Tropical Ecology. 2010;26:271-284

[32] Latiff A, Faridah-Hanum I, Ibrahim AZ, Jaman R. Biomass and floristics of Sayap-Kinabalu Park, Sabah. ASEAN Review of Biodiversity and Environmental Conservation (ARBEC). 1998. pp. 1-7. Article I

[33] Hamzah MZ, Arifin A, Zaidey AK, Azirim AN, Zahari I, Hazandy AH, et al. Characterizing soil nutrient status and growth performance of planted dipterocarpand non-dipterocarp on degraded forest land in Peninsular Malaysia. Journal of Applied Science. 2009;9:4215-4223

[34] Sands R. Forestry in a Global Context. United Kingdom: CABI Publishing; 2005. 262p

[35] Food and Agriculture Organization of the United Nations (FAO). Soil Map of the World. Paris: UNESCO; 1974

[36] Ng FSP, Low CM, Mat Asri NS. Endemic trees of the Malay Peninsula. In: FRIM Research Pamphlet No. 106. Kepong: Forest Research Institute Malaysia; 1990

[37] Wong KM. Patterns of plant endemism and rarity in Borneo and the Malay Peninsular, In: Peng CI, Lowry PP, editors. Rare, Threatened and Endangered Floras of Asia and the Pacific Rim, Monograph Series No. 16. Institute of Botany, Academia Sinica; 1998. pp. 139-169

[38] Primack RB, Corlett R. Tropical Rain Forests: An Ecological and
Biogeographical Comparison. Oxford, UK: Blackwell Science Ltd; 2005

[39] Schulte A, Schöne D. Dipterocarp Forest Ecosystems: Towards Sustainable Management. Berlin: World Scientific Publishing Co.; 1996

[40] Symington CF. Forester's manual of Dipterocarps. In: Malayan Forest Records No. 16. Kuala Lumpur: Forest Research Institute Malaysia and Malaysian Nature Society; 2004

[41] Suratman MN, Hamid ANH, Md Sabri MD, Kusin M, Yamani SAK. Changes in tree species distribution along altitudinal gradients of montane forests in Malaysia. In: Öztürk M, Hakeem KR, Farida-Hanum I, Efe R, editors. Climate Change Impacts on High-Altitude Ecosystems. Switzerland: Springer; 2015. pp. 491-522

[42] Whitmore TC. Tropical Rainforest of the Far East. 2nd ed. Oxford: Clarendon Press; 1984

[43] Suratman MN, Mohamad R, Abdullah Z, MAM A. Kuala Keniam: Nature's Treasure Trove in the Heartland. UiTM Press; 2011. 134p

[44] Suratman MN, Noh NAM, Nawi L. Spatial distribution and demographic structure of the critically endangered Dipterocarpaceae in fragmented habitat in Malaysia. In: Poster presented at the International Union of Forest Research Organizations (IUFRO). Salt Lake City, USA; 5-11 October 2014

[45] Dubois JCL. The present status of research into management of the rainforest of Amazonian Brazil. In: Mez-Pompa A, Whitmore TC, Hadley M, editors. Rain Forest Regeneration and Management. Paris: Parthenon; 1991. pp. 431-436

[46] Asner GP, Keller M, Pereira R, Zweede JC, Silva JNM. Canopy damage 
and recovery after selective logging

in Amazonia: Field and satellite

studies. Ecological Applications.

2004;14:280-298

[47] Ferozet SM, Yoshimura K,

Hagihara A. Architectural stratification

and woody species diversity of a

subtropical forest grown in a limestone

habitat in Okinawa Island Japan. World

Academic of Science, Engineering and

Technology. 2006;17:11-20

[48] Gentry AH. Changes in plant community diversity and floristic composition on environment and geographical gradients. Annals of the Missouri Botanical Garden. 1988;75(1):1-34

[49] Ter Steege HN, Pitman D,

Sabatier H, Castellanos P, Van der HDC, Daly M, et al. A spatial model of tree alpha-diversity and tree density for the amazon. Biodiversity and Conservation. 2003;12:2255-2277

[50] Smith RL. Ecology and Field Biology. New York: Harper and Row; 1990

[51] Odum EP. Dasar-dasar ekologi. Indonesia: Gajah Mada University Press; 1993. p. 1993 


\title{
Forest Biodiversity and Deforestation in Bangladesh: The Latest Update
}

\author{
Ahm Ali Reza and Md. Kamrul Hasan
}

\begin{abstract}
Located in the Indo-Burma biodiversity hotspot, Bangladesh is a tropical country in Southeast Asia and a transitional point for flora and fauna between the IndoHimalayan and Indo-Chinese subregions. About $11 \%$ land area (1,429,000 hectares) of the country is covered with four major forest types: mixed-evergreen forests, deciduous forests, mangrove forests, and freshwater swamp forests. Though Bangladesh is a small and densely populated country, it is the home of 1952 species of invertebrates, 653 fish, 50 amphibians, 147 reptiles, 566 birds, and 127 mammalian species of which many of them are globally threatened. We have discussed the latest status of all the major vertebrate groups in this chapter. Thirty-one species of vertebrates have gone extinct from Bangladesh over the last century. Many of the species are facing continuous threat of extinction due to deforestation and degradation of habitat caused by various anthropogenic activities. In this chapter, we are going to discuss about the current management and conservation practices and issues related to the forests and wildlife of Bangladesh.
\end{abstract}

Keywords: wildlife of Bangladesh, forest biodiversity, conservation, deforestation, evergreen forest, mangrove forest, protected area

\section{Introduction}

Bangladesh is a very small but densely populated country with very rich biological diversity. It is located at the cross roads of the Indo-Himalayan and Indo-Chinese subregions in the oriental region and is the transitional zone for the flora and fauna of the subcontinent and that of the Southeast Asia $[1,2]$. The country is also a part of the Indo-Burma biodiversity hotspot, demanding high conservation priorities on a global aspect [3]. Because of its zoogeographical location, Bangladesh plays a significant role in terms of the migratory species, acting as the flyways or the staging ground for wildlife movements of the region [1].

Bangladesh has a total of 2,600,000 hectares of forest cover which is about $17 \%$ of the total land area of the country. About $61.52 \%$ of the forestlands $(1,600,000$ hectares) is owned and managed by the Bangladesh Forest Department (BFD), $26.80 \%$ of unclassified forest (697,000 hectares) is under the jurisdiction of the deputy commissioner (executive chief of district), and $10.38 \%$ of the land ( 270,000 hectares) is private woodland and community forests, controlled by the community $[4,5]$. Despite of having a rich biodiversity, Bangladesh has one of the lowest per capita forestlands in the world [6] mostly due to the high human 
population density in the urban areas. Moreover, the country has also experienced one of the highest rates of deforestation in south Asia, 2600 hectares per year $[7,8]$.

\section{Forests of Bangladesh}

Even in a small land area, Bangladesh hosts four major types of forests: (a) hill forests (mixed-evergreen forest), (b) sal forest (deciduous forest), (c) mangrove forest (natural mangrove), and mangrove plantation (Figure 1). Three other types of forest also contain substantial biodiversity of the country: (d) freshwater swamp forests, (e) homestead forest, and (f) village common forest, which is a natural forest conserved by communities for their uses $[5,10]$. Many of these forests are protected by laws in Bangladesh, and designated protected areas (PAs) are shown in Figure 2.

\subsection{Hill forests (mixed-evergreen forests)}

Hill forests are mostly mixed-evergreen forests which cover 680,000 hectares of land and mostly situated in the northeast and southeast parts of Bangladesh [11-13]. The forests of northeast are mostly fragmented, and some relatively large patches of mixed-evergreen forests still exist in the Chittagong Hill Tracts (CHT) in the southeast [14]. The dominating plants in these forests are Dipterocarpus turbinatus, D. pilosus, Swintonia floribunda, Hopea odorata, Syzygium grande, Salmalia insignis, Lophopetalum fimbriatum, and Duabunga sonnerationides. Evergreen plants dominate the mixed-evergreen forests; however, deciduous plants are quite common and abundant $[5,15]$. The mixed-evergreen forests of Bangladesh support large populations of wild mammals including Asian elephants, Asiatic black bear, hoolock gibbon, sambar deer, wild dog, leopard, and other globally threatened species $[10,16]$.

\subsection{Sal forests (deciduous forests)}

The Sal forest or moist deciduous forests of Bangladesh cover roughly about 120,000 hectares, which is about $0.81 \%$ land of the country. The central part of the country has the largest single mass of deciduous forest [17]. The single dominating

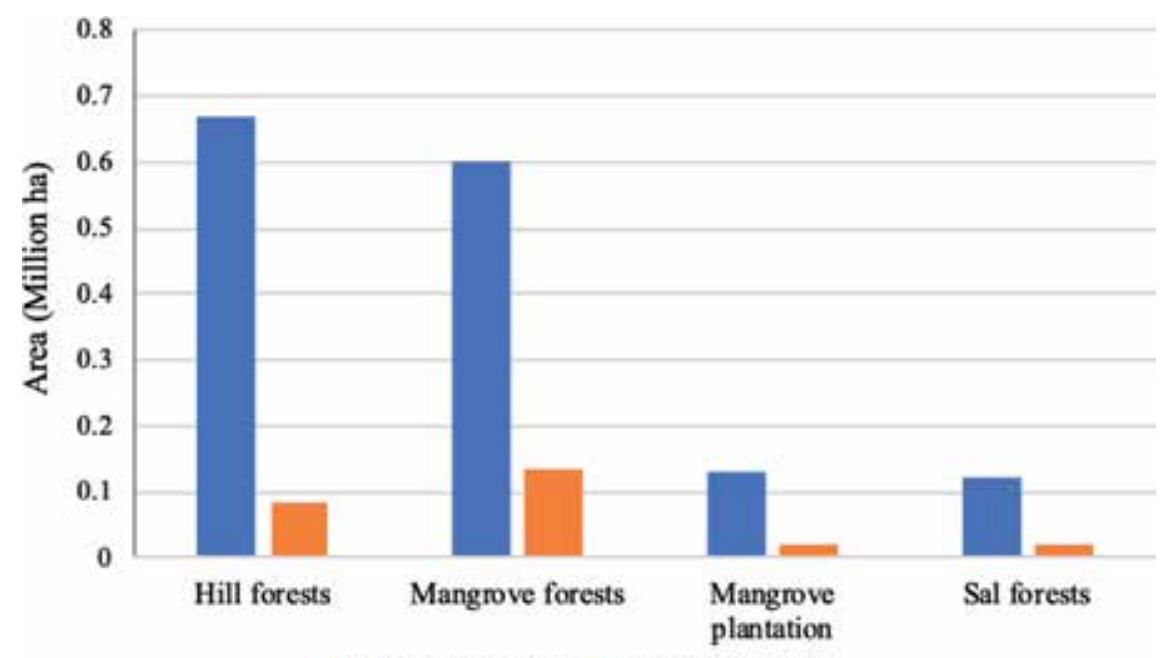

= Total Forest Area $=$ Protected Areas

Figure 1.

Various forest ecosystems by protected areas in Bangladesh (Source: [9]). 


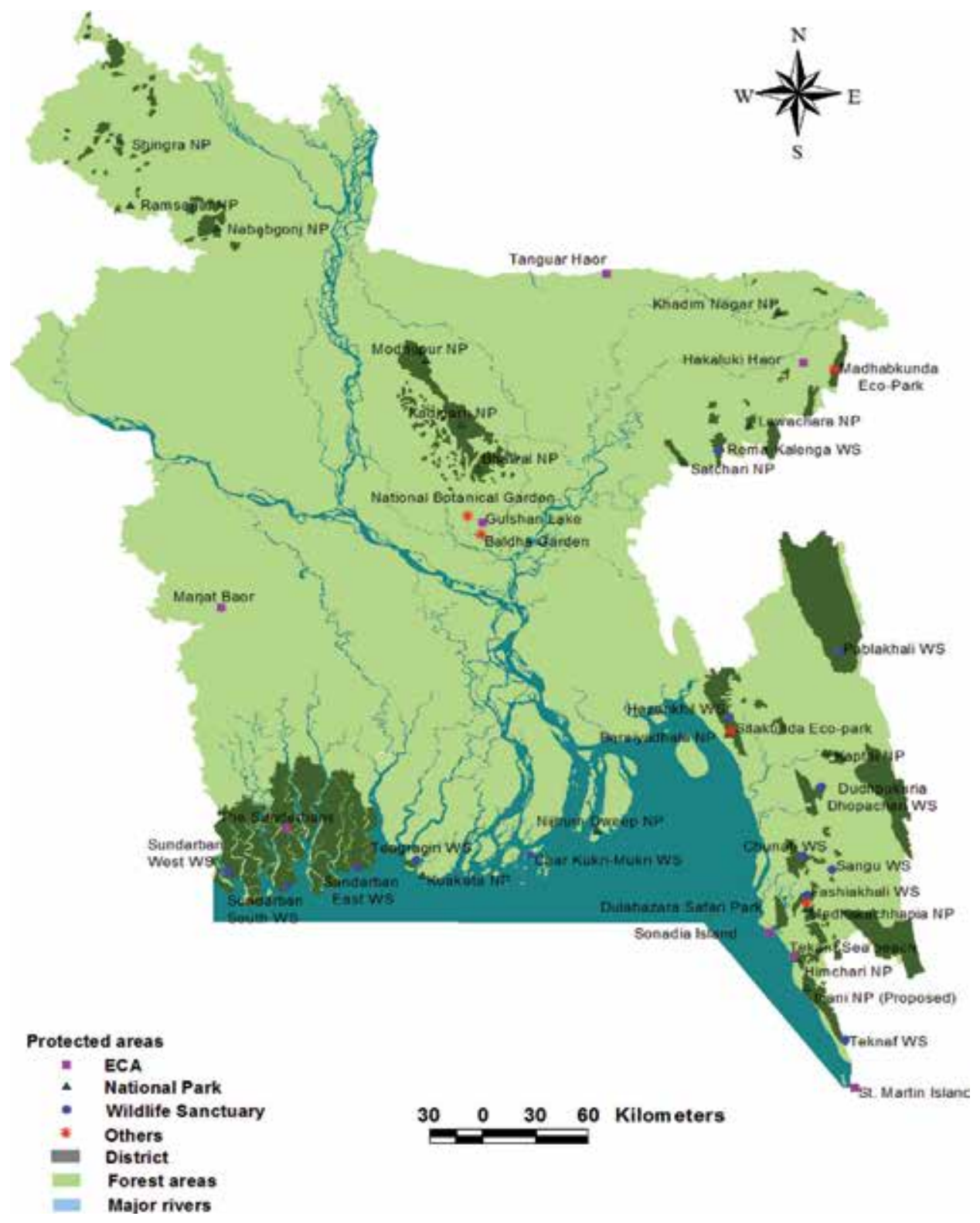

Figure 2.

Location of the protected areas (PAs) in Bangladesh (Source: [11]).

plant of this forest is Sal (Shorea robusta). Most of the other plants of this forest are Butea monosperma, Careya arborea, Terminalia belerica, Terminalia chebula, Dillenia pentagyna, Aphanamixis polystachya, Streblus asper, and Phyllanthus emblica $[15,18]$. This ecosystem is the home of the largest population of capped langur of Bangladesh [10].

\subsection{Natural mangrove forests and mangrove plantation}

The mangrove forests cover an area of 801,700 hectares along the coast of the Bay of Bengal. Out of the total coastal forest, 601,700 hectares are natural mangroves, the Sundarbans - the single largest chunk of productive mangrove forest of the world-and 200,000 hectares are coastal plantations [19,20]. This forest 
includes fairly dense evergreen plant species, which are adapted for life under saline conditions and frequent inundation by the tides. Major plants of this forest are Heritiera fomes, Excoecaria agallocha, Sonneratia apelata, Avicennia officinalis, Avicennia alba, Hibiscus tiliaceus, Phoenix paludosa, and Acrostichum aureum [20].

The Sundarbans harbors 334 species of plants and 269 species of wild vertebrates. The Sundarbans is currently the last abode of important elements of South Asia's threatened megafauna, including the Bengal tiger, Ganges and Irrawaddy dolphins and saltwater crocodiles, a number of threatened bird species, and at least 176 species of fish $[5,16]$. The flagship tree species of Sundarbans, a mangrove Heritiera fomes, has also been declared as an "endangered species" in 2010 under the International Union for Conservation of Nature (IUCN) Red List category of threatened species [21].

\subsection{Freshwater swamp forests}

This type of forest is situated in the lowlands of the northeastern region of Bangladesh. Freshwater swamp forest consists of flood-tolerant evergreen trees of about 10-12 $\mathrm{m}$ in height. These trees have vast rooting system and form a close canopy. The major tree species of this forest are Barringtonia acutangula, Millettia pinnata, Saccharum spontaneum, Phragmites karka, Acanthus ilicifolius, Alpinia allugas, and Schumannianthus dichotoma $[5,10]$. Seeds of these trees disperse through water and regenerate in mudflats. The freshwater swamp forests are the home of many species of wading birds, reptiles, and amphibians [5].

\subsection{Homestead forest}

There are approximately 25.53 million homestead forests in Bangladesh [22] to fulfill the basic needs of the householders such as fruits, vegetables, other foods, and timbers. Planting native fruits and timber trees and bamboos near homesteads is a traditional land use practice in Bangladesh; however, amount of this forest is declining at an alarming rate due to various reasons. Major plants of the homestead forests are Mangifera indica, Artocarpus heterophyllus, Syzygium cumini, Bambusa spp. Areca catechu, and Musa spp. Homestead forests are the home of many threatened mammals including jungle cat, fishing cat, golden jackal, Bengal fox, mongoose, and civets [5].

\subsection{Village common forest}

Village common forests are natural forests other than the government reserve forests near the households of the indigenous communities that are managed to fulfill their daily demands [23, 24] and also harbor considerable biodiversity. Most of the village common forests are situated in the southeastern hilly areas of the country. Village common forests are small forest patches but harbor a good number of threatened wild animals [13].

\section{Protected areas of Bangladesh}

Protected areas and forests of Bangladesh are home of many flagship species of global concern (Figure 2). Terrestrial PAs particularly in northeast and southeast regions of the country contain considerable biodiversity, and those in the CHT are part of the Indo-Burma biological hotspot. Madhupur National Park, the first protected forest situated in the central part of Bangladesh was established in 1962 
under the provision of the Forest Act 1927. After the implementation of the Wildlife Act 1974, the legal status of the PAs was improved considerably. Several new PAs were declared after the signing of the Rio Convention in 1992.

A total of 41 protected areas have been declared for the conservation of wild animals of Bangladesh, of which 20 are wildlife sanctuaries, 17 are national parks, 2 are special biodiversity conservation areas, 1 is marine protected area, 1 is eco-park, and 2 are vulture safe zones (Figure 2 ). Moreover, five migratory bird flyway sites have been declared in 2011 for the conservation of migratory birds of the country. Many globally threatened species such as Asian elephant, Asiatic black bear, Malayan sun bear, leopard, clouded leopard, marbled cat, hoolock gibbon, slow loris, Chinese pangolin, and greater hornbill are still found in those PAs [5, 10].

The Sundarbans is the home of the only viable population of Bengal tiger in the country. Many other threatened wild animals like saltwater crocodile, Irrawaddy dolphin, white-bellied sea eagle, lesser adjutant stork, rock python, and king cobra are still in good condition in the Sundarbans $[10,16,20]$. PAs in deciduous forests (particularly Madhupur NP) also support a good population of capped langur.

Biodiversity and forests of Bangladesh provide a buffer against climate change and provide sources of natural products of value to both local villagers and in the markets. Forests also serve to hold soil from excessive erosion and to maintain the integrity of watersheds and freshwater supplies. Tourism, both foreign and domestic, to natural areas of the country has been advertised for its potential to allow sustainable development of ecosystems and to provide incentives to preserve these areas instead of converting them to other uses. Bangladesh has a great potentiality to develop sustainable ecotourism in the PAs spread over the whole country [25].

\section{The status of wildlife diversity in Bangladesh}

Bangladesh is the home of 1952 species of invertebrates, 653 fish species (251 freshwater; 402 marine) [2, 10, 16], 50 species of amphibians, 147 species of reptiles, 566 species of birds including residents and migrants, and 127 species of mammals [16]. Many of these species are reported from Bangladesh in the last couple of decades; especially the number of amphibians and reptiles has grown up very fast, and it is expected to go even higher in near future $[26,27]$. A total of 11 species of mammals, 19 species of birds, and 1 species of reptile has gone extinct from Bangladesh over the last century [16]. Many species such as hoolock gibbon, long-tailed macaque, Malayan sun bear, Asian elephant, and gharial are at the brink of extinction and demand attention for conservation management [16]. Distribution of some distinct wildlife species has been mentioned with the major forest types in Bangladesh (Figure 3).

\subsection{Amphibians}

Among the 50 recorded species of amphibians, 46 species are found in forested areas of which 36 species are exclusively restricted to different types of forests [16]. The number of recorded amphibians from Bangladesh is even higher in other reports, and the reported species is up to 57 [27]. About 33\% amphibian species are threatened in different categories (Figure 4). According to IUCN's Red List, Fuller's caecilian (Chikila fulleri) and Khare's stream frog (Pterorana khare) are critically endangered and restricted to the particular forests in Bangladesh. Bush frogs like Doria's pygmy frog (Chiromantis doriae), Anderson's bush frog (Philautus andersoni), and pied warty frog (Theloderma asperum) are endangered species and only found in mixed-evergreen forests of the country. Cascade frog (Amolops marmoratus) is a vulnerable species and restricted to some particular hill streams of Bangladesh. 


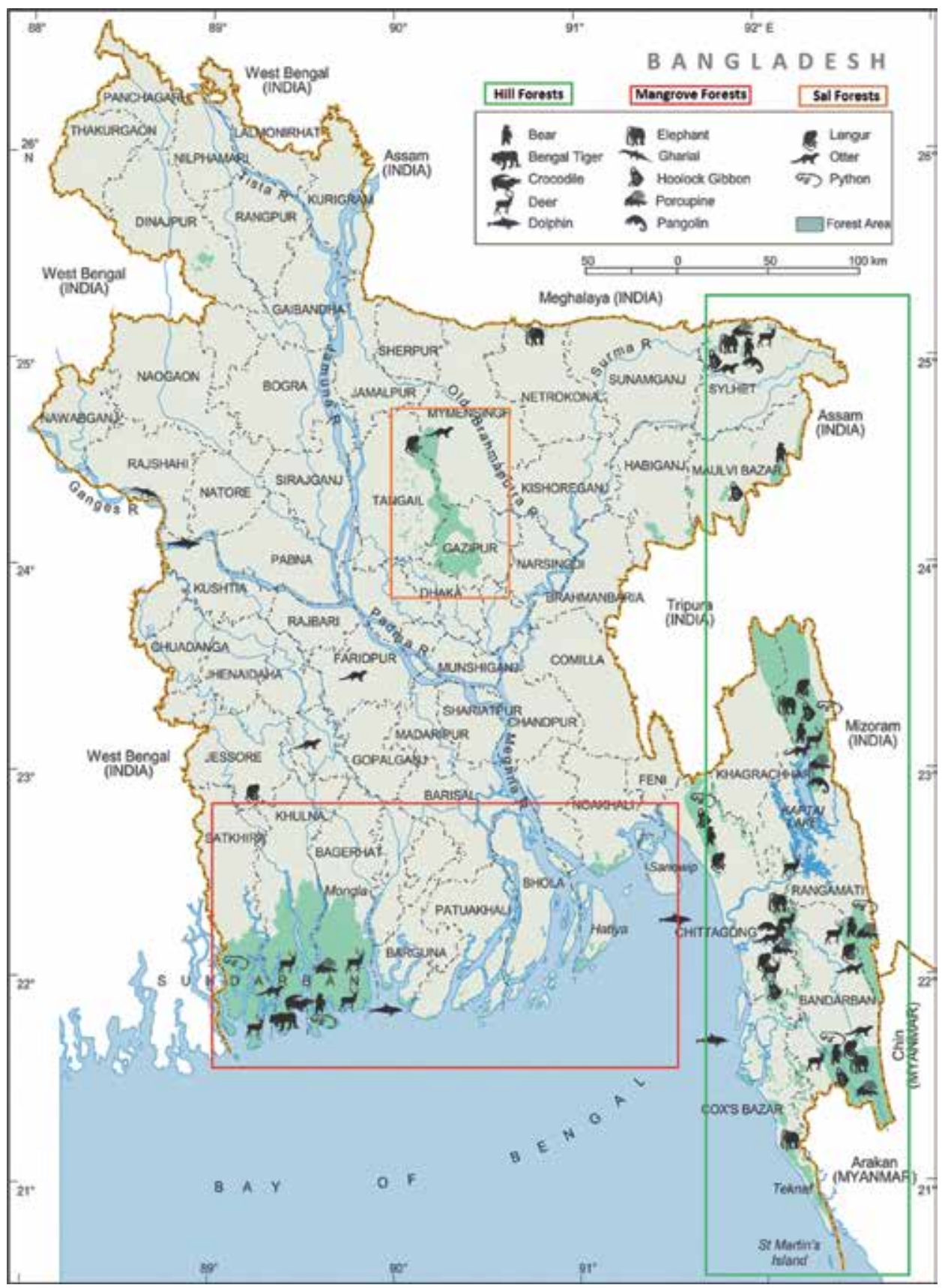

Figure 3.

Major forest types of Bangladesh with distinct wildlife species (Source: [9]).

\subsection{Reptiles}

A total of 30 species of turtles and tortoises, 35 species of lizards, 80 species of snakes, 2 species of crocodiles, and 1 gharial species has been reported from Bangladesh [16]. Forests of the country harbor 110 species of reptiles, of which 98 species are exclusively restricted to the different types of forest. About 38\% reptiles of the country are threatened under different categories (Figure 5). Marsh crocodile (Crocodylus porosus) has been extinct from the wild. Gharial (Gavialis gangeticus) is at the brink of extinction and has been categorized as "critically 
endangered." Salt water crocodile (Crocodylus palustris) is also facing different kinds of conservation threats and categorized as "endangered" [16].

About $87 \%$ turtle species are threatened, of which 14 species are "critically endangered" and 4 species are "endangered" and "vulnerable" each. Larger-sized turtles and tortoises are more vulnerable to local consumption for meat and are victim of illegal trade. Large snakes (e.g., pythons and boas) and venomous snakes (e.g., cobras) are also threatened due to illegal trade for skin and venom. Reticulated python (Malayopython reticulatus), Burmese python (Python bivittatus), monocled cobra (Naja kaouthia), spectacled cobra (Naja naja), and king cobra (Ophiophagus hannah) are frequently associated with illegal trade and are threatened with various categories [16].

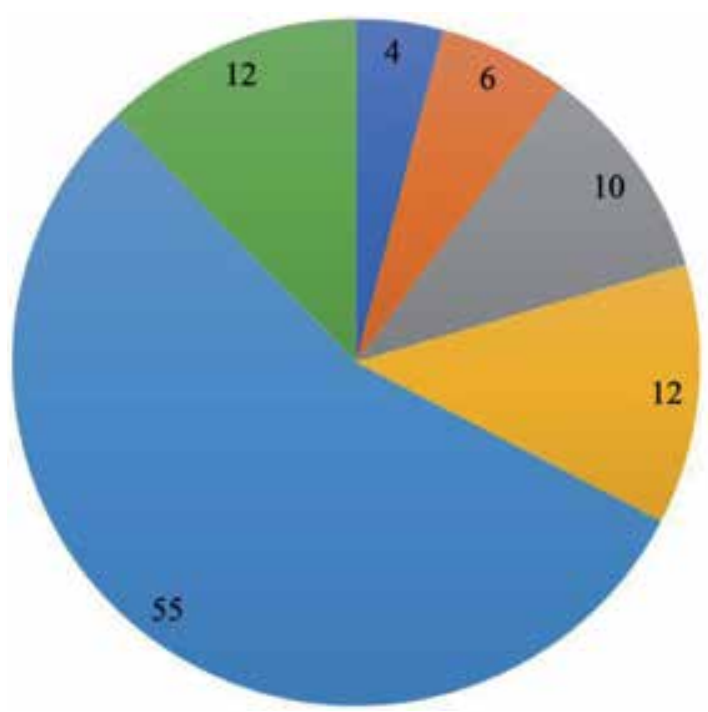

\section{Amphibia}

Critically Endangered

$\equiv$ Endangered

$=$ Vulnerable

Near Threatened

$=$ Least Concern

$=$ Data Deficient

Figure 4 .

The latest threat status of amphibians in Bangladesh (percent value, $N=50$ ).

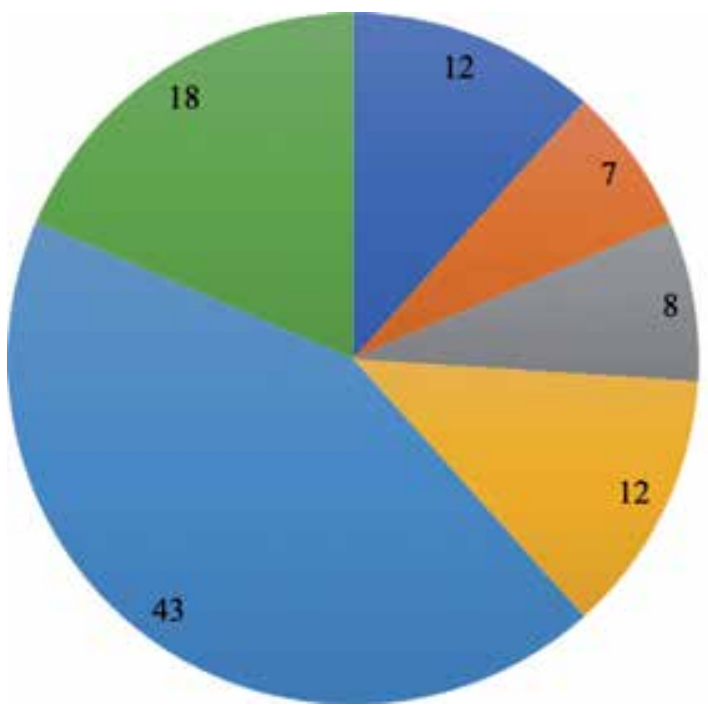

\section{Reptilia}

=Critically Endangered

$=$ Endangered

$\approx$ Vulnerable

$=$ Near Threatened

= Least Concern

=Data Deficient

Figure 5.

Latest threat status of reptiles in Bangladesh (percent value, $N=147$ ). 


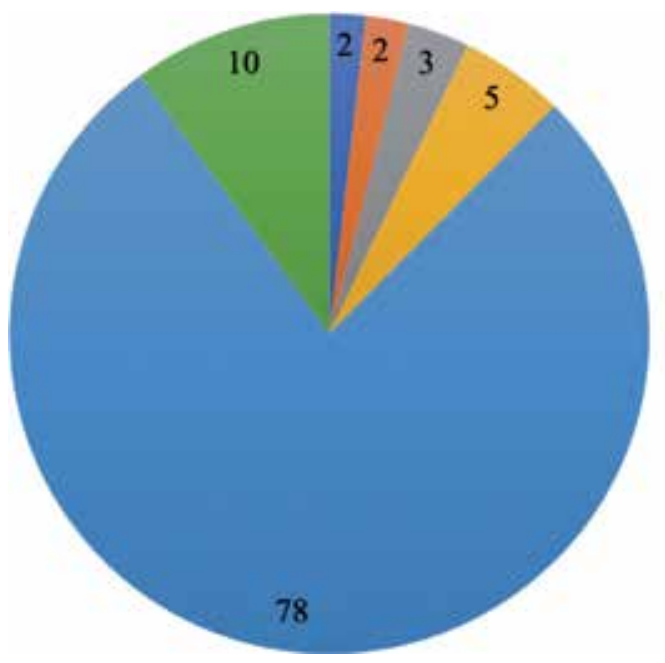

Aves

= Critically Endangered

= Endangered

=Vulnerable

= Near Threatened

= Least Concem

$=$ Data Deficient

Figure 6.

The latest threat status of birds in Bangladesh (percent value, $N=566$ ).

\subsection{Birds}

Bangladesh harbors a total of 566 species of birds [16]. A large number of birds (19 species) have already been extinct from the country, and currently 68 species of birds are facing conservation threats of various kinds (Figure 6). Among the regionally extinct birds, seven species were forest dwellers, six species were from grasslands and bamboo tickets, and five species were wetland birds. Terrestrial birds are more likely to face greater threats of extinction. Size and weight were another important factor for their extinction. Among extinct birds, 11 species were large sized, e.g., spot-billed pelican (Pelecanus philippensis), greater adjutant (Leptoptilos dubius), sarus crane (Antigone antigone), white-bellied heron (Ardea insignis), Indian peafowl (Pavo cristatus), and green peafowl (Pavo muticus) [16].

Out of the 10 species of critically endangered birds of Bangladesh, eight species are migratory, and other two species are resident. Survival of migratory birds in Bangladesh mostly depends on the health status of the migratory bird habitats. Two species of critically endangered migratory birds, spoon-billed sandpiper (Calidris pygmaea) and Indian skimmer (Rynchops albicollis), are only found in two isolated coastal sites in southern Bangladesh, and their survival is greatly dependent on the habitat protection [16]. The causes of declining population of critically endangered white-rumped vulture (Gyps bengalensis) are mostly related to the use of a lethal veterinary drug "diclofenac" in Bangladesh [28].

\subsection{Mammals}

Bangladesh is the home of 127 species of mammals [16], 10 species of primates, 27 species of rodents, and 29 species of bats; the Asian elephant and the Bengal tiger are the most notable species. Forests of Bangladesh are the home of 86 species of mammals, of which 60 species are fully restricted to forests. Eleven species of mammals have already been extinct from the country. The extinct species are mostly large mammals, and principal causes of their extinction were uncontrolled hunting and habitat loss. The existing large mammals of Bangladesh are facing continuous pressure of extinction threats. About $40 \%$ mammals of the country are threatened, and $33 \%$ are data deficient (Figure 7). Nineteen species of mammals are "critically endangered," and many of them are at the brink of extinction, e.g., long-tailed macaque (Macaca fascicularis), hog 


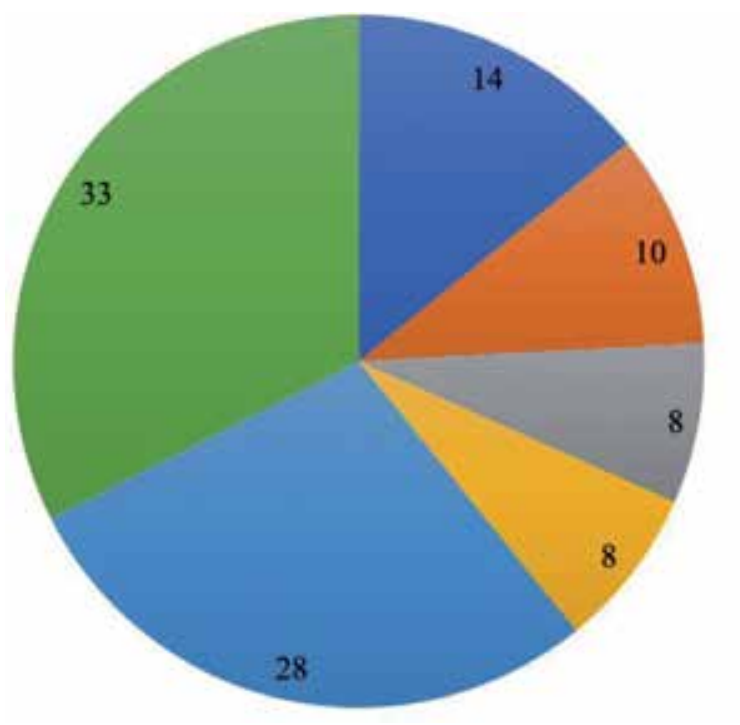

\section{Mammalia}

= Critically Endangered

= Endangered

॥ Vulnerable

$=$ Near Threatened

= Least Concern

$=$ Data Deficient

Figure 7.

Threat status of mammals in Bangladesh (percent value, $N=127$ ).

deer (Axis porcinus), sambar deer (Rusa unicolor), gaur (Bos gaurus), Malayan sun bear (Helarctos malayanus), Eurasian otter (Lutra lutra), clouded leopard (Neofelis nebulosa), leopard (Panthera pardus), and Indian pangolin (Manis crassicaudata) [16].

\section{Threats to the forest and wildlife}

Like most other developing countries, Bangladesh is facing different kinds of threats to the forest and its wildlife. With accelerating economic development and the growing population, it is easily understandable that many of these threats will intensify in future leaving a huge challenge for conservation professionals [5, 10, 29]. Some of the major threats are important to discuss which have been summarized below.

\subsection{Direct threats}

\subsubsection{Hunting and poaching}

Hunting and poaching is one of the major threats for wildlife species in Bangladesh especially for the game species. Wild animals are hunted illegally either for local consumption for meat and trophies or for international trade. Poachers usually target animals that are in high demand in illegal market. Tigers are killed for the hide as well as other body parts to be used in traditional Chinese medicine. Other smaller cats are also poached for their hides. Deer are hunted for meat and skin, whereas elephants are killed for the ivory. Turtles and tortoises are poached for meat and demand in pet markets. Many birds like hill myna, parrots, and sunbirds have a great demand in illegal pet markets. Python skin and snake venom have also high demand in illegal markets $[4,30,31]$.

\subsubsection{Local and international trade}

Illegal wildlife trade is one of the most serious threats to wild animals in the region, and Bangladesh is no exception. For its geographic location, being 
conveniently located between India and Myanmar, Bangladesh is being used as a source of animals as well as the transit route of international wildlife trade. Wildlife species are killed for their meat, skins, bones, fur, and other body parts which are used for traditional medicine, clothing, jewelry, and trophy and also for unconventional exotic food. These animal products have demands mostly in the international illegal market, and their destination is the traditional Chinese medicine market [32].

While wildlife poaching and trafficking pose a great threat to the flagship species of the country but the status of the lesser known species (e.g., golden jackal, civets, mongoose, and small cats), the latest situation is currently unknown. These animals play a vital role in the ecosystem, and if this process continues, the conservation of mammalian species of the country would be a huge challenge [32].

\subsubsection{Local consumption}

There are at least 29 ethnic communities in Bangladesh, and most of them find their protein source from wild animals. These ethnic communities are spread over the country, but most of them inhabit in the southeastern and northeastern part of Bangladesh. Ethnic communities usually hunt wild animals such as wild boar, barking deer, Indian hare, small cats, primates, mongoose, civets, squirrels, rats, bats, turtles and tortoises, snakes, and frogs [32].

\subsubsection{Use of live animals}

Some of the wildlife species have growing demand as pet or zoo animals in both local and international markets. Wildlife traders illegally collect the harvested animals from the poachers. Keeping wild animals in private collection or establishment of mini zoo is not legal in Bangladesh according to the existing laws, but many private collections are established in several parts of the country. Most commonly found animals of these private collections include but not limited to hoolock gibbon, rhesus macaque, pig-tailed macaque, Assamese macaque, slow loris, spotted deer, barking deer, marbled cat, fishing cat, civet, large birds, pythons, cobras, turtles, and tortoises. This is a total violation of the Bangladesh Wildlife (Conservation and Security) Act, 2012, as most of these animals are protected by the current laws of the country [4, 32].

\subsubsection{Human-wildlife conflict}

Human-wildlife conflict is currently a burning issue as it influences a group of people against wild animals and also against the people who want to conserve and restore wildlife [33]. The growing human population of Bangladesh is forcing rapid urbanization and habitat loss for the wildlife and also forcing wild animals to live in close proximity to humans. Many wildlife species of Bangladesh such as Bengal tiger, Asian elephant, leopard, fishing cat, golden cat, jungle cat, civets, etc. are facing various threats of extinction due to human-wildlife conflict [30, 31].

\subsubsection{Moving vehicle as a growing threat}

Roads through the natural habitats are intrusion to the wildlife habitats which adversely affect the wild animals. Effect of road ranges from habitat loss and fragmentation to the distribution pattern [34] of the animals, movement and reproductive behavior [35], and direct mortality by the moving vehicles [36, 37]. In Bangladesh, many forest areas have been bisected by roads, highways, and railway tracts which contribute negatively in losing biodiversity at a much faster rate. Nocturnal animals 
are also harmed by the bright headlights at night and are often killed by the moving vehicle. Many threatened species are also killed by the vehicles on a regular basis.

\subsubsection{Tourist pressure}

Excessive and uncontrolled tourism activities pose a great threat to wild animals especially for small forest patches like Satchari and Lawachara National Parks. These parks are critical habitats for critically endangered mammalian species like hoolock gibbon and other primates. With the growing tourist activities in the core of these critical habitats especially during winter season, the daily activity of wildlife activities is heavily impacted both diurnal and nocturnal species. The breeding activities are interrupted by such unwise human activities [4].

\subsection{Habitat degradation and fragmentation}

Habitat fragmentation and degradation are currently the most important factor for the biodiversity loss in Bangladesh. With the ever-growing human population in the country and coupled up with other reasons, wildlife habitats are being destroyed and fragmented in an alarming rate $[5,10,15]$, and as such, different vertebrate wildlife groups face conservation threats at various levels (Figure 8). We would like to summarize the major reasons of habitat degradation and fragmentation in a very brief way.

\subsubsection{Illegal timber extraction}

Timber harvest from the natural forests is currently banned in Bangladesh as a measure to restore country's forestland. But, timber extraction is still going on, in many cases with the support from corrupt forest managers. It is assumed that local timber merchants persuade unemployed poor people to take down the large-sized hard wood trees from the forests and sell it to the local market. In many of this forestland, the upper canopy is not connected, and forests are fragmented [15]. Distant canopy cover creates problem to highly arboreal mammals, e.g., hoolock

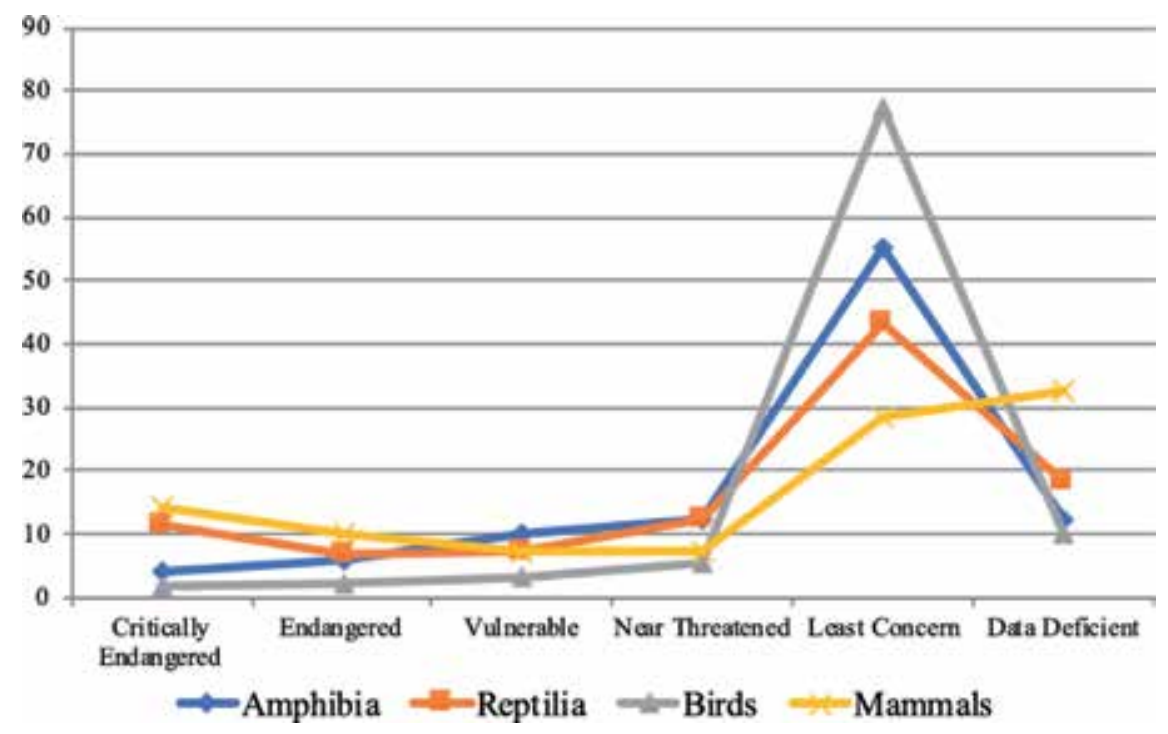

Figure 8.

Overall threat status on the vertebrate wildlife groups in Bangladesh. 
gibbons, capped langurs, macaques, and squirrels for their movement and breeding activities. Fragmentation of forest also restricts the movement of mammals from one habitat to another, which poses more threats to their existence. Moreover, due to the softwood demand in plywood industry, illegal poaching of softwood trees is also happening in Bangladesh, which would otherwise provide food for the wild animals [4].

\subsubsection{Fuel wood extraction}

Almost all households, in and around the forests, use fuel wood for daily livelihood. Majority of the fuelwoods are sourced from the nearby forests. The local people generally collect dead or fallen trees or branches, which do not contribute directly to the destruction of trees in the forest; but it has other ecological consequences. Some local community members live on selling the fuelwood extracted from the forest. Fallen leaves collection is a major problem in deciduous forests in the central as well as in the northern part of the country. Leaf and fuelwood collectors clean up the undergrowth of the forest and also cut down seedlings which hinder regeneration of the forest [4].

\subsubsection{Expansion of agricultural activities}

Several crops are extensively cultivated on the hill slopes and in the low-lying areas in and around the forestland in Bangladesh. Pineapple, banana (Musa spp.), citrus, bean (Vigna spp.), and papaya (Carica papaya) are mainly cultivated on the hilltop. Paddy (Oryza spp.) is cultivated in the low land between two hills [4]. For making the land cultivable, local people usually clean the forest floor, burn the unwanted vegetation, and cultivate the desired crops, resulting in destruction of natural vegetation. Local farmers slowly expand their cultivation land each year, which causes rapid fragmentation of the forestland. Expansion of agricultural land is one of the major problems of deforestation in Bangladesh except the Sundarbans mangrove forest [5].

\subsubsection{Modification of undergrowth}

Alteration and modification of undergrowth vegetation is one of the major conservation issues, a lot of the forestlands are facing in Bangladesh. Both the Bangladesh Forest Department (BFD) and local community contribute to this factor. Collection of dead leaves from the forest floor prevents natural seed germination, which eventually hinder undergrowth plant diversity. The forest department permits local people to clean up undergrowth and eventually plant canes (Calamus rotang) in the forestland. The rapid growth and aggressive nature of canes prevents growth of other plant species. The forest department also encourages bamboo plant during winter season, which results the monoculture of bamboo undergrowth and ultimately contributes to the topsoil erosion of the forests [5].

\subsubsection{Grazing by livestock}

Deforestation is closely associated with overgrazing in many parts of the world, and Bangladesh is no exception [4]. Overgrazing by domesticated animals and farming play a major role in natural forest regeneration. Free-range cattle in the forestland would eliminate seedlings, which would potentially regenerate the forest. Grazing also accelerates soil erosion [10]. 


\subsubsection{Land erosion}

Huge landslide during rainy season in the hilly region (Chittagong and CHT) of Bangladesh is quite common and one of the major reasons for the lack of vegetation cover of the area. Landslides change the hydrological pattern of forest and could be an issue for animal movement [2].

\subsection{Indirect threats}

\subsubsection{Poor institutional capacity}

The Ministry of Environment and Forests (MoEF) is the sole authority from the government side to implement and enforce natural resource-related activities and laws. The Bangladesh Forest Department and Department of Environment operates under the MoEF and two major wings to manage natural resources in Bangladesh. However, limitations like poor institutional capacity, lack of logistical and operational support, and insufficient funding and manpower are holding the country behind. Most of the field offices in the peripheral forest range have no vehicles or travel allocations to make necessary field interventions [4].

\subsubsection{Lack of coordination among different agencies}

There is lack of coordination in the management of biodiversity and natural resources among different government agencies in Bangladesh. For example, there are overlaps between the jurisdictions of the Bangladesh Forest Department, Department of Environment (DoE), and Ministry of Land (MoL). Coordination gaps or overlaps are also found among different projects and among different donor agencies, especially in high-profile areas like the Sundarbans. Lack of coordination is also observed at the transboundary level, especially between water rights and usage between Bangladesh and neighboring countries that are the upstream sources of water [4].

\subsubsection{Policy and information gap}

Information is not widely available in Bangladesh, and with regard to field level baseline data on natural resources, there is no single place to get everything. Aside from some modest university efforts, there is a dire lack of scientific data on forest, wetland, and aquatic species. This information is crucial for effective management of natural resources and biodiversity of the country. There are no long-term monitoring efforts to evaluate any changes in species occurrence, abundance, and distribution in Bangladesh [4]. Bangladesh managed to have a number of sound environmental policies, but that is not enough, and there are many gaps. For example, donor-initiated conservation projects are not sustained after the funding tenure is over. The government either does not have their interest or no self-funding capability to continue the project initiated by a donor agency [32].

\subsubsection{Lack of enforcement}

Environmental crime is not treated as seriously as other types of crime either by the local communities or by the law enforcement agencies. Although there are laws related to natural resources in Bangladesh, enforcement of these laws is very poor. Poachers are often politically connected and often are protected by their leaders or contractors [4]. Even when a case makes it into the court, there are no incentives (monitory or logistic) for the forest officials who are willing to testify before court. 


\subsubsection{Inadequate and poorly managed protected areas}

Many of the forests in Bangladesh are recently declared as protected areas, but the actual implementation is still in very rudimentary stage (Figure 2 ). The idea of the PA is not very welcomed and well perceived by the local people, and also there is lack of coordination between the stakeholders and the government. Although there are dozens of PAs in the country, many are 500 hectares or less: too small to provide adequate habitat to preserve biodiversity. In addition, protected area system includes only forestland and does not include some of the most critically important wetland habitat of the country.

\subsubsection{Corruption}

Corruption is evident at all levels of the government system in Bangladesh where biodiversity and forest conservation are an integral part. It is expected that folks with strong political connections or wealth can circumvent existing laws to obtain individual favors, rights to use protected land, and immunity to environmental crimes [4].

\subsubsection{Lack of awareness}

Most country people are not properly aware of the importance of maintaining a healthy biodiversity and its conservation. Being a developing country, Bangladesh is fighting with poverty, high population density, and lack of education. Most local stakeholders have no idea about the existing laws of the land, especially with regard to environmental crimes [32].

\subsubsection{Climate and biophysical changes}

Climate change is being recognized as a global crisis threatening any forms of life on the face of earth. The biophysical changes in the environment have an underlying effect on the present and future biodiversity in Bangladesh [19]. Some of these biophysical factors are changes in temperature and precipitation pattern, sea level rise, frequent natural disasters, increase of salinity in the southern coast, drastic changes in upstream water flow, high sedimentation in inland water, etc. [38].

\subsubsection{Alternate income and recent human migration}

Most people living in and around the forests and protected areas support themselves using forest resources collected either legally or illegally. Bangladesh already has a very high population density, and this problem has been intensified by allowing thousands of outside people settled in by the government in the southeastern part of the country. The presence of large refugee camps of Rohingya people from Myanmar in Teknaf Wildlife Sanctuary has already been identified as a major threat for the biodiversity of the region. With no other income options, these Rohingya people are engaged in unsustainable practices in forest resources along the coast. This problem would even go out of control if it is not taken seriously and a solution is chalked out by the governments of the two neighboring countries [2,13].

\section{Conclusion}

The high and rapidly growing population of Bangladesh places a great strain on the natural resources, and PAs are no exception [39]. The situation in Bangladesh 
is not atypical; the majority of PAs around the world, not only those in developing countries or the tropics, face a variety of problems [40]. Among many others, shortage of skilled manpower, insufficient logistics, political influence, corruption, and lack of interagency coordination are some of the major reasons for the improper enforcement of law. Review and proper implementation of laws; institutional development; promotion of collaboration among different agencies; habitat protection and restoration; and human-wildlife conflict mitigation are some of the urgently needed factors for the conservation of wildlife and forest in Bangladesh.

Although there are lots of limitations, Bangladesh has several laws and policies that still safeguard the existing forest and wildlife species, and we hope that proper implementation of these laws would help to thrive the unique biodiversity and diverse wildlife of the country. Some of the important laws and policies for the conservation of forest and wildlife of Bangladesh are Forest Act, 1927; Wildlife (Conservation and Security) Act, 2012; Environment Conservation Act, 1995; Environment Protection Act, 2000; Climate Change Trust Act, 2010; Biological Diversity Act, 2012; Forest Policy, 1994; Environment Policy, 1992; Wetland Policy, 1998; and Coastal Zone Policy, 2005. The country needs to work hard to implement these laws and eliminate corruption from the government system.

The Bangladesh Forest Department (BFD) is the primary government agency that deals with forests and forest management and monitoring of biodiversity. The BFD manages PAs, forests, and most biodiversity activities in the field and operates through three management plan divisions. BFD's Wildlife Crime Control Unit (WCCU) was established in 2013 to combat wildlife trafficking and coordinate efforts with other agencies both national and international. Bangladesh Forest Department's capability for preventing wildlife crimes is currently not sufficient, and the country should invest more resources and manpower to the agency.

The BFD manages two large safari parks: Bangabandhu Safari Park, Gazipur, and Dulahazra Safari Park, Cox's Bazar. These facilities maintain animals in near natural conditions and also serve as a repository for animals that have been confiscated through the illegal wildlife trade. The BFD also manages a few botanical gardens around the country, and the National Botanical Garden in Dhaka displays many native and exotic species sells roses and fruit trees to the public, and engages in minor activities in the field; their space limitations prevent the addition of new species that may need ex situ conservation.

\section{Acknowledgements}

The content of this manuscript is the outcome of many field visits and research activities made by the Wildlife Research Group of the Department of Zoology, Jahangirnagar University, Bangladesh, where the authors actively participated. The authors are thankful to the other group members and the university. The authors are also thankful to the Bangladesh Forest Department for their cooperation. Thanks go to the Arannayk Foundation, Bangladesh, and Wildlife Rescue Center of the Department of Zoology, Jahangirnagar University, for providing valuable references. The first author would like to thank Delta State University for its cooperation and support to his research activities in Bangladesh. 


\section{Author details}

Ahm Ali Reza ${ }^{1 *}$ and Md. Kamrul Hasan ${ }^{2}$

1 Division of Mathematics and Sciences, Delta State University, Cleveland, MS, USA

2 Department of Zoology, Jahangirnagar University, Dhaka, Bangladesh

*Address all correspondence to: areza@deltastate.edu

\section{IntechOpen}

(C) 2019 The Author(s). Licensee IntechOpen. This chapter is distributed under the terms of the Creative Commons Attribution License (http://creativecommons.org/licenses/ by/3.0), which permits unrestricted use, distribution, and reproduction in any medium, provided the original work is properly cited. (cc) BY 


\section{References}

[1] Stanford CB. The Capped Langur in Bangladesh: Behavioral Ecology and Reproductive Tactics. Switzerland: Karger Publishers; 1991

[2] Feeroz MM. Biodiversity of Protected Areas of Bangladesh. Vol. III: Teknaf Wildlife Sanctuary. Bangladesh: BioTrack, Arannayk Foundation; 2013

[3] Myers N, Mittermeier RA, Mittermeier CG, Da Fonseca GA, Kent J. Biodiversity hotspots for conservation priorities. Nature. 2000;403(6772):853-858

[4] Foster-Turley P, Das R, Hasan MK, Hossain PR. Bangladesh Tropical Forests and Biodiversity Assessment. United States Foreign Assistance Act, Section 118/119 Report. Washington, USA:

Integra Government Service, LLC.; 2016

[5] Dey TK. Introduction to the Wildlife of Bangladesh and Management Techniques. Lalmatia, Dhaka, Bangladesh: Nature Conservation Society; 2018. p. 1148

[6] Mukul SA, Quazi SA. Communities in conservation: Changing protected area management and enhanced conservation in Bangladesh. In: Leslie RN, editor. The Future of Forests in Asia and the Pacific: Outlook for 2020. Bangkok, Thailand: Food and Agriculture Organization of the United Nations, (FAO-RAP Publication no 2008/3); 2009. pp. 143-159

[7] FAO. Global Forest Resources Assessment 2015. Rome, Italy: Food and Agriculture Organization of the United Nations; 2015

[8] Poffenberger M. Communities and Forest Management in South Asia. Philippines: IUCN, DFID, and Asia Forest Network; 2000

[9] Mukul SA, Rashid AZMM, Khan NA. Forest protected area systems and biodiversity conservation in Bangladesh. In: Mukul SA, AZMM $\mathrm{R}$, editors. Protected Areas: Policies, Management and Future Directions. Nova Publishers; 2017

[10] Khan MMH. Photographic Guide to the Wildlife of Bangladesh. Dhaka, Bangladesh: Arannayk Foundation; 2018. 488 p

[11] Feeroz MM. Biodiversity of Chunati Wildlife Sanctuary: Fauna. Dhaka, Bangladesh: Arannayk Foundation; 2014

[12] Feeroz MM, Hasan MK, Khan MMH. Biodiversity of Protected Areas of Bangladesh. Vol. I: RemaKalenga Wildlife Sanctuary. Bangladesh: BioTrack, Arannayk Foundation; 2011

[13] Feeroz MM. Biodiversity of Inani Protected Forest. Dhaka, Bangladesh: Arannayk Foundation; 2016. 168 p

[14] Khan MMH. Protected Areas of Bangladesh-A Guide to Wildlife. Dhaka, Bangladesh: Nishorgo Program, Bangladesh Forest Department; 2008

[15] Mukul SA, Uddin MB, Uddin MS, Khan MASA, Marzan B. Protected areas of Bangladesh: Current status and efficacy for biodiversity conservation. Proceedings of the Pakistan Academy of Sciences. 2008;45(2):59-68

[16] IUCN Bangladesh. Red list of Bangladesh volume 1-6. In: IUCN, International Union for Conservation of Nature. Dhaka, Bangladesh: Bangladesh Country Office; 2015

[17] Gittins SP, Akonda AW. What survives in Bangladesh? Oryx. 1982;16:275-281

[18] Chowdhury MSH, Koike M. An overview on the protected area system for forest conservation in Bangladesh. Journal of Forest Research. 2010;21(1):111-118 
[19] Payo A, Mukhopadhyay A, Hazra S, Ghosh T, Ghosh S, Brown S, et al. Projected changes in area of the Sundarban mangroveforestin Bangladesh due to SLR by 2100. Climatic Change. 2016;139(2):279-291

[20] Khan MMH. Tigers in the Mangrove:Reserarch and Conservation of the Tigers in the Sundarbans of Bangladesh. Dhaka, Bangladesh: Arannayk Foundation; 2011. 191 p

[21] IUCN Bangladesh. Red book of threatened mammals of Bangladesh. In: IUCN-The World Conservation Union. Dhaka, Bangladesh: Bangladesh Country Office; 2000. p. 71

[22] BBS. Bangladesh Bureau of Statistics. Dhaka, Bangladesh; 2011

[23] Baten MA, Khan NA, Ahammad R, Misbahuzzaman K. Village common forests in Chittagong Hill Tracts, Bangladesh: Balance between conservation and exploitation. Dhaka: Unnayan Onneshan. The Innovators; 2010. p. 13

[24] Roy RCK. Land Rights of the Indigenous Peoples of the Chittagong Hill Tracts, Bangladesh. Copenhagen: International Work Group for Indigenous Affairs; 2000

[25] Uddin MS, van Steveninck EDR, Stuip M, Shah MAR. Economic valuation of provisioning and cultural services of a protected mangrove ecosystem: A case study on Sundarbans Reserve Forest, Bangladesh. Ecosystem Services. 2013;5:88-93

[26] Hasan MK, Khan MMH, Feeroz MM. Amphibians and Reptiles of Bangladesh-A Field Guide. Bangladesh: Arannayk Foundation; 2014

[27] Reza AHMA. Status, distribution and conservation of the amphibians of Bangladesh. In: Heatwole $\mathrm{H}$, Das I, editors. Conservation Biology of Amphibians of Asia: Status of Conservation and Decline of Amphibian: Eastern Hemisphere. Kota Kinabalu, Malaysia: Natural History Publications (Borneo); 2014

[28] Khan MMH. Population, breeding and threats to the white-rumped vulture (Gyps bengalensis) in Bangladesh.

Forktail. 2013;29:66-70

[29] Sarker SK, Reeve R, Thompson J, Paul NK, Matthiopoulos J. Are we failing to protect threatened mangroves in the Sundarbans world heritage ecosystem? Scientific Reports. 2016;6:21234

[30] Rawshan K, Feeroz MM, Hasan MK. Human-carnivore conflicts in Bangladesh. Tigerpaper.

2012;39(3):17-21

[31] Rawshan K, Feeroz MM, Giordano AJ, Hasan MK. Use of the media to characterize recent trends in human-wildlife conflict in Bangladesh: 1990-2010. In: The Festschrift on the 50th Anniversary of the IUCN Red List of Threatened Species. Compilation of Papers and Abstracts. Bangladesh: IUCN; 2014. pp. 144-149

[32] Hasan MK. Mammal Management Strategy with Emphasis on HumanWildlife Conflicts in Bangladesh.

Dhaka, Bangladesh: Bangladesh Forest

Department; 2015. p. 112

[33] Karanth KU, Madhusudan MD. Mitigating human-wildlife conflicts in southern Asia. In: Terborgh J, Van Shaik CP, Rao M, Davenport LC, editors. Making Parks Work: Identifying Key Factors to Implementing Parks in the Tropics. Covelo, California: Islands Press; 2002. pp. 250-264

[34] Carr LW, Fahrig L. Effect of road traffic on two amphibian species of differing vagility. Conservation Biology. 2001;15:1071-1078

[35] Desai A, Baskaran N. Impact of human activities on the ranging 
behaviour of elephants in the Nilgiri Biosphere Reserve, South India. Journal of the Bombay Natural History Society. 1996;93:559-569

[36] Foster ML, Humphrey SR. Use of highway under-passes by Florida panthers and other wildlife. Wildlife Society Bulletin. 1995;23(1):95-100

[37] Das A, Ahmed MF, Lahkar BP, Sharma P. A preliminary report of reptilian mortality on road due to vehicular movement near Kaziranga National Park, Assam, India. Zoos' Print Journal. 2007;22(7):2742-2744

[38] Mukul SA, Alamgir M, Sohel MSI, Pert PL, Herbohn J, Turton SM, et al. Combined effects of climate change and sea-level rise project dramatic habitat loss of the globally endangered Bengal tiger in the Bangladesh Sundarbans. Science of the Total Environment. 2019;663:830-840

[39] Millat-e-Mustafa M. A review of forest policy trends in Bangladesh. Policy Trend Report. 2002:114-121

[40] Tol GV, Gidda SB. Protected forest areas: Their representativeness and efficacy for the conservation of biological diversity. In: Biodiversity Issues for Consideration in the Planning, Establishment and Management of Protected Area Sites and Networks (CBD Technical Series no. 15). Montreal, Canada: SCBD; 2004. pp. 63-69 



\title{
Colombian Forest Monitoring System: Assessing Deforestation in an Environmental Complex Country
}

\author{
Edersson Cabrera, Gustavo Galindo, Jose González, \\ Lina Vergara, Cristhian Forero, Alexander Cubillos, \\ Javier Espejo, Juan Rubiano, Xavier Corredor, \\ Leonardo Hurtado, Diana Vargas and Alvaro Duque
}

\begin{abstract}
Colombia is a key actor related with the adoption of the relevant UNFCC provisions referred in the context of obtaining result-based payments for REDD+ actions. Since 2012, the Colombian Forest Monitoring System (SMByC, Spanish acronym) has generated wall-to-wall historical information about the deforestation process over the last 27 years at national and regional levels. The SMByC generates a methodology that integrates tools for the preprocessing and semi-automated processing of satellite imagery to detect and quantify the loss of forest cover by deforestation. Also, the SMByC has done an extensive literature review, collecting qualitative and quantitative information to identify how the drivers of deforestation (illicit crops, illegal mining and postconflict scenario) could result in an increased forest lost during a postconflict scenario. Given that Colombia is a country conformed by regions that have differentially socioeconomic and environmental conditions, the study shows how the methods could generate official information and specifies the context of deforestation process of those regions.
\end{abstract}

Keywords: forest monitoring, deforestation, drivers, postconflict

\section{Introduction}

The Institute of Hydrology, Meteorology and Environmental Studies-IDEAM (Spanish acronym) is the forestry authority in Colombia, among other responsibilities. Since 2012, in coordination with the Ministry of Environment and Sustainable Development, the operation of the Forest and Carbon Monitoring System for Colombia, SMByC, began as a functional tool to generate annual official information on the monitoring of the forest cover and deforestation, early warnings for deforestation, and to estimate carbon stocks and GHG emissions related to natural forests. 
The SMByC complies with the provisions of the relevant decisions of the United Nations Framework Convention on Climate Change-UNFCCC and the Intergovernmental Panel on Climate Change (IPCC) in its guidelines of good practices, and operates under the principles of transparency, completeness, comparability, consistency and precision. Likewise, it complies with the requirements established by National Statistics Agency (DANE, Spanish acronym) to be considered as official information. For the generation of this type of information, the SMByC developed a specific methodology through a publicly available digital satellite image processing protocol $[1,4,25]$ and updated in [23]. All the information generated by the SMByC is available on the Web page of the system, with the exception of the one that has restrictions on use, at link [2].

The information generated by the SMByC allows the IDEAM to carry out its mission activities to monitor the biophysical resources of the nation, especially those related to forest resources, generating statistics, reports, maps and official reports that give an account of their status and dynamics. More information on the indicators can be found in [3].

The main components of the SMByC are: (i) monitoring of forest/deforestation, (ii) monitoring of biomass in natural forests, and (iii) causes and agents of deforestation. The SMByC is an instrument that generates crucial information to design and implement national policies on climate change and forests.

\section{Methods}

\subsection{Forest and deforestation definitions}

We defined a forest as a piece of land mainly covered by trees that might contain shrubs, palms, guaduas, grass, and vines, in which tree cover predominates with a minimum canopy density of $30 \%$, a minimum canopy height (in situ) of $5 \mathrm{~m}$ at the time of identification, and a minimum area of $1.0 \mathrm{ha}$. Commercial forest plantations, palm crops, and planted trees for agricultural production are excluded. This definition is in line with the criteria defined by the UNFCCC in decision 11/CP.7 [9], the definition adopted by Colombia under the Kyoto Protocol [10], and the definition of forest cover used by the Colombian National Greenhouse Gas Inventory [11].

Deforestation is defined as the direct and/or induced conversion of forest cover to another type of land cover in a given time [12].

\subsection{Forest and deforestation monitoring}

The SMByC developed a digital image processing protocol to assess the distribution, extension, and changes in forest cover in Colombia [6-8]. This protocol is implemented through the use of LANDSAT images [13]. The LANDSAT program of satellite images has several advantages for the monitoring of forest cover, such as a good record of images through time (historical availability), high temporal and spatial resolution, easy access to data, and possibilities of program permanence. The image processing protocol applied for the forest monitoring includes the following four major phases: (i) the digital preprocessing of satellite images, (ii) digital image processing, (iii) data validation, and (iv) monitoring data reporting. These phases are summarized in 12 methodological steps [14], described below in each technical phase. 


\subsubsection{Phase 1: digital preprocessing of satellite images}

In this phase, corrections, calibrations, radiometric normalizations, exact coregistration, and reduction in atmospheric effects are applied, to assure the comparability of images and to ensure that the detection of changes is not due to this type of factors. The specific steps followed during image preprocessing are as the following:

\subsubsection{Step 1: images select and download}

For each reference year, the SMBYC downloads the entire Landsat satellite program (7 ETM+ and OLI 8), image catalog with L1T level (reflectance surface), and selects all those images with less than $90 \%$ cloud cover available between January 1 and December 31 of the reference year. We give special emphasis for the images of the last quarter of the year that compiles the highest deforestation effect, mainly at the Amazon region in Colombia.

Images affected since 2003 by the failure in the Scan Line Corrector of Landsat $7 \mathrm{ETM}+$ are processed applying a masking. To optimize this task, the SMByC developed a specific tool implemented in QGIS ${ }^{\circledR}$ [15]. When Landsat data does not provide sufficient cloud-free coverage, images from the CBERS, RapidEye, ASTER, and Sentinel 2 satellites programs are used.

\subsubsection{Step 2: stacking bands}

In order to archive the complete images, each image is reconstructed by stacking all bands, excluding the thermal infrared wavelength bands. In case of Landsat 8 OLI, the aerosols and cirrus layers are also excluded.

Given the large number of images used (for example, more than 1400 images were used in 2015), specific algorithms have been developed to facilitate handling and processing, all of which are available for download:

- Algorithm to stack the bands [16].

- Algorithm to rename the images according to the SMByC structure [17].

- Algorithms to extract information from Landsat metadata files [18].

\subsubsection{Step 3: geometric correction}

For the construction of the annual image composite, it is necessary to have an exact co-registration at the pixel level among all the images acquired for each scene. The L1T products supplied by the Earth Resources Observation and Science Center (EROS) usually have an exact correspondence of the pixels. However, before performing the interpretation, a review of each image is made and those that do not meet this condition are adjusted.

\subsubsection{Step 4: cloud masking and shadow}

This allows masking and eliminates areas of clouds, banding, shadows, or haze. Before performing a change analysis, a semiautomated procedure is executed to integrate the results of the masks produced with different filtering tools implemented by the IDEAM with a QGIS Plugin named cloud masking [15], (see Figure 1). For additional documentation on the operation of the Cloud masking tool, refer [19]. 


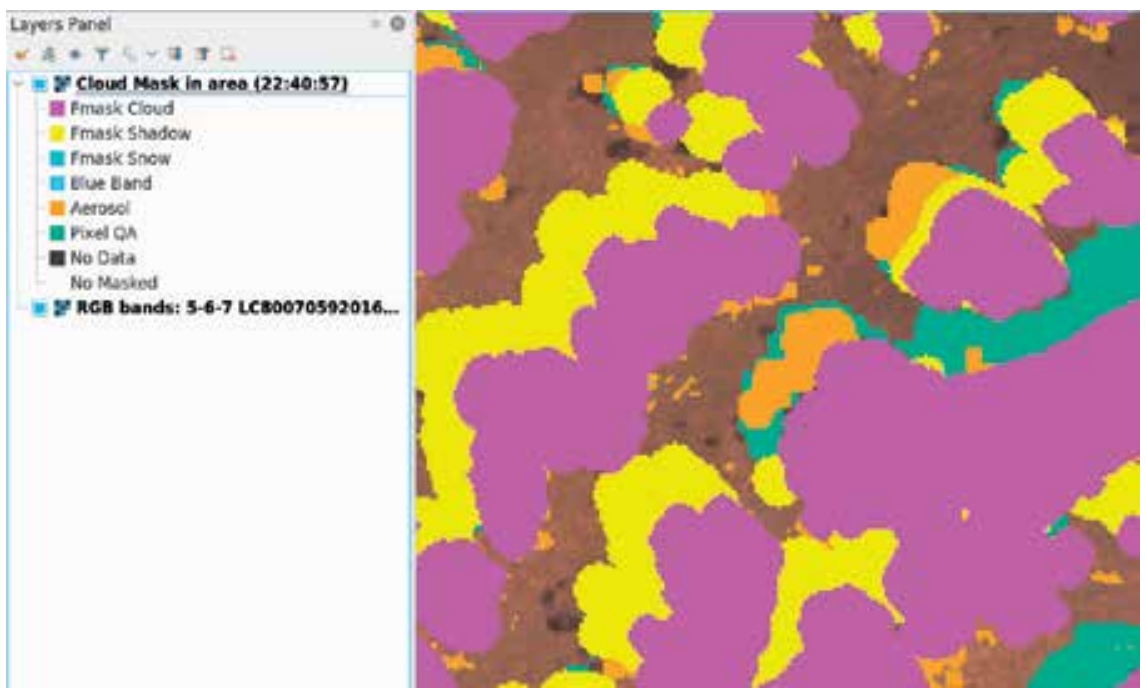

Figure 1.

Example of cloud masking filters available in tool developed by IDEAM.

\subsubsection{Step 5: radiometric normalization}

We used relative radiometric normalization of the images to adjust the radiometric values in order to reduce the variability between the images due to atmospheric differences, lighting, sensor calibration, and geometric distortions, among others. This step allows the images of different years to be comparable and ensures that the changes detected are not due to this type of factors [20,21]. Python scripts are available to execute this procedure-ARRNorm [22].

\subsubsection{Step 6: generation of the annual composite of images}

This step uses all satellite images available for Colombia of the corresponding year, allowing for each pixel a series of annual time values that include the reflectance surface data valid for that year. The main metric used is the annual median of each spectral band, which has shown good results for the detection of changes. Thus, for each observation unit, a single radiometric value of annual reflectance surface is obtained in each one of the radiometric bands (Red, NIR, and SWIR-1 and SWIR-2). The creation of these annual composites for the whole country is done through specific tools developed in the Python language [23]. Figure 2 shows the final result of the phase 1 using an RGB combination 453 that remarks the healthy vegetation distribution (brown tones), related mainly to forest distribution.

Although the use of the annual median values of reflectance reduces the areas without information, the error by omission could also increase if the forest cover changes occur during the last year's months. To avoid this problem, after the process described above, a visual verification and manual adjustment of the results is performed using the data of the last pixel of the year (last pixel) and the last available image of the last year's quarter.

\subsubsection{Phase 2: digital image processing}

This involves the automated detection of changes in forest areas using algorithms, the visual verification of detected changes, and the execution of a quality control protocol. 
Colombian Forest Monitoring System: Assessing Deforestation in an Environmental Complex... DOI: http://dx.doi.org/10.5772/intechopen.86143

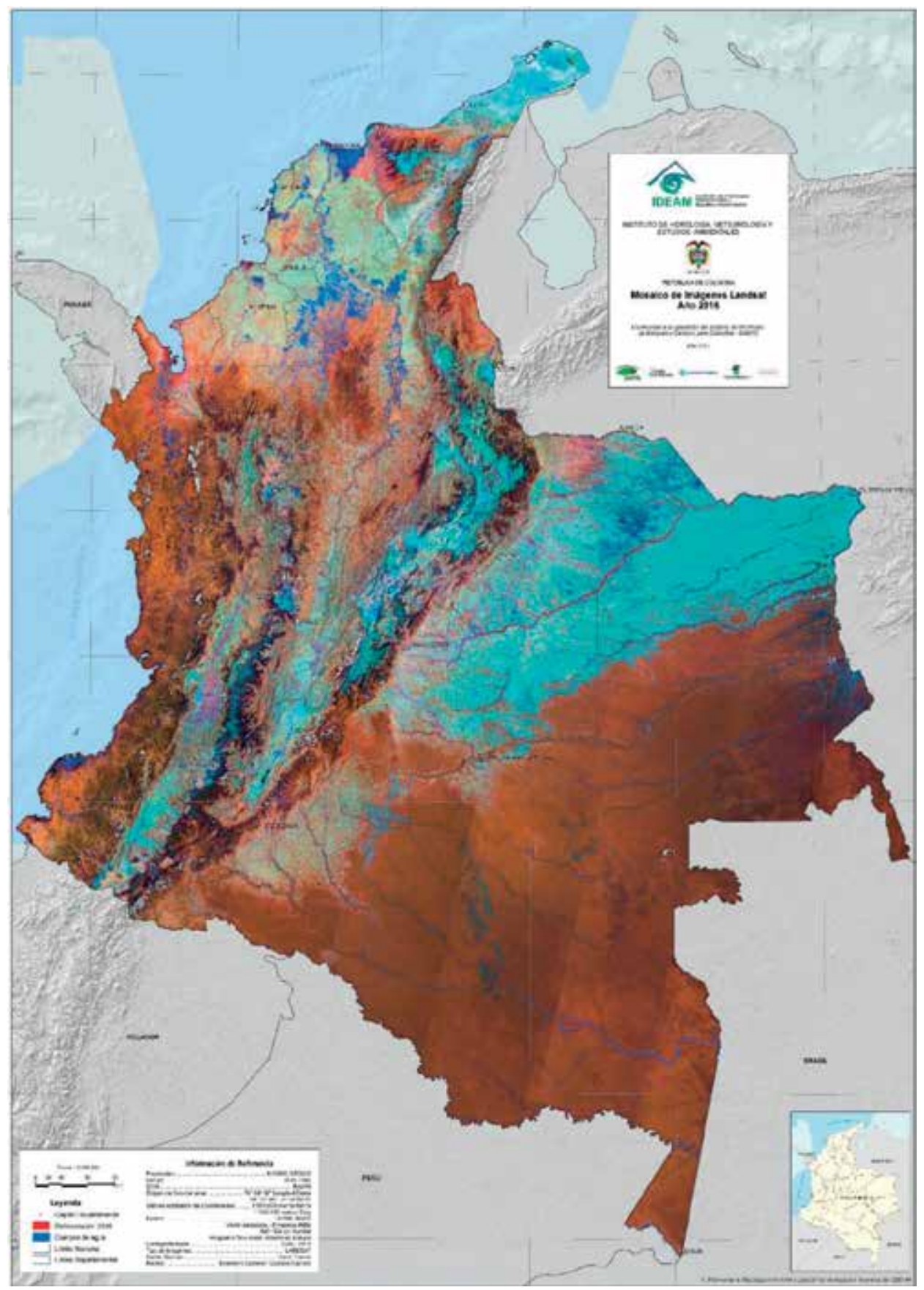

Figure 2.

Annual image composite of surface reflectance for the year 2017 (Landsat ETM and Landsat 8 OLI images from January 1 to December 31).

\subsubsection{Step 7: detection of changes}

To identify forest cover change, a direct and automated method is used applying the principal component analysis (PCA), over the image annual composite generated in the previous step, to then make a reclassification of the values of the pixels to the value of the corresponding class. The legend and the values assigned in the 
reclassification for each class are as follows: (1) stable forest, (2) stable nonforest, (3) deforestation, (4) regeneration, and (5) without information (corresponding to masked data). To adjust the areas without information detected for each reporting period, a time series analysis is applied to verify the temporal consistency. For this process, the information from the most recent reporting period is considered, and the areas "without information" are adjusted compared with the other reporting periods.

\subsubsection{Step 8: visual verification of the changes detected}

Once the PCA process has been executed by scene or set of scenes, each interpreter codes each pixel to the corresponding thematic class, obtaining a preliminary forest change map with the following classes or strata:

\section{Stable forest}

\section{Deforestation}

\section{No information}

\section{Regeneration}

\section{Stable Nonforest.}

For this step, each interpreter uses the following information: (i) the last images of each reference year, (ii) the annual composite images for each reference year, and (iii) the median compounds for the last quarter of the reference year. By implementing this step, we seek to evaluate and revise the first version of the map of forest cover change in order to identify inconsistencies with respect to the changes detected in previous years and to generate an adjusted version of the map.

\subsubsection{Step 9: quality control}

The quality control process involves monitoring all the technical steps executed, from the download of the satellite images and the intermediate products to the final results of the Forest Change Map and Forest Cover Map. The SMByC has consolidated a set of tools to guarantee the quality, completeness, and consistency of the data, through a Python script executed in ArcGIS $@$ to produce quality control reports for each scene.

\subsubsection{Phase 3: thematic accuracy assessment}

Thematic accuracy assessment allows generating reliability metrics of the official forest monitoring data generated to: (1) avoid bias, which means to avoid a systematic underestimate or overestimate of forest cover and forest change, and (2) to reduce uncertainty as much as possible [24], in line with guidelines proposed by the Global Forest Observation Initiative (GFOI). This procedure applies user's precision (commission error) and the producer's precision (omission error) following recommendations developed by [25] over the forest change map. For the execution of thematic accuracy assessment, a team of four experts is formed under the following structure:

- A leader of the evaluation, in charge of coordinating the interpreters, who designs and implements a probabilistic sample. The leader performs the consolidation and verification of the interpretation as well as the accuracy analysis. 
- Three interpreters, with extensive experience in visual and digital interpretation, who are trained to apply the forest definition in medium-resolution optical images.

\subsubsection{Step 10: sampling design}

This analysis consists of the implementation of a stratified random sampling. The size of the sample $(n)$ is selected following [26]. The assigned proportion of each class uses a proportional allocation based on the area of each stratum compared to the total area allocated [27]. The proportions of each of the strata are based on the forest change map for the reference year, which are as follows: (1) stable forest, (2) stable nonforest, and (3) deforestation. Additionally, each stratum is subdivided based on a deforestation risk map that identifies two main areas (low risk and high risk) based on the historical trends of deforestation.

Equation (1) shows the math expression used to calculate the proportion $\left(W_{i}\right)$ of mapped area $\left(A_{m, i}\right)$ for each stratum $i$, related to the total area of all classes $\left(A_{t o t}\right)$ :

$$
W_{i}=\frac{A_{m, i}}{A_{t o t}}
$$

The classes with the largest mapped area are assigned a p-value of 0.9 , considering that these classes have a high accuracy, while the change classes, high-risk deforestation areas (DEF-AR) and low-risk deforestation areas (DEF-BR), are assigned a $p$-value of 0.8 , considering that for these classes, there is a greater uncertainty and therefore less accuracy.

The standard error $\left(S_{i}\right)$ associated to each class is calculated as the square root of the variance. The total size of the sample $(n)$ is calculated as the sum of the products of the area ratio $\left(W_{i}\right)$, associated to each class $i$, multiplied by the standard errors $\left(S_{i}\right)$ of each class, and divided by a general standard error of the classification $\left(S_{o}\right)$, squared Eq. (2)

$$
n=\left[\frac{\sum_{i=1}^{n}\left(W_{i} S_{i}\right)}{S_{o}}\right]^{2}
$$

For each reference year, a value of 0.005 is assumed for the expected general standard error of classification. The assigned proportion of each stratum is based on a simplified approach to the optimum, based on the proportion of area of each stratum compared to the total area allocated. Thus, the smallest strata are adjusted by minimizing the variance estimator for the accuracy of these user classes, in accordance with the recommendations of [25].

\subsubsection{Step 11: sampling implementation}

The sampling implementation, as well as the sampling point interpretation, is done in Acatama, a self-developed software that is available for QGIS at https:// bitbucket.org/smbyc/qgisplugin-acatama.

\subsubsection{Step 12: sampling points interpretation}

The interpreter team performs a visual interpretation of each unit of verification (point), applying the forest and deforestation definitions adopted by the SMByC. This procedure is applied using Acatama tool [14] that allows defining a fixed spatial reference scale for interpretation, using all the satellite data available. 
During this procedure, we also perform the classification and identify the nonclassified samples (Figure 3).

We used the satellite data as reference data for the sampling point interpretation for periods before and after annual composite generated in Step 6. Also, we used Google Earth Engine, Bing images, or other high-resolution image repositories if available.

\subsubsection{Step 13: error matrix and confidence intervals}

Thematic accuracy assessment of the forest cover and deforestation data for the reference year is done by constructing a confusion matrix [20], using the data generated in the previous step. Subsequently, from the error matrix, a new matrix is constructed and is expressed in terms of the proportion of the estimated area.

\subsubsection{Phase 4: calculations and reports}

To calculate the deforested area between two analysis periods, only the areas with available data in the two analysis periods are considered, so the associated (un) certainty that the event occurred in the period is analyzed.

Forest losses detected after one or several dates without information were not included in the reports in order to avoid overestimated rates due to different factors (e.g., high cloudiness or sensor failures). After each deforestation monitoring period, an analysis of consistency of the time series is performed, verifying that each pixel marked as deforestation has not been marked in the previous periods (at least 6 years) as deforested. If this is the case, the most recent result is corrected and marked as no forest (NB) or the specific area is reviewed retrospectively. The same procedure is applied for "forest recovering," maintaining the same check process in which a pixel marked as deforested could not be assigned as "forest" class until after 6 years.

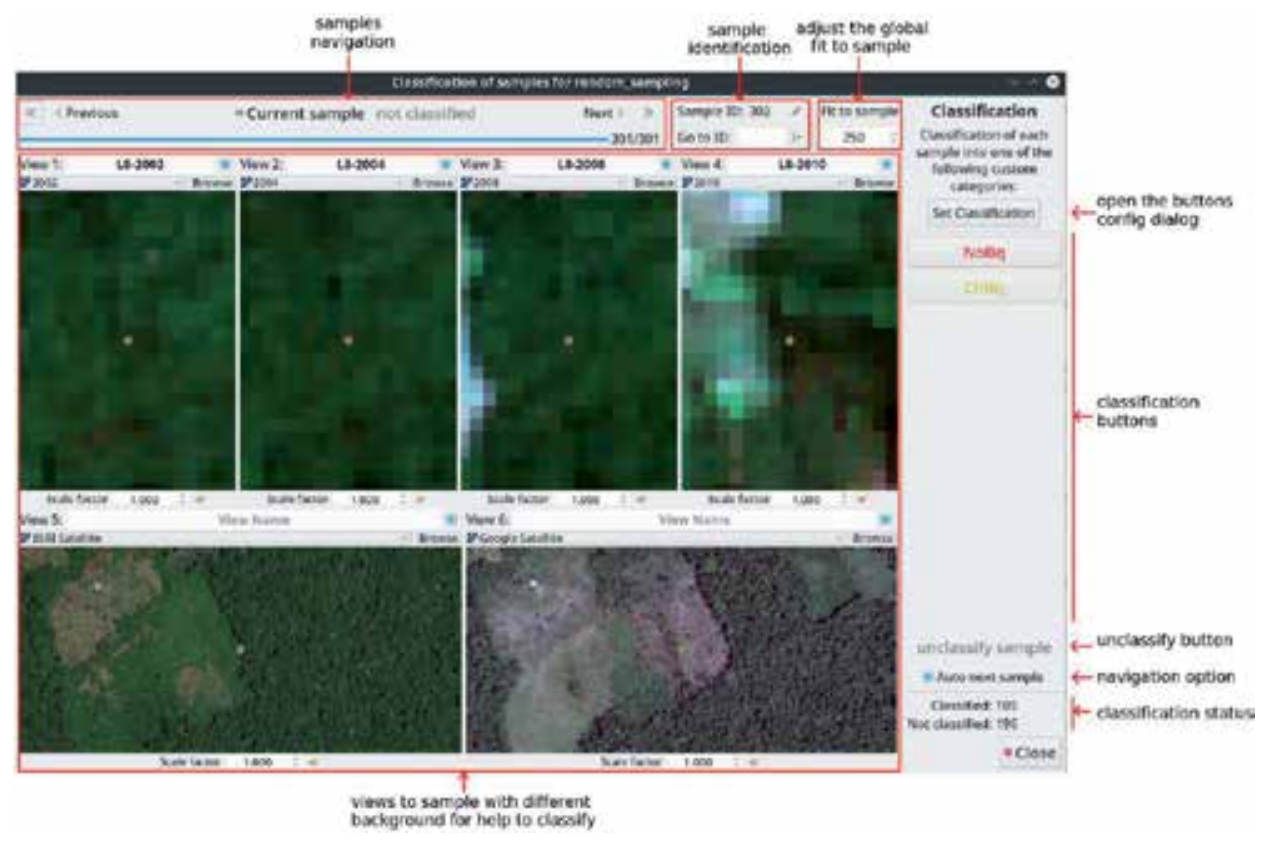

Figure 3.

Acatama QGIS@ tool. Verification window for sampling point interpretation. 
Colombian Forest Monitoring System: Assessing Deforestation in an Environmental Complex... DOI: http://dx.doi.org/10.5772/intechopen.86143

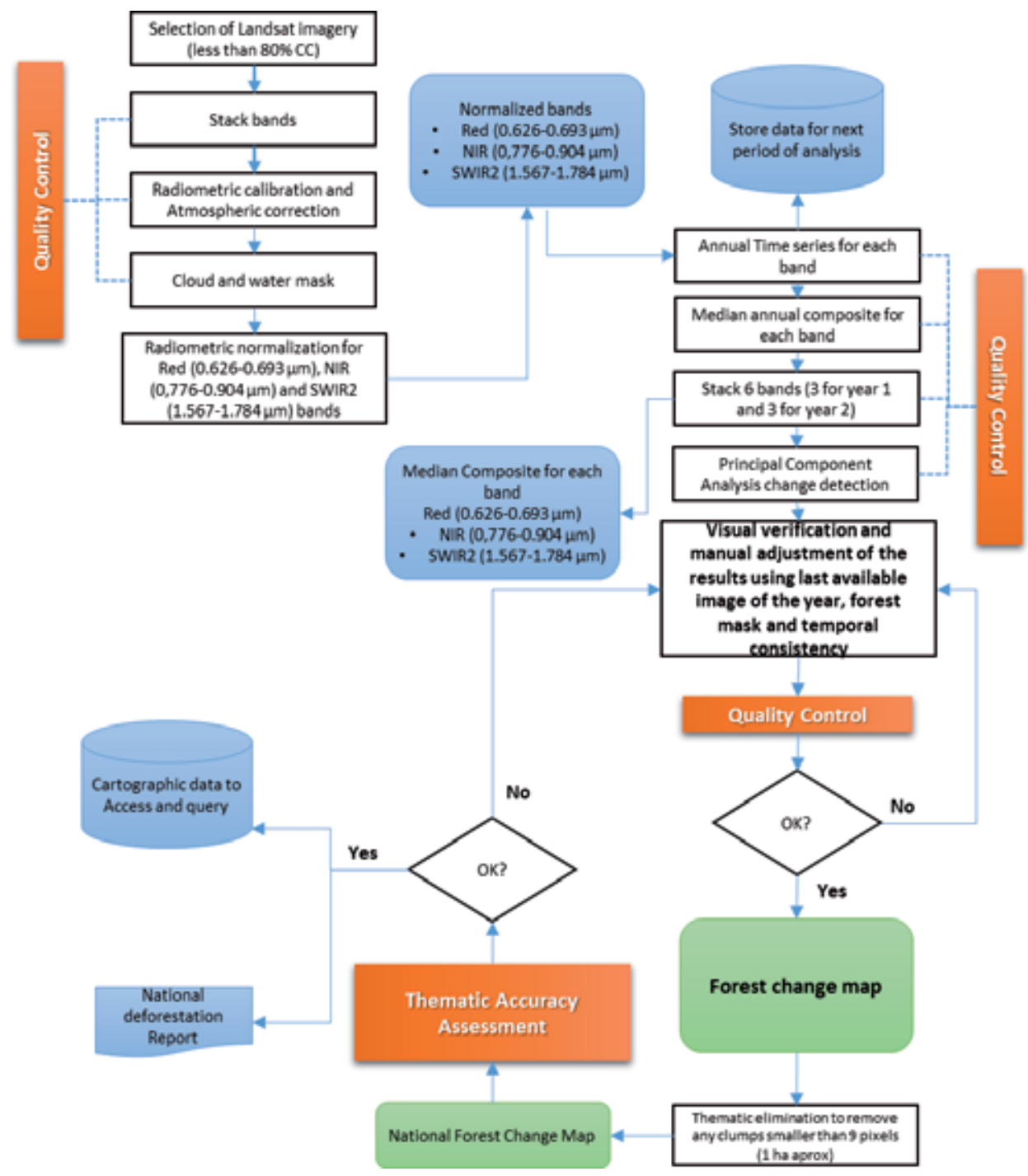

Figure 4.

Methodological workflow applied in the digital image processing protocol V.2 (Source [11]).

The implementation of this methodology allowed to identify the changes in forest cover (expressed in hectares) for the last 27 years in Colombia, generating reports for the years 1990, 2000, 2005, 2010, and 2012, and five annual reports for the years 2013-2017. Figure 4 presents the workflow implemented. Additional information is available at [28].

\section{Results and discussion}

\subsection{Forest cover in Colombia}

In 2017, the natural forest area in Colombia was 59'312.369 ha, which represented $51.9 \%$ of the continental and insular Colombian territory (Figure 5). At a regional level, some provinces show high forest cover like Amazonas (97.3\%), Vaupés (96.5\%), and Guainía (92.9\%). Likewise, other departments like Atlántico (1.4\%), Sucre $(2.6 \%)$, and Cesar $(8.7 \%)$ have the smallest area of their territory with natural forests. 


\subsection{Patterns of forest loss in Colombia}

In the last 27 years (1990-2017), Colombia lost more than 6.7 million ha of natural forest. Only in the last 5 years (2013-2017), a forest loss of 783,899 ha was identified. Deforestation has mainly been concentrated in the so-called "Colombian Amazon deforestation arc," located between the departments of Putumayo, Caquetá, Meta, and Guaviare. Other deforestation hotspots are Serranía de San Lucas (Antioquia and Bolívar departments), Chocó department, and Catatumbo (Norte de Santander department) (see Figure 5).

In regional terms, the Colombian Amazon presented the highest deforestation in the last 5 years (2013-2017), accumulating 46\% of the total deforestation, especially in areas

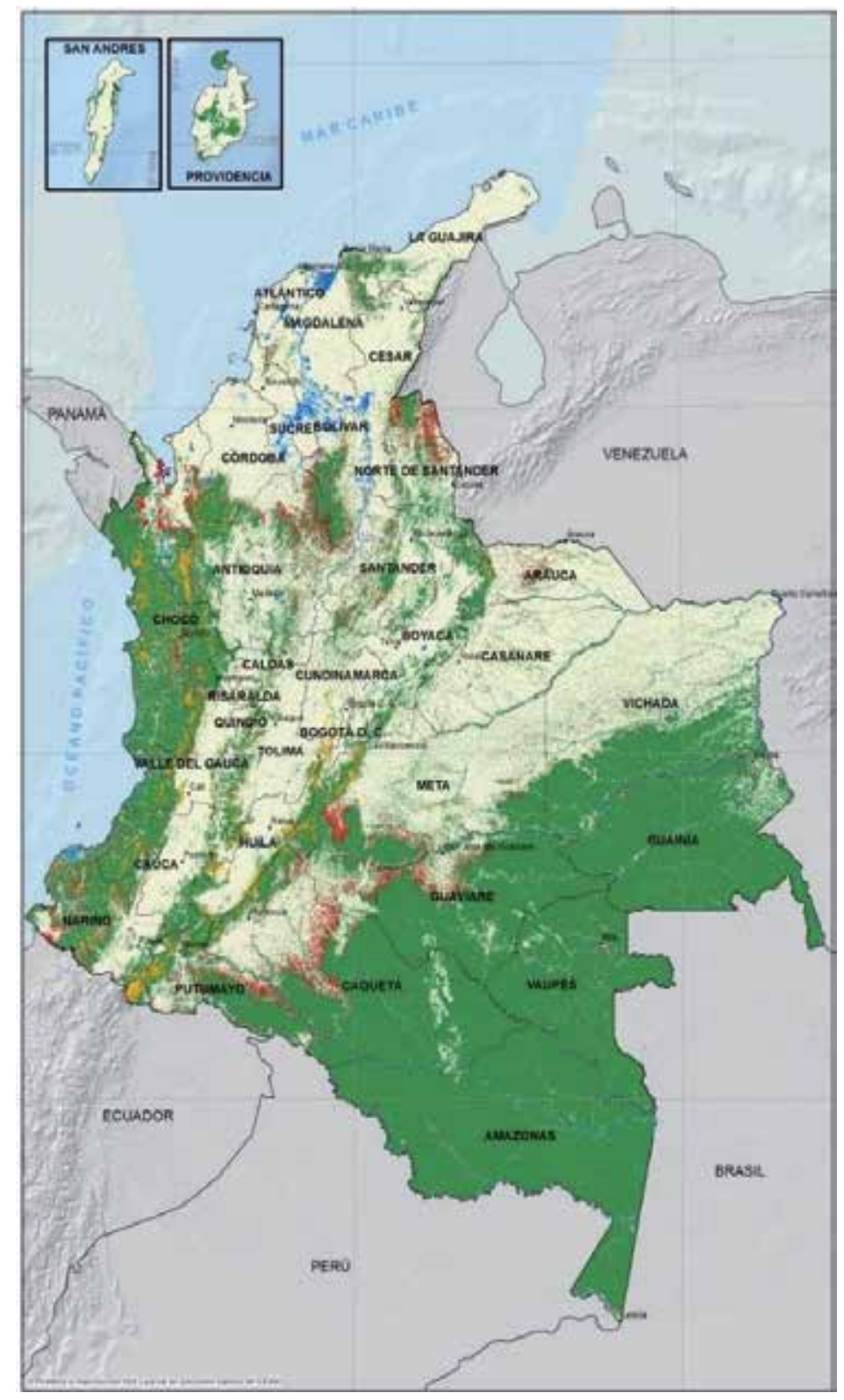

Figure 5.

Forest cover in Colombia for the year 2017 (green) and deforestation distribution for the period 2013-2017 (red). 
such as the so-called "Sabanas del Yarí-4" (limits of Meta and Caquetá departments), northwest of the Guaviare department-2, Meta department-3, and the middle and lower sectors of the Río Caguán basin-1 (Caquetá department), (Figure 6).

During 2017, the deforestation in Colombia raised to 219,973 ha, an increase of $23 \%$ compared with the deforestation reported for the year 2016. In total, $65 \%$ of forest loss was concentrated in the Colombian Amazon deforestation arc.

It is important to mention that deforestation is ostensibly less in areas such as National Natural Parks, Indigenous Lands, and Afro Colombian community Lands, compared with the rest of the country. In 2017, in 723 municipalities, at least 1 ha was deforested.

Overall, $74 \%$ of the deforestation in the whole country was concentrated in 25 municipalities, being San Vicente del Cagüan (Caquetá department), Cartagena del Chairá (Caquetá department), San José del Guaviare (Guaviare department), La Macarena (Meta department), and Calamar (Guaviare department), the ones with the largest deforested area.

\subsection{Rates of forest loss}

At the national level, in 2017, the deforestation rate in Colombia was -0.38 , which is the highest value of the last 17 years, only overpassed by the rates registered in the

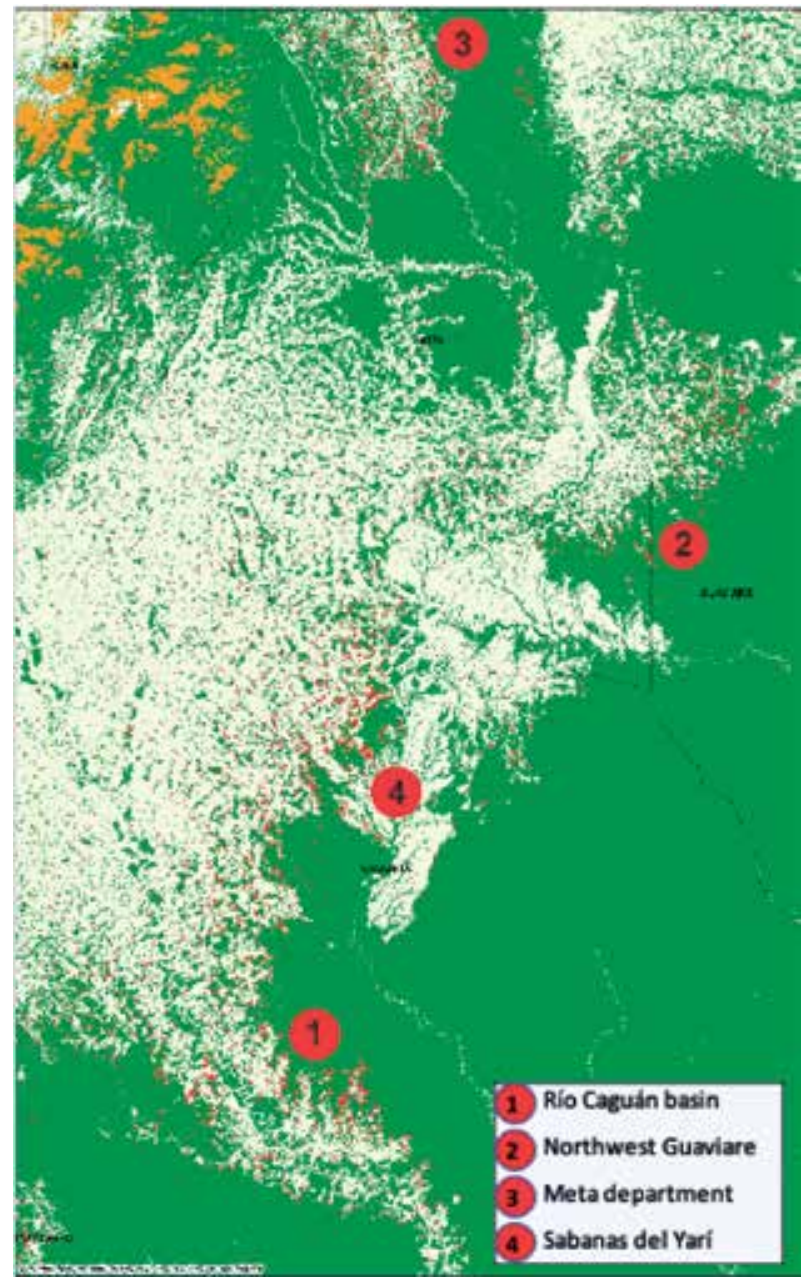

Figure 6.

Main deforestation hotspots in the Colombian Amazon (period 2013-2017). 
1990s. At the regional level, there were departments with deforestation rates ostensibly lower than the national average, such as the case of the departments of Amazonas $(-0.01 \%)$, Vaupés $(-0.04 \%)$, and Vichada $(-0.09 \%)$. On the contrary, the deforestation rate in Antioquia (-0.96), Caquetá $(-0.92)$, and Guaviare $(-0.8)$ was ostensibly higher than the national average. In these cases, the government should put special attention because they are well above the average world deforestation rate of $-0.21 \%$ [26], and even above countries such as Indonesia $(-0.7 \%)$ or Bolivia $(-0.5 \%)$.

\subsection{The early warning system}

The implementation of the described methodology has allowed to identify the main recent active cores of deforestation for the year 2018. IDEAM generates four deforestation early warning bulletins per year that are available through the institutional platform. These bulletins are based on the digital image processing of low spatial resolution (MODIS Terra/Aqua), medium spatial resolution (sentinels 1 and 2), and high spatial resolution satellite data (Planet Scope), with the use of automated change detection algorithms, to detect quarterly (inclusive monthly) the main forest loss cores. With these bulletins, users can know the distribution and geographic location of the early alerts (including specific coordinates) or the location of the active deforestation nuclei (maps with tonalities indicate the magnitude of the alert), to detect the forest areas with loss of natural forest (Figure 7). This information is useful as a basis for effective control to carry out timely actions against activities such as the illegal mining, illicit crops, praderization, illegal logging, conversion to agricultural crops, and forest fires, among others.

In 2018, it was identified that the arc of deforestation in the Colombian Amazon is the area that concentrated the greatest warning of deforestation, mainly in the first and fourth quarters. Other areas with active deforestation cores are Catatumbo (Norte de Santander department), Serranía de San Lucas (Antioquia and Bolivar departments), Paramillo (Antioquia and Córdoba departments), and some sectors of Cauca and Chocó departments.

Likewise, the IDEAM performs an analysis of active fires [29] as a proxy of active deforestation, which monitors the possible occurrence of burning areas or active fires. This platform (see Figure 8) allows to access active fire information on a daily basis or an aggregated basis for the national, departmental, and regional levels since 2000.

\subsection{Drivers and agents of deforestation}

Agricultural and livestock activities generate the greatest pressures on natural areas, by establishing productive systems that are characterized by low levels of productivity and for promoting new zones of colonization or expansion from the existing ones [30]. Traditional agricultural production represents about $10 \%$ of the total agricultural productive area of the country $[2,31]$. The activity represented about $7 \%$ of the new land transformed between 2005 and 2012, mainly impacting the Andean and Amazonian regions, among which $86 \%$ of the agricultural land transformed in Colombia is distributed. However, livestock, especially cattle, which is one of the main economic activities of the country, appears as the main driver of deforestation at the national level. Overall, we have estimated that $51 \%$ of the total forest loss was due to the increase of areas in pastures, in theory to settle livestock productive systems [11].

The production of illicit crops, in particular coca leaf, has also been recognized as an important cause of deforestation [32]. Although its direct impact is usually reduced compared to other causes of deforestation, the fragmentation of the forest matrix caused by this driver has a decisive indirect impact on the advance of the agricultural frontier [4]. In 2017, the estimated proportion of forest loss due to illegal 


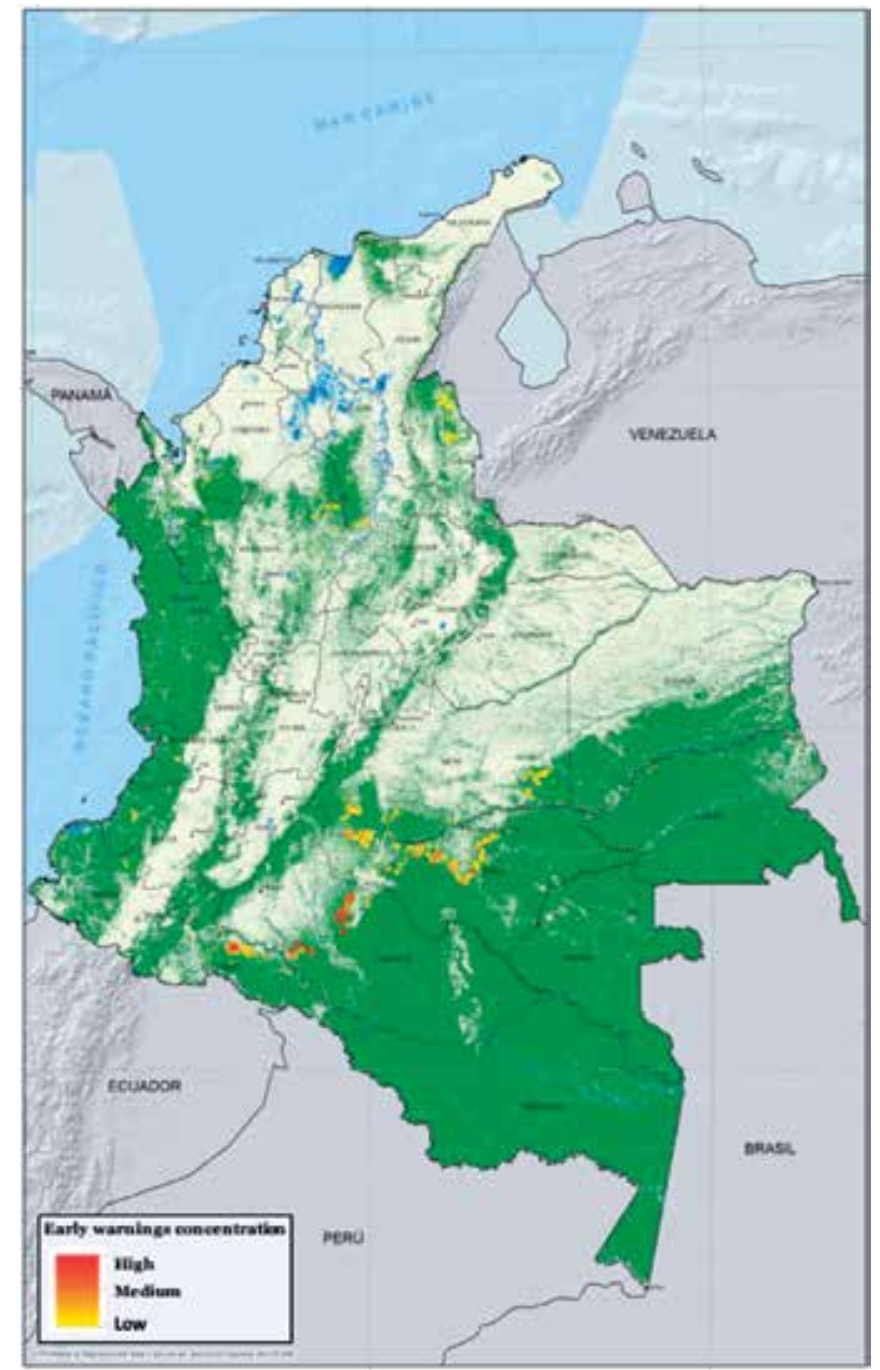

Figure 7.

Deforestation early warning persistence for the year 2018.

crops is 6\% [33] and is primarily concentrated in the hotspots of deforestation of the country. Another smaller but still important driver of deforestation is forest fires related to land tenure conflicts, certain agricultural management practices, activities such as hunting, pest and weed control, and expansion of crops and pastures for livestock $[34,35]$. In our work, we identified that 2800 ha were deforested by 117 fires in 61 municipalities, which is equivalent to $2.3 \%$ of the total deforested in the period of 2014-2015 [4, 36]. Likewise, illegal mining is having an important effect on forest loss. In total, we quantified the direct loss of natural forest cover associated with alluvial gold exploitation activities in 2681 ha for the year 2014 [37]. In 2015, deforestation associated with alluvial gold mining reached 7890 ha (7\% of national deforestation) and was concentrated mainly in three natural regions (Pacific, Andes, and Caribbean) [33]. A study carried out by UNODC and the Government of Colombia indicates that $38 \%$ of the territory affected by alluvial gold exploitation at the national level registers the presence of illicit crops $[5,37]$. In the territories affected by coca, the phenomenon of alluvial gold exploitation has been growing rapidly, in a pattern of clear spatial and social association between the two activities [4]. 


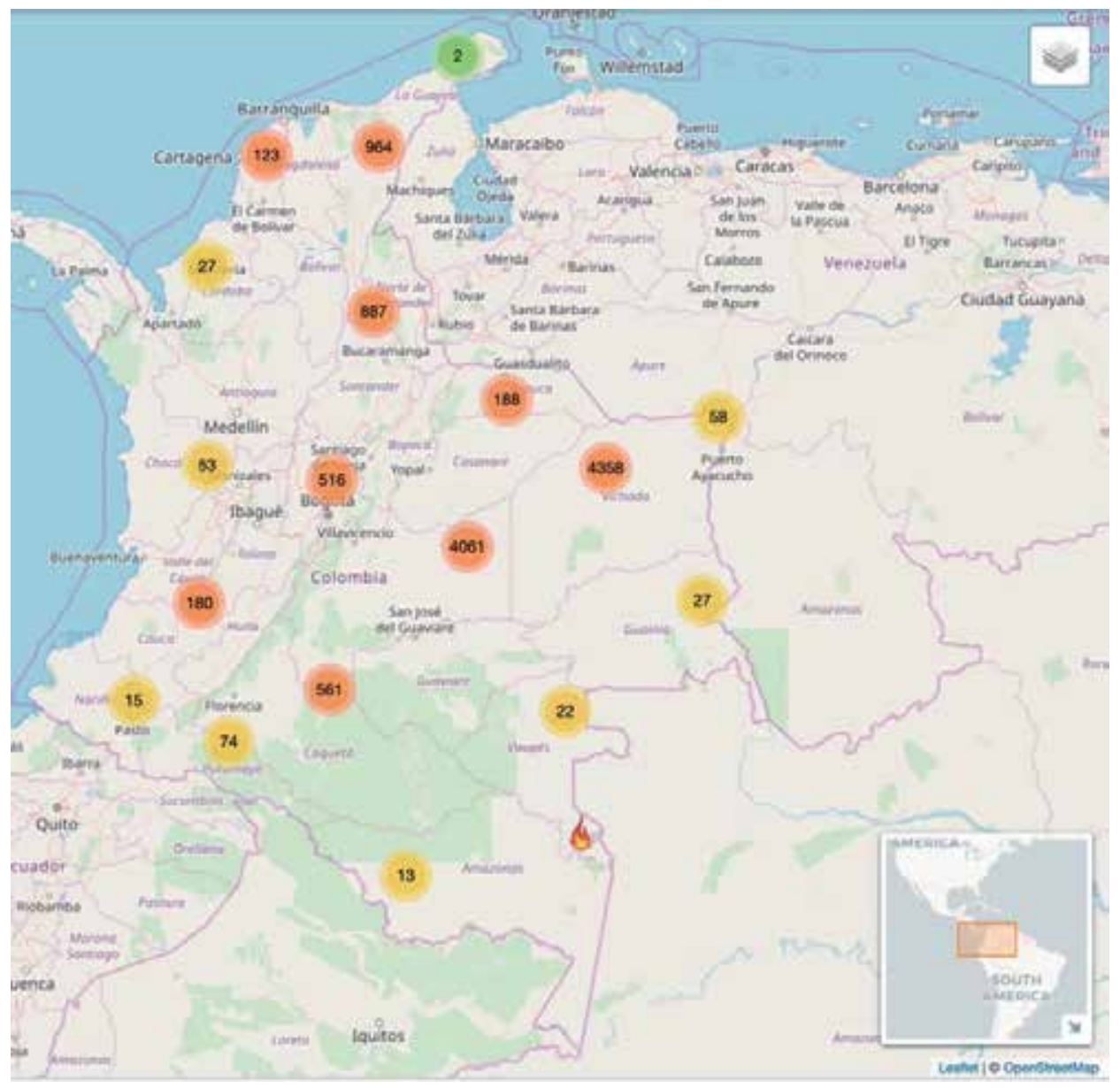

Figure 8.

Active fire platform at IDEAM's web portal [29].

Finally, since the peace talks began between Colombia's government and the Revolutionary Armed Forces of Colombia (FARC) in 2012, experts warned that the postconflict period could have negative consequences of forests, mainly due to access to areas that were restricted during the conflict and the lack of planning for the sustainable development of these territories $[38,39]$. In the vast majority of cases, the areas with the greatest forest presence and the threat of deforestation are located in small- and medium-sized municipalities (up to 100,000 inhabitants), where the end of the conflict would surely increase its development at expenses of the removal of vast areas covered by natural forests. Even in the most environmentally optimistic postconflict scenario, it can be expected that at least during a transitional period, the first economic benefits at the end of the conflict will come from the abundant natural capital available in the region. In this context of accelerated economic growth with few restrictions, forests will continue to be one of the most affected resources [4].

\section{Conclusions}

Colombia is considered a forestry country. The natural forest area covers $59^{\prime} 312.369$ ha, which represents $51.9 \%$ of continental and insular Colombian territory. Nevertheless, in the last 27 years (1990-2017), Colombia lost more than 6.7 million ha 
of natural forest, and in the last 5 years (2013-2017), the estimated forest loss was of 783,899 ha. This finding ranks Colombia within the top 15 countries with one of the highest forest covers on earth (52\%) and shows the high utility and need to maintain and improve the Forest and Carbon Monitoring System for Colombia-SMByC.

Overall, the SMByC is a prominent tool to help the country to accomplish with its commitments in terms of minimizing deforestation and carbon emissions in the coming decade. Forest monitoring indicators have a special importance to follow one of the goals established at 2030 for the Sustainable Development Goals-SGD, related to the conservation of at least $50 \%$ of the continental and insular territory covered by forests. Here, we show that based on the optimal use of digital image processing protocol, it is possible to generate reliable official information on the distribution, extension, and changes in forest cover at the national level. The SMByC will certainly play a key role on facing the expected changes of the ongoing climate change.

Since many of the armed conflicts in tropical regions occur in areas with high forest cover, like the one we have had in Colombia, the main challenges for both society and government are to take advantage of the great opportunity contributing toward peacebuilding, reducing deforestation, while promoting sustainable development [40].

\section{Acknowledgements}

The authors express their special thanks to all of the assistants of the IDEAM Forest and Carbon Monitoring System that helped with data processing. We emphasize on the help of Carol Franco, Rosa Lozano, Mónica Rivera, Omar Sotelo, Ivan Pérez, Edilneyi Zuñiga, and Alvaro Cubillos, and also, for all the support and comments given by officials of the Ecosystems Division at IDEAM.

This work was supported by the REM Colombia Amazon Vision Program and the GEF 5 Initiative "Corazón de la Amazonia."

\section{Author details}

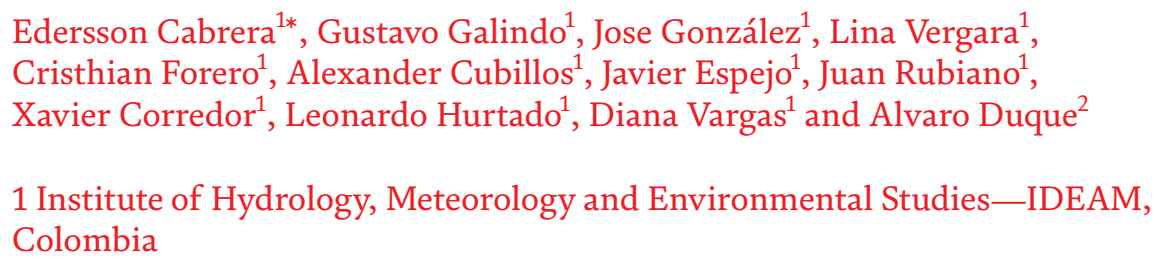

2 Departamento de Ciencias Forestales, Universidad Nacional de Colombia-Sede Medellín, Colombia

*Address all correspondence to: ecabreram@ideam.gov.co

\section{IntechOpen}

(C) 2019 The Author(s). Licensee IntechOpen. This chapter is distributed under the terms of the Creative Commons Attribution License (http://creativecommons.org/licenses/ by/3.0), which permits unrestricted use, distribution, and reproduction in any medium, provided the original work is properly cited. (cc) BY 


\section{References}

[1] Palacio G, editor. Naturaleza en Disputa: Ensayos de Historia Ambiental de Colombia 1850-1995. Bogotá D.C.: Universidad Nacional de Colombia; 2001

[2] Etter A, McAlpine C, Pullar D, Possingham $\mathrm{H}$. Modelling the conversion of Colombian lowland ecosystems since 1940: Drivers, patterns and rates. Journal of Environmental Management. 2006;79:74-87

[3] Uribe T. Exploitation and war: The configuration of national borders and the pillaging of indigenous people in the Amazon. Memory and Society. 2013;17(34):34-48. ISSN: 0122-5197

[4] González J, Cubillos A, Chadid M, Cubillos A, Arias M, Zúñiga E, et al. Caracterización de las Principales Causas y Agentes de la Deforestación a Nivel Nacional Período 2005-2015. Bogotá: Instituto de Hidrología, Meteorología y Estudios AmbientalesIDEAM. Ministerio de Ambiente y Desarrollo Sostenible. Programa ONUREDD Colombia; 2018

[5] UNODC, MinJusticia. Explotación de oro de Aluvión. Evidencias a Partir de Percepción Remota, Año 2014. 2016. Available from: https://www.unodc. org/documents/colombia/2016/junio/ Explotacion_de_Oro_de_Aluvion.pdf (Spanish version)

[6] Galindo G, Espejo OJ, Rubiano JC, Vergara LK, Cabrera E. Protocolo de Procesamiento Digital de Imágenes para la Cuantificación de la Deforestación en Colombia. V 2.0. Bogotá D.C., Colombia: Instituto de Hidrología, Meteorología y Estudios AmbientalesIDEAM; 2014. 52 pp

[7] MADS and IDEAM. Ministry of Environment and Sustainable development-MADS and Institute of Hydrology, Meteorology and Environmental Studies-IDEAM. 2014.
Available from: https://redd.unfccc.int/ files $/ 20.10 .15 \mathrm{col}$ frel_english_clean_ numbers.pdf (Spanish version)

[8] Available from: http://www. ideam.gov.co/web/ecosistemas/ ecosistemas-recursos-forestales

[9] Available from: https://unfccc. int/sites/default/files/resource/docs/ cop7/13a01.pdf

[10] Ministerio de Medio Ambiente, Vivienda y Desarrollo Territorial_MAVDT. Definición de Bosque para Proyectos de uso del Suelo, Cambio de uso del Suelo y Silvicultura para el Primer Período de Compromiso. Bogotá D.C., Colombia; 2002. 19 p

[11] Pérez M, Urrego D, Rodríguez C, Samaniego X, Morales A, Vargas D, Cabrera E, Galindo G, González J, Vergara L, Barbosa A, Turriago J, Hernández C. Anexo Técnico de Conformidad con lo Establecido en la Decisión. 2019. Available from: https://unfccc.int/sites/default/files/ resource/47096251_Colombia-BUR2-12BUR\%20COLOMBIA\%20SPANISH. pdf (Spanish version)

[12] Defries R, Achard F, Brown S, Herold M, Murdiyarso D, Schalamadinger B, De Souza C. Reducing greenhouse gas Emissions from Deforestation in developing countries: Considerations for monitoring and measuring. Report of the Global Terrestrial Observing System (GTOS) Number 46. Roma, Italia: GOFC-GOLD Report 26; 2006. p. 23

[13] United States Geological Service. USGS Landsat Project. 2014. Disponible en línea en: http://landsat.usgs.gov/

[14] Galindo G, Vergara L, Forero C, Espejo J, Rubiano J, Corredor X, Hurtado L, Cabrera E. 2019. Forest Monitoring in Colombia: A Novel 
Approach Based on Digital Image Processing Methodology. In press

[15] Available from: https://smbyc. bitbucket.io/qgisplugins/cloudmasking/

[16] Available from: https://smbyc. bitbucket.io/scripts/layer_stack/

[17] Available from: https://smbyc. bitbucket.io/scripts/rename_landsat/

[18] Available from: https:// smbyc.bitbucket.io/scripts/ extract_landsat_files/

[19] Available from: https://smbyc. bitbucket.io/qgisplugins/cloudmasking/ cloud_filters/

[20] Olthof I, Pouliot D, Fernandes R, Latifovic R. Landsat-7 ETM+ radiometric normalization comparison for northern mapping applications. Remote Sensing of Environment. 2005;95(3):388-398

[21] Potapov PV, Turubanova S, Hansen MC, Adusei B, Broich M, Altstatt A, et al. Quantifying forest cover loss in Democratic Republic of the Congo, 2000-2010, with Landsat ETM+ data. Remote Sensing of Environment. 2012;122:106-116

[22] Available from: https://bitbucket.org/ smbyc/arrnorm

[23] Available from: https://smbyc. bitbucket.io/stackcomposed/

[24] Penman J, Gytarsky M, Hiraishi T, Krug T, Kruger D, Pipatti R, et al. Good Practice Guidance for Land Use, LandUse Change and Forestry. Hayama, Japan: IPCC by the Institute for Global Environmental Strategies; 2003

[25] Olofsson P, Foody GM, Herold M, Stehman SV, Woodcock CE, Wulder MA. Good practices for estimating area and assessing accuracy of land change. Remote Sensing of Environment. 2014;148:42-57. DOI: 10.1016/j. rse.2014.02.015
[26] Cochran WG. Sampling Techniques. 3rd ed. New York: John Wiley \& Sons; 1977

[27] Stehman SV. Impact of sample size allocation when using stratified random sampling to estimate accuracy and area of land-cover change. Remote Sensing Letters. 2012;3(2):111-120. DOI: 10.1080/01431161.2010.541950

[28] Ministerio de Ambiente y Desarrollo Sostenible e Instituto de Hidrología, Meteorología y Estudios Ambientales. Reporte de Reducción de EmisionesAño 2015. Bioma Amazonia, Colombia. Septiembre de 2018. 2018. Disponible en: http://visionamazonia.minambiente. gov.co/content/uploads/2019/01/ Reporte_REs-REM2015_09262018.pdf

[29] Available from: http:// incendiosactivos.ideam.gov.co/

[30] Castiblanco C, Etter A, y Mitchell T. Oil palm plantations in Colombia: A model of future expansion. Journal of Environmental Science \& Policy. 2013;27:172-183. DOI: 10.1016/j. envsci.2013.01.003

[31] Ministerio de Agricultura y Desarrollo Rural, Colombia. MADR. Anuario Estadístico del Sector Agropecuario 2013. 2014. Available from: https://agronet.gov.co/www/ htm3b/public/Anuario/

[32] Dávalos LM, Bejarano AC, Hall MA, Correa HL, Corthals A, y Espejo OJ. Forests and drugs: Coca-driven deforestation in tropical biodiversity hotspots. Environmental Science \& Technology. 2011. p. 853-858

[33] IDEAM. Actualización de Cifras de Monitoreo de Bosque. Año 2017. 2018. Avilable from: http://documentacion. ideam.gov.co/openbiblio/ bvirtual/023835/Resultados_Monitoreo_ Deforestacion_2017.pdf

[34] Armenteras D, González T, Retana J. Forest fragmentation and 
edge influence on fire occurrence and intensity under different management types in Amazon forests. Biological Conservation. 2013;159:73-79. DOI: 10.1016/j.biocon.2012.10.026

[35] Barreto JS, González T, Armenteras D. Dinámica espacio temporal de ocurrencia de incendios en zonas con diferentes tipos de manejo en el noreste de la Amazonia: ¿Barrera Efectiva? Revista Facultad de Ciencias Básicas. 2017;13(1):19-25

[36] IDEAM. Presentación Lanzamiento Cifras de Deforestación Anual 2015. 2016. Bogotá, Colombia, Septiembre. Available from: http://www.andi. com.co/Ambiental/SiteAssets/ Presentaci\%C3\%B3n\%20Tasa\%20 Deforestacion\%20IDEAM.pdf

[37] Government of Colombia and UNODC 2014. Caracterización Regional de la problemática asociada a las drogas ilícitas en el departamento de Chocó

[38] MADS, IDEAM. Nivel de Referencia de Emisiones Forestales para el Bioma de la Amazonia colombiana. 2015

[39] CERAC, y PNUD. ¿Qué ganará Colombia con la paz? 2014. Available from: http://www.co.undp.org/content/ dam/colombia/docs/Paz/undp-coganapaz-2014.pdf

[40] Castro-Nunez A, Mertza O, Buritica A, Sosa C, Lee S. Land related grievances shape tropical forest-cover in areas affected by armed-conflict. Applied Geography. 2017;85:39-50 


\title{
Deforestation in India: Consequences and Sustainable Solutions
}

\author{
Rima Kumari, Ayan Banerjee, Rahul Kumar, Amit Kumar, \\ Purabi Saikia and Mohammed Latif Khan
}

\begin{abstract}
Deforestation is one of the most pressing environmental issues that the world is facing currently. It is the conversion of forested land to non-forested land by humans. Deforestation occurs when a land dominated by naturally occurring trees is converted to provide certain services in response to the human demand. The indiscriminate felling of trees has resulted in a reduction of $3.16 \%$ in the global forest cover from 1990 to 2015. Although India has seen an increment in the total forest cover of ca. $1 \%$, still there are certain regions in the country that have sought a decrease in the forest cover. The main reasons attributed to the reduction in forest cover are shifting cultivation, rotational felling, other biotic pressures, diversion of forest lands for developmental activities, etc. Continuous illicit cutting of trees has impacted the microclimatic conditions, hydrological cycle, soil quality, biodiversity, etc. of the country, thereby making the country more vulnerable for any uneventful happening. Sustainable forest management practices, alternatives for shifting cultivation, promotion of plantation outside the forest and the usage of certified forest products, etc. are some of the measures that can be adopted to curb the rate of deforestation.
\end{abstract}

Keywords: deforestation, forest cover, sustainable solutions

\section{Background}

Forest is a conditional renewable resource which can be regenerated but needs a certain period of time to maintain its sustainable functioning. In India, the forest resources have been found to be depleting at a pace which is much high [1]. Rapid industrialization, urbanization and over-exploitation have resulted not only in decline but also in permanent loss of forest cover to an alarming rate [2]. The major driver behind all these factors is the uncontrolled population growth of humans which leads to the dramatic increase in the demand for wood and forest products. The over-exploitation of forest resources has taken place beyond the sustained yields to fulfil the needs of humans, thus bringing a change in the net forest cover $[2,3]$. With the current rate of population explosion, the world population could be expected to increase from 7.6 billion to about 10 billion in the next 30 to 35 years [4]. The growing demand for food can be expected to rise by $50 \%$ in the given period, and it is a matter of serious concern. Rational utilization and proper management of 
the forest resources are the most viable ways to prevent mass destruction of forests and large-scale species extinction. It is necessary to find the links between the growing demands and meeting the demands in a sustainable manner. The scope of future studies must focus on the solution to establish this link by incorporating the principles of forestry, restoration ecology and natural resource economics.

Deforestation occurs when a land initially dominated by naturally occurring tree species is converted to provide certain services in response to the human demand. The UN Food and Agricultural Organization (FAO) has defined deforestation as the conversion of forest to another land use or the long-term reduction of tree canopy cover below the 10\% threshold. Forest areas around the world are majorly cleared for agriculture, logging, mining and large-scale developmental projects. The Food and Agricultural Organization [5] coordinated the Global Forest Resources Assessment (FRA) which reported a 3.16\% decline in the global forest cover from 1990 to 2015, and the total forest cover stands at about 30.6\% in the present time compared to $31.6 \%$ in 1990 . The rate at which the forest cover is declining poses a direct threat in the near future if not checked. With an estimated annual loss of 18.7 million acres, it is evident that future demands on forest resources would certainly lead to immense competition among nations [6]. Recently, in 2016, a study from the Maryland University reported that 73.4 million acres of the global tree cover were lost. Such a destruction of this essential and self-sustaining resource puts the implementation of the principle of sustainable development as mentioned in the Brundtland Report and Sustainable Development Goals of the 1992 of Rio Earth Summit in the state of question. And, it is an urgency to conserve the forests of which a vital part is already lost.

The value of forest is simple to understand but sometimes tough to quantify. The various values of the forest have been shown in Figure 1. Forest has a major contribution on the global economy and supports livelihood of the majority of rural populations in the world [7]. The direct uses of forest are most easy to quantify as it is directly related to economic returns. The indirect use and option value although play a major role in defining the valuation of the forest resources are seldom quantified and are being intangible in nature [8]. There is also a no-use value of the forest

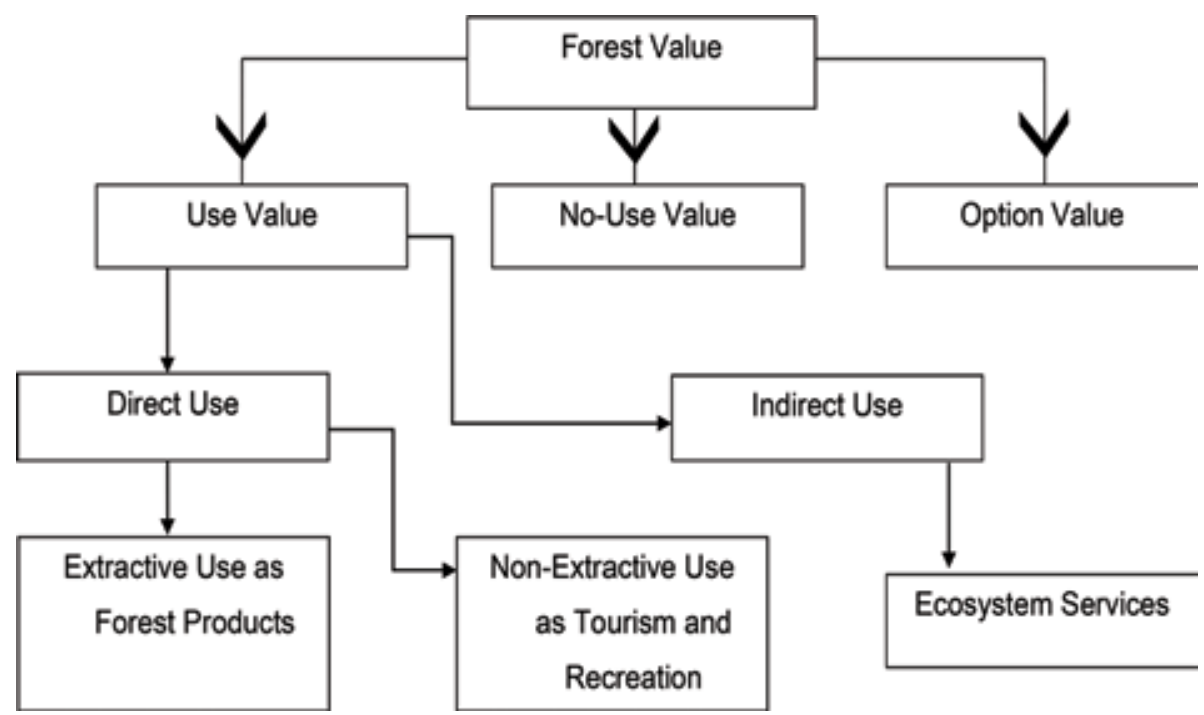

Figure 1.

Different values of forests ecosystems 
resources which considers leaving the current forest intact as a heritage for the future generation and for satisfaction and happiness of the current population. But, these eco-centric views alone cannot suffice the support for a change in policy and land use pattern. There are some other important values of forests that are difficult to quantify. One of the major roles that forests play is that it acts as a major carbon sink [9-11]. Plants utilize carbon dioxide in the process of photosynthesis and store it in the form of carbohydrates, and these carbohydrates reach the soil as dead organic matter and contribute to soil carbon sink. When forests are cleared, less $\mathrm{CO}_{2}$ is absorbed by plants, and atmospheric $\mathrm{CO}_{2}$ concentration increases with the passage of time due to unavailable sink. Also, there is a marked reduction in soil organic carbon with the loss of vegetation cover, thereby affecting the productivity of the ecosystem. Productivity is believed to be an indicator of carbon assimilation capacity, and hence the more productive the forests are, the more carbon it stores [12-14]. The tropical forests are among the most productive as well as the most threatened ecosystem in present time with the maximum rate of deforestation. Thus, it is imperative to control the rate of deforestation in order to avoid the adversities associated with it.

\section{Impacts of deforestation}

The value and functions of forests are immense and diverse. Similarly, the impacts of deforestation are global and commune the whole forest community. One of the major constraints in understanding the true impact of desertification on forests is the inadequacy and imprecise form of data.

\subsection{Impacts on global climate}

The effect of large-scale deforestation is global, but it is necessary to assess its impacts on microclimate, regional climate and global climate to form a holistic understanding of mechanism [15]. The association of deforestation with the increased $\mathrm{CO}_{2}$ concentration in the atmosphere and changes in the mass balances and surface energy can result in climate change at the local and global level [16]. The change in land use pattern especially the clearing of forest cover affects both hydrometeorological and global $\mathrm{CO}_{2}$ concentrations leading to more warming as $\mathrm{CO}_{2}$ readily absorbs infrared radiation [17]. Clearing tree cover and vegetation leads to increase in albedo of the region as bare soil reflects more solar radiation than vegetation, which again is a factor for altering regional radiation flux $[15,18]$. One of the noticeable changes in regional climates occurs when the cloud formation shifts to higher elevations from lowland plains as a result of deforestation in the later area [19]. In a global scale, deforestation leads to warmer and drier weather due to the synergistic effect of reduced evapotranspiration, increased albedo and $\mathrm{CO}_{2}$ concentration that triggers desertification, loss in biodiversity and melting of polar ice caps, ultimately leading to food insecurity. All these effects are successors of extremes in climate variation that are produced by the large-scale reduction in forest cover [20]. The estimated quantity of $\mathrm{CO}_{2}$ added to the atmosphere due to deforestation in the tropics is roughly two billion tonnes [21]. It is interesting to note that the $\mathrm{CO}_{2}$ emissions due to clearing of forest will almost be equivalent to $25 \%$ of what is added to the atmosphere due to anthropogenic emissions [22]. The shift in climate is somehow correlated to reducing forest cover. Further researches can clearly define the mechanisms and pathways by which these shifts are progressing and how they can be mitigated. 


\subsection{Impact on hydrology and soil quality}

The global water cycle depends on the amount and distribution of precipitation for which one of the influencing factors is evapotranspiration [23]. There is a direct effect on drinking water on the basis of quality and quantity, fisheries and aquatic habitats, occurrence of flood and drought, life of dams on account of increase siltation and agriculture due to poor quality irrigation and crop yield [24, 25]. It must be recognized that the protective role of forests is operative and has a major impact on urban water resources [26]. Forests play an important role in maintaining the watersheds [27]. The degraded or degrading watersheds can be recovered by forestation, but once the forest or vegetation cover is lost, the watershed becomes vulnerable to erosion. This erosion leads to siltation in the downstream areas and consequently reduces the depth of river bed increasing the chances of flood. There are two main effects of deforestation that increase the chances of flooding. One is by reducing the tree fountain effect, i.e. interception and moisture uptake by the trees would cease after deforestation reducing the moisture holding capacity of soil that leads to greater runoff and erosion. And other is by the process of soil compaction and poor soil structure that will lead to reduced organic matter content of soil devoid of vegetation cover [28]. There are severe long-term effects on soil as a cause of deforestation. During slash-and-burn or shifting cultivation, an area of forests clears and exposes the bare soil to weather extremes of high solar insolation and heavy rainfall [29]. In the absence of the forest cover and organic matter, soil could not accommodate heavy precipitation, and the fertile layers of soil used to be easily washed away ultimately reduces the long-term productivity. The effect on soil is dependent on the interrelation and synergistic effect of evapotranspiration and infiltration that are directly altered due to loss in vegetation cover [23].

Deforestation directly increases erosion and siltation rates. There is an increased risk of flooding in Yangtze River basin in China and the major river basins in East Asia and the Amazonian basin [23, 30]. The slopes and terrains are more vulnerable to such situations. There are formations of shallow gullies which may be accounted for the concentrated flow of runoff that prevails due to long-term erosion. Cultivation and ploughing along the slopes cause rapid erosion in the areas with less vegetation cover [31]. In the Loess Plateau, the slopes of steepness greater than $15^{\circ}$ showed shallow gully erosion as a result of cultivation activities [32]. The availability of dead vegetation can reduce the surface runoff from the early season rain and check soil erosion [33]. It is necessary to sustain the forest and vegetation cover to maintain the soil productivity and water quality of both the surface and underground sources.

\subsection{Impact on biological diversity}

Forests are very rich in biodiversity and store a vast gene pool, and the majority of species occur in the tropical forests. It consists of two-thirds of all known species and $65 \%$ of 10,000 species that are recognized as endangered by the International Union for Conservation of Nature (IUCN) [34]. The biodiversity could be regarded as an important asset that is necessary to conserve for future utilization. The World Health Organization states that the traditional people, almost $80 \%$ of them, rely on the local biodiversity for traditional medicines. A loss in the biodiversity may directly affect their health care and well-being [35]. Another most noticeable impact of deforestation is the increasing human-wildlife conflict. The decreasing forest cover is limiting the habitats of many species due to which is forcing them to intrude with human welfare [36]. There are increasing instances of invasion and animal killing. The northern margin of West Bengal, India, forms a significant 
portion of the Himalaya Biodiversity Hotspot. The area has observed heavy fragmentation in the last decade, and as a result, there was a huge loss in the agricultural crop and both human and elephant life due to conflicts. There are reports of mortality of 20 elephants and 50 persons annually from this area [37]. It is also estimated that if deforestation in the Himalayas continue at the current rate, the dense forest cover ( $>40 \%$ canopy cover) will be restricted to $10 \%$ of land area in the Indian Himalayas by 2100 . This may lead to a significant loss of 366 endemic plants and 35 endemic vertebrates [38]. The loss in biodiversity is of global concern irrespective of regional and local importance. Conserving the forest and an increase in forest cover certainly find a positive correlation with the increase and sustenance of biodiversity. Conversion of forest land to agricultural fields and other land use could be a threat to major loss in biological diversity in the near future.

\subsection{Impact on economic and social welfare}

Forests contribute to the world economy in terms of timber production and other forest produces. There are different contributions of forest as a means of direct employment in forestry services and other value-added contributions as recreation and aesthetics. The loss of tropical forest cover annually may account for about 45 billion US dollars [39]. The destruction of forest eliminates the sources of economic gain directly obtained and also eliminates the potential gain from the resources that the forest sustains as biodiversity, soil and water. Also, the destruction of forest increases the negative externalities in the form of increasing $\mathrm{CO}_{2}$ concentration, risk of flood and human-wildlife conflict [40]. The proximity of settlements to protected areas further intensifies the chances of human-wildlife conflict (HWC). It is reported that settled households face high risk of HWC due to their close proximity of the Kanha National Park in Central India [41]. Deforestation has its social influence in the form of long-term effect. Development is a serious concern for indigenous community as it certainly leads to a change or shift of their culture and tradition. The cultural and religious aspects of the community are seldom preserved amid infrastructural advancement that leads to land and social conflict [42]. In a study of household survey from rural areas of Madhya Pradesh and Chhattisgarh state of India, it was found that the poorest of the local community gained about 30\% of their living from forest produce which was claimed to be even higher than the returns from agriculture. Also, forest provides an option as safety net during the period of crisis in rural areas [43]. Various ecological services provided by the forests have been lost due to deforestation which in turn has immediate effects on the local communities dependent on these services for their daily needs. The inclusive approach for the sustainable management of forest resource is a vital consideration that considers economy as a subset of the society which in itself is a subset of the environment. Such considerations can help sustaining the constantly declining forest cover and its long-term impacts.

\section{Forest cover status in India}

The forest cover was found to be increased by ca. 1\% for the year 2017 which is $21.54 \%$ of the total geographic area when compared to that of forest cover status in 2015 which is a positive sign towards the constant efforts that are being put in to protect the forest (Figure 2). This positive change in the forest cover is mainly attributed to the conservation and management practices that include afforestation activities, participation of local peoples for better protection 


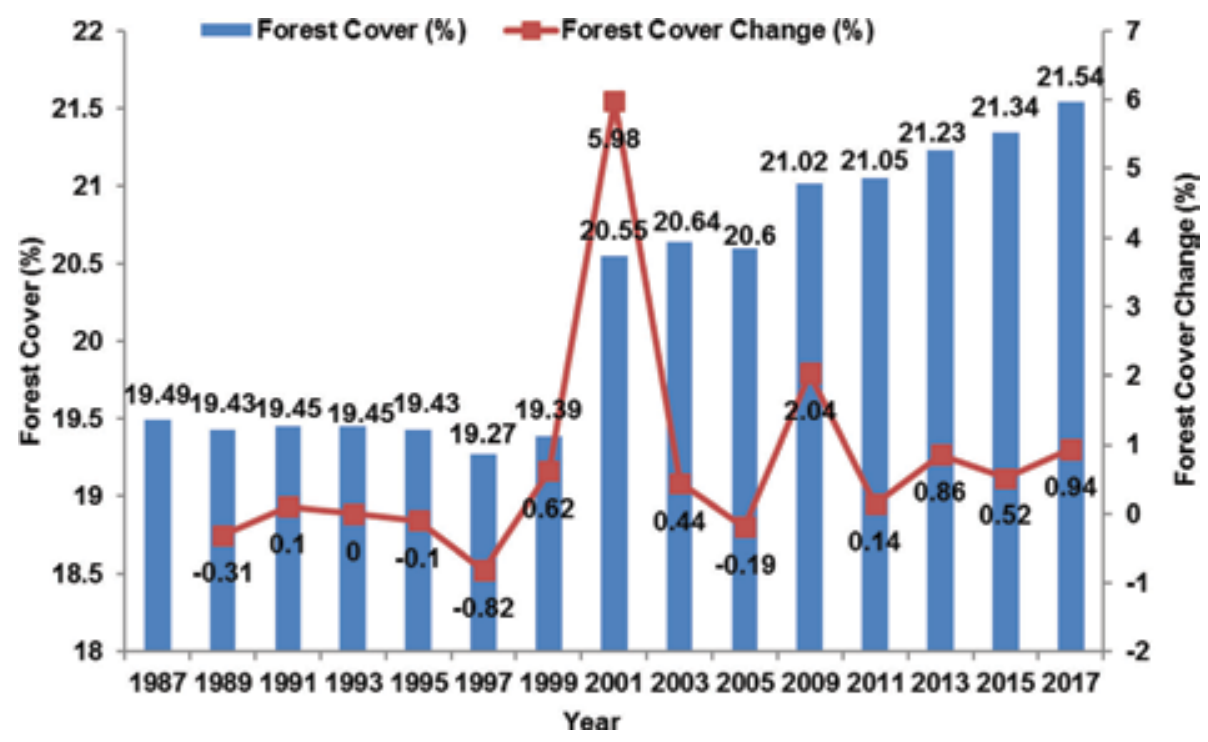

Figure 2.

Forest cover status in India for the last 30 years (1987 to 2017).

measures in plantation areas and traditional forest areas, expansion of trees outside forest, etc. Also, with this increase in the forest cover, the country has procured 8th position among the top 10 countries reporting the greatest annual forest area gain. Although there has been an increase in the total forest cover in India, still there are certain regions within the country that has sought a reduction in the same (Figure 3 ). The main reasons attributed for this reduction are

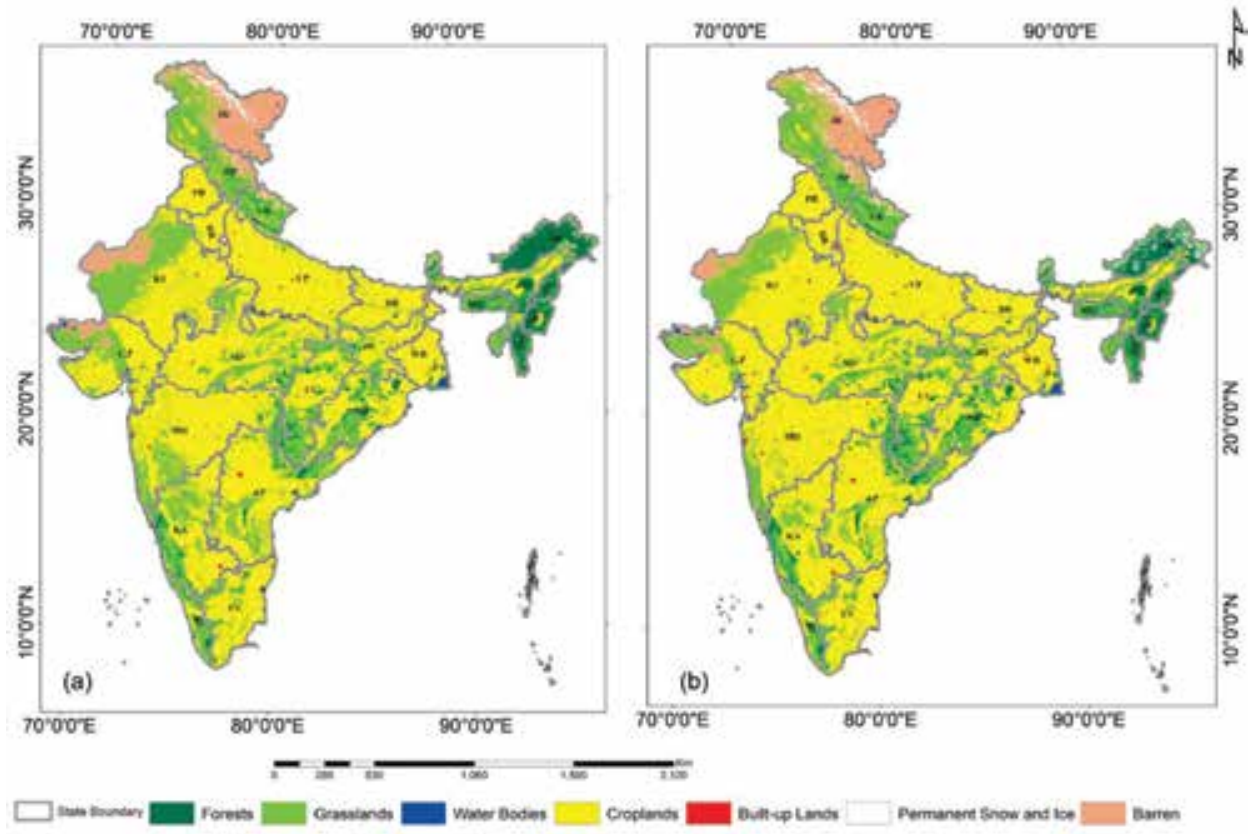

Figure 3.

MODIS-based land use/land cover map of India for the year (a) 2001 and (b) 2017. 


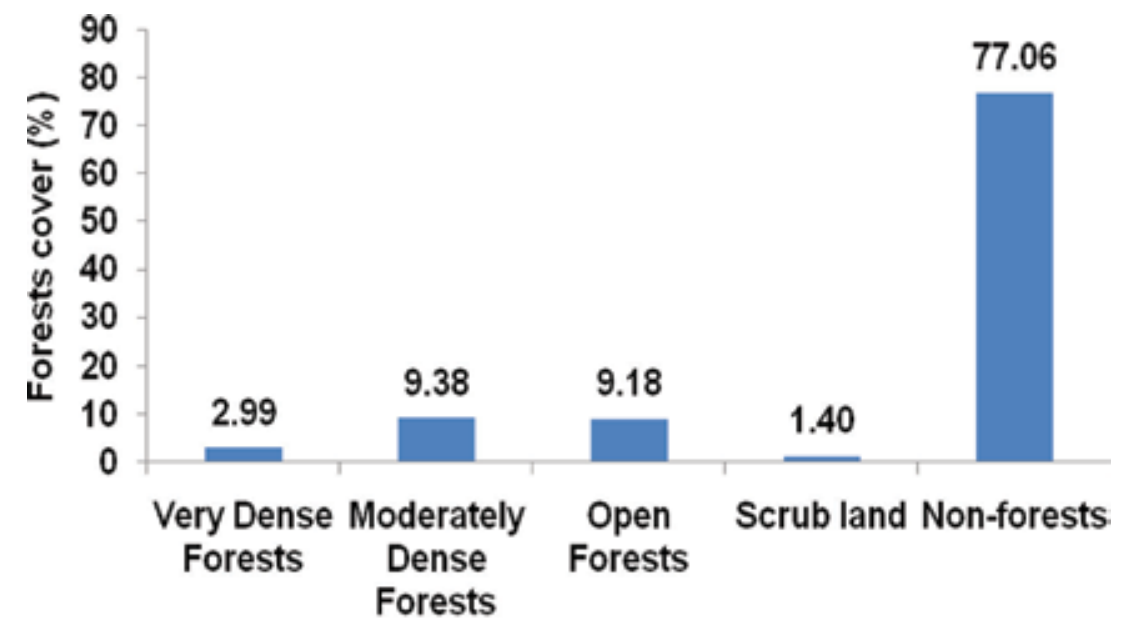

Forests types

Figure 4.

Forest cover (\%) of India for the year 2017 (Source: [44]).

shifting cultivation, rotational felling, other biotic pressures, diversion of forest lands for developmental activities, etc. [44]. A transition in the various forest cover classes has also occurred over the past. The present status of forest cover (\%) of India belonging to various forest cover classes has been shown in Figure 4. It has been found that there is a reduction in the moderately dense forest and an increment in the open forest depicting degradation of forest cover to some extent. Changes within the forest cover classes result in decrease in the production capacity, thereby leading to forest degradation [45]. Control and regular check of these activities can help in strengthening the conservatory efforts of forest protection. This is the necessity of the present time to conserve the forests in order to sustain the vital ecosystems and the major carbon sink to combat the effects of global climate change and ultimately maintain the environmental balance.

\section{Case studies of forest disturbances from different parts of India}

Forests are an invaluable resource that is being subjected to so many threats. In order to protect our forests, it is very much necessary to understand the reasons behind their destruction. Differentiating the agents and causes of deforestation will enable in understanding the same [36]. Several disturbances within the forest directly or indirectly contribute in destruction of the forest. This can be interpreted from the results obtained while surveying in different forest patches in India.

\subsection{Disturbances in the forests of Arunachal Pradesh}

Arunachal Pradesh is one of the states that has more than $75 \%$ forest cover and has the maximum very dense forest cover type [44]. The state is highly diverse in terms of climate as well as forest cover with tropical, sub-tropical, temperate and alpine forests having higher NDVI ( $\geq 7.0)$ [46]. However, the pressure on forest resources is consistently increasing with the rise in population, development 


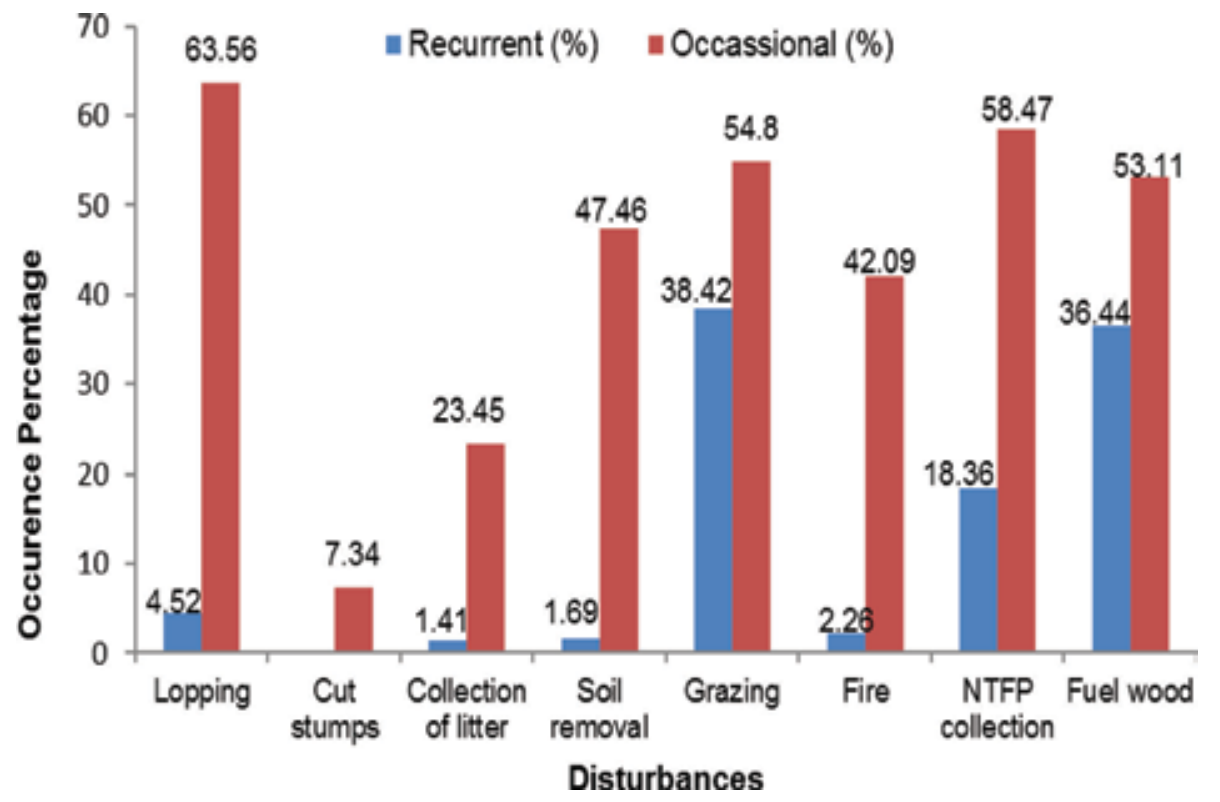

Figure 5.

Major disturbances in the forests of Arunachal Pradesh.

activities, large number of wood-based industries and unsustainable land use practices resulting in their degradation [47]. This has also resulted in decrease in the forest cover of the state [44]. Several disturbances were being observed during the field survey in the forests of Arunachal Pradesh during 2007 to 2010. The major disturbances that were found include lopping, cut stumps, litter collection, soil removal, grazing, fire, NTFP collection and fuelwood collection (Figure 5). Of these, fuelwood collection was found to be the most recurrent activity followed by grazing. Generally, fuelwood collection has not been considered as the major cause of deforestation but leads to the same in certain regions with reduced forest area such as in the Philippines, Thailand and parts of Central America [36]. Forest fire has also been observed as an occasional event in certain parts of Arunachal Pradesh. Fires are generally used as a tool in clearing the forest for shifting cultivation which is one of the major agricultural practices performed in the state. Fires when used responsibly act as a valuable tool in managing forest and agriculture, but when abused, it can lead to deforestation $[48,49]$. Other disturbances that can be an indicator of deforestation include NTFP collection and presence of cut stumps in certain forests. Forests of the state are highly diverse in endemic as well as nonendemic species, which need intensive monitoring and management to conserve the species-rich ecosystems from ever increasing anthropogenic pressure and changing climatic conditions [50].

\subsection{Disturbances in the forests of Madhya Pradesh}

Madhya Pradesh is among one of the states of India which is endowed with rich and diverse forests and comprises the largest forest cover in the country [44]. This is mainly because of the efforts that the state has put in to conserve and harness this invaluable resource through innovative measures like community participation and decentralization (MP) [51]. Even after these continuous efforts, there are certain regions within the state where the occurrence of several types of disturbances in the forest has been found. The common disturbances that were being observed 


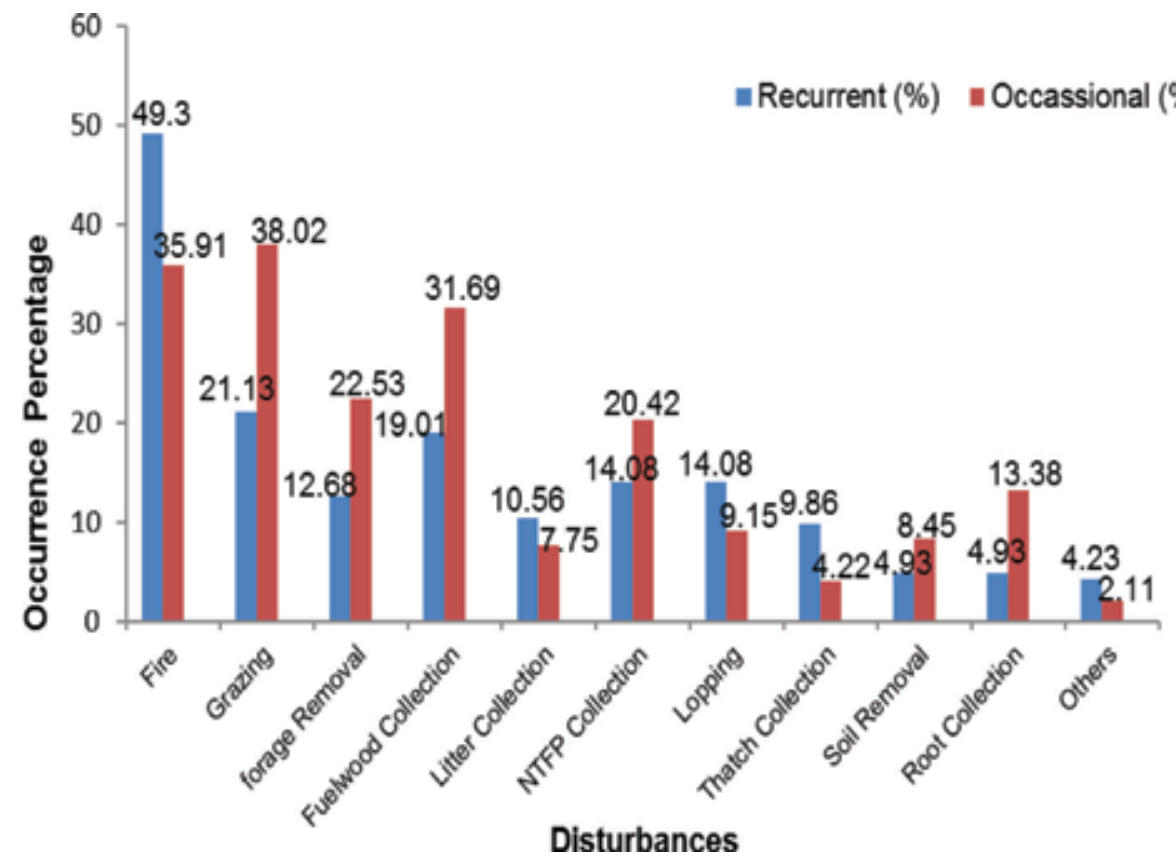

Figure 6.

Major disturbances in the forests of Madhya Pradesh.

during the field survey (2017-2019) include fire, grazing, fuelwood collection, forage removal, litter collection, NTFP collection, lopping, thatch collection, root collection, soil removal, etc. (Figure 6). Among all these fire has been found as the major recurrent type of disturbance in the forests of Madhya Pradesh. Other major disturbances were grazing followed by fuelwood collection. Since every type of deforestation is not intentional but some which are the results of amalgamation of anthropogenic and natural factors like wildfires and subsequent overgrazing can prevent the growth of young trees [52] and thus eventually degrade the quality and productivity of the forest.

\subsection{Disturbances in the forests of Jharkhand}

The name of the state 'Jharkhand' itself connotes 'area of land covered with forests' and has been exhibiting a unique relation with forests since time immemorial [53]. During the forest cover assessment [44], a net increase of 29 sq. km in the forest cover has been observed in the state which is mainly because of the plantation and conservation efforts within recorded forest areas. Although, there was an increment of $314 \mathrm{sq}$. $\mathrm{km}$ in the forest cover within the recorded forest areas, because of the felling of trees outside the forests area, its effect on forest cover has been offset. Also, several types of disturbances can be seen within the forest areas during the field survey (2016-2018), and the major disturbances were fuelwood collection, grazing, forage removal, lopping, cut stumps, thatch collection, root collection, soil removal, litter collection and NTFPs collection (Figure 7). Most of these disturbances were occasional in nature. Although these disturbances are not that recurrent, a regular check is necessary in order to prevent the forests from degrading and in achieving a sustainable forest cover. The forest management strategies should focus on the increasing demands of different timber and non-timber forest produce to conserve the plant diversity of the natural forests of the state [54]. 


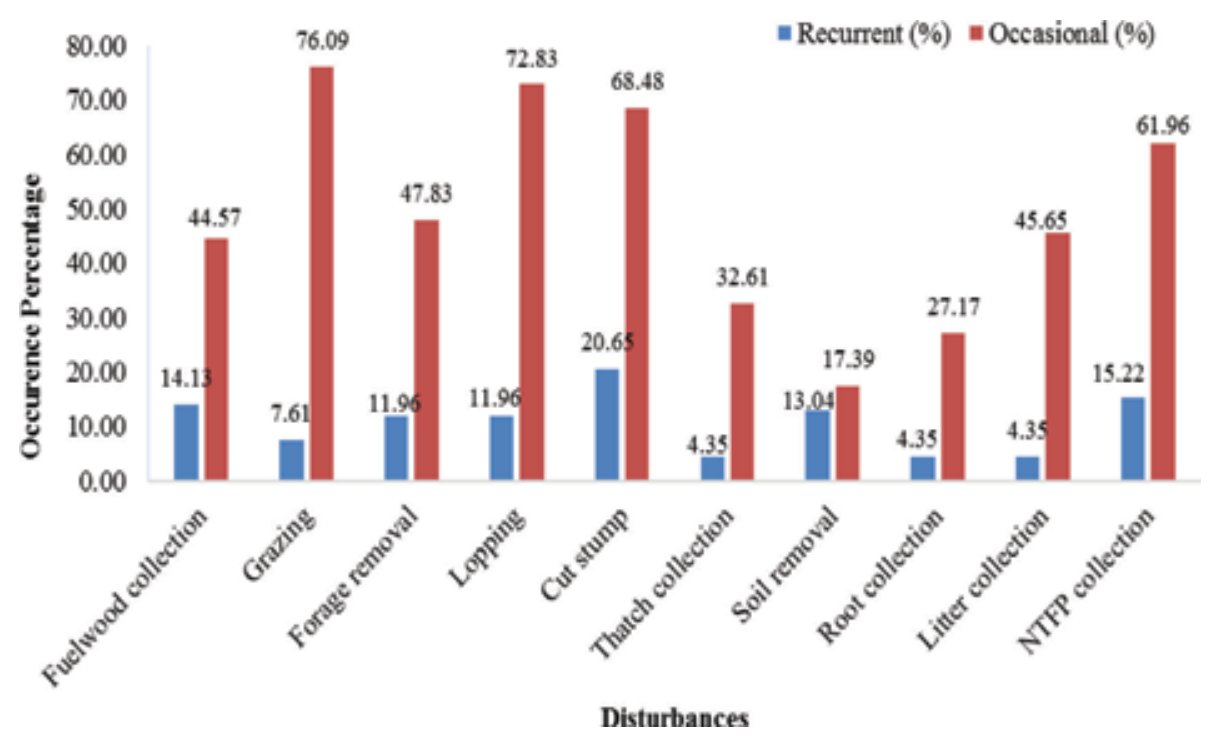

Figure 7.

Major disturbances in the forests of Jharkhand.

\section{Joint Forest Management in India: a case study}

Forest management and protection by the local communities is an age-old practice in India which can be traced back to the protective nature of the Bishnoi Community of Rajasthan towards the local forest and animals as the black buck. The idea of community-based forest management emerged in an administrative level in the 1970s and 1980s. The declaration of the Government of India in June 1990 marked the establishment of Joint Forest Communities in different India states as per the National Forest Policy of 1988. The Earth Summit of 1992 provided with a clear objective of Sustainable Forest Management to which India responded in a positive way. From an increase in the forest cover, non-timber forest product (NTFP) to conservation of native flora and fauna, a whole new realm of forest management strategy by the collaboration of forest departments and local communities aided in decelerating the degradation of natural forest in India [55]. The Participatory Forest Management (PFM) is equivalent to an informal contract in which the local communities are allowed to consume a portion of harvest and NTFP if they protect and conserve it for 5-10 years. In India there is no legal authority of the local community on the forest resource where as in other countries as in Nepal the Community Forest User Groups (CFUG) are registered under their Forest Act, 1993 [56]. It is the positive effort of the local communities of India that the area under Joint Forest Management increased from 22,017,583 ha to 2,144,000 ha in March 2006 with 106,482 recognized Joint Forest Management committees countrywide [57].

\section{Mitigation measures to curb deforestation}

Deforestation is a major environmental challenge which has been persistent from the past, and the situation is more worsened at present. Therefore, there is an urgent need to focus on the mitigative measures in order to prevent the distressing effects of deforestation in the near future. In order to alleviate the problem of deforestation, the strategies should be based on the underlying causes of the 
same. Also, the strategies for mitigating the problem of deforestation require its effective implementation that needs the recognition of the roles of national, state and municipal governments along with the pro-active role of the civil society and private society [36]. The continuous increase in the human population especially in the developing countries has resulted in enhanced pressure on the forests for human settlements and other land use practices. A reduction in the growth rate of human population plays a crucial role in reducing the practice of deforestation [36]. Alternatives to slash-and-burn agriculture can be adopted as a strategy to mitigate the deforestation by boosting the agricultural and forestry productions for the shifting cultivators $([58,59])$. The sustainable alternatives for slash-and-burn cultivation will assist the poor farmers in leading a better life without destroying additional forests [60]. Public policies and laws with greater security, accessibility to the minimal inputs required to maintain or enhance food production and an opportunity to the cultivators to market their products will aid in the sustainability of shifting cultivation systems [61].

Another strategy that can be applied to control the rate of deforestation is through the adoption of sustainable agroforestry, sustainable logging, agro-pastoral production systems, etc. [62]. The sustainable forest management practices can be promoted only if it is ecologically, economically and socially sustainable [36]. Agroforestry has been considered as one of the methods to curb deforestation which in turn aid in reduction of $\mathrm{CO}_{2}$ emissions and mitigation of climate change effect $[63,64]$. The adoption of agroforestry practices has resulted in an increase in the income of agroforestry adopters as compared to that of non-agroforestry adopters and has also contributed towards improving soil fertility, reducing deforestation and conserving soil and water [65]. The provision of protected areas is one of the key steps towards an attempt to reduce deforestation which is generally motivated through biodiversity conservation [34]. Also, the global endeavours to reduce tropical deforestation are dependent heavily on the establishment of protected areas. It has been found that protection reduced deforestation as approximately $10 \%$ of the protected forests would have been deforested if they would have not been protected [66]. Tropical protected areas reduced deforestation which was liable for around one-tenth of total anthropogenic carbon emissions, thus playing a significant role in mitigating the effects of climate change and protecting biodiversity and ecosystem services [67]. Similarly, a total loss of $15.4 \%$ in the unprotected mangrove cover was compensated by the $15.7 \%$ rise in the protected mangrove cover (protected by government as per Ramsar Convention) which resulted in a net increase of $13.3 \%$ in mangrove cover across India in the last 25 years [68]. Implementation of forest certification can be among one of the strategies to control deforestation around the world. Forest certification is a process through which the producers identify their products in the marketplace and receive greater market accessibility and higher prices for their products by fulfilling certain stringent sustainable forestry standards [69]. Certification has played an important role in protecting Penten forests from 1986 to 2007, and the certified forests experience 20 times less deforestation than non-certified areas [70]. Thus, certification of forest can play a major role in controlling deforestation since the timber certification was found to be negatively related with deforestation, i.e. the increase in the certification process has resulted in a declination in the deforestation rate [71].

\section{Role of Indian government in forest conservation}

The Government of India has been continuously putting significant efforts in terms of conserving the forest resources. They have not only taken measures to 
conserve the present forest cover but also have initiated several measures to increase the forests and tree cover of the country. Both the national and state governments are jointly responsible for the sustainable management of the forest resources in India. Various steps, rules and laws have been brought and implemented in order to conserve the forest cover of India. Some of these rules and laws are [72]:

- The Indian Forest Act, 1927: The act is an amalgamation of laws relating to forests, the transit of forest produce and the duty leviable on timber and other forest produces. It defines the procedures for declaring an area of a reserved forest, a protected forest or a village forest by the state government. With the amendment in the Act in 2012, it also prohibited the fresh clearances in forests and setting fire in a reserved forest.

- Forest Conservation Act, 1980 (with an amendment in 1988): The main purpose of the proposition of this act was to conserve the forests and to look into the matters connected therewith or ancillary or incidental thereto. With the implementation of this act, a prior approval of the Central Government is required for any sort of diversion of forest areas for the non-forestry purposes.

- [73]: The establishment of the National Forest Policy was also among one of the steps taken by the Government of India in order to ensure compensatory afforestation, essential environmental safeguards, sustainable utilization, maintenance, restoration and enhancement of forest areas.

- Wildlife Protection Act, 1972: The wildlife protection act was enacted basically to protect wild animals, birds and plants and for matters connected therewith or ancillary or incidental thereto with a view to ensure the ecological and environmental security of the country.

- The Scheduled Tribes and Other Traditional Forest Dwellers (Recognition of Forest Rights) Act, 2006: The act was framed with the purpose to recognize and vest the forest rights and occupation in forest land in forest dwelling scheduled tribes and other traditional forest dwellers who have been residing in such forests for generations but whose rights could not be recorded. These recognized rights of the forest dwelling scheduled tribes and other traditional forest dwellers include the responsibilities and authority for sustainable use, conservation of biodiversity and maintenance of ecological balance which in turn aid in strengthening the conservation regime of the forests while ensuring livelihood and food security of the forest dwellings scheduled tribes and other traditional forest dwellers.

Apart from these laws, the Government of India has also established Forest Survey of India (FSI), an organization under the Ministry of Environment, Forest and Climate Change, whose primary work is to gather and evaluate the country's forest wealth through a nationwide survey to measure forest areas [74]. This in turn aids in determining the factors and drivers behind the loss or gain in forest cover of any particular region in India. Another council, i.e. the Compensatory Afforestation Fund Management and Planning Authority (CAMPA), was established by the Government of India in 2009 as a National Advisory Council under the chairmanship of the Union Minister of Environment, Forest and Climate Change for the monitoring, technical assistance and evaluation of compensatory afforestation activities. This was particularly meant to promote afforestation and regeneration activities as a way of compensating for forest land diverted to non-forest uses [75]. 
Certain scheme such as Integrated Forest Protection Scheme (IFPS) was being formulated by the government to save the forests from fire. The scheme was designed by combining the forest fire protection and management technique along with forest conservation. Various other missions and programmes such as the National Mission for a Green India (NMGI) and National Afforestation Programme (NAP) were also being launched by the Government of India where the main aim of NMGI was to improve the quality of five million hectares of degraded forests and to bring another five million hectares of non-forest areas under forest cover through social and farm forestry. On the other hand, the NAP was launched with the objective to develop the forest resources with people's participation, with a focus on improving the livelihood of the forest-fringe communities, especially the poor [75].

The Ministry of Environment, Forest and Climate Change has been optimistic in strengthening the role of women in conservation of forest at local community levels since long. The National Forest Policy [73], for the first time, acknowledged the necessity of including woman members in forestry schemes. The Joint Forest Management Policy of 1990 mandated woman representatives not less than $40 \%$ in general body and 50\% in executive body of the local forestry institutions like the JFM committee. Later in 2002, the Biodiversity Authority of India reframing the local biodiversity management committee structure mandated the reservation of one-third of its members as women. Thus, this understanding of the role of women in the local-level conservation measures and implementation of related rules has aided in improving the management of forest in rural regions of the country [76].

\section{Author details}

Rima Kumari ${ }^{1}$, Ayan Banerjee ${ }^{1}$, Rahul Kumar ${ }^{1}$, Amit Kumar ${ }^{2}$, Purabi Saikia ${ }^{1 *}$ and Mohammed Latif Khan ${ }^{3}$

1 Department of Environmental Sciences, Central University of Jharkhand, Ranchi, Jharkhand, India

2 Department of Land Resource Management, School of Natural Resource Management, Central University of Jharkhand, Ranchi, Jharkhand, India

3 Department of Botany, Dr. Harisingh Gour Central University, Sagar, Madhya Pradesh, India

*Address all correspondence to: purabi.saikia83@gmail.com

IntechOpen

(C) 2019 The Author(s). Licensee IntechOpen. This chapter is distributed under the terms of the Creative Commons Attribution License (http://creativecommons.org/licenses/ by/3.0), which permits unrestricted use, distribution, and reproduction in any medium, provided the original work is properly cited. (cc) BY 


\section{References}

[1] Bowonder B. Deforestation in India. International Journal of Environmental Studies. 1982;18:223-236

[2] Nagdeve DA. Population growth and environmental degradation in India. Asian Pacific Journal on Environment and Development. 2007;14:41-63

[3] Basnayat B. Impacts of demographic changes on forests and forestry in Asia and the Pacific. In: Working Paper of the Asia-Pacific Forestry Sector Outlook Study (APFSOS II). Bangkok: FAO of the United Nations; 2009

[4] Department of Economics and Social Affairs. 2015. United Nations. Retrieved from: http://www. un.org/en/development/desa/news/ population/2015-report.html; Accessed on: $05 / 12 / 2018$

[5] FAO. Global Forest Resources Assessment. FAO forestry paper No. 1. Rome: UN Food and Agriculture Organization; 2015

[6] Bradford A. 2018. Deforestation: Facts, Causes and Effects. Retrieved from: https://www.livescience. com/27692-deforestation.html; Accessed on: 28/01/2019

[7] Biswas PK. Forest, People and Livelihoods: The Need for Participatory Management. Quebec City, Canada: XII World Forestry Congress; 2003

[8] Bishop JT. Valuing Forests: A Review of Methods and Applications in Developing Countries. London: International Institute for Environment and Development; 1999

[9] Malhi Y, Meir P, Brown S. Forests, carbon and global climate. The Royal Society. 2002;360:1567-1591

[10] van Minnen JG, Strengers BJ, Eickhout B, Swart RJ, Leemans R.
Quantifying the effectiveness of climate change mitigation through forest plantations and carbon sequestration with an integrated land use model. Carbon Balance and Management. 2008;3(1):1-20

[11] Sedjo RA. 2001. Forest Carbon Sequestration: Some Issues for Forest Investments. RFF Discussion Paper 01-34, Washington, D.C

[12] Albaladejo J. Impact of the degradation processes on soil quality in arid mediterranean environment. In: Rubio JL, Rickson RJ, editors. Strategies to Combat Desertification in Mediterranean Europe. Luxembourg: Commission of the European Communities; 1990. pp. 193-215

[13] Diaz E, Roldan A, Lax A, Albaladejo J. Formation of stable aggregates in degraded soils by amendment with urban refuse and peat. Geoderma. 1994;63:277-288

[14] Nikolic G, Spalevic V, Curovic M, Darvishan AK, Skataric G, Pajic $\mathrm{M}$, et al. Variability of soil erosion intensity due to vegetation cover changes: Case study of Orahovacka Rijeka, Montenegro. Notulae Botanicae Horti Agrobotanici Cluj-Napoca. 2019;47(1):237-248

[15] Gupta A, Thapliyal PK, Pal PK, Joshi PC. Impact of deforestation on Indian monsoon- A GCM sensitivity study. Journal of Indian Geophysical Union. 2005;9:97-104

[16] Longobardi P, Montenegro A, Beltrami H, Eby M. Deforestation Induced Climate Change: Effects of Spatial Scale. PLoS One. 2016;11(4):e0153357

[17] Pinker R. The microclimate of a dry tropical forest. Agricultural Meteorology. 1980;22:249-265 
[18] Rowntree PR. Review of general circulation models as a basis for predicting the effects of vegetation change on climate. In: Reynolds ERC, Thompson FB, editors. Forests, Climate and Hydrology, Regional Impacts. UK: Kefford Press; 1988. pp. 162-193

[19] Lawton RO, Nair US, Pielke RA Sr, Welch RM. Climatic impact of tropical lowland deforestation on nearby Montane Cloud Forests. Science. 2001;294:584-587

[20] Anonymous. Breaking the Logjam: Obstacles to Forestry Policy Reform in Indonesia and the United States. Washington: World Resource Institute; 1994a

\section{[21] Houghton RA. Tropical} deforestation as a source of greenhouse gas emissions. In: Moutinho P, Schwartzman S, editors. Tropical Deforestation and Climate Change. Belem Brazil: Amazon Institute for Environmental Research; 2005. pp. $13-20$

[22] Asdrasko K. Climate Change and Global Forests: Current Knowledge of Political Effects, Adaptation and Mitigation Options. Rome: FAO; 1990

[23] Bruijnzeel LA. Hydrological functions of tropical forests: Not seeing the soils for the trees? Agriculture, Ecosystems and Environment. 2004;104:185-228

[24] Anonymous. Deforestation technical support package. In: Third International Conference on Environment Enforcement, Oaxaca Mexico April 25-28, 1994. World Wildlife Fund; U. S. Environmental Protection Agency and U. S. Agency for International Development; 1994b

[25] Bruijnzeel LA, Bonell M, Gilmour DA, Lamb D. Forest, water and people in the humid tropics: An emerging view. In: Bonell M, Bruijnzeel LA, editors. Forest, Water and People in the Humid Tropics. Cambridge United Kingdom: Cambridge University Press; 2005

[26] Chomitz KM, Griffiths

C. Deforestation, shifting cultivation and tree crops in Indonesia: Nationwide patterns of smallholder agriculture at the forest frontier. In: Research Project on Social and Environmental Consequences of Growth-Oriented Policies, Working Paper 4. Washington DC: World Bank; 1996

[27] Ekhuemelo DO, Amonum JI, Usman IA. Importance of Forest and Trees in Sustaining Water Supply and Rainfall. Nigeria Journal of Education, Health and Technology Research.

2016;8:273-280

[28] Chomitz KM, Buys P, Luca GD, Thomas TS, Wertz-Kanounnikoff S. At Loggerheads? Agricultural Expansion, Poverty Reduction and Environment in the Tropical Forests. World Bank Policy Research Report. Washington DC: World Bank; 2007

[29] Lawson TL. Deforestation and induced changes in meso/micro-climate. In: Lal R, Sanchez PA, Cummings RW Jr, editors. Land Clearing and Development in the Tropics. Rotterdam/Boston: Balkema; 1986. pp. 195-202

[30] Yin H, Li C. Human impacts on floods and flood disasters on the Yangtze River. Geomorphology. 2001;41:105-109

[31] Foster GR, Lane LJ, Milder WF. Seasonally ephemeral cropland gully erosion. In: Proceedings of Natural Resources Modeling Symposium, Oct. 16-21. Pingree Park, CO., USA; 1983. pp. 263-365

[32] Zheng FL. Effect of vegetation changes on soil erosion on the loess plateau. Pedosphere. 2006;16:420-427 
[33] Merzer T. The effects of different vegetative cover on local hydrological balance of a semiarid afforestation. M.Sc. thesis, Jacob Blaustein Institute for Desert Research; 2007

[34] Myers N, Mittermeier

RA. Biodiversity hotspots for conservation priorities. Nature. 2000;403:853-854

[35] Millennium Ecosystem Assessment (MEA). Ecosystems and Human Well-Being: Biodiversity Synthesis. Washington, DC: World Resources Institute; 2005

[36] Chakravarty S, Ghosh SK, Dey AN, Shukla G. Deforestation: Causes, effects and control strategies. In: Global Perspectives on Sustainable Forest Management. Rijeka: InTech; 2012. pp. 3-28

[37] Mangave HR. A study of Elephant population and its habitats in the northern West Bengal, North East India, M. Sc. Thesis. Bharathidasan University; 2004

[38] Pandit MK, Sodhi NS, Koh LP, Bhaskar A, Brook BW. Unreported yet massive deforestation driving loss of endemic biodiversity in Indian Himalaya. Biodiversity and Conservation. 2007;16:153-163

[39] Hansen CP. Making Available Information on the Conservation and Utilization of Forest Genetic Resources. The FAO Worldwide Information System on Forest genetic resources; 1997

[40] Gibson C, McKean MA, Ostrom E. Explaining deforestation: The role of local institutions. In: Forest, Trees and People Programme, Working paper no.3. 1998

[41] Neelakantan A, DeFries R, Krishnamurthy R. Resettlement and landscape-level conservation: Corridors, human-wildlife conflict, and forest use in Central India. Biological

Conservation. 2019;232:142-151

[42] Schmink M, Wood C. Contested Frontiers in Amazonia. New York: Columbia University Press; 1992

[43] Damania R, Joshi A, Russ J. India's forests - Stepping stone or millstone for the poor? World Development. 2018. DOI: 10.1016/j.worlddev.2018.11.007 (in press)

[44] Forest Survey of India (FSI). An Assessment Report on Forest Cover Status of India. Government of India: Ministry of Environment and Forest (MoEF); 2017

[45] Hermosilla AC. The Underlying Causes of Forest Decline. In: Centre for International Forestry Research (CIFOR) Occasional Paper No.30; 2000. pp. 1-23

[46] Saikia P, Kumar A, Khan ML. Biodiversity status and climate change scenario in Northeast India. In: Nautiyal S, Schaldach R, Raju KV, Kaechele H, Pritchard BI, Rao KS, editors. Climate Change Challenge (3C) and Social-Economic-Ecological Interface-Building. Switzerland: Springer International Publishing; 2016. pp. $107-120$

[47] Department of Environment and Forest, Government of Arunachal Pradesh. 2018. Retrieved from: arunachalforests.gov.in; Accessed on: $12 / 12 / 2018$

[48] Repetto R. Deforestation in the Tropics. Scientific American. 1990;262(4):18-24

[49] Rowe R, Sharma NP, Bowder J. Deforestation: Problems, causes and concern. In: Sharma NP, editor. Managing the World's Forest: Looking for Balance Between Conservation and Development. Iowa: Kendall/Hunt Publishing Company; 1992. pp. 33-46 
[50] Saikia P, Deka J, Bharali S, Kumar A, Tripathi OP, Singha LB, et al. Plant diversity patterns and conservation status of Eastern Himalayan forests in Arunachal Pradesh, Northeast India. Forest Ecosystems. 2017a;4(28):1-12

[51] Madhyam MP. 2013. Government of Madhya Pradesh. Retrieved from: www.mp.gov.in/en/web/guest/forest; Accessed on: 12/12/2018

[52] Anonymous. 2018. Deforestation facts, information and effects. Retrieved from: https://www. nationalgeographic.com/environment/ global-warming/deforestation; Accessed on: 03/12/2018

[53] Environment and Climate Change Division. 2016. Government of Jharkhand. Retrieved from: www. jharkhand.gov.in; accessed on $12 / 12 / 2018$

[54] Kumar R, Saikia P. Floristic analysis and dominance pattern of a Sal (Shorea robusta C. F. Gaertn.) Forests of Ranchi, Jharkhand, Eastern India. Journal of Forestry Research. 2019 (in press)

[55] Singh KD, Sinha B. 2005. Exploring Options for Joint Forest Management in India. A World Bank/WWF alliance Project

[56] Bhatta B, Karna AK, Dev OP, Oliver SB. Participatory forest management in the Nepalese Tarai: Policy, practice and impacts. In: Oliver SB, editor. Forest, People and Power. The Political Ecology of Reform in South Asia. London, UK: Earth Scan; 2008. pp. 177-220

[57] Pai R, Datta S. 2006. Measuring Milestones: Proceedings of the National Workshop on Joint Forest Management (JFM), October 17, 2006, New Delhi

[58] Serageldin I. Saving Africa's Rainforests 1991. contribution to Conference on the Conservation of West and Central Africa Rainforests. Abijan,
Cote d'Ivoire, Washington, D.C.: World Bank; 5-9 Nov 1990

[59] Sanchez PA, Bandy DE. Alternatives of slash and burn: A pragmatic approach to mitigate tropical deforestation. Anais da Academia Brasileira de Ciências. 1992;64:7-33

[60] Sanchez PA, Garrity D, Bandy DE. Sustainable Alternatives to Slash and Burn Agriculture and the Reclamation of Degraded Lands in the Humid Tropics. Nairobi, Kenya: International Centre for Research in Agroforestry; 1993

[61] Brady NC. Alternatives to slash-and-burn: A global imperative. Agriculture, Ecosystems and

Environment. 1996;58:3-11

[62] Scherr SJ. The evolution of agroforestry practices over time in the crop-livestock system in Western Kenya. In: Dvorak K, editor. Social Science Research in Agricultural Development: Spatial and Temporal Dimensions. USA: Oxford University Press; 1993. pp. $118-143$

[63] Saikia P, Kumar A, Khan ML. Agroforestry: A sustainable land use system for livelihood security and climate change mitigation. In: Pandey CB, Gaur MK, Goyal RK, editors. Climate Change and Agroforestry: Adaptation, Mitigation and Livelihood security. New Delhi, India: New India Publishing Agency; 2017b. pp. 61-70

[64] Verchot L, Noordwijk MV, Kandji S, Tomich T, Ong C, Albrecht A, et al. Climate change: Linking adaptation and mitigation through agroforestry. Mitigation and Adaptation Strategies for Global Change. 2007;12(5):901-918

[65] Kiyani P, Andoh J, Lee Y, Lee DK. Benefits and challenges of agroforestry adoption: A case of Musebeya sector, Nyamagabe District in southern province of Rwanda. 
Forest Science and Technology. 2017;13(4):174-180

[66] Andam KS, Ferraro PJ, Pfaff A, Azofelefa GAS, Roballno JA. Measuring the effectiveness of protected area networks in reducing deforestation. PNAS. 2008;105(42):16089-16094

[67] Bebber DP, Butt N. Tropical protected areas reduced deforestation carbon emissions by one third from 2000-2012. Scientific Reports. 2017;7:14005. DOI: 10.1038/ s41598-017-14467-w

[68] Jayanthi M, Thirumurthy S, Nagaraj G, Muralidhar M, Ravichandran P. Spatial and temporal changes in mangrove cover across the protected and unprotected forests of India. Estuarine, Coastal and Shelf Science. 2018;213:81-91

[69] Gullison RE. Does forest certification conserve biodiversity? Oryx. 2003;37(2):153-165

[70] Hughell D, Butterfield R. 2008. Impact of FSC Certification on Deforestation and the Incidence of Wildfires in the Maya Biosphere Reserve. Report, Rainforest Alliance

[71] Damette O, Delacote P. Unsustainable timber harvesting, deforestation and the role of certification. Ecological Economics. 2011;70:1211-1219

[72] Ministry of Environment, Forest and Climate Change. 2019. Forest Conservation. Retrieved from: http://envfor.nic.in/division/forestconservation; Accessed on: 01/03/2019

[73] National Forest Policy. 1988. Govt. of India, New Delhi

[74] Anonymous. 2017. Deforestation Solutions. Retrieved from: https:// www.indiacelebrating.com/ environmental-issues/deforestationsolutions/; accessed on: 01/03/2019

[75] World Resources Institute. 2014. Forest Legality Initiative. Retrieved from: https://forestlegality.org/ risk-tool/country/india; accessed on: 04/03/2019

[76] Tyagi N, Das S. Assessing gender responsiveness of forest policies in India. Forest Policy and Economics. 2018;92:160-168 


\title{
Forest Decline Under Progress in the Urban Forest of Seoul, Central Korea
}

\author{
Chang Seok Lee, Songhie Jung, Bong Soon Lim, A Reum Kim, \\ Chi Hong Lim and Hansol Lee
}

\begin{abstract}
Vegetation in the urban area showed not only a difference in species composition but also lower diversity compared with that of the natural area. Successional trend was normal in natural area, but that in urban areas showed a retrogressive pattern. Korean mountain ash (Sorbus alnifolia (Siebold \& Zucc.) K.Koch), a shade intolerant species, dominated such a retrogressive succession. The vegetation decline is due to changes of mesoclimate and soil properties that imbalanced distribution of green space induced as the result of urbanization. In recent years, new environmental stress due to climate change is imposed additively to this forest decline. Drought is the very environmental stress. Drought-induced plant damage started from withering of leaves of plants introduced for landscaping in the urban area. Over time, branches died and death of the whole plant body followed. In particular, damage of Korean mountain ash, the product of retrogressive succession, was remarkable. As retrogressive succession has already progressed much, thus such phenomenon could be recognized as crisis of urban forest.
\end{abstract}

Keywords: drought, forest decline, retrogressive succession, Seoul, urban forest

\section{Introduction}

Urbanization expanding globally is recognized as a major causing environmental change [1]. Reduction of habitat size, fragmentation, and imbalanced distribution of green space due to urbanization led to influences on dynamics of vegetation remaining in urban area [2,3]. Increases of temperature, precipitation, and nitrogen deposition due to urbanization also altered abiotic conditions of habitat patches remaining in urban area $[1,4]$. These changes influence habitat quality, and, consequently, the species composition, species diversity, and functional diversity of vegetation remaining there $[3,5,6]$, which in turn affect the ecosystem functions [7].

Forests are the typical types of urban green space [8]. Urban forests function as habitat of native species as well as recreation site for citizens $[9,10]$. Urban forests can play a role of refugia of rare and threatened species and thus can display high conservation value $[11,12]$. Among urban landscape elements, forest has substantially different site history, intensity of management and disturbance, and consequently different species composition from other landscape elements $[3,12,13]$. 
Urban forests are remnants of former continuous forests, a result of succession or artificial plantation [14]. They can also include urban orchards, urban park, cemeteries overgrown by trees, or residential garden $[12,13]$.

Land transformation and increase of impervious surface cover affect forests throughout the landscape through increased local temperatures and altered ecosystem processes. Anthropogenic drivers of global change, i.e., land-use change, introduction of exotic species, pollution, and climate change, affect forest composition and function across the landscape [15]. In particular, change of land-use pattern including urbanization and their effects on remaining vegetation constitute one of the major factors influencing on natural ecosystems $[16,17]$. In the case of forests, about $70 \%$ of remaining forest around the world is within $1 \mathrm{~km}$ from the forest's edge [18]. Therefore, it is very difficult that they maintain integrate structure and healthy function. As land is transformed into urbanized area, the effects of the transformation on the remaining vegetation are getting more apparent. Increased local temperature and altered hydrologic and nutrient cycle, land transformation, and increased impervious surface cover have been recognized as elements affecting forest health and resilience to other stress factors [19-21]. Those remaining natural forest patches are still critical in terms of air quality improvement, flooding reduction, urban heat island effect mitigation, and supply of other ecosystem services that are important to both human societies and natural environment [22-24]. Therefore, understanding how urbanization affects structure and function of remnant forest ecosystems is critical to both conservation and management of this ecological resource.

One of the principal changes that urbanization induced is the increase of land covered by impervious surfaces such as asphalt and concrete pavement, concrete buildings, and tightly compacted soils. Percentage-paved land surface is an appropriate proxy for urban heat island effects as a main factor increasing the land surface temperature $[25,26]$. Urban heat islands develop around areas with high heat absorptive capacity such as asphalt, concrete buildings, bare ground, and other developed lands, which heat up rapidly and increase local temperature greatly compared with surrounding natural areas $[27,28]$. In an area that natural forest is conserved to urbanized area, land surface temperature increased more than $70 \%$ and soil moisture decreased about $15 \%$. These changes of the microclimate in urbanized areas can affect vegetation remaining there [29]. Trees growing in areas covered by impervious surface densely represented low drought resilience compared with trees in forested areas [30] and experienced severer moisture stress and insect damage compared with trees in intact forests [31]. In general, increased impervious surface cover increases water stress and vulnerability to drought and thus makes trees in intensively urbanized landscapes more sensitive to cavitation and lower protection from embolism formation [32].

Increasing urbanization could aggravate the impact of climate change on forest. Increasing temperature accompanies severer and more frequent droughts that could increase tree mortality $[33,34]$. Even though most forest species can tolerate changes in mean climatic conditions, it is not clear that they could withstand the extreme weather events like drought $[35,36]$.

Thus, the synergistic effects of extreme weather events, like drought and temperature increase in relation to urbanization, could influence severely on the health and resilience of forests remaining in urban areas $[37,38]$. A decline of forest health and the following changes in species composition and vegetation structure would lead to change of ecosystem function and ultimately alter ecosystem services in those ecosystems [39, 40].

In Korea, forest began to show decline symptoms around the industrial complexes and large cities [41, 42]. Further, change of mesoclimate due to excessive land use in urban area led to changes of vegetation structure and dynamics as well 
as soil properties [39, 42-48]. In addition, new environmental stress due to climate change is imposed additively to this forest decline and thereby incites degradation of urban forest in recent years.

This chapter addresses the following: (1) landscape structure in Seoul, (2) changes of mesoclimate and soil due to imbalanced distribution of greenery space, (3) retrogressive succession due to such environmental changes, and (4) droughtinduced tree mortality.

Forest decline here includes deforestation, forest degradation, or a combination of both based on the definition of FAO [49].

\section{Study area}

Seoul, the capital of South Korea, is located in the Central Korean Peninsula and covers $605 \mathrm{~km}^{2}$ of land $\left(126^{\circ} 46^{\prime} 15^{\prime \prime}\right.$ to $127^{\circ} 11^{\prime} 15^{\prime \prime}$ E longitude, $37^{\circ} 25^{\prime} 50^{\prime \prime}$ to $37^{\circ} 41^{\prime} 45^{\prime \prime}$ N latitude; Figure 1). Topography of Seoul is the typical basin that Han River runs through the center and is backed by mountains. The elevation of the study area ranges from 20 to $800 \mathrm{~m}$ above sea level. The parent rock of the mountainous areas around Seoul is usually composed of granite and gneiss, and the flat land beside rivers and streams is consisted of alluvium. Soil in these areas was classified into the Suam, Osan, Asan, and Anryong series, which developed on gneiss and granite bedrock $[39,50]$. The climate of Seoul is continental, with warm and moist summers and cold and dry winters. From 1981 to 2010, the mean annual temperature was $12.5^{\circ} \mathrm{C}$ and the mean annual precipitation was $145.1 \mathrm{~cm}$ [51].

The mountainous vegetation of Seoul is consisted of four major plant communities distributed along an elevation gradient: the Korean red pine (Pinus densiflora

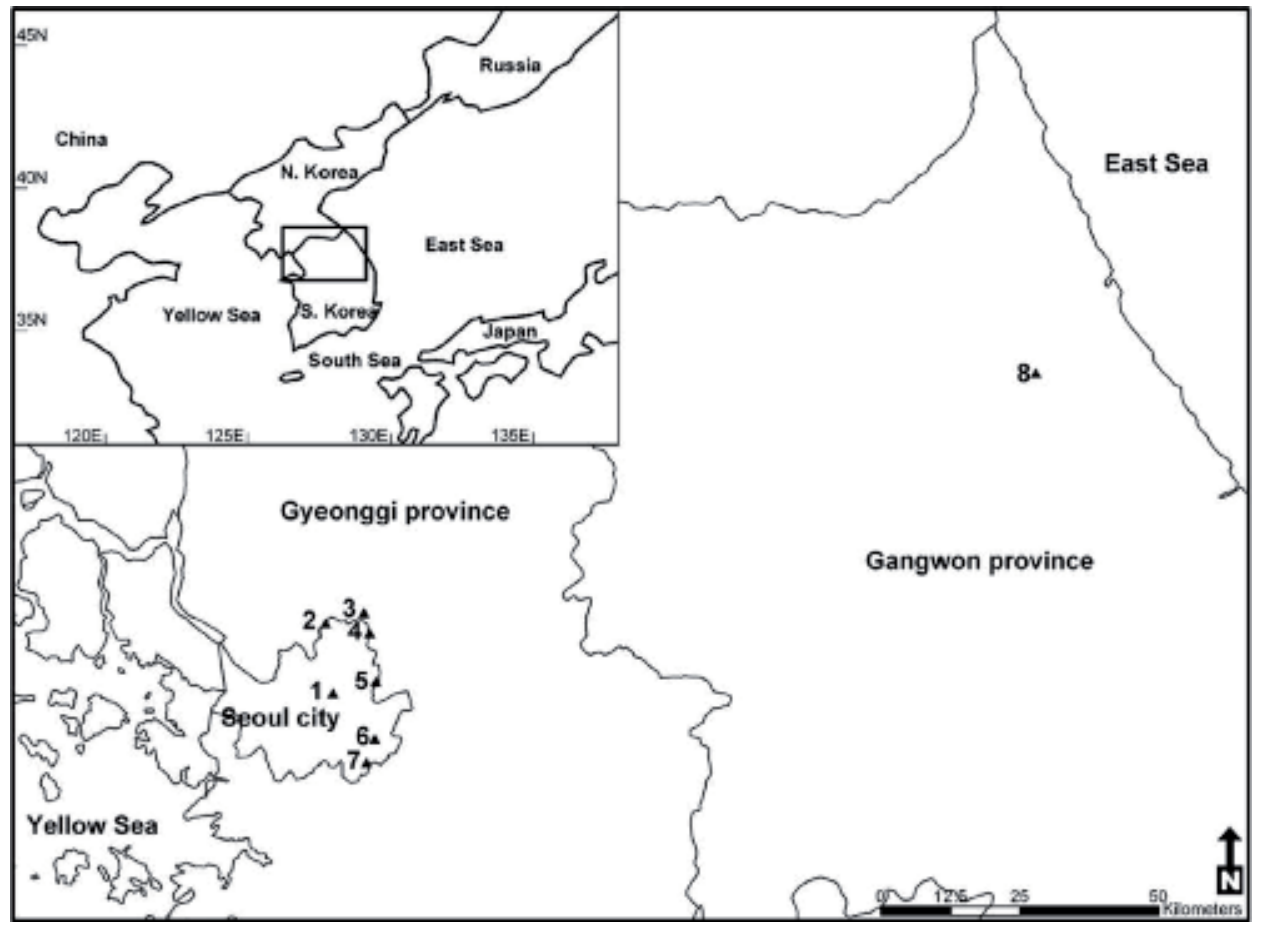

Figure 1.

A map showing the study area, Seoul, the capital of South Korea. (1) Mt. Nam, (2) Mt. Bukhan, (3) Mt. Surak, (4) Mt. Bulam, (5) Mt. Acha, (6) Mt. Daemo, (7) Mt. Cheonggye, (8) Mt. Jeombong. 
Siebold \& Zucc.) community in the mountain peaks and around the residential area, the Mongolian oak (Quercus mongolica Fisch. ex Ledeb.) community in the upper slopes, the hornbeam (Carpinus laxiflora (Siebold \& Zucc.) Blume) community in the lower slopes, and the sawleaf zelkova (Zelkova serrata (Thunb.) Makino) community in the mountain valleys [52]. East Asian alder (Alnus japonica (Thunb.) Steud.) stands remained in the plains and valleys of lowlands that escaped from urbanization [53-55]. Much of the natural forest in the Seoul metropolitan area disappeared due to extensive deforestation for fuel, building material, and other purposes during the twentieth century [56]. The human population of Seoul has increased from 2.4 million in 1960 to 9.8 million as of 2010 [57]. During this period, the percentage of green space decreased from $70 \%$ in 1960 to $29 \%$ in 2015, mostly to accommodate residential area $[54,56,58]$. Korean government designated most of the forested mountains in suburban areas of Seoul as greenbelt zones in order to prevent further loss of green space. Under the current greenbelt ordinance, no commercial, industrial, or urban development is permitted in those forests [58].

\section{Methods}

An ecological map to grasp landscape structure was obtained from Seoul City [59]. Landscape ecological analyses of the maps were determined with ArcGIS program (ver. 10.0).

Soil samples were collected from 150 grids, dividing $2 \mathrm{~km} \times 2 \mathrm{~km}$ intervals, throughout the entire area of Seoul (all $605 \mathrm{~km}^{2}$ ). Soil properties were measured for $\mathrm{pH}, \mathrm{Ca}^{2+}, \mathrm{Mg}^{2+}$, and $\mathrm{Al}^{3+}$ contents, which can explain acidification and its effects. Soil $\mathrm{pH}$ was measured with a benchtop probe after mixing the soil with distilled water (1:5 ratio, weight per volume) and filtering the extract through Whatman No. 44 paper. Exchangeable $\mathrm{Ca}^{2+}, \mathrm{Mg}^{2+}$, and $\mathrm{Al}^{2+}$ concentrations were measured after extraction with $1 \mathrm{~N}$ ammonium acetate $\left(\mathrm{pH}=7.0\right.$ for $\mathrm{Ca}^{2+}$ and $\mathrm{Mg}^{2+}$ and $\mathrm{pH}=4.0$ for $\mathrm{Al}^{3+}$ ) and using inductively coupled plasma (ICP) atomic emission spectrometry (Shimadzu ICPQ-1000) described in Allen [60].

Vegetation data were collected in the urban areas (Mts. Nam, Daemo, Bulam, Acha, Surak, Bukhan, and Cheonggye) and a natural area (Mt. Jeombong) (Figure 1). Vegetation survey was conducted in 66 plots, with 8, 10, 7, 8, 10, 4, 10, and 9 plots in each of the following sites: Mts. Nam (Mt. N hereafter), Daemo (Mt. D), Bulam (Mt. Bl), Acha (Mt. A), Surak (Mt. S), Bukhan (Mt. $\mathrm{Bk}$ ), Cheonggye (Mt. $\mathrm{Cg}$ ), and Jeombong (Mt. J), respectively. The size of each plot was $20 \mathrm{~m} \times 20 \mathrm{~m}$. All the plant species in each plot were identified using the Korea Plant Name Index [61]. For major tree species, stem diameters (at breast height for mature trees or at stem base for seedlings and saplings) were measured and sorted by diameter classes. The vegetation survey was conducted by applying the phytosociological procedure of Braun-Blanquet [62]. Dominance of each species in each plot was estimated by ordinal scale ( 1 for $\leq 5 \%$ up to 5 for $\geq 75 \%$ ), and each ordinal scale was converted to the median value of percent cover range in each cover class. Relative coverage was regarded as the importance value of each species. Relative coverage was determined by dividing the cover fraction of each species by the summed cover of all species in each plot and then multiplying by 100 . A matrix of importance values for all species in all plots was constructed and used as data for ordination using detrended correspondence analysis (DCA) [63]. To describe and compare species diversity and dominance among sites, rank abundance curves $[55,64,65]$ were plotted. The Shannon-Wiener diversity index $\left(\mathrm{H}^{\prime}\right)[65]$ was also calculated for each stand in each site. 


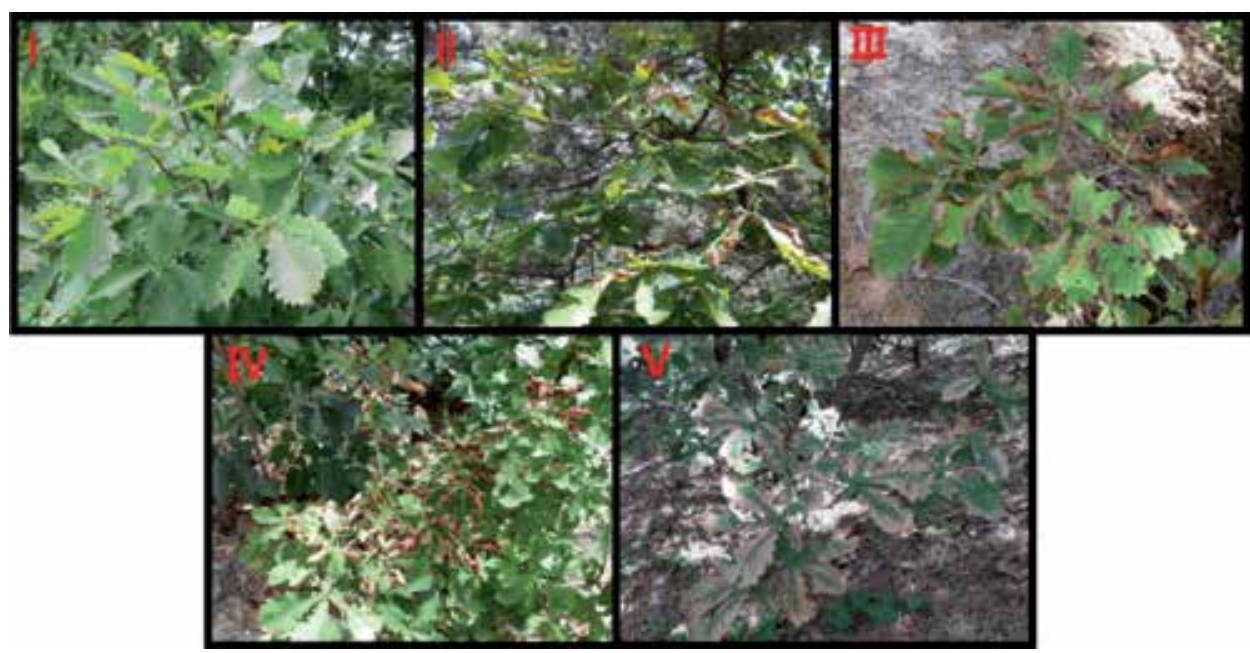

Figure 2.

Photos showing the grades for assessing drought-induced plant damage. I, none damaged; II (slight), less than 25\% damaged; III (moderate), 25-50\% damaged; IV (severe), 50-75\% damaged; V (very severe), more than $75 \%$ damaged.

Meteorological data to confirm drought state were obtained from the Korea Meteorological Administration (https://data.kma.go.kr). The amount of evapotranspiration and evaporative demand was obtained by applying a method of Blaney and Criddle [66].

Field survey for investigating drought-induced plant damage was carried out from May to early July before rainy season in 2017 and from July to August in 2018. Survey in 2018 focused on verifying the result assessed in 2017 survey.

Field survey was conducted by recording degree of leaf surface injury of all plants appearing along the trampling path. Damage degree was classified into five groups based on the percentage of injury showed on leaf surface: very severe ( $\mathrm{V}$, more than $75 \%$ of total leaf area damaged), severe (IV 50-75\% damaged), moderate (III, 25-50\% damaged), slight (II, less than 25\% damaged), and none (I, 0\%) (Figure 2). We regarded the plant that all leaves were withered as dead individual in survey of 2017 and confirmed the result in the survey of 2018. The length of trampling path where field survey was conducted was about $4.0 \mathrm{~km}$, and horizontal range was within $10 \mathrm{~m}$ in both sites.

\section{Landscape structure}

As the result of analysis on the landscape ecological map generated for Seoul, urban area occupied the widest as $60.8 \%$ of total area, secondary forests $(12.7 \%)$, plantations (8.6\%), river and reservoir (5.6\%), landscape architectural plantation $(4.5 \%)$, agricultural fields $(2.5 \%)$, grasslands $(2.4 \%)$, inaccessible area $(2.3 \%)$, and bare ground $(0.7 \%)$ followed (Figure 3$)$. Forests composed of secondary forests and plantations and agricultural fields were usually concentrated to the city's fringe, and the urban center has little vegetation. Moreover, vegetation in the urban center was of low ecological quality, as most were fragmented into small patches and consisted of species introduced by landscape architects without ecological consideration or exotic plants $[39,40]$. Therefore, green space showed severe imbalanced spatial distribution (Figure 3). 


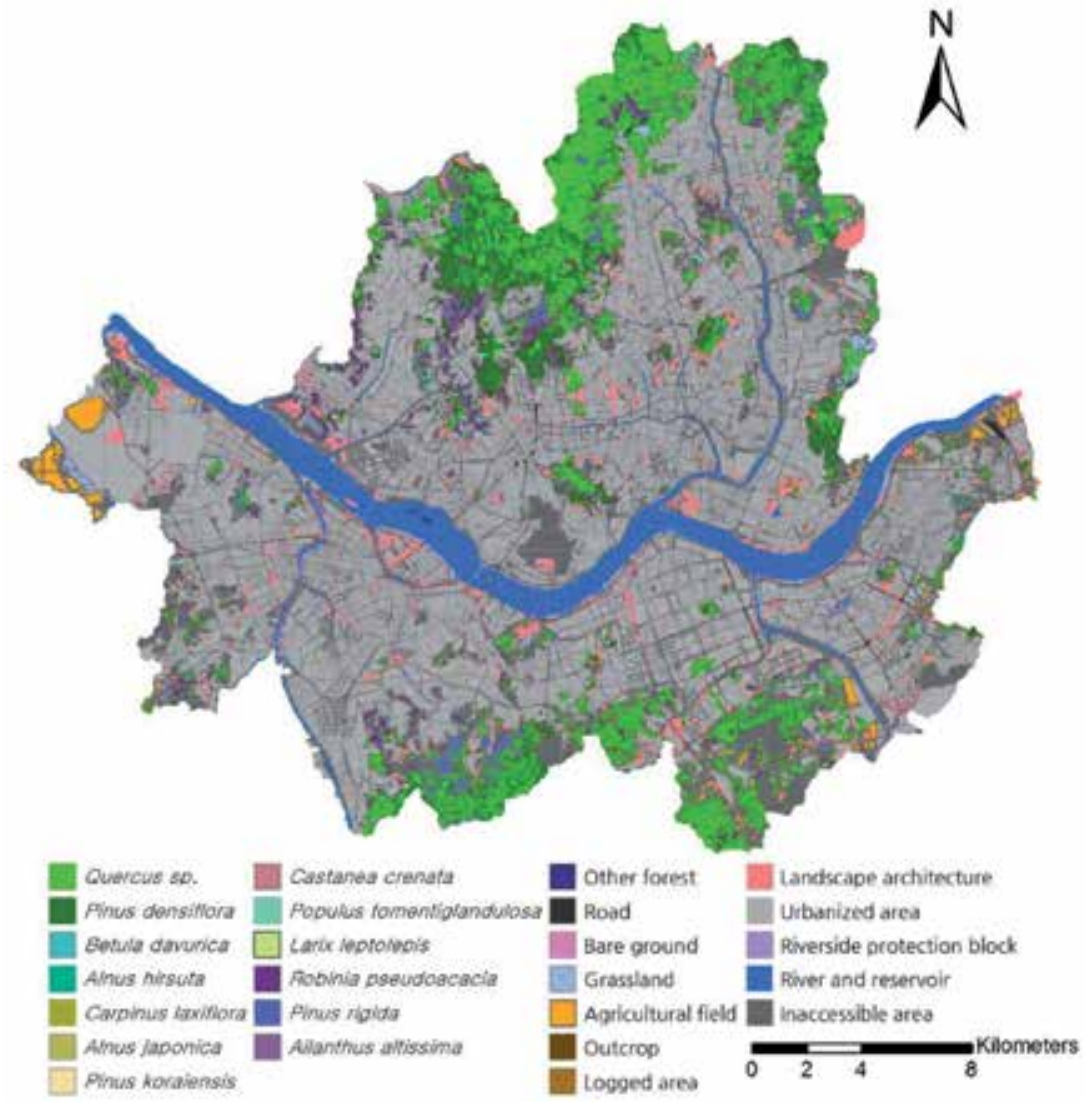

Figure 3.

A map showing spatial distribution of vegetation and land-use types in the Seoul metropolitan area (redrawn from Seoul City [59]).

\section{Spatial structure of urban heat island}

Spatial structure of the urban heat island in Seoul was investigated based on temperature data measured at 23 automatic weather stations (AWSs) in the Seoul metropolitan area.

Figure 4 shows the average spatial distribution of air temperature in the Seoul metropolitan area for each season and the whole year for 20 years from 1998 to 2017. A relative warm area extends in the east-west direction, and warm cores are pronounced in residential and commercial area with high-story buildings and heavy traffics. A relative cold area is observed in mountainous areas, which is near the borderline of Seoul except the southwestern and southeastern borderlines where the sprawling expansion of urbanization has already progressed.

Cities are often referred to as urban heat islands, with the urban center having the highest temperatures. This is primarily due to the low amount of vegetation in urban center compared to the suburbs and beyond (Figure 1). Cities also use large amounts of energy, and emit this energy as waste heat, further exacerbating the urban heat island effect.

On the other hand, forests and other vegetation types use large amounts of solar energy and evaporate water by means of transpiration to cool leaf surfaces. Evaporative water used through transpiration also contributes in reducing air temperatures in urban areas. Forests and other vegetation can also contribute indirectly to temperature reduction by reducing urban energy consumption 

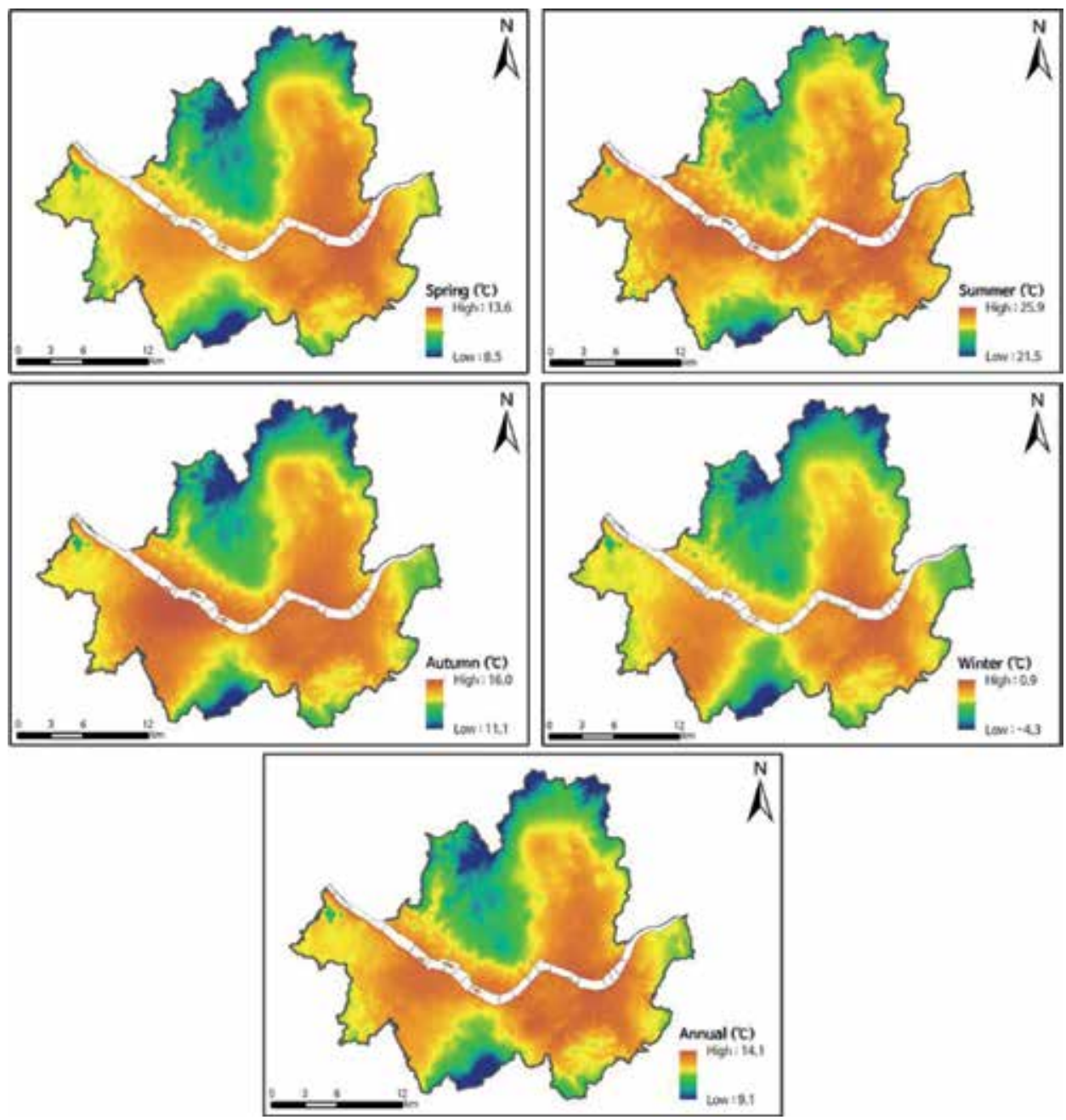

Figure 4.

Spatial distribution of air temperature in the Seoul metropolitan area averaged for each season and year.

through intercepting and using solar energy and by reducing building energy demand through shading and reducing wind speed. Therefore, low vegetation coverage in urban center results in larger temperature gradients between urban center and urban fringe or beyond [67-69]. Indeed, Seoul's heat island effect is very large $[27,70]$, as the temperature difference between the urban center and boundary was about $5^{\circ} \mathrm{C}$ (Figure 4).

The urban heat island is closely linked to the land-use pattern (Figure 3).

Buildings, asphalt, and concrete pavement absorb solar radiation and emit long-wave radiation that warms the atmosphere [71-73]. Moreover, those artificial structures hold heat for extended periods. This heat moves from buildings, asphalt, and concrete pavement to the cool air as the air temperature decreases after sunset to form atmospheric temperature inversion (warm air over cold air) [74-77]. Therefore, many cities located in basins with limited ventilation like Seoul experience serious air pollution problems. The ventilation of an urban basin can be limited not only by orographic barriers but also by urban heat island-induced circulations and/or the capping effect of temperature inversions. Furthermore, land-use and land-cover changes caused by urbanization alter the dynamics of temperature inversions and urban heat islands, thereby affecting air quality in an urban valley [78]. 
Temperature inversions are frequently observed in most urban areas including Seoul. Temperature inversion results in poor dispersion of pollutants. Strong thermal inversion induces pollutant accumulation and thereby become a primary cause of the heavy air pollution. In addition, Seoul is backed by mountains, which intensified the accumulation of pollutants generated in the city itself and blown from other regions, particularly China, which is relatively closely located to Seoul.

In recent decades, East Asia has been significantly industrialized and urbanized through its rapid economic growth. The industrialization and urbanization have resulted in adverse effect on air quality not only in this region but also in neighboring countries [78].

\section{Effects of urban mesoclimate on soil physicochemical properties}

Temperature gradient between urban center and suburbs results in a local circulation of air. As air heated in urban center rises and relatively cool air of suburbs flows into urban center, a micro-current is formed. In this air circulation process, temperature inversion layer formed in the urban air inhibits the vertical movement of air, and thereby the polluted air from urban center comes down on the urban fringe [77]. Such an air circulation occurring through interaction of temperature differences between urban and suburban areas and temperature inversion can transport light gaseous air pollutants from the urban center to the urban fringe [74, 79].

Spatial distribution of soil properties reflected the effects of such an air circulation. Soil $\mathrm{pH}$ tended to be lower in grids in the urban fringe than in grids within the urban center (Figure 5). $\mathrm{Ca}^{2+}$ and $\mathrm{Mg}^{2+}$ concentrations of soil followed the $\mathrm{pH}$
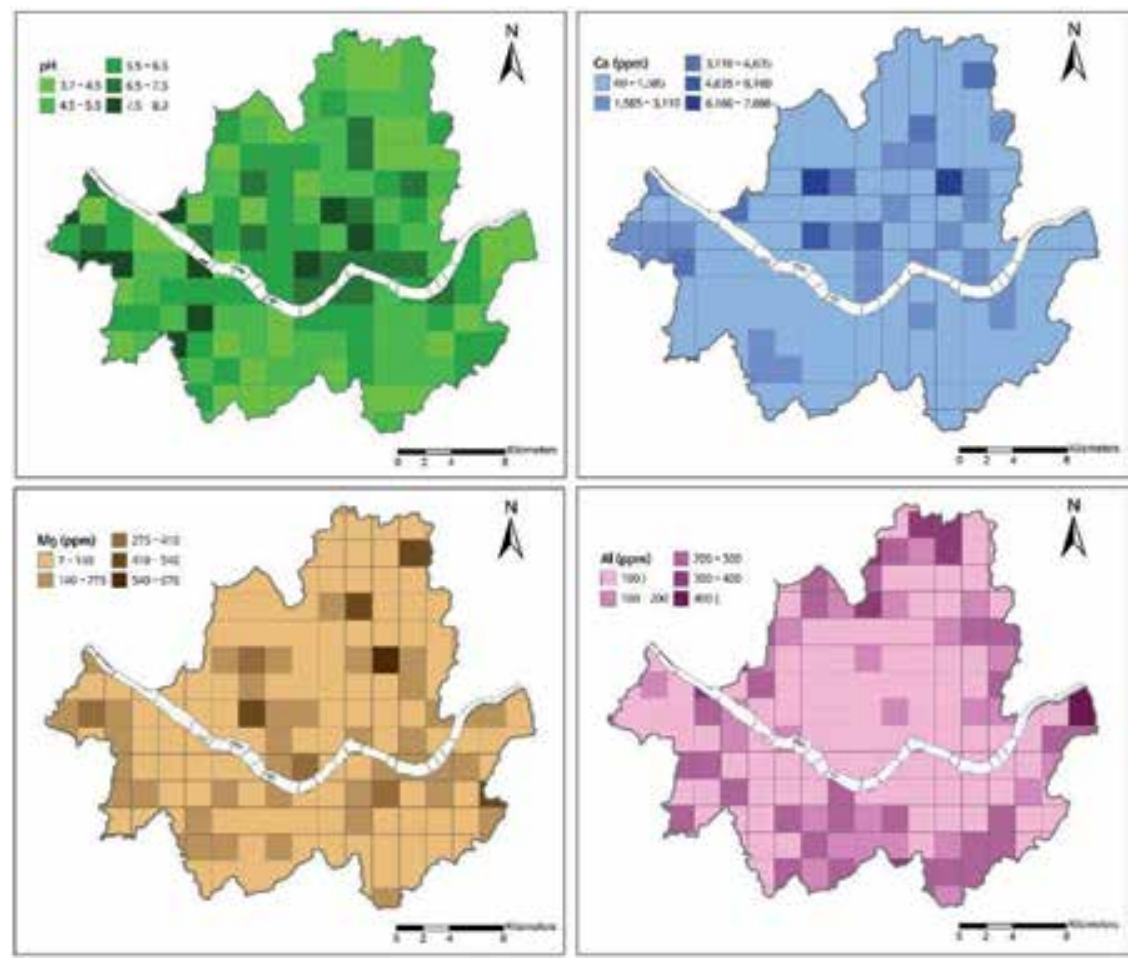

Figure 5 .

Spatial distribution of physicochemical properties of soil, such as $\mathrm{pH}, \mathrm{Ca}^{2+}, \mathrm{Mg}^{2+}$, and $\mathrm{Al}^{3+}$, in the Seoul metropolitan area. 
trends (Figure 4), but $\mathrm{Al}^{3+}$ concentration was the vice versa as it was higher in the urban fringe than in the urban center (Figure 4). Most of these chemical properties of soil are strongly related to soil acidification and to each other (Figure 5).

Soil acidification in those sites was due to deposition of acid precipitates, such as $\mathrm{SO}_{\mathrm{x}}$ and $\mathrm{NO}_{\mathrm{x}}$ [46]. Gaseous $\mathrm{SO}_{\mathrm{x}}$ and $\mathrm{NO}_{\mathrm{x}}$ are transformed to sulfuric acid $\left(\mathrm{H}_{2} \mathrm{SO}_{4}\right)$ and nitric acid $\left(\mathrm{HNO}_{3}\right)$ as they interact chemically with water in the air and soil and are deposited in dry and wet form on soil $[80,81]$.

Acidified soils of the urban periphery contained lower concentrations of basic cations, such as $\mathrm{Ca}^{2+}$ and $\mathrm{Mg}^{2+}$, than soils in the urban center, because they were leached through cation exchange mechanisms [82]. But higher concentrations of $\mathrm{Ca}^{2+}$ and $\mathrm{Mg}^{2+}$ in soils in the urban center are also related to deposition of heavy particulate probably from building materials (e.g., cement concrete; [83]) or to direct applications of calcium chloride $\left(\mathrm{CaCl}_{2}\right)$ used for melting snow. In addition, acidified soil releases the $\mathrm{Al}^{3+}$ ion when soil is particularly acidified to below $\mathrm{pH}$ 4.5. Such an $\mathrm{Al}^{3+}$ ion inhibits plant cell division and consequently retards plant growth as a toxic ion [84]. These serial changes in soil chemistry are known to cause forest decline [82].

Changes of those soil properties tend to be intensified compared with the result of the former research [39].

\section{Responses of urban forest on the changed mesoclimate and soil properties}

Mongolian oak (Quercus mongolica) forests are the most widely distributed and dominant forest of the late successional stage in Korea [85]. The DCA ordination (Figure 6) showed that stands in the urban area (Mts. Nam, Acha, Daemo, Bulam,

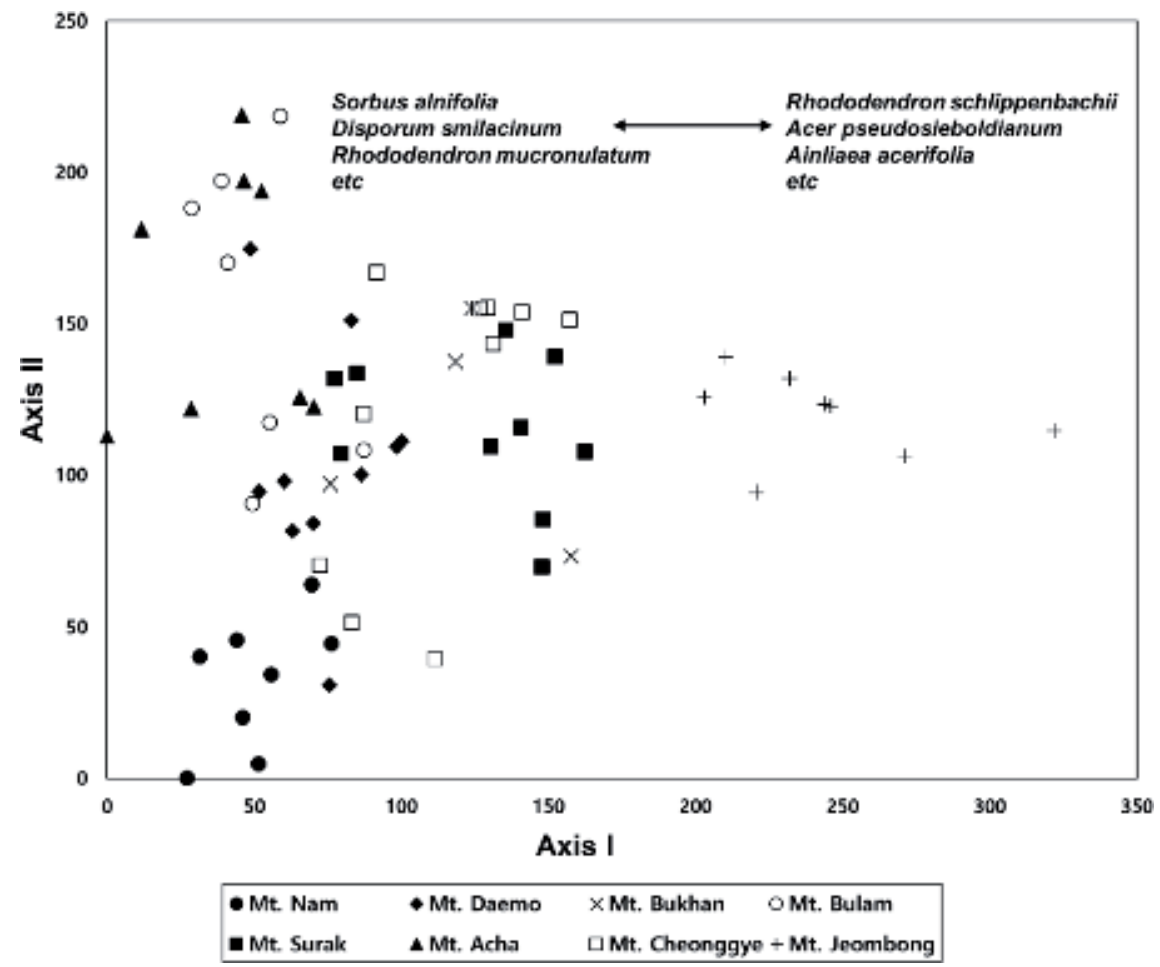

Figure 6.

Stand ordination of the Mongolian oak forest established in urban and suburban areas around Seoul. 
Bukhan, Cheonggye, and Surak) were clustered in the left corner of the graph, with stands in the natural area (Mt. Jeombong) on the opposite end of axis I. This result shows that species composition in the urban forest was differed from that in the natural forest.

Species richness was usually lower in the urban areas than that in natural areas although a few exceptional areas exist such as Mts. Surak, Bukhan, Bulam, and Cheonggye (see $x$-axis in Figure 7). The slope of species rank-dominance curve was steeper in sites with low species richness than that in sites with high species richness and thereby showed lower evenness (Figure 7).

Mongolian oak stands established in urban area showed a difference even in successional trend from those in natural area. In mountains located on urban area, the diameter class distribution of major trees in these Mongolian oak stands revealed that oaks dominated the larger diameter classes, while Sorbus alnifolia dominated the smaller diameter classes. On the other hand, Mongolian oak dominated all diameter classes in natural areas (Figure 8).

Size distributions of trees are useful indicators for understanding the structure of tree populations and for predicting dynamics of them [86-88]. The diameter class distribution of plant populations has generally been computed as frequency histograms [89]. Frequency distribution patterns of each diameter class indicate the potential change of the population in a plant community. A plant population, where young individuals are numerous and mature ones are fewer, is recognized as having a reverse J-shaped diameter distribution pattern [90, 91]. It is recognized that the population that shows a reverse J-shaped distribution pattern can persist continuously [90-93]. On the other hand, the normal population pattern with fewer

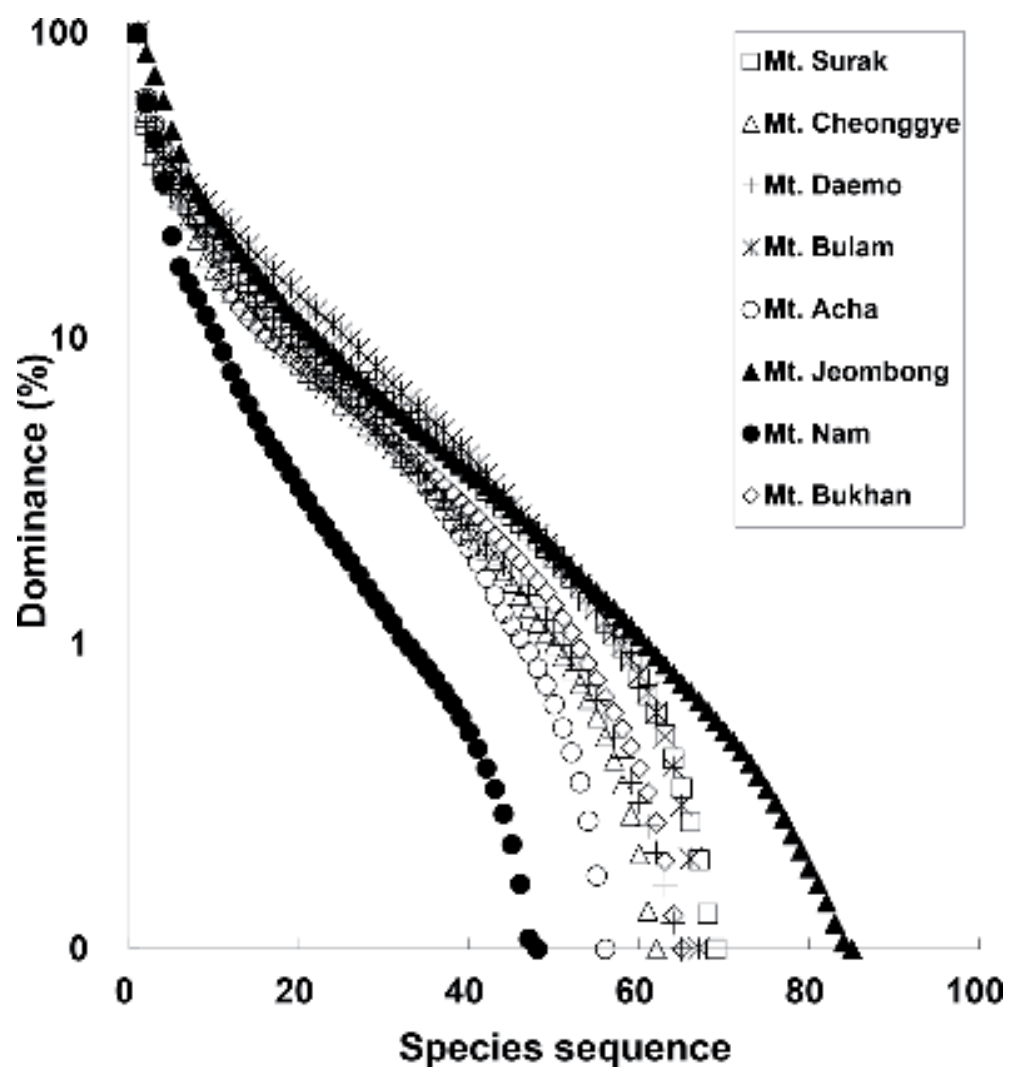

Figure 7 .

Rank-abundance curves of the Mongolian oak forests established in 10 study areas. 

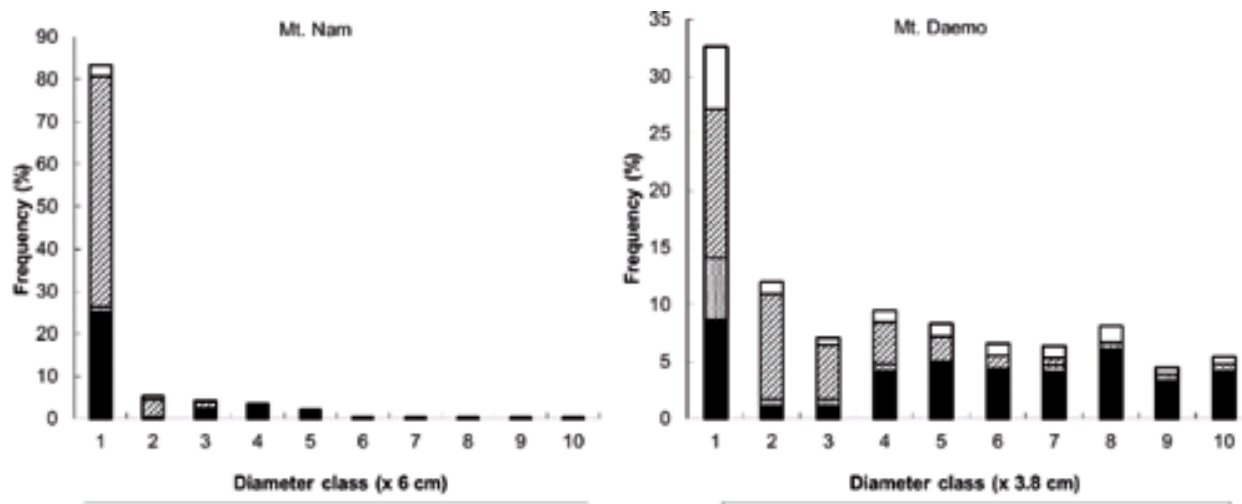

ص. mongalica aThe other oaks os. alnifolla oOthers

-Q. mangolica DThe other oaks oS. alnifolla oOthers
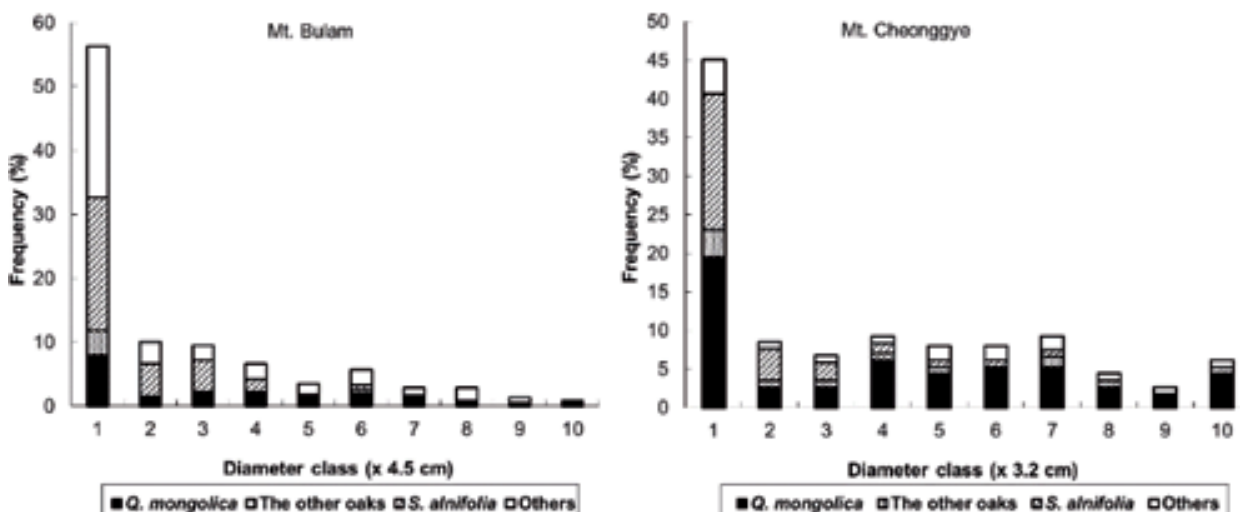

-Q. mongolles aThe other oaks as. alnifolla gothers
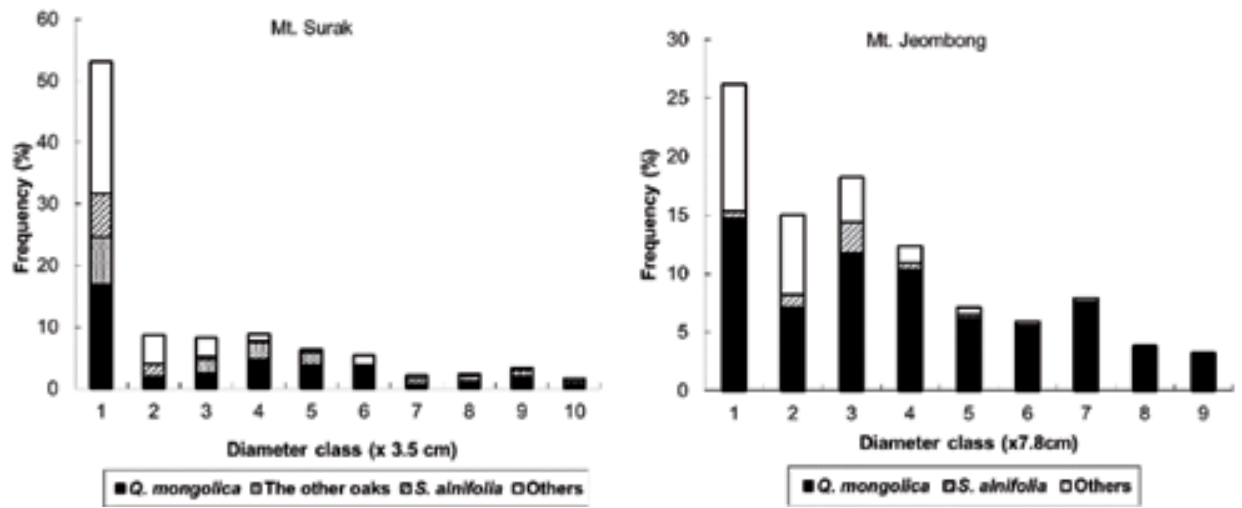

Figure 8.

Frequency distribution of diameter classes of major tree species composed of the Mongolian oak forests established in several mountains of Seoul and in Mt. Jeombong as a natural area.

juveniles relative to adults is typically replaced by another population in the future $[92,93]$, but a bimodal pattern is shown in a population that is regenerated with periodic disturbance $[94,95]$.

Based on this principle, it is expected that Mongolian oak stands in the natural area could be maintained continuously, whereas urban oak stands would be replaced by Korean mountain ash. Considered that Mongolian oak stands are the representative vegetation of the late successional stage in the Korean peninsula [85], this successional trend could be interpreted as being retrogressive [95].

As was mentioned above, the Mongolian oak forests in urban area of Seoul had different species composition, lower diversity, and retrogressive successional 
trends compared to those in natural area (Figures 6-8). These differences are likely due to the development of thin canopy crowns in overstory composed of Mongolian oaks, which have been exposed to severe air pollution stress over long years $[39,47,48]$. By increasing the supply of light and precipitation to the forest floor, thin crowns of canopy trees cause dense growth of subcanopy trees, such as the Korean mountain ash. Therefore, vegetation structure and successional trends change over time [96-99]. Once the subcanopy layer becomes denser, light again decreases, and species richness can be expected to decline, a pattern we observed in our urban forests (Figure 7).

Retrogressive succession, signs of which appeared in our urban oak communities, is usually caused by frequent or intense disturbance [100,101]. Although such situations have been frequently observed in the vicinity of industrial complexes exposed to severe air pollution [102-107], it is a very rare phenomenon in urban areas. Retrogressive succession would be expected where pollution damage to forests is usually intense and acute. However, pollution in most urban areas is less severe than near industrial sites but is chronic [106]. Although we could observe signs of severe air pollution damage from analyzing the vegetation structure in Seoul, severe visible damage on vegetation surface was not found as observed in forests near the industrial areas $[50,108]$. Therefore, our results in Seoul could be explained as resulting from synergistic interactions between chronic air pollution and urban climate, rather than resulting solely from severe pollution [109]. Air circulation specific to urban area from interaction of atmospheric temperature inversions and microcurrents occurred due to local temperature differences, and soil acidification due to air pollutants transported along the air circulation interact to cause a change in vegetation structure and consequently change vegetation dynamics. From these results, we can recognize a new type of forest decline in Mongolian oak stands as a general phenomenon occurring on the upper slopes surrounding the Seoul basin $[39,53,54]$.

\section{Occurrence of drought due to climate change}

Although annual precipitation showed a variation, precipitation when the amount was low, for example, 2014 and 2015, fell short of the threshold that temperate forest can be persisted in this region (Figure 9). Considering that annual mean temperature in Seoul is $12.2^{\circ} \mathrm{C}$, precipitation more than $100 \mathrm{~cm}$ is required to maintain temperate forest [110, 111]. But precipitations in 2014 and 2015, $80.89 \mathrm{~cm}$ and $79.21 \mathrm{~cm}$, did not fulfill the level.

Trends of monthly mean precipitation and potential evapotranspiration also showed very dangerous pattern (Figure 9). Gaps between precipitation and potential evapotranspiration during spring and fall seasons in 2017 when droughtinduced plant damage was investigated were far bigger than that between mean values of them. In 2018, rainfall during spring season is far more than that of normal year, while that during rainy season, usually July to August, was very short (Figure 10). Consequently, rainfall pattern was deviated greatly from the normal pattern. Patterns in 2014 and 2015 when precipitation was very short resembled that in 2018. Water budget in 2014 and 2015 evaluated based on relationship between precipitation and potential evapotranspiration was more severe. Potential evapotranspiration exceeded precipitation.

From those results we can deduce that plants would endure severe water deficiency during growing season particularly. In fact, drought-induced plant damage investigated in urban forest of Seoul reflects those results. 


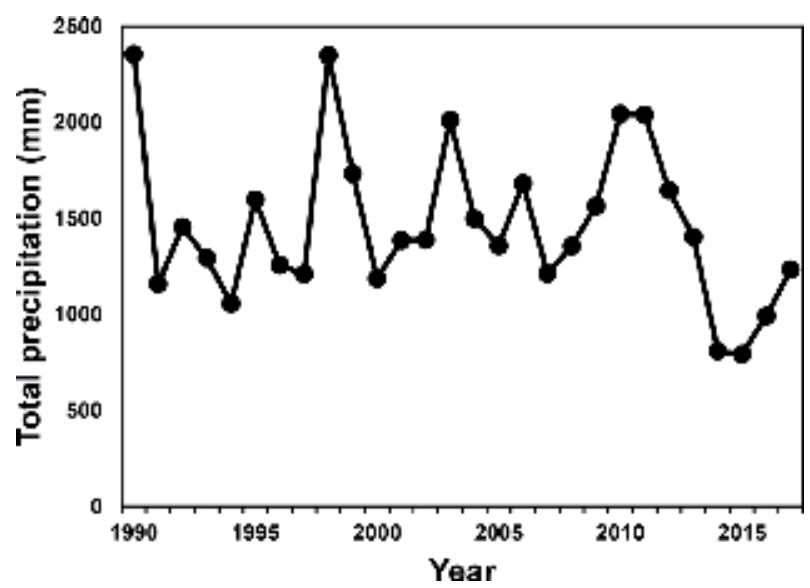

Figure 9.

Changes of annual precipitation for recent 30 years in Seoul. Considered annual mean temperature is $12.2^{\circ} \mathrm{C}$; precipitation more than $100 \mathrm{~cm}$ is required to maintain temperate forest. But years, which is not fulfill the level, for example $2014(80.89 \mathrm{~cm})$ and $2015(79.21 \mathrm{~cm})$ appear in recent years due to climate change.
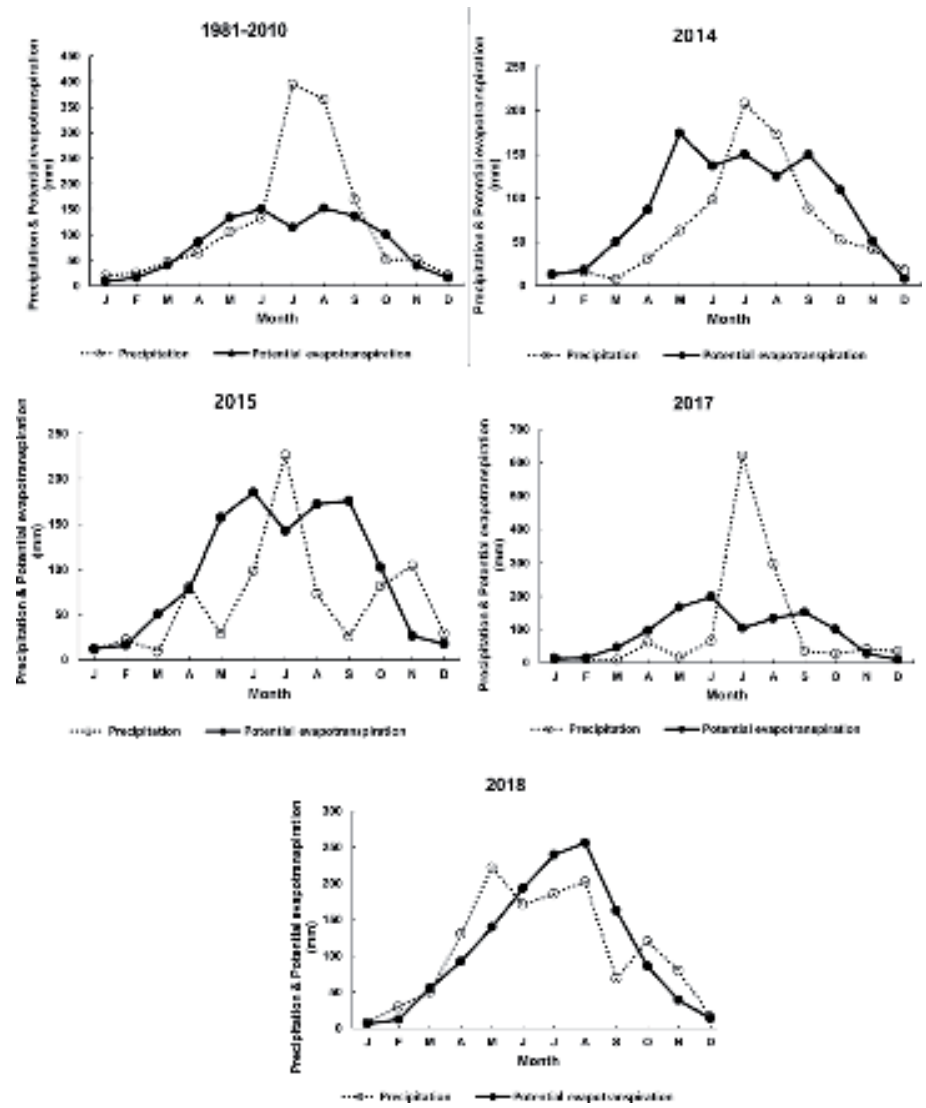

Figure 10.

Mean monthly trends of precipitation and potential evapotranspiration in 2014, 2015, 2017, and 2018 compared with mean values for recent 30 years from 1981 to 2010 in Seoul. Seoul, which is attributed to Asian monsoon climate zone, usually shows water balances with deficits in the spring season of the year, but the phenomenon was severer in 2017 and showed very different pattern in 2018. Patterns in 2014 and 2015 when precipitation was very short resembled that in 2018. Potential evapotranspiration exceeded precipitation in 2014 and 2015. Potential evapotranspiration was obtained applying a method of Blaney and Criddle [66]. Data were derived from Korea meteorological agency (https://data.kma.go.kr). 


\section{Drought-induced plant damage}

Drought-induced plant damage was shown in Table 1. Among canopy trees and understoried trees, S. alnifolia showed very severe damage (Table 1). C. scabrida, P. sargentii, and Crataegus pinnatifida showed severe damage, and Q. mongolica, Q. serrata, and Q. variabilis showed severe damage depending on site.

$R$. pseudoacacia, Q. acutissima, Q. dentate, and P. rigida showed moderate damage, and P. densiflora, Alnus hirsuta var. sibirica, Carpinus laxiflora, and Styrax obassia showed moderate damage depending on site. Fraxinus rhynchophylla, F. mandshurica, and Lindera obtusiloba showed slight damage. On the other hand, Sorbus commixta and Acer pseudosieboldianum did not show any visible damage. Among shrubs, Parthenocissus tricuspidata showed very severe damage depending on site. S. incisa showed severe damage, and Juniperus rigida, Symplocos chinensis for. Pilosa, and Weigela florida showed severe damage depending on site. Callicarpa japonica, R. mucronulatum, Lespedeza cyrtobotrya, Viburnum erosum, and Smilax sieboldii showed moderate damage. On the other hand, Corylus heterophylla showed slight damage.

Around 310 damaged plants in 34 species were observed (Table 1). Sorbus alnifolia, Robinia pseudoacacia, Q. mongolica, P. densiflora, etc. were the most damaged plants.

Around 107 plants in 7 species died due to drought (Table 1). Sorbus alnifolia, Castanea crenata, Robinia pseudoacacia, Q. mongolica, etc. were the plants that died the most.

\begin{tabular}{|c|c|c|c|c|}
\hline Life form & Species & $\begin{array}{l}\text { Damage } \\
\text { degree }\end{array}$ & $\begin{array}{l}\text { No. of damaged } \\
\text { individuals }\end{array}$ & $\begin{array}{l}\text { No. of dead } \\
\text { individuals }\end{array}$ \\
\hline \multirow{20}{*}{$\begin{array}{l}\text { Tree and } \\
\text { understory } \\
\text { tree }\end{array}$} & Sorbus alnifolia & $\mathrm{V}$ & 100 & 96 \\
\hline & Castanea crenata & IV & 3 & \\
\hline & Robinia pseudoacacia & III & 50 & \\
\hline & Prunus sargentii & IV & 9 & 1 \\
\hline & Quercus mongolica & I - IV & 27 & 6 \\
\hline & Pinus densiflora & I - III & 23 & \\
\hline & P. rigida & III & 1 & \\
\hline & Quercus serrata & II - IV & 15 & \\
\hline & Sorbus commixta & I & 1 & \\
\hline & Q. variabilis & II - IV & 8 & 1 \\
\hline & Q. acutissima & III & 2 & \\
\hline & Alnus hirsuta var. sibirica & II - III & 2 & \\
\hline & Fraxinus mandshurica & II & 1 & \\
\hline & Acer pseudosieboldianum & I & 1 & \\
\hline & F. rhynchophylla & II & 2 & \\
\hline & Carpinus laxiflora & I- III & 2 & \\
\hline & Q.aliena & $\mathrm{I}-\mathrm{V}$ & 2 & 1 \\
\hline & Q. dentata & III & 1 & \\
\hline & Lindera obtusiloba & II & 2 & \\
\hline & Styrax obassia & II - III & 3 & \\
\hline
\end{tabular}


Forest Decline Under Progress in the Urban Forest of Seoul, Central Korea DOI: http://dx.doi.org/10.5772/intechopen.86248

\begin{tabular}{lllll}
\hline Life form & Species & $\begin{array}{l}\text { Damage } \\
\text { degree }\end{array}$ & $\begin{array}{l}\text { No. of damaged } \\
\text { individuals }\end{array}$ & $\begin{array}{c}\text { No. of dead } \\
\text { individuals }\end{array}$ \\
\hline & Fraxinus sieboldiana & I & 1 & 1 \\
\cline { 2 - 4 } & Juniperus rigida & III - IV & 4 & \\
\cline { 2 - 4 } & Indigofera kirilowii & II & 1 & \\
\hline Stephanandra incisa & IV & 20 \\
\hline Rhododendron mucronulatum & III & 8 \\
\hline Viburnum erosum & III & 1 \\
\hline Smilax sieboldii & III & 1 \\
\hline Rhododendron schlippenbachii & III & 3 \\
\hline Lespedeza cyrtobotrya & III & 2 \\
\hline Symplocos chinensis for. pilosa & III - IV & 2 \\
\hline Corylus heterophylla & II & 1 \\
\hline Parthenocissus tricuspidata & I - V & 2 \\
\hline Weigela florida & III - IV & 7 \\
\hline Callicarpa japonica & III & 2 \\
\hline
\end{tabular}

Table 1.

Degree of leaf surface damage, the number of damaged plants, and the number of dead plants due to drought in an urban forest (Mt. Bulam) of Seoul, central Korea.

Drought-induced plant damage started from withering of leaves of plants introduced for landscaping in the urban area. Over time, branches died and death of the whole plant body followed. We regarded these phenomena due to that they were introduced without ecological consideration at this time. But die-off of Ligustrum obtusifolium, Callicarpa japonica, Euonymus japonicas, etc., which were introduced by reflecting potential natural vegetation, and/or Pinus densiflora, Buxus koreana etc., which are familiar with present concrete ground or changes of Anthropocene, began to be observed.

As drought continues, plant damage spreads toward the urban forest beyond the residential area in the urban center. Damage of exotic plants, such as Robinia pseudoacacia, Crataegus scabrida, etc., or plants introduced for landscaping such as Prunus serrulata var. spontanea, Rhododendron yedoense for. Poukhanense, etc. was observed first of all. But damage of the native plants began to appear soon after. In particular, damage of Sorbus alnifolia, the product of retrogressive succession [39], was remarkable. As retrogressive succession has already progressed much and thus the number of individuals of Sorbus alnifolia increased greatly (Figure 7), it can be recognized as crisis of urban forest.

Retrogressive succession from forests of stable late successional stage such as Quercus or Carpinus dominated forests to Sorbus alnifolia or Styrax japonica dominated forests, which favor infertile and instable environment of early successional stage, has progressed in urban area of Seoul by complex interactions of chronic air and soil pollution, and urban microclimate regime is changed by excessive land use [39]. Not only biodiversity decreases remarkably but also vegetation stratification became simple, and thus both ecological diversity and ecosystem stability deteriorated severely in the place that retrogressive succession occurred [39].

In this situation, severe drought due to climate change continued for several years and threatened ecological stability of the region substantially. Annual precipitation of the region, which experiences severe drought at present, falls short to the level, about $1000 \mathrm{~mm}$, that temperate forest can establish in this region [110]. 
In addition, aggravation of spring drought, which comes from reduction of snow fall due to temperature rise during winter season and temperature rise and evaporation increase due to climate change, incites vegetation damage $[37,38]$.

Climate change does not induce temperature rise only simply but accompanies diverse and complex environmental changes likewise drought that we experience now. Moreover, vegetation damage spreads into various native plants beyond several sensitive plants. Environmental change due to climate change may cause additive retrogressive succession into poor vegetation near to open woodland rather than simple change from the deciduous broad-leaved forest to the evergreen broadleaved forest as the general public think.

The damage of Castanea crenata and Prunus sargentii was severe, and damage of Q.mongolica and Carpinus laxiflora, which composes late successional vegetation, was also found. Of more concern is that most plants without any relation with species and life form over all layers composing vegetation stratification such as canopy tree, understory tree, shrub, and herb layers were injured or died. For example, $P$. densiflora and $Q$. variabilis, which composes vegetation of the representative dry land and Juniperus rigida, Weigela florida, Rhododendron mucronulatum, etc., which forms their undergrowth, were damaged or died. Indeed, serious phenomenon progressed around us. Continuous monitoring and synthetic consideration for preparing on climate change are urgently required.

\section{Conclusion}

In Seoul, the capital of South Korea, most flat plains and hilly terrain were transformed from the natural land surface to the artificial impervious one with the increase of population due to both birth and influx from the rural area. Consequently, green space shows imbalanced spatial distribution as it is restricted to the urban fringe, where the land is mountainous and thus development is difficult topographically and deficient in urban center. This imbalanced distribution of green space led to severe urban heat island effect, and the effect was followed by temperature inversion. Subsequently, this change produced altered air circulation patterns specific to city, particularly city with basin-type topography like Seoul $[77,79]$. Movement of air pollutants from urban area is likely dominated by this air circulation. In this process, relatively heavy particulates are felled in urban center, while light gaseous pollutants are transported to the forested area in urban boundary. Spatial distribution of physicochemical properties of soil reflects the trends. Forest of this area experiences retrogressive succession from Mongolian oak forest of the late successional stage to Korean mountain ash forest of the earlier successional stage as it is continuously exposed to air pollutants blowing from urban center, and soil is acidified due to the effect. As the results of such changes, urban Mongolian forest shows decline symptom that species composition is different and species diversity is lower than that in natural landscape. Further, the result increases vulnerability to environmental stresses related to climate change including drought.

Plant damage due to drought begun from withering of leaves of plants introduced for landscaping in the urban park. Over time, branches died and death of the whole plant body followed. As drought continues, plant damage spreads toward the urban forest beyond the residential area in the urban center. Damage of exotic plants or plants introduced for landscaping was observed first of all. But damage of the native plants began to appear soon after. In particular, damage of Sorbus alnifolia, the product of retrogressive succession, was remarkable. As retrogressive succession has already progressed much and thus the number of individuals of Sorbus alnifolia increased greatly, it was surmised as the level so that this phenomenon can 
be recognized as crisis of urban forest. In this situation, severe drought due to climate change is being continued for several years; annual precipitation of the region, which experiences severe drought at present, records less than $1000 \mathrm{~mm}$; the level approaches the threshold of ecological condition that forest can be established. In this respect, continuous monitoring and synthetic measure based on the results for coping with drought due to climate change are urgently required.

\section{Acknowledgements} Korea.

This paper was supported by LTER program of the Ministry of Environment of

\section{Conflict of interest}

This paper was prepared by supplementing and reediting papers that prof. C.S. Lee had published [39, 40, 46, 47, 99].

\section{Author details}

Chang Seok Lee ${ }^{1 *}$, Songhie Jung ${ }^{1}$, Bong Soon Lim ${ }^{1}$, A Reum Kim ${ }^{1}$, Chi Hong Lim ${ }^{2}$ and Hansol Lee ${ }^{3}$

1 Seoul Women's University, Seoul, Korea

2 National Institute of Ecology, Seocheon, Korea

3 Miami University, Ohio, USA

*Address all correspondence to: leecs@swu.ac.kr

\section{IntechOpen}

(C) 2019 The Author(s). Licensee IntechOpen. This chapter is distributed under the terms of the Creative Commons Attribution License (http://creativecommons.org/licenses/ by/3.0), which permits unrestricted use, distribution, and reproduction in any medium, provided the original work is properly cited. (cc) BY 


\section{References}

[1] Grimm NB, Faeth SH, Golubiewski NE, Redman CL, Wu J, Bai X, et al. Global change and the ecology of cities. Science. 2008;319(5864):756-760. DOI: 10.1126/science.1150195

[2] Niemelä J. Ecology and urban planning. Biodiversity and Conservation. 1999;8(1):119-131

[3] McKinney ML. Urbanization, biodiversity, and conservation the impacts of urbanization on native species are poorly studied, but educating a highly urbanized human population about these impacts can greatly improve species conservation in all ecosystems. Bioscience. 2002;52(10): 883-890. DOI: $10.1641 / 0006-$ 3568(2002)052[0883:UBAC]2.0. $\mathrm{CO} ; 2$

[4] Pickett ST, Cadenasso ML, Grove JM, Boone CG, Groffman PM, Irwin E, et al. Urban ecological systems: Scientific foundations and a decade of progress. Journal of Environmental Management. 2011;92(3):331-362. DOI: 10.1016/j. jenvman.2010.08.022

[5] Sukopp H. Urban ecology—Scientific and practical aspects. In: Breuste J, Feldmann H, Uhlmann O, editors. Urban Ecology. Berlin, Heidelberg: Springer Berlin Heidelberg; 1998. pp. 3-16

[6] Concepción ED, Moretti M, Altermatt F, Nobis MP, Obrist MK. Impacts of urbanisation on biodiversity: The role of species mobility, degree of specialisation and spatial scale. Oikos. 2015;124(12):15711582. DOI: $10.1111 /$ oik.02166

[7] Chapin FS, Walker BH, Hobbs RJ, Hooper DU, Lawton JH, Sala $\mathrm{OE}$, et al. Biotic control over the functioning of ecosystems. Science. 1997;277(5325):500-504. DOI: 10.1126/ science. 277.5325 .500
[8] Rall L, Niemela J, Pauleit S, Pintar M, Lafortezza R, Santos A, et al. A typology of urban green spaces, ecosystem services provisioning services and demands. Report D3. 2015;1

[9] Bolund P, Hunhammar S. Ecosystem services in urban areas. Ecological Economics. 1999;29(2):293-301. DOI: 10.1016/S0921-8009(99)00013-0

[10] Croci S, Butet A, Georges A, Aguejdad R, Clergeau P. Small urban woodlands as biodiversity conservation hot-spot: A multi-taxon approach. Landscape Ecology. 2008;23(10):11711186. DOI: 10.1007/s10980-008-9257-0

[11] Godefroid S, Koedam N. Urban plant species patterns are highly driven by density and function of built-up areas. Landscape Ecology. 2007;22(8):1227-1239. DOI: $10.1007 /$ s10980-007-9102-x

[12] Horák J, Rom J, Rada P, Šafářová L, Koudelková J, Zasadil $\mathrm{P}$, et al.

Renaissance of a rural artifact in a city with a million people: Biodiversity responses to an agro-forestry restoration in a large urban traditional fruit orchard. Urban Ecosystems. 2018;21(2):263-270. DOI: $10.1007 /$ s11252-017-0712-z

[13] Kowarik I, Buchholz S, von der Lippe M, Seitz B. Biodiversity functions of urban cemeteries: Evidence from one of the largest Jewish cemeteries in Europe. Urban Forestry \& Urban Greening. 2016;19:68-78. DOI: 10.1016/j. ufug.2016.06.023

[14] Gilbert OL. The Ecology of Urban Habitats. London: Chapman and Hall; 1994. $369 \mathrm{p}$

[15] Coomes DA, Simonson WD, Burslem DF. Forests and Global Change. Cambridge: Cambridge University Press; 2014. 462 p 
[16] Sala OE, Chapin FS, Armesto JJ, Berlow E, Bloomfield J, Dirzo R, et al. Global biodiversity scenarios for the year 2100. Science. 2000;287(5459):1770-1774. DOI: $10.1126 /$ science. 287.5459 .1770

[17] Etter A, McAlpine C, Possingham H. Historical patterns and drivers of landscape change in Colombia since 1500: A regionalized spatial approach. Annals of the Association of American Geographers. 2008;98(1):2-23. DOI: $10.1080 / 00045600701733911$

[18] Haddad NM, Brudvig LA, Clobert J, Davies KF, Gonzalez A, Holt RD, et al. Habitat fragmentation and its lasting impact on Earth's ecosystems. Science Advances. 2015;1(2):e1500052. DOI: 10.1126/sciadv.1500052

[19] Gavier-Pizarro GI, Radeloff VC, Stewart SI, Huebner CD, Keuler NS. Housing is positively associated with invasive exotic plant species richness in New England, USA. Ecological Applications. 2010;20(7):1913-1925. DOI: 10.1890/09-2168.1

[20] Kaye JP. Carbon fluxes, nitrogen cycling, and soil microbial communities in adjacent urban, native and agricultural ecosystems. Global Change Biology. 2005;11(4):575-587. DOI: 10.1111/j.1365-2486.2005.00921.x

[21] McDonnell MJ, Pickett STA, Groffman P, Bohlen P, Pouyat RV, Zipperer WC, et al. Ecosystem processes along an urban-to-rural gradient. Urban Ecosystems. 1997;1(1):21-36. DOI: 10.1023/A:1014359024275

[22] Xiao Q, McPherson EG, Simpson JR, Ustin SL. Rainfall interception by Sacramento's urban forest. Arboriculture \& Urban Forestry. 1998;24(4):235-244

[23] Nowak DJ, Crane DE, Stevens JC. Air pollution removal by urban trees and shrubs in the United States. Urban Forestry \& Urban Greening. 2006;4(3):115-123. DOI: 10.1016/j. ufug.2006.01.007

[24] Lin BB, Philpott SM, Jha S. The future of urban agriculture and biodiversity-ecosystem services: Challenges and next steps. Basic and Applied Ecology. 2015;16(3):189-201. DOI: 10.1016/j.baae.2015.01.005

[25] Yuan F, Bauer ME. Comparison of impervious surface area and normalized difference vegetation index as indicators of surface urban heat island effects in Landsat imagery. Remote Sensing of Environment. 2007;106(3):375-386. DOI: $10.1016 /$ j.rse.2006.09.003

[26] Zhou W, Qian Y, Li X, Li W, Han L. Relationships between land cover and the surface urban heat island: Seasonal variability and effects of spatial and thematic resolution of land cover data on predicting land surface temperatures. Landscape Ecology. 2014;29(1):153-167. DOI: $10.1007 /$ s10980-013-9950-5

[27] Lee HY. A study on the urban temperature in Seoul. Ehwa Bulletin of Geography. 1985;1:104

[28] Kim HH. Urban heat island. International Journal of Remote Sensing. 1992;13(12):2319-2336. DOI: $10.1080 / 01431169208904271$

[29] Jiang Y, Fu P, Weng Q. Assessing the impacts of urbanization-associated land use/cover change on land surface temperature and surface moisture: A case study in the Midwestern United States. Remote Sensing. 2015;7(4):4880. DOI: 10.3390/ rs70404880

[30] Fahey RT, Bialecki MB, Carter DR. Tree growth and resilience to extreme drought across an urban land-use gradient. Arboriculture \& Urban Forestry. 2013;39(6):279-285 
[31] Cregg BM, Dix ME. Tree moisture stress and insect damage in urban areas in relation to heat island effects. Arboriculture \& Urban Forestry. 2001;27(1):8-17

[32] Savi T, Bertuzzi S, Branca S, Tretiach M, Nardini A. Droughtinduced xylem cavitation and hydraulic deterioration: Risk factors for urban trees under climate change? The New Phytologist. 2015;205(3):1106-1116. DOI: $10.1111 / \mathrm{nph} .13112$

[33] Winkler JA, Arritt RW, Pryor SC. Climate Projections for the Midwest: Availability, Interpretation and Synthesis. United States: US National Climate Assessment; 2012. 22 p

[34] Gustafson EJ, Sturtevant BR. Modeling forest mortality caused by drought stress: Implications for climate change. Ecosystems. 2013;16(1):60-74. DOI: 10.1007/s10021-012-9596-1

[35] Suarez ML, Ghermandi L, Kitzberger T. Factors predisposing episodic drought-induced tree mortality in Nothofagus-Site, climatic sensitivity and growth trends. Journal of Ecology. 2004;92(6):954-966. DOI: 10.1111/j.1365-2745.2004.00941.x

[36] Pasho E, Camarero JJ, de Luis M, Vicente-Serrano SM. Impacts of drought at different time scales on forest growth across a wide climatic gradient in north-eastern Spain. Agricultural and Forest Meteorology. 2011;151(12):1800-1811. DOI: 10.1016/j. agrformet.2011.07.018

[37] Allen CD, Macalady AK, Chenchouni H, Bachelet D, McDowell $\mathrm{N}$, Vennetier $\mathrm{M}$, et al. A global overview of drought and heat-induced tree mortality reveals emerging climate change risks for forests. Forest Ecology and Management. 2010;259(4):660-684. DOI: 10.1016/j. foreco.2009.09.001
[38] Allen CD, Breshears DD, McDowell NG. On underestimation of global vulnerability to tree mortality and forest die-off from hotter drought in the Anthropocene. Ecosphere. 2015;6(8):art129. DOI: $10.1890 /$ ES15-00203.1

[39] Lee CS, Cho YC, Lee AN. Restoration planning for the Seoul Metropolitan Area, Korea. In: Carreiro MM, Song Y-C, Wu J, editors. Ecology, Planning, and Management of Urban Forests: International Perspectives. New York: Springer; 2008. pp. 393-419. DOI: 10.1007/978-0-387-71425-7_25

[40] Kim GS, Song HK, Lee CH, Cho HJ, Lee CS. Ecological comparison of Mongolian oak (Quercus mongolica Fisch. ex Ledeb.) community between Mt. Nam and Mt. Jeombong as a Long Term Ecological Research (LTER) site. Journal of Ecology and Field Biology. 2011;34(1):75-85

[41] National Institute of Environmental Research (NIER). Studies on the Ecosystem Around the Industrial Complexes. Seoul: National Institute of Environmental Research; 1981

[42] Lee CS. A study on restoration of vegetation destroyed by air pollution. A Research Report for Post-Doc. Fellowship Program funded by Scientific Research Foundation of Korea. 1992. 70 p

[43] Kim JH. Forest decline syndrome affected by air pollution. In: Proceedings of symposium held by the Korean Society of Landscape Architecture and the Forestry Research Institute of Korea. 1991. pp. 3-25

[44] Kim JC. Ecophysiological responses of Quercus mongolica stand to air pollutants and a model for its productivity affected by ambient ozone [Ph.D. thesis]. Seoul: Seoul National 
University (in Korean with English abstract); 1994

[45] Rhyu TC. Mechanism of forest decline syndrome of Pinus rigida stands by acid pollutants and its recovery in Seoul metropolitan region [Ph.D. thesis]. Seoul: Seoul National University (in Korean with English abstract); 1994

[46] Rhyu TC, Kim KD, Kim JH. Growth decline of pitch pine caused by soil acidification in Seoul metropolitan area. The Korean Journal of Ecology. 1994;17(3):287-297

[47] Cho YC, Cho HJ, Lee CS. Urban thermo-profiles and community structure of Quercus mongolica forests along an urban-rural land use gradient: Implications for management and restoration of urban ecosystems. Journal of Ecology and Environment. 2009;32(3):167-176. DOI: 10.5141/ JEFB.2009.32.3.167

[48] Cho YC, Cho HJ, Lee CS. Greenbelt systems play an important role in the prevention of landscape degradation due to urbanization. Journal of Ecology and Environment. 2009;32(3):207-215. DOI: 10.5141/JEFB.2009.32.3.207

[49] Food, Agriculture Organization of the United N. State of the World's Forests. Rome: Food and Agriculture Organization of the United Nations; 1997

[50] Seoul City. Environment of Seoul. Seoul: Seoul City; 1997

[51] Korea Meteorological Administration. Annual climatological report. Seoul (Korea): Korea Meteorological Administration; 2011. $247 \mathrm{p}$

[52] Lee EB. Actual vegetation and potential natural vegetation. Korean Journal of Ecology. 1997;20(6):I439-I450
[53] Seoul City. A Report of Detailed Survey on the Forest Ecosystems in Seoul, 1nd Report. Seoul: Seoul City; 1997. $492 \mathrm{p}$

[54] Seoul City. A Report of Detailed Survey on the Forest Ecosystems in Seoul, 2nd Report. Seoul: Seoul City; 1998. $455 \mathrm{p}$

[55] Lee CS, You YH, Robinson GR. Secondary succession and natural habitat restoration in abandoned rice fields of Central Korea. Restoration Ecology. 2002;10(2):306-314. DOI: 10.1046/j.1526-100X.2002.00003.x

[56] Yim YJ. Urban environment and green belt. Nature Conservation. 1989;67:1251-1255

[57] Seoul City. Statistics of Seoul [Internet]. 2005. Available from: http://data.si.re.kr/2015br10-trend-ofpopulation-growth [Accessed: 01 March 2019]

[58] Kim JC, Choe SC. Seoul: The Making of a Metropolis. New York: Chichester; 1997. 261 p. DOI: 10.5860/ CHOICE.35-2279

[59] Seoul City. Biotop Map [Internet]. 2015. Available from: http://gis.seoul. go.kr/SeoulGis/Naver/MetroInfo.jsp [Accessed: 01 March 2019]

[60] Allen SE, Grimshaw HM, Rowland AP. Chemical analysis. In: Moore PD, Chapman SB, editors. Methods in plant Ecology. Oxford: Blackwell; 1986. p. $285-344$

[61] Korea National Arboretum. Korea Plant Name Index [Internet]. 2004. Available from: http:// wwwforestgokr/newkfsweb/kfs/idx/ SubIndexdo?orgId=kna\&mn=KFS_15 [Accessed: 01 March 2019]

[62] Braun-Blanquet J. Pflanzensoziologie-Grundzüge der 
Vegetationskunde. Berlin: SpringerVerlag; 1964

[63] Hill MO. Program for detrended correspondence analysis and reciprocal averaging. DECORANA-A FORTRAN. 1979

[64] Kent M, Coker P. Vegetation Description and Analysis: A Practical Approach. Chichester: John Wiley \& Sons; $1992.363 \mathrm{p}$

[65] Magurran AE. Measuring Biological Diversity. Oxford: Blackwell Pub; 2004. $256 \mathrm{p}$

[66] Blaney HF, Criddle WD.

Determining Consumptive Use and Irrigation Water Requirements. US Department of Agriculture; $1962.59 \mathrm{p}$

[67] Akbari H, Davis S, Huang J, Dorsano S, Winnett S. Cooling Our Communities: A Guidebook on Tree Planting and Light-colored Surfacing. US Environmental Protection Agency, Report\# PM-221/22p-200; 1992

[68] Boukhabla M, Alkama D, Bouchair A. The effect of urban morphology on urban heat island in the city of Biskra in Algeria. International Journal of Ambient Energy. 2013;34(2):100-110. DOI: $10.1080 / 01430750.2012 .740424$

[69] Gunawardena KR, Wells MJ, Kershaw T. Utilising green and blue space to mitigate urban heat island intensity. Science of the Total Environment. 2017;584-585:1040-1055. DOI: 10.1016/j.scitotenv.2017.01.158

[70] Kim YH, Baik JJ. Spatial and temporal structure of the urban heat Island in Seoul. Journal of Applied Meteorology. 2005;44(5):591-605. DOI: 10.1175/JAM2226.1

[71] Akbari H, Rosenfeld AH, Taha HG. Summer heat islands, urban trees, and white surfaces. In : 1990 The American society of Heating, Refrigerating and Air conditioning Engineers Transaction(Atlanta, GA). California: Berkeley; 1990.8 p

[72] Shahmohamadi P, Che-Ani A, Ramly A, Maulud KNA, Mohd-Nor M. Reducing urban heat island effects: A systematic review to achieve energy consumption balance. International Journal of Physical Sciences. 2010;5(6):626-636

[73] Shahmohamadi P, Che-Ani A, Maulud K, Tawil N, Abdullah N. The impact of anthropogenic heat on formation of urban heat island and energy consumption balance. Urban Studies Research. 2011; Article ID 497524.9 p. DOI: $10.1155 / 2011 /$ 497524

[74] Miller RW. Urban Forestry:

Planning and Managing Urban Greenspaces. Upper Saddle River, New Jersey: Prentice-Hall Inc.; 1996. 502 p

[75] Seoul City. A Study on Urban Planning Technique Based on Meteorological Characteristics of Seoul City. Seoul: Seoul City; 2000

[76] Chiras CD. Environmental Science: Creating A Sustainable Future, 6. Painos. Sudbury, USA: Jones and Bartlett Publishers Inc; 2001

[77] Rao VL. Effects of urban heat island on air pollution concentrations. International Journal of Current Microbiology and Applied Sciences. 2014;3(10):388-400

[78] Ning G, Wang S, Yim SHL, Li J, Hu $Y$, Shang Z, et al. Impact of low-pressure systems on winter heavy air pollution in the northwest Sichuan Basin, China. Atmospheric Chemistry and Physics. 2018;18(18):13601-13615. DOI: 10.5194/ acp-18-13601-2018

[79] Bonan GB. Ecological Climatology: Concepts and Applications. New York: Cambridge University Press; 2002. 678 p 
[80] Kennedy IR. Acid Soil and Acid Rain: The Impact on the Environment of Nitrogen and SuIphur Cycling. Letchworth: Research Studies Press; 1986. $272 \mathrm{p}$

[81] Reuss JO, Johnson DW. Acid Deposition and the Acidification of Soils and Waters. New York: Springer-Verlag; 1986. $119 \mathrm{p}$

[82] Ulrich B. Die Wälder in Mitteleuropa: Messergebnisse ihrer Umweltbelastung, Theorie ihrer Gefährdung, Prognose ihrer Entwicklung. Allg Forstz. 1980;35(1):198-2202

[83] Lovett GM, Traynor MM, Pouyat RV, Carreiro MM, Zhu W-X, Baxter JW. Atmospheric deposition to oak forests along an urban-rural gradient. Environmental Science \& Technology. 2000;34(20):4294-4300. DOI: 10.1021/ es001077q

[84] Wong M, Swift RS. Role of organic matter in alleviating soil acidity. In: Handbook of Soil Acidity. New York: Marcel Dekker; 2003. pp. 337-358

[85] Krestov PV, Song J-S, Nakamura Y, Verkholat VP. A phytosociological survey of the deciduous temperate forests of mainland Northeast Asia. Phytocoenologia. 2006;36(1):77-150. DOI: $10.1127 / 0340-269 \mathrm{X} / 2006 /$ 0036-0077

[86] Wright SJ, Muller-Landau HC, Condit R, Hubbell SP. Gap-dependent recruitment, realized vital rates, and size distributions of tropical trees. Ecology. 2003;84(12):3174-3185. DOI: 10.1890/02-0038

[87] White EP, Ernest SK, Kerkhoff AJ, Enquist BJ. Relationships between body size and abundance in ecology. Trends in Ecology \& Evolution. 2007;22(6):323330. DOI: 10.1016/j.tree.2007.03.007

[88] Deb P, Sundriyal RC. Tree regeneration and seedling survival patterns in old-growth lowland tropical rainforest in Namdapha National Park, north-east India. Forest Ecology and Management. 2008;255(12):3995-4006. DOI: $10.1016 /$ j.foreco.2008.03.046

[89] Westphal C, Tremer N, Oheimb G, Hansen J, Gadow K, Hardtle W. Is the reverse J-shaped diameter distribution universally applicable in European virgin beech forests? Forest Ecology and Management. 2006;223(1-3):75-83. DOI: 10.1016/j.foreco.2005.10.057

[90] Peet RK. Forest vegetation of the Colorado Front Range. Vegetatio. 1981;45(1):3-75. DOI: $10.1007 /$ BF00240202

[91] Dyakov NR. Successional pattern, stand structure and regeneration of forest vegetation according to local environmental gradients. Ecologia Balkanica. 2013;5(1):69-85

[92] Lykke AM. Assessment of species composition change in savanna vegetation by means of woody plants' size class distributions and local information. Biodiversity and Conservation. 1998;7(10):1261-1275. DOI: 10.1023/A:1008877819286

[93] Bin Y, Ye W, Muller-Landau HC, $\mathrm{Wu}$ L, Lian J, Cao H. Unimodal tree size distributions possibly result from relatively strong conservatism in intermediate size classes. PLoS One. 2013;7(12):e52596. DOI: 10.1371/ journal.pone.0052596

[94] Chew RM, Chew AE. The primary productivity of a desert-shrub (Larrea tridentata) community. Ecological Monographs. 1965;35(4):21. DOI: 10.2307/1942146

[95] Barbour MG. Terrestrial Plant Ecology. The Benjamin/Cummings: California; $1999.649 \mathrm{p}$

[96] Smith WH. Air pollutionEffects on the structure and 
function of the temperate forest ecosystem. Environmental Pollution (1970). 1974;6(2):111-129. DOI: 10.1016/0013-9327(74)90027-5

[97] McClenahen JR. Community changes in a deciduous forest exposed to air pollution. Canadian Journal of Forest Research. 1978;8(4):432-438. DOI: 10.1139/x78-063

[98] Scale PR. Changes in plant communities with distance from an $\mathrm{SO}_{2}$ source. Effects of air pollutants on Mediterranean and temperate forest ecosystems. General Technical Report PSW-43. 1980. p. 248

[99] Lee CS, Hong SK, You YH, Kim JE, Moon JS, editors. Landscape structure in the green belt around the metropolitan area of Seoul, Korea. In: Proceedings of the International Association of Vegetation Science Symposium. 2000. pp. 230-233

[100] Runkle JR. Disturbance regimes in temperate forests. In: Pickett STA, White PS, editors. The Ecology of Natural Disturbance and Patch Dynamics. New York: Academic press, Inc.; 1985. p. 17-33

[101] Walker LR, Walker J, Hobbs RJ. Linking Restoration and Ecological Succession. New York, NY: Springer; 2007. 190 p

[102] Kozlowski TT. Measurement of effects of environmental and industrial chemicals on terrestrial plants. Methods for Estimating Risk of Chemical Injury: Human and Non-Human Biota and Ecosystems, Scope. 1985;35:573-609

[103] Shugart HH, McLaughlin SB Jr. Modeling $\mathrm{SO}_{2}$ Effects on Forest Growth and Community Dynamics. California: Stanford University Press; 1985. 494 p

[104] Lee CS. Regeneration of Pinus densiflora community around the Yeocheon industrial complex disturbed by air pollution. Korean Journal of Ecology. 1993;16(3):305-316

[105] Moravčík P. Development of new forest stands after a large scale forest decline in the Krušné hory Mountains. Ecological Engineering. 1994;3(1):57-69. DOI: 10.1016/0925-8574(94)90012-4

[106] Freedman B. Environmental Ecology: The Ecological Effects of Pollution, Disturbance, and Other Stresses. 2nd ed. San Diego: Academic Press; $1995.619 \mathrm{p}$

[107] Gunn JM. Restoration and Recovery of an Industrial Region. New York: Springer-Verlag; 1995. 345 p

[108] Korea Ministry of Environment. A White Book on Environment. Korea Ministry of Environment; 2005. 720 p

[109] Olson RL Jr, Sharpe PJH. Toward a mechanistic understanding of plant responses to SO2. In: Winner WE, Mooney HA, Goldstein RA, editors. Sulfur Dioxide and Vegetation. Stanford: Stanford University Press; 1985. pp. 507-520

[110] Whittaker RH. Communities and Ecosystems. New York: Macmillan; 1975. $162 \mathrm{p}$

[111] Ricklefs RE. The Economy of Nature. New York: W.H. Freeman and Co.; 2010. 620 p 
Section 2

\section{Forest Degradation and its Issues in the Tropics}





\title{
Prologue: Sustainable Development, Economic Growth and the Fate of Tropical Forests
}

\author{
Gabriel de Oliveira, Nathaniel A. Brunsell, \\ Yosio E. Shimabukuro and Carlos A.C. dos Santos
}

\section{Tropical deforestation and its actors}

We are experiencing, especially in the past few years, critical discussions, both in science and in the general public, about the role of tropical forests to support a more sustainable world, and how we can act to protect these ecosystems [1, 2]. There is a significant concern, especially in developing countries, on how to obtain economic growth using the natural resources within the areas covered by pristine forests without compromising future generations to meet their own needs.

The sustainable development is based on the balance or trade-offs between economic, environmental and social sustainability. It seems to be a simple equation; however, it is important to consider that many actors are included in these three pillars, and to find a common point between them is often complicated. So, how to convince a farmer that it is not possible to extend the area used for agriculture because there is a natural preserved area nearby? Or how to convince mining companies that it is not possible to clear-cut the forest for oil/natural gas exploration since the land is located within an indigenous reserve? And how to convince the urban population that is better to preserve the forest standing instead of producing meat or corn for their food needs or oil/natural gas for their transportation? As we can see, this balancing is not easy to achieve, especially when we talk about developing countries and their need to make economic growth at all costs.

Most of the funding to protect the tropical forests against deforestation in developing countries comes from developed countries that need to achieve their own goals on reducing emissions of carbon to the atmosphere, thus mitigating the impacts caused by climate change. This started in the mid-1990s with the Kyoto Protocol and has been ratified more recently, in 2015, with the Paris Agreement. There has been a considerable scepticism, especially in the population of third world countries, about the fact that developed countries feel entitled to the areas covered by tropical forests, especially the Amazon, because they fund programs to protect and study these regions, and they are neither completely wrong nor completely right. There are two things to be highlighted here. The first is that no country should feel entitled to the vast and luxurious Amazon forest just because they send funds for protection and research. The second is that yet the majority of the Amazon forest belongs to Brazil, and for the indigenous people who live there, this ecosystem acts as a large carbon sink and an enormous source of water to the atmosphere and is of fundamental importance to the survival of future generations. 


\section{An integrative knowledge for an integrative action}

Tropical forests influence the terrestrial climate system due to the exchanges of energy, water and carbon between the surface and the atmosphere. In addition to providing water vapour to the environment, influencing the atmospheric general circulation and contributing to regional precipitation, these ecosystems are important in the global carbon cycle [3, 4]. Consequently, deforestation in the tropics can result in changes on the availability of energy at the surface for the evaporative processes and in the amount of carbon released the atmosphere.

Recent research has shown that tropical forests are a system in biophysical transition $[5,6]$. In order to understand the effects of this transition on the environment, and vice-versa, it is necessary to focus on the trade-offs between biodiversity loss and ecosystem services. Yet this balancing between economic growth and sustainable development in tropical regions is still far from being solved, there are a few things that we can do to address some of the issues caused by deforestation: the construction of strategies and conservation plans by the public stakeholders using the knowledge obtained by academic research. That is the only way that we can assure that the tropical regions and their forests will help the future generations by mitigating the impacts of climate change.

This section of the book aims to provide the reader with a comprehensive overview of the current state-of-the-art in habitat fragmentation, natural recovery, soil erosion, river discharge, land-atmosphere exchanges, water cycle, carbon balance, and resilience of the forests to extreme events, taking into consideration the drivers of land degradation and deforestation and further transitions under a climate change scenario.

We hope the issues addressed here contribute to a more integrative knowledge of the impacts of deforestation in the environment and help to the understanding both of the public stakeholders and general population that there is just one way to obtain benefits from tropical forests: keep the trees standing.

\section{Author details}

Gabriel de Oliveira $^{1 *}$, Nathaniel A. Brunsell ${ }^{1}$, Yosio E. Shimabukuro ${ }^{2}$ and Carlos A.C. dos Santos ${ }^{3}$

1 Department of Geography and Atmospheric Science, University of Kansas, Lawrence, KS, USA

2 Brazilian National Institute for Space Research, Sao Jose dos Campos, SP, Brazil

3 Academic Unit of Atmospheric Sciences, Federal University of Campina Grande, Campina Grande, PB, Brazil

*Address all correspondence to: gabrieloliveira@ku.edu

IntechOpen

(C) 2020 The Author(s). Licensee IntechOpen. This chapter is distributed under the terms of the Creative Commons Attribution License (http://creativecommons.org/licenses/ by/3.0), which permits unrestricted use, distribution, and reproduction in any medium, provided the original work is properly cited. (cc) BY 


\section{References}

[1] Lambin EF, Geist HJ, Lepers E.

Dynamics of land-use and land-cover change in tropical regions. Annual Review of Environment and Resources. 2003;28:205-241. DOI: 10.1146/annurev. energy.28.050302.105459

[2] Kalamandeen M, Gloor E, Mitchard E, Quincey D, Ziv G, Spracklen D, et al. Pervasive rise of small-scale deforestation in Amazonia. Scientific Reports. 2018;8:1600

[3] Malhi Y, Pegoraro E, Nobre AD, Pereira MGP, Grace J, Culf AD, et al. Energy and water dynamics of a central Amazonian rain forest. Journal of Geophysical Research-Atmospheres. 2002;107:1-45

[4] Stark SC, Breshears DD, Garcia ES, Law DJ, Minor DM, Saleska SR, et al. Toward accounting for ecoclimate teleconnections: Intra- and intercontinental consequences of altered energy balance after vegetation change. Landscape Ecology. 2016;31:181-194. DOI: $10.1007 / \mathrm{s} 10980-015-0282-5$

[5] Davidson EA, de Araújo AC, Artaxo P, Balch JK, Brown IF, Bustamante MM, et al. The Amazon Basin in transition. Nature. 2012;481:321-328. DOI: 10.1038/ nature10717

[6] Aragao L, Anderson LO, Fonseca MG, Rosan TM, Vedovato LB, Wagner FH, et al. 21st century droughtrelated fires counteract the decline of Amazon deforestation carbon emissions. Nature Communications. 2018;9:536 



\title{
Estimating Aboveground Biomass Loss from Deforestation in the Savanna and Semi-arid Biomes of Brazil between 2007 and 2017
}

\author{
Eduarda Martiniano de Oliveira Silveira, \\ Marcela Castro Nunes Santos Terra, Fausto Weimar Acerbi-Júnior \\ and José Roberto Soares Scolforo
}

\begin{abstract}
Brazilian Savannas and Semi-arid woodlands biomes exhibit high levels of aboveground biomass (AGB) associated with high rates of deforestation. The state of Minas Gerais (MG), southeast of Brazil, encompasses landscape variations ranging from Savanna and Atlantic Forest to Semiarid woodlands. The understanding of land-cover changes in these biomes is limited due to the fact that most of the efforts for estimating forest cover changes has been focused on the tropical rain forests. Hence, the question is: What is the total amount of AGB loss across Savanna and Semi-arid woodland biomes in MG state, during the period 2007-2017? We first used a total of 1914 field plots from a forest inventory to model the AGB using a combination of remote sensing and spatio-environmental predictor variables to produce a spatial-explicit AGB map. Second, from a global map of forest cover change (GFC), we obtained deforestation patches. As a result, from 2007 to 2017, the Savanna and the Semiarid woodland biomes lost together 508,042 ha of native vegetation in MG state, leading to $21,182,150 \mathrm{Mg}$ of AGB loss (4.65\% of total AGB). In Savannas and Semi-arid woodland biomes in MG state, conservation initiatives must be implemented to increase the forests protection and expand AGB.
\end{abstract}

Keywords: aboveground biomass, land-cover changes, remote sensing, spatial analysis

\section{Introduction}

The high levels of biomass found in Brazil's forest biomes associated with land-cover changes, such as deforestation and fires, make Brazil one of the five biggest carbon dioxide-emitting nations globally [1]. Brazil has a total area of about $8,514,877 \mathrm{~km}^{2}$, from which 7\% occurs in Minas Gerais (MG) state, southeast region $\left(586,528 \mathrm{~km}^{2}\right.$ ). This large area encompasses landscape variations and vegetation types ranging from Savanna and Atlantic Forest to Semi-arid woodland (Figure 1) [2]. The current 

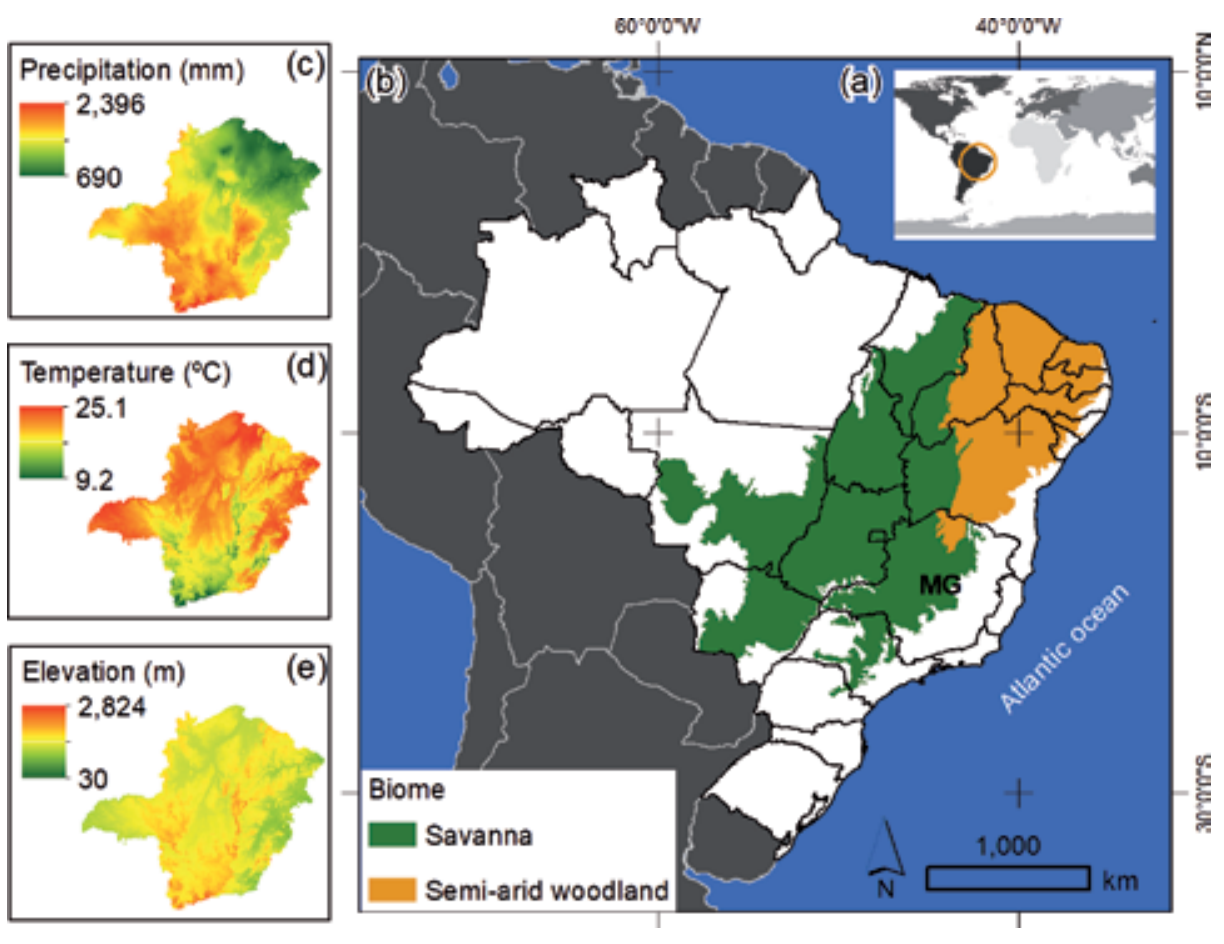

Figure 1.

(a) Geographic location of Brazil; (b) the Savannas and Semi-arid woodland biome in Minas Gerais (MG) state, Brazil; (c) average annual precipitation in MG state; $(d)$ average annual temperature in $M G$ state; and (e) elevation of $M G$ state.

understanding of land-cover changes in the so called "forgotten ecosystems"-Savanna and Semi-arid woodland biomes-is still limited $[3,4]$ due to most of the efforts for estimating forest cover changes have been focused on the tropical rain forests, with far less attention dedicated to the less humid seasonal region [5].

The Brazilian Savanna (also known as Cerrado) is a heterogeneous biome [6], dominated by grasslands, shrublands, and woodlands [7, 8]. Savannas are mixed tree-grass systems characterized by a discontinuous tree canopy in a continuous grass layer [9]. Tree cover is highly variable such that they range from sparsely "treed" grasslands to heavily "treed" woodlands, often along a gradient of increasing precipitation, but also modified by edaphic factors and fire regimes $[10,11]$. Semi-arid woodland (also known as Caatinga) is an ecosystem occupied by seasonally dry tropical forests, which is characterized by leaf deciduousness during the prolonged dry season. Semi-arid woodland biome is located in areas with high temperatures and low amount of rain, being characterized as the region with the greatest meteorological limitations and water-stress in MG [12].

These biomes exhibit high levels of terrestrial carbon stocks and biomass $[13,14]$, estimated mainly from remotely sensed data $[15,16]$. In general, these data are empirically linked to AGB measurements of field plots, ranging from simple linear regression to complex machine learning algorithms (MLA) [17, 18], and regression Kriging technique [19, 20]. Landsat images are the most mediumresolution data commonly used due the longest data record along with a spatial resolution of $30 \mathrm{~m}$. However, Savannas and Semi-arid woodland biomes are the Brazilian biomes that have most suffered human-induced disturbances [5, 21, 22], and are among the most fragmented and threatened ecosystems in the world [23]. 
The expectations regarding their future are not very optimistic. For instance, based on recent trends in deforestation [24], the Savannas may effectively no longer exist in 25 years' time $[25,26]$. Estimates indicate between 39 and $55 \%$ of the Brazilian Savannas have already been modified [27]. Tropical dry forests are among the most threatened and overlooked biomes, where conversion to pasture and agriculture are major threats [24].

Hence, the question is: What is the total amount of aboveground biomass (AGB) loss across Savanna and Semi-arid woodland biomes in MG state, during 2007-2017?

In order to answer this question, we assessed the reduction of AGB due to deforestation. We produced a spatial-explicit AGB map from forest inventory measures linked with remote sensing and spatio-environmental predictor variables and we also used a reliable global map of forest cover change [28] to measure the AGB loss.

\section{Savanna and Semi-arid woodland biomes in MG state}

The Minas Gerais (MG) state is located in the southeast Brazil (Figure 1a), encompassing the Savanna (57\%) and Semi-arid woodland (2\%) biomes (Figure 1b). The Brazilian Savannas comprise vegetation types of shrub savanna (shrub type of savanna, encompassing both herbaceous vegetation, and scattered small trees), woodland savanna (savanna formation with twisted trees and shrubs up to 8-10 $\mathrm{m}$ high and with a grass understory), and densely wooded savanna (forest formation with trees up to a height of $20 \mathrm{~m}$ ) [7]. Semi-arid woodland represents the vegetation type of deciduous forest. Semideciduous forests are present in both biomes (Table1).

The climate variability of MG state indicates a negative precipitation and a positive temperature gradient from south to north (Figure 1c, d). This variability helps to explain the predominance of these biomes. The elevation ranges from 30 to $2824 \mathrm{~m}$ and the greatest altitude variation is found in the eastern region (Figure 1e).

\begin{tabular}{lll}
$\begin{array}{l}\text { Vegetation } \\
\text { types }\end{array}$ & Panoramic view & $\begin{array}{l}\text { Aerial view Landsat TM } \\
\text { R3G2 B1 }\end{array}$ \\
\hline $\begin{array}{l}\text { Shrub savanna } \\
\text { (Ss) }\end{array}$ &
\end{tabular}




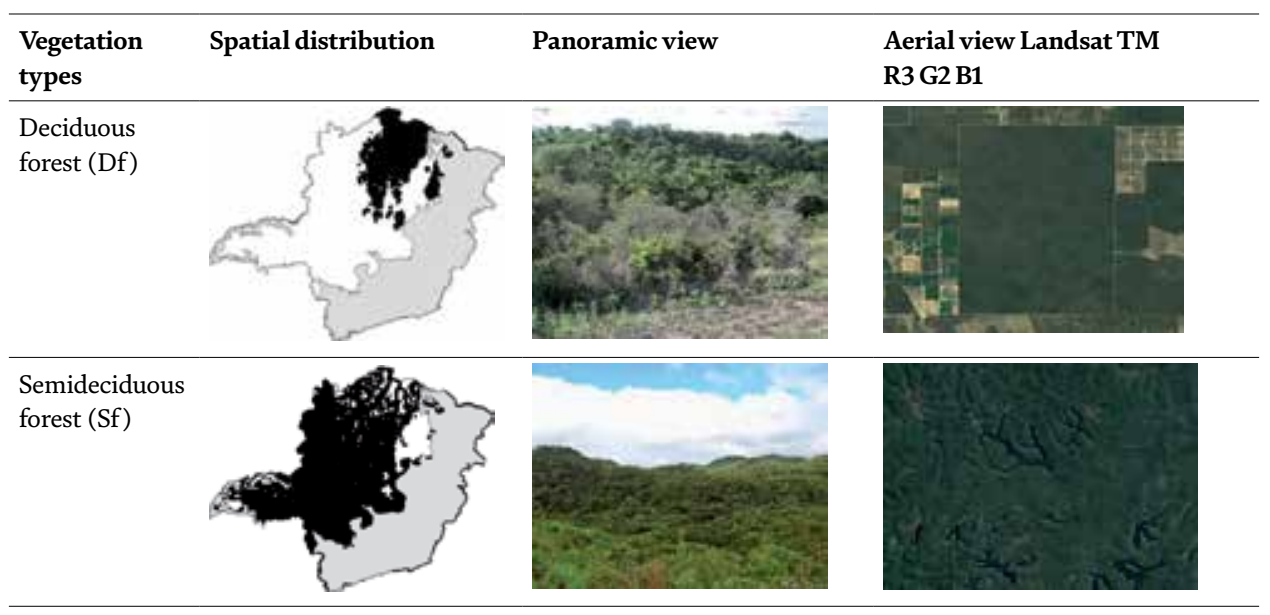

Table 1.

Vegetation types comprised on Savannas and Semi-arid woodlands biomes of the Minas Gerais (MG) state.

\section{Aboveground biomass modeling}

In order to model and map the AGB within Savannas and Semi-arid woodland biomes in MG state, we used a total of 1914 field plots $(10 \times 100 \mathrm{~m})$, spatially well distributed (Figure 2), established from 2006 to 2008 during the implementation of the Project "Forest Inventory of Minas Gerais," conducted by the Federal University of Lavras (UFLA), MG, Brazil. The plots comprised five vegetation types: Shrub savanna-Ss, Woodland savanna-Ws, Densely wooded savannaDws, Deciduous forest-Df, and Semideciduous forest-Sf. The trees used to determine the AGB (2060 trees) were all from destructive sampling campaigns, scaled and divided into categories according to diameter and height, proportioned by the relative density of species. The methodology is described in Ref. [29].

The plots presented high AGB variability due to different degrees of anthropization, different site conditions, different successional stages, and presence of trees with different diameters and heights. The descriptive statistics for each vegetation type (Table 2) highlight the structural variability among them. High biomass and standard deviation values were observed in semideciduous and deciduous forest. The lowest biomass value in shrub savanna occurs because this vegetation type is characterized by herbaceous vegetation with scattered bushes and small trees.

To model the AGB, we used two groups of predictive variables to train the random forest $(\mathrm{RF})$ [30] regression algorithm:

\section{Remote sensing:}

- Six reflective spectral bands from Landsat TM: B1 (blue), B2 (green), B3 (red), B4 (NIR), B5 (SWIR 1), and B7 (SWIR 2);

- Three vegetation indices from Landsat TM: Normalized Difference Vegetation Index (NDVI), Enhanced Vegetation Index (EVI), and Vegetation Index SoilAdjusted (SAVI);

- Seventeen monthly data of six Moderate Resolution Imaging Spectroradiometer (MODIS) product composites: MOD9Q1-Surface reflectance; MOD13Q1—Vegetation index; MOD44B —-Vegetation Continuous Cover/Fields; MOD17A2H_Gross primary productivity; MOD15A2H_LAI/ FPAR; and M11A2_Land Surface Temperature and Emissivity. 
Estimating Aboveground Biomass Loss from Deforestation in the Savanna and Semi-arid Biomes... DOI: http://dx.doi.org/10.5772/intechopen.85660

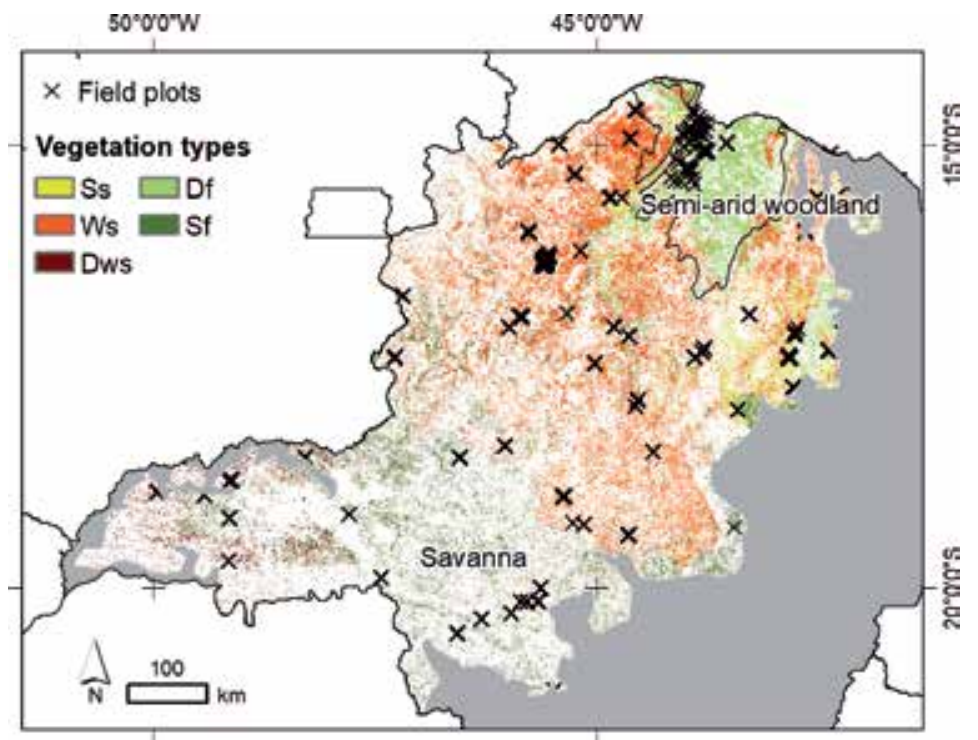

Figure 2.

Plots spatially distributed in Savanna and Semi-arid woodland biomes of MG state. Ss = shrub savanna; $W s=$ woodland savanna; Dws = densely wooded savanna; $D f=$ deciduous forest ; and $S f=$ semideciduous forest.

\begin{tabular}{|c|c|c|c|c|c|c|c|c|}
\hline \multirow[t]{2}{*}{ Vt } & \multicolumn{4}{|c|}{ Savanna } & \multicolumn{4}{|c|}{ Semi-arid woodland } \\
\hline & Min & Mean & Max & SD & Min & Mean & $\operatorname{Max}$ & SD \\
\hline Ss & 1.08 & 13.83 & 49.67 & 10.72 & - & - & - & - \\
\hline Ws & 10.81 & 57.12 & 177.97 & 30.67 & - & - & - & - \\
\hline Dws & 10.02 & 36.10 & 170.23 & 22.86 & 16.59 & 22.84 & 33.08 & 6.15 \\
\hline Df & 38.26 & 119.88 & 279.41 & 51.03 & 10.61 & 74.68 & 295.45 & 55.63 \\
\hline Sf & 10.34 & 97.74 & 398.16 & 63.58 & - & - & - & - \\
\hline
\end{tabular}

Table 2.

Descriptive statistics of the aboveground biomass ( $A G B, M g / h a$ ) estimated for each vegetation type.

2. Spatio-environmental data:

- Nineteen climatic variables of $1 \mathrm{~km}^{2}$ of spatial resolution from WorldClim dataset [31].

- Digital elevation model (DEM) with $30 \mathrm{~m}$ of spatial resolution developed from the Shuttle Radar Topography Mission (SRTM).

- Geographical coordinates (latitude and longitude).

From Landsat TM, we acquired 35 images to cover the study area (one image date by scene completely cloud-free). Four MODIS tiles were necessary to cover MG state, namely, h13v10, h13v11, h14v10, and h14v11. We selected one image per month to explore the temporal resolution of these products. 


\begin{tabular}{lcc}
\hline Vegetation types & \multicolumn{2}{c}{ Stratified model } \\
\cline { 2 - 3 } & RMSE (Mg/ha) & MAE (\%) \\
\hline Shrub savanna (Ss) & 7.72 & 54.73 \\
\hline Woodland savanna (Ws) & 14.53 & 31.51 \\
\hline Densely wooded savanna (Dws) & 16.47 & 23.62 \\
\hline Deciduous forest (Df) & 42.76 & 34.74 \\
\hline Semideciduous forest (Sf) & 51.25 & 37.84 \\
\hline
\end{tabular}

Table 3.

Random forest models analysis by root mean squared error (RMSE, in t/ha) and mean absolute error (MAE, in \%).

The RF regression algorithm was adopted due to its capability to select and rank important variables for AGB prediction. We adopted a stratified random forest approach based on the five native vegetation types of our study area, so we created five individual RF models. The accuracy of the models was analyzed based on the statistical precision: mean absolute error (MAE, in \%) and root mean squared error (RMSE, in $\mathrm{Mg} / \mathrm{ha}$ ) (Table 3). Many factors, such as saturation of remotely sensed data, complex forest stand structures, quality and quantity of sample plots, selection of suitable variables, and the modeling algorithms, can affect the accuracy of AGB estimation [15]. In our study, the challenge affecting AGB estimation is related to the complex forest stand structures of tropical forests, which increase the data heterogeneity, impairing the performance of the modeling algorithm.

To derive the AGB maps, we created continuous cells with dimensions of 1 ha $(100 \times 100 \mathrm{~m})$ covering all vegetated areas in MG state. In each cell containing the selected variables values, we applied the RF regression model to predict the AGB. We thus merged the AGB maps of each individual vegetation type to generate the final AGB map.

The total AGB estimate for Savanna and Semi-arid woodland biome is $363,290,145$ and 92,200,203 Mg, respectively, ranging from 3.66 to $214.40 \mathrm{Mg} / \mathrm{ha}$ (Figure 3). At a broad scale, it has long been recognized that the distributions of these biomes are mainly governed by precipitation and its seasonality [12]. The high values of Savannas and Semi-arid woodland's AGB are concentered in the west and south part of the state, where densely wooded savannas and semideciduous forests are more representative, followed by the north region, where deciduous forests and woodland savannas are predominant. Moreover, these forests have experienced anthropogenic disturbances, such as exploitation of vegetation for charcoal production, cattle grazing, and conversion for agricultural practices, and are also in an advanced degradation stage.

The low AGB values obtained for the middle region of the state occurred due to climatic effects related to a geographical barrier (Espinhaço Range), which generates an unfavorable situation for vegetation growth, and also due to the predominance of shrub savannas. The lower overall humidity and the stronger climate seasonality certainly have a negative impact on plant growth [32]. The edaphic component also plays an important role in vegetation structure. Therefore, despite the presence of "enclaves" of highly fertile soils, where dry forests predominate [33], there is a general trend towards sandier soils, like the Cambisol and Lythollic Neossol. These soils generally have low fertility that, together with the physical characteristics, low precipitation and high temperatures, create conditions that are unfavorable for plant growth. 


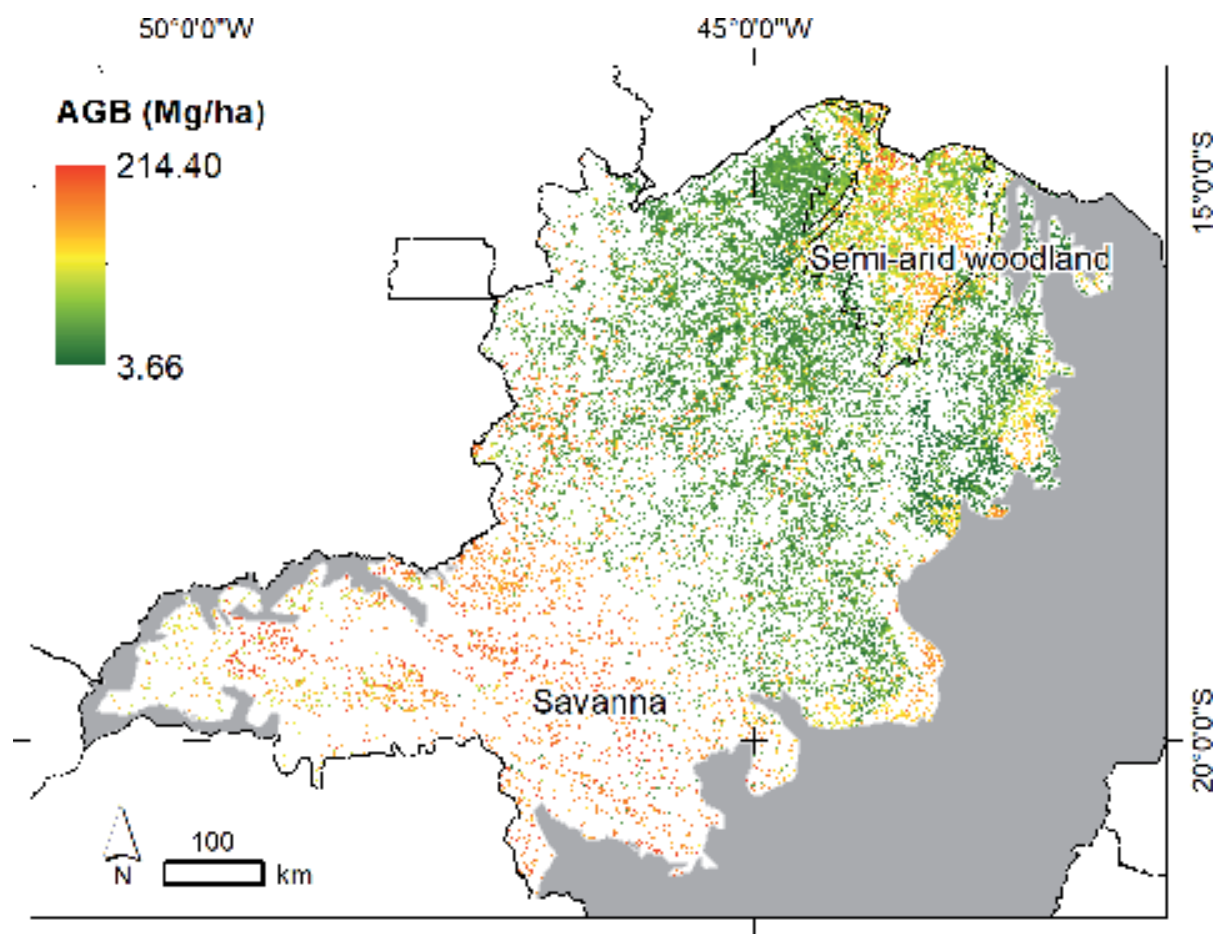

Figure 3.

The spatial distribution of aboveground biomass (AGB) in Savanna and Semiarid woodland biomes in Minas Gerais state.

Similarly, aboveground carbon (AGC) maps were produced by Refs. [13] and [29]. Both mapped the spatial distribution of AGC stocks of the arboreal vegetation in Brazilian biomes of Savanna, Atlantic Forest, and Semi-arid woodland in MG state. They found the lowest weighted average of carbon stock per hectare in the Savanna Biome, particularly in the central, northern, and northwestern regions of MG state.

\section{Deforestation analysis}

To analyze the deforestation across the Minas Gerais state from 2007 to 2017, we used the Global Forest Change (GFC) map [28]. These authors mapped global annual loss at a spatial resolution of $30 \mathrm{~m}$, based on Landsat time series. Forest loss was defined as a stand-replacement disturbance or the complete removal of tree cover canopy at the Landsat pixel scale. Forest was defined as canopy closure for all vegetation taller than $5 \mathrm{~m}$ in height. From these maps, we calculated the deforestation density (N/ha) within Savanna (Figure 4) and Semi-arid woodland (Figure 5) biomes in MG state, as well as deforestation areas from 2007 to 2017. We masked the deforestation polygons into our five vegetation types (Shrub savanna-Ss, Woodland savanna-Ws, Densely wooded savanna-Dws, Deciduous forest-Df, and Semideciduous forest-Sf).

For the Savanna biome, the spatial analysis showed deforested areas concentrated on the northeast region of the biome, with exception in the year 2008 with high density in the south region. The vegetation loss between 2007 and 2017 was 423,798 ha. From this total, $11.97 \%$ of the deforested areas were in 2007 , while 

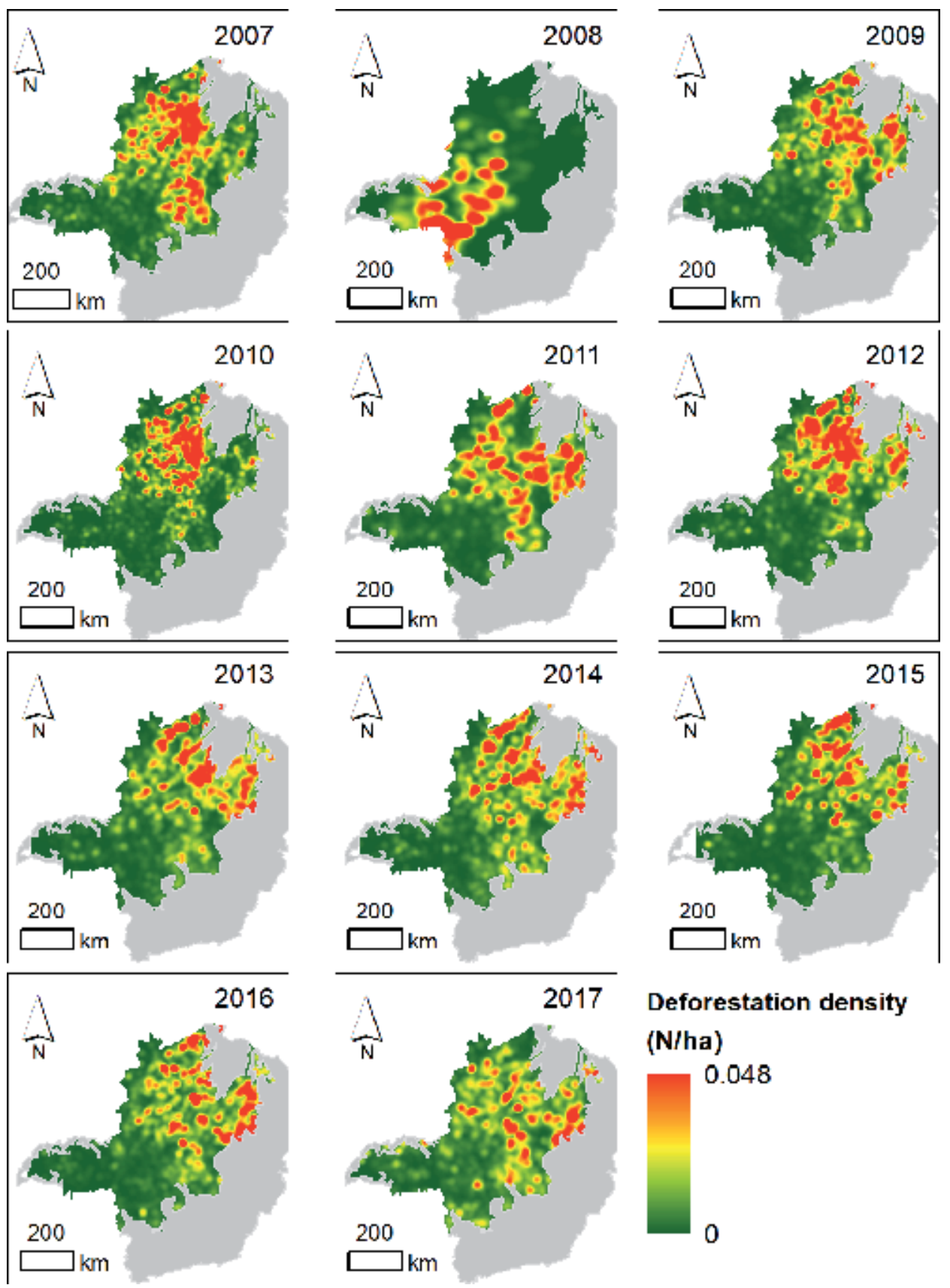

(N/ha)

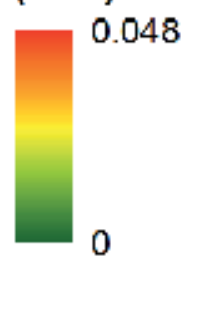

Figure 4.

Annual deforestation density (N/ha) across Savanna biome in MG state from 2007 to 2017.

$3.76 \%$ was in 2011 . Analyzing the Semi-arid woodland biome, the spatial analysis did not indicate a clear pattern, with deforestations areas scattered along the biome. The vegetation loss between 2007 and 2017 was 84,244 ha. From this total, 16.44\% of the deforested areas were in 2013, while $3.57 \%$ was in 2008.

Overall, from 2007 to 2017, the Savanna and the Semi-arid woodland biomes lost together 508,042 ha of native vegetation (Figure 6). We identify a continued loss of natural vegetation types for both biomes during the analyzed period.

Reference [5] provided consistent information on historical and recent vegetation cover changes in the Brazilian Savannas and Semi-arid woodland biomes from 

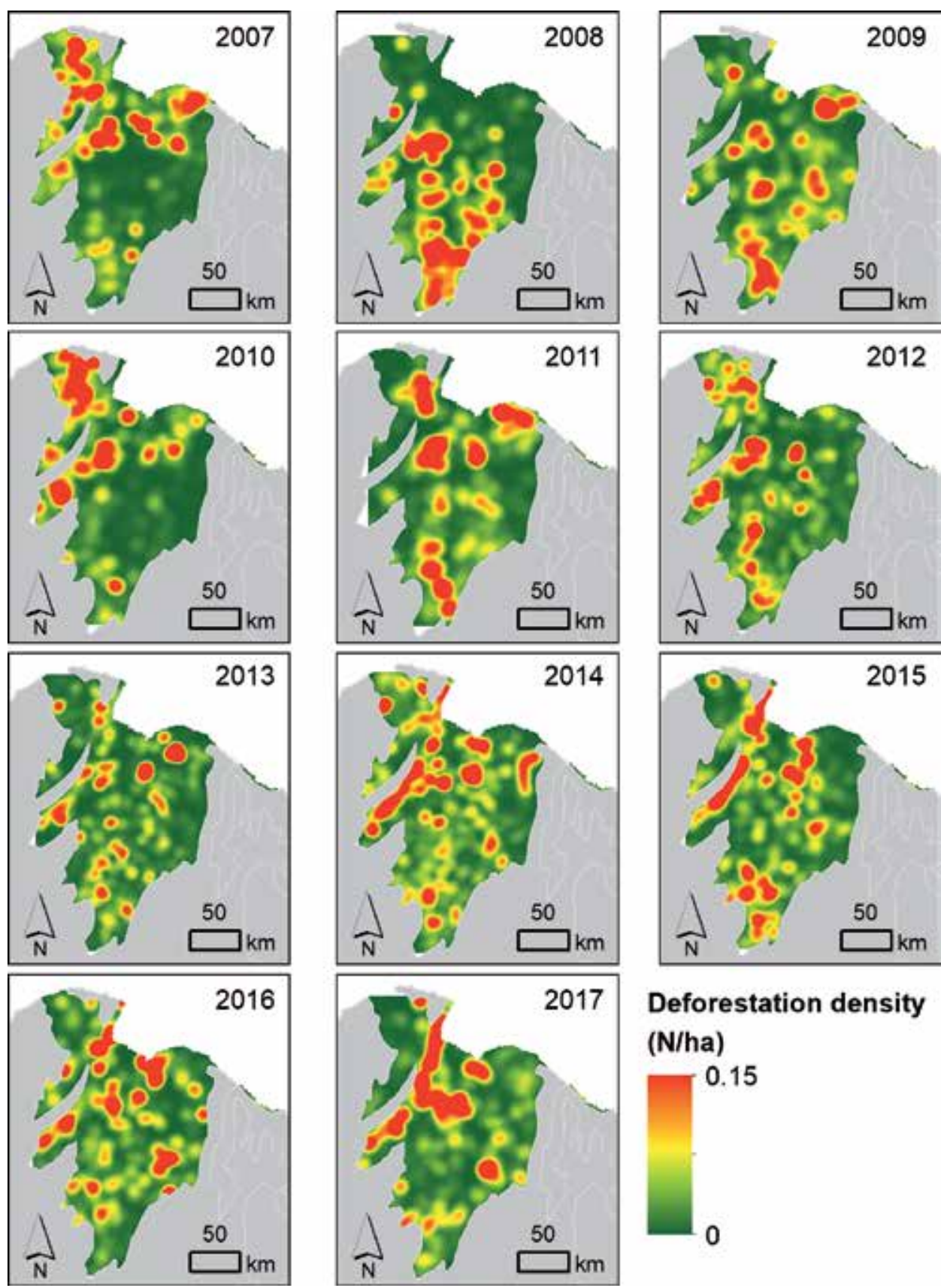

\section{Deforestation density}

(N/ha)

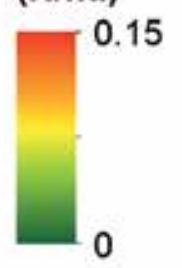

Figure 5.

Annual deforestation density (N/ha) across Semi-arid woodland biome in MG state from 2007 to 2017.

1990 to 2010, based on the analysis of Landsat imagery acquired over a systematic sample of $10 \times 10 \mathrm{~km}$ size units. Although their analysis was not "wall to wall," their study covered the whole area of these biomes in Brazil. They estimated that the Savanna lost approximately 11,787,000 ha of tree cover between 1990 and 2010. For the Semi-arid woodland biomes, their results showed that the tree cover loss was 2,533,500 ha. For Savannas, the annual rates of change were -0.79 from 1990 to $2010,-0.44$ from 2000 to 2010 , and -0.61 from 1990 to 2010 . Considering the Semi-arid woodland biome, the annual rates of change for 1990-2000, 2000-2010 and $1990-2010$ were $-0.19,-0.44$, and -0.32 , respectively 


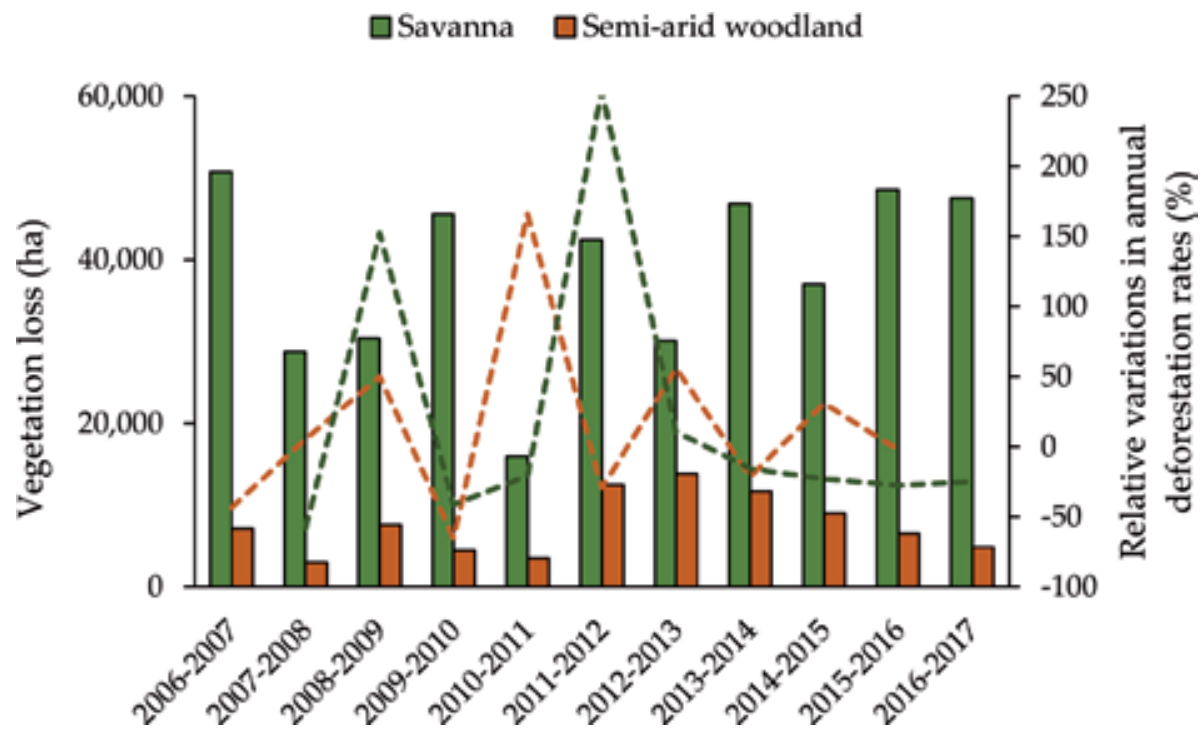

Figure 6.

Annual deforestation area (ha) and relative variations in annual deforestation rates (\%) across Savannas and Semi-arid woodland biome in MG state from 2007 to 2017.

\begin{tabular}{lcc}
\hline Annual rates of change & Savanna & Semi-arid woodland \\
\hline $2006-2007$ & - & - \\
\hline $2007-2008$ & -43.33 & -58.08 \\
\hline $2008-2009$ & 5.64 & 152.33 \\
\hline $2009-2010$ & 50.19 & -41.21 \\
\hline $2010-2011$ & -65.02 & -20.65 \\
\hline $2011-2012$ & 165.75 & 253.73 \\
\hline $2012-2013$ & -29.06 & 10.68 \\
\hline $2013-2014$ & 55.83 & -15.62 \\
\hline $2014-2015$ & -21.00 & -22.99 \\
\hline $2015-2016$ & 31.13 & -27.43 \\
\hline $2016-2017$ & -2.09 & -25.03 \\
\hline Average & 14.80 & 20.57 \\
\hline
\end{tabular}

Table 4.

Relative variations (\%) in annual rates of natural vegetation loss.

According to their results, the average annual rate of change is higher in the Savanna than in the Semi-arid woodland biome. On the contrary, our analysis showed contrasted results, where Semi-arid woodland biome presented higher annual rate of change than the Savanna biome (Table 4). The discrepancies can be explained by the different land-cover maps used as basis for analysis, the area of analysis (Brazil versus Minas Gerais state), and the analyzed period. Another important point is that GFC only include vegetation taller than $5 \mathrm{~m}$ in height in their analysis, thus not always capturing deforestation under shrub savannas vegetation types.

According to the results obtained from the GFC, the tropical dry forests of South America had the highest rate of tropical forest loss due to deforestation dynamics in Argentina (Chaco woodlands), Paraguai, and Bolivia. Brazil presented the largest 
decline in annual forest loss, with a high of over 40,000 km²/year in 2003 to 2004 and a low of under $10,000 \mathrm{~km}^{2} /$ year from 2000 through 2003 and a high of over $20,000 \mathrm{~km}^{2} /$ year in 2011 to 2012 [28]. Although the decline of Brazilian deforestation is well documented, recent studies are reporting high deforestation rates. For example, between 2001 and 2012, according to the GFC data set, more than $8,300,000$ ha of forest were lost in Mato Grosso, a Brazilian state inserted in the Amazon biome [34].

In the period from 2000 to 2015, tropical dry forests in the north of MG state undergone a considerable change in land cover, expressed as 982,000 ha [35]. From 2002 to 2008, the GFC data estimated 2,000,000 ha of forests were lost per year in the Amazon biome. From 2006 to 2008 rates then felt to 1,000,000 ha. Significant deforestation occurred in 2010 and 2012, when loss rates increased to approximately 1,500,000 ha per year [36]. Ref. [37] analyzed forest loss patterns across Amazon biome over a 14-year period (2001-2014). Their results showed that Amazonian forest losses are moving away from the southern Brazilian Amazon to Peru and Bolivia and the number of deforestation patches less than 1 ha increased over time. This last result presents a significant challenge on remote sensing change detection, highlighting the use of high resolution images to capture small scale deforestation.

\section{Estimating aboveground biomass loss from deforestation}

The deforestation across Savanna biome in MG state (423,798 ha) generated an AGB loss of 16,549,138 Mg from year 2007 to 2017 (Figure 7). This amount represents about $4.56 \%$ of the total AGB in 2007 (363,290,145 Mg). The higher AGB loss occurred in the year 2017 (2,231,755 Mg), followed by the year $2007(2,050,366 \mathrm{Mg})$. The lower AGB loss occurred in the year 2011 (586,282 Mg). The high rates of deforestation were found during 2007, 2016, and 2017, indicating that along 10 years, Brazil is not avoiding deforestation across Savannas biome in MG state, with a decrease from 2007 to 2011 and an increase from 2011 to 2017. Compared to other Brazilian states and even to studies in Savannas and Semi-arid woodland in MG state, our deforestation rates are underestimated. This fact is because we analyzed deforestation patches within our five vegetation types, not considering all vegetation

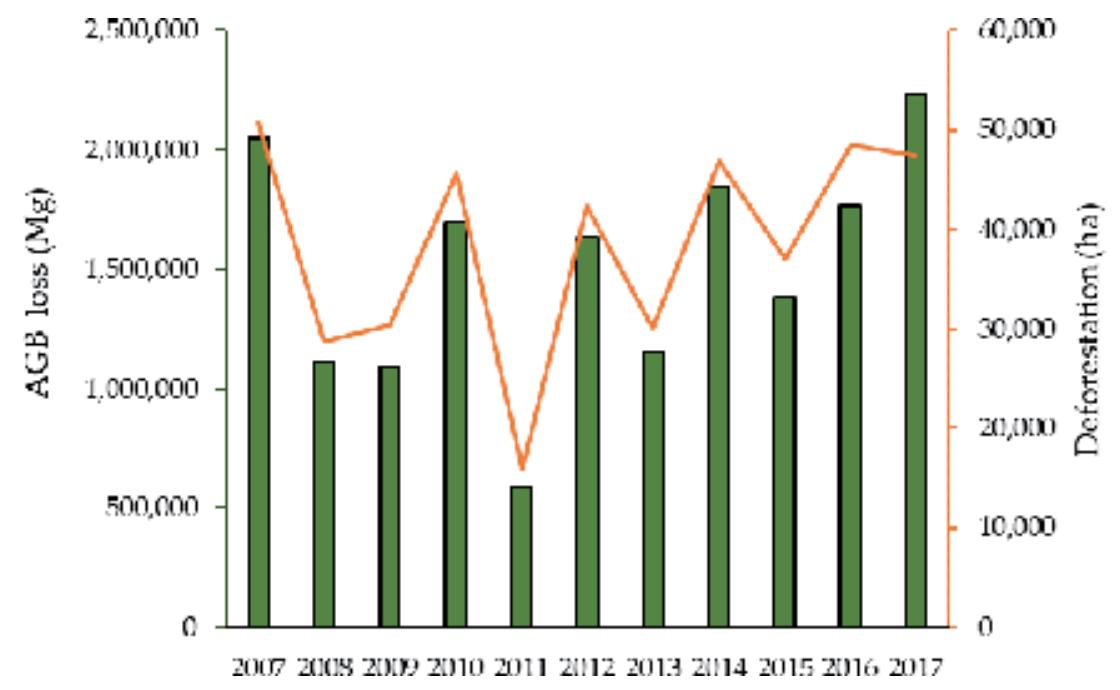

Figure 7 .

Savanna's aboveground biomass loss $(A G B / M g)$ and deforested areas from 2007 to 2017. 


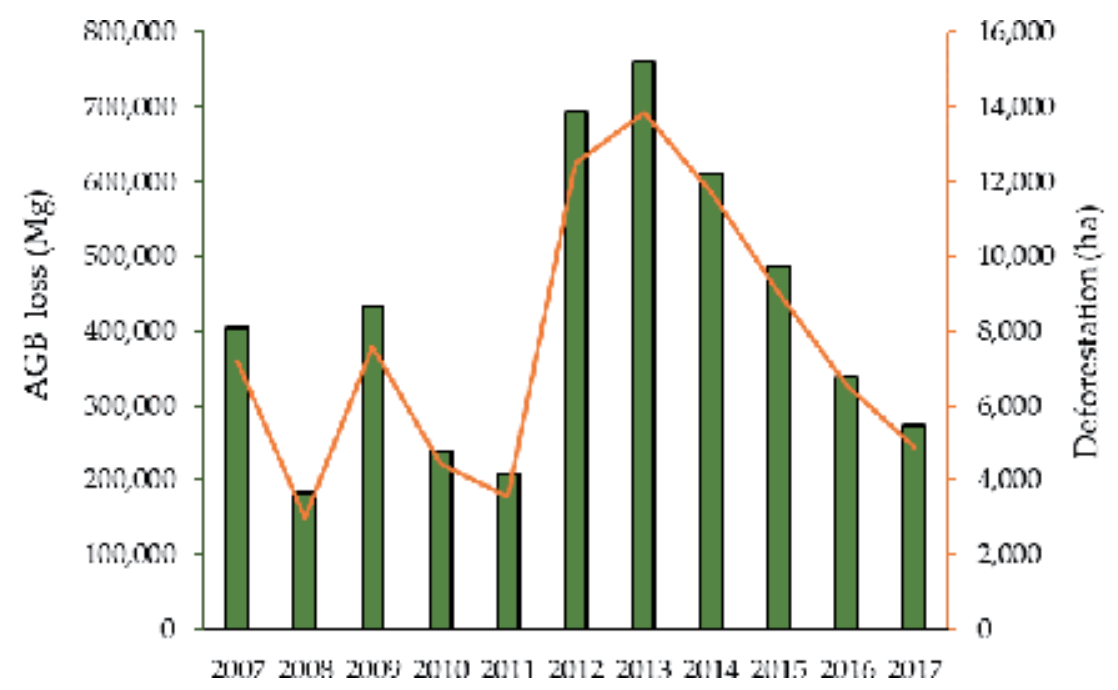

Figure 8.

Semiarid woodland's aboveground biomass loss $(A G B / M g)$ and deforested areas from 2007 to 2017.

types which occur in MG state. Another point is the problems associated with the use of the GFC map. This product does not capture herbaceous plant, may leading to an underestimate of deforestation into shrub savannas.

The deforestation across Semi-arid woodland biome in the MG state $(84,244 \mathrm{ha})$ generated an AGB loss of 4,633,011 Mg from year 2007 to 2017 (Figure 8). This amount represents about 5.02\% of the total AGB in 2007 (92,200,203 Mg). The higher AGB loss occurred in the year 2013 (761,271 Mg), followed by the year 2012 $(694,546 \mathrm{Mg})$. The lower AGB loss occurred in the years 2008 (183,203 Mg), 2010 $(238,628 \mathrm{Mg})$, and $2011(209,485 \mathrm{Mg})$. These results indicate an increase in deforestation from years 2012 and 2013 and a decrease towards 2017.

In summary, the total AGB loss from 2007 to 2017 of Savannas and Semiarid woodland biomes in MG state was $21,182,150 \mathrm{Mg}$ (4.65\% of total AGB) due to 508,042 ha of deforestation. The remaining AGB of Savanna and Semi-arid woodland biomes is $346,741,007 \mathrm{Mg}$ and $87,567,192 \mathrm{Mg}$, totaling 434,308,198 Mg.

The absolute values of AGB loss are expressive. The implications of such AGB loss are vast. Biomass loss usually leads to impacts on carbon and nutrients cycles $[38,39]$ and possibly on regional and global climate $[40]$. Biomass density (the quantity of biomass per unit area-Mg dry weight per ha) determines the amount of carbon emitted to the atmosphere (such as $\mathrm{CO}_{2}, \mathrm{CO}$, and $\mathrm{CH}_{4}$ through burning and decay) when ecosystems are disturbed. Although biomass density over biomes may change little over time, the biomass density of individual stands and plots is continuously changing and the sum of these changes is largely responsible for the net sources and sinks of terrestrial carbon [39].

Furthermore, biomass loss is intrinsically linked with biodiversity loss. Both biomass and biodiversity are important drivers of ecosystem functions and services and may represent key elements in climate change mitigation. The potential for forest regeneration in these areas is often limited by continuous disturbances and climate change effects [41] worsening this issue. Previous studies have suggested a positive relationship between forest productivity and biodiversity at global scales [42], as well as at the regional level in tropical biomes [43]. Biodiversity is needed for maintaining primary productivity and nutrient uptake and can also improve water quality by removing nitrates through niche partitioning [44]. 
Estimating Aboveground Biomass Loss from Deforestation in the Savanna and Semi-arid Biomes... DOI: http://dx.doi.org/10.5772/intechopen.85660

\section{Conclusion}

We analyzed the aboveground biomass loss from deforestation in the Savanna and Semi-arid biomes of Brazil between 2007 and 2017. In summary, from 2007 to 2017, the Savanna and the Semi-arid woodland biomes lost together 508,042 ha of native vegetation, leading to $21,182,150 \mathrm{Mg}$ of AGB loss (4.65\% of total AGB). The remaining AGB in 2017 is 434,308,198 Mg.

Our study provides a contribution to the knowledge of the deforestation impact on aboveground biomass on Brazilian Savanna and Semi-arid woodland biomes. Our results indicate that land-cover changes continue to reduce the AGB/carbon storage of the Savanna and Semi-arid woodland biomes in MG state. Due to the expressive absolute values of AGB loss, conservation initiatives in Savannas, and Semi-arid woodland biomes in MG state, such as law protection, creation of new protected areas (parks), payments for ecosystem services must be implemented to increase the forests protection and expand AGB.

As major challenge, we highlight the problems associated with the use of the global forest cover map to realize deforestation analysis under Savannas and Semiarid woodland biomes. This product does not distinguish forests from plantations and even herbaceous plant, leading to an underestimate of deforestation patches. In this sense, a more accurate global forest cover map would significantly improve our estimates.

\section{Acknowledgements}

The authors would like to thank the "Conselho Nacional de Desenvolvimento Científico e Tecnológico" (CNPq-Brazil) and the "Fundação de Amparo à Pesquisa do Estado de Minas Gerais" (FAPEMIG_-Brazil) for financing part of this study.

\section{Conflict of interest}

No potential conflict of interest.

\section{Author details}

Eduarda Martiniano de Oliveira Silveira*, Marcela Castro Nunes Santos Terra,
Fausto Weimar Acerbi-Júnior and José Roberto Soares Scolforo
Forest Science Department, Federal University of Lavras (UFLA), Lavras, Brazil

*Address all correspondence to: dudalavras@hotmail.com

IntechOpen

(C) 2019 The Author(s). Licensee IntechOpen. This chapter is distributed under the terms of the Creative Commons Attribution License (http://creativecommons.org/licenses/ by/3.0), which permits unrestricted use, distribution, and reproduction in any medium, provided the original work is properly cited. (cc) BY 


\section{References}

[1] Matthews HD, Graham TL, Keverian S, Lamontagne C, Seto D, Smith TJ. National contributions to observed global warming. Environmental Research Letters. 2014;9(1):014010. DOI: 10.1088/1748-9326/9/1/014010

[2] Terra MCNS, Santos RM, Fontes MAL, Mello JM, Scolforo JRS, Gomide LR, et al. Tree dominance and diversity in Minas Gerais, Brazil. Biodiversity and Conservation. 2017;26:2133-2153. DOI: 10.1007/s10531-017-1349-1

[3] Marris E. Conservation in Brazil: The forgotten ecosystem. Nature. 2005;437(13):944-945. DOI: $10.1038 / 437944 a$

[4] Santos JC, Leal RI, Almeida-Cortez JS, Fernandes GW, Tabarelli M. Caatinga: The scientific negligence experienced by a dry tropical forest. Tropical Conservation Science. 2011;4(3):276286. DOI: $10.1177 / 194008291100400306$

[5] Beuchle R, Grecchi RC, Shimabukuro YE, Seliger R, Eva HD, Sano E, et al. Land cover changes in the Brazilian Cerrado and Caatinga biomes from 1990 to 2010 based on a systematic remote sensing sampling approach. Applied Geography. 2015;58:116-127. DOI: 10.1016/j.apgeog.2015.01.017

[6] Miranda a C, Mirnda HS, LLoyd J, Grace J, Francey RJ, McIntyre JA, et al. Fluxes of carbon, water and energy over Brazilian cerrado: An analysis using eddy covariance and stable isotopes. Plant, Cell \& Environment. 1997;20:315-328. DOI: 10.1046/j.1365-3040.1997.d01-80.x

[7] Ribeiro SC, Fehrmann L, Soares CPB, Jacovine LAG, Kleinn C, de Oliveira Gaspar R. Above- and belowground biomass in a Brazilian Cerrado. Forest Ecology and Management. 2011;262 (3):491-499. DOI: 10.1016/j. foreco.2011.04.017
[8] Silveira EMO, Bueno IT, Acerbi junior FW, Mello JM, Scolforo JRS, Wulder MA. Using spatial features to reduce the impact of seasonality for detecting tropical forest changes from Landsat time series. Remote Sensing. 2018;10:808. DOI: 10.3390/rs10060808

[9] House JI, Archer S, Breshears DD, Scholes RJ. Conundrums in mixed woody-herbaceous plant systems. Journal of Biogeography. 2003;30(11):1763-1777. DOI: 10.1046/j.1365-2699.2003.00873.x

[10] Arruda FV, Izzo TJ. Trends and gaps of the scientific literature about the effects of fire on Brazilian Cerrado. Biota Neotropica. 2018;18(1):1-6. DOI: 10.1590/1676-0611-BN-2017-0426

[11] Lloyd J, Bird MI, Vellen L, Miranda AC, Veenendaal EM, Djagbletey $G$, et al. Contribution of woody and herbaceous vegetation to tropical savanna ecosystem productivity: A quasi-global estimate. Tree Physiology. 2008;28:451-468. DOI: 10.1093/treephys/28.3.451

[12] Terra MCNS, Santos RM, Prado Junior JA, Mello JM, Scolforo JRS, Fontes MAL, et al. Water availability drives gradients of tree diversity, structure and functional traits in the Atlantic-Cerrado-Caatinga transition, Brazil. Journal of Plant Ecology. 2018;11:rty017. DOI: 10.1093/jpe/ rty017/5032688

[13] Scolforo HF, Scolforo JRS, de Mello JM, de Mello CR, Morais VA. Spatial interpolators for improving the mapping of carbon stock of the arboreal vegetation in Brazilian biomes of Atlantic forest and Savanna. Forest Ecology and Management. 2016;376: 24-35. DOI: 10.1016/j.foreco.2016.05.047

[14] David HC, de Araújo EJG, Morais VA, Scolforo JRS, Marques JM, Péllico Netto S, 
et al. Carbon stock classification for tropical forests in Brazil: Understanding the effect of stand and climate variables. Forest Ecology and Management. 2017;404:241-250. DOI: 10.1016/j. foreco.2017.08.044

[15] Lu D. The potential and challenge of remote sensing-based biomass estimation. International Journal of Remote Sensing. 2006;27(7):1297-1328. DOI: $10.1080 / 01431160500486732$

[16] Lu D, Chen Q, Wang G, Moran E, Batistella M, Zhang M, et al.

Aboveground forest biomass estimation with Landsat and LiDAR data and uncertainty analysis of the estimates. International Journal of Forestry Research. 2012;2012(1):1-16. DOI: $10.1155 / 2012 / 436537$

[17] Baccini A, Laporte N, Goetz SJ, Sun M, Dong H. A first map of tropical Africa's above-ground biomass derived from satellite imagery. Environmental Research Letters. 2008;3(4). DOI: 10.1088/1748-9326/3/4/045011

[18] Powell SL, Cohen WB, Healey SP, Kennedy RE, Moisen GG, Pierce KB, et al. Quantification of live aboveground forest biomass dynamics with Landsat time-series and field inventory data: A comparison of empirical modeling approaches. Remote Sensing of Environment. 2010;114(5):1053-1068. DOI: 10.1016/j.rse.2009.12.018

[19] Galeana-Pizaña JM, López-Caloca A, López-Quiroz P, Silván-Cárdenas JL, Couturier S. Modeling the spatial distribution of above-ground carbon in Mexican coniferous forests using remote sensing and a geostatistical approach. International Journal of Applied Earth Observation and Geoinformation. 2014;30(1):179-189. DOI: 10.1016/j. jag.2014.02.005

[20] Su Y, Guo Q, Xue B, Hu T, Alvarez O, Tao S, et al. Spatial distribution of forest aboveground biomass in China:
Estimation through combination of spaceborne lidar, optical imagery, and forest inventory data. Remote Sensing of Environment. 2016;173:187-199. DOI: 10.1016/j.rse.2015.12.002

[21] Silveira EMO, Mello JM, Acerbi Júnior FW, Carvalho LMT. Objectbased land-cover change detection applied to Brazilian seasonal savannahs using geostatistical features. International Journal of Remote Sensing. 2018;39(8):2597-2619. DOI: 10.1080/01431161.2018.1430397

[22] Silveira EMO, Espírito-Santo FDB, Acerbi-Júnior FW, Galvão LS, Withey KD, Blackburn GA, et al. Reducing the effects of vegetation phenology on change detection in tropical seasonal biomes. GIScience \& Remote Sensing. 2018;00(00):1-19. DOI: 10.1080/15481603.2018.1550245

[23] Miles L, Newton AC, Defries RS, Ravilious C, May I, Blyth S, et al. A global overview of the conservation status of tropical dry forests. Journal of Biogeography. 2006;33:491-505. DOI: 10.1111/j.1365-2699.2005.01424.x

[24] Bianchi CA, Haig SM. Deforestation trends of tropical dry forests in Central Brazil. Biotropica. 2012;45(3):1-6. DOI: 10.1111/btp.12010

[25] Hunke P, Mueller EN, Schröder B, Zeilhofer P. The Brazilian Cerrado:

Assessment of water and soil

degradation in catchments under intensive agricultural use. Ecohydrology. 2015;8:1154-1180. DOI: 10.1002/eco.1573

[26] Cabral OMR, Humberto R, Gash JH, Freitas HC, Ligo MA V. Water and energy fluxes from a woodland savanna (cerrado) in southeast Brazil. Journal of Hydrology: Regional Studies. 2015;4: 22-40. DOI: 10.1016/j.ejrh.2015.04.010

[27] Sano EE, Rosa R, Brito JLS, Ferreira LG. Land cover mapping of the tropical 
savanna region in Brazil. Environmental Monitoring and Assessment.

2010;166:113-124. DOI: $10.1007 /$

s10661-009-0988-4

[28] Hansen MC, Potapov PV, Moore R, Hancher M, Turubanova SA,

Tyukavina A. High-resolution global maps of forest cover change. Science. 2013;342(6160):850-853. DOI: 10.1126/ science. 1244693

[29] Scolforo HF, Scolforo JRS, Mello CR, Mello JM, Ferraz Filho AC. Spatial distribution of aboveground carbon stock of the arboreal vegetation in Brazilian Biomes of Savanna, Atlantic Forest and Semi-arid woodland. PLoS One. 2015;10:1-20. DOI: 10.1371/ journal.pone. 0128781

[30] Breiman L. Random forests. Machine Learning. 2001;45(1):5-32. DOI: 10.1023/A:1010933404324

[31] Hijmans RJ, Cameron SE, Parra JL, Jones PG, Jarvis A. Very high resolution interpolated climate surfaces for global land areas. International Journal of Climatology. 2005;25(15):1965-1978. DOI: $10.1002 /$ joc.1276

[32] Esquivel-Muelbert A, Baker TR, Dexter KG, Lewis SL, ter Steege H, Lopez-Gonzalez G, et al. Seasonal drought limits tree species across the Neotropics. Ecography. 2016:1-12. DOI: 10.1111/ecog.01904

[33] Apgaua DMG, Santos RM, Pereira DGS, Oliveira Menino GC, Pires GG, Fontes MAL, et al. Betadiversity in seasonally dry tropical forests (SDTF) in the Caatinga Biogeographic Domain, Brazil, and its implications for conservation. Biodiversity and Conservation. 2014;23(1):217-232. DOI: $10.1007 /$ s10531-013-0599-9

[34] Richards PD, VanWey L. Farmscale distribution of deforestation and remaining forest cover in Mato Grosso.
Nature Climate Change. 2016;6:418-425.

DOI: $10.1038 /$ nclimate2854

[35] Dupin MGV. Land use policies and deforestation in Brazilian tropical dry forests between 2000 and 2015. Environmental Research Letters. 2018;13:035008

[36] Richards P, Arima E, VanWey L, Cohn A, Bhattarai N. Are Brazil's deforesters avoiding detection? Conservation Letters. 2017;10:469-475. DOI: $10.1111 /$ conl.12310

[37] Kalamandeen M, Gloor E, Mitchard E, Quincey D, Ziv G, Spracklen D, et al. Pervasive rise of small-scale deforestation in Amazonia. Nature. 2018;8:1-10. DOI: 10.1038/ s41598-018-19358-2

[38] Withey KD, Berenguer E, Palmeira AF, Espírito-Santo FDB, Lennox GD, Silva CVJ, et al. Quantifying immediate carbon emissions from El Niño-mediated wildfires in humid tropical forests. Philosophical Transactions of the Royal Society, B: Biological Sciences. 2018;373:20170312. DOI: $10.1098 /$ rstb.2017.0312

[39] Houghton RA, Hall F, Goetz SJ. Importance of biomass in the global carbon cycle. Journal of Geophysical Research - Biogeosciences. 2009;114(3): 1-13. DOI: $10.1029 / 2009 J G 000935$

[40] Galbraith D, Levy PE, Sitch S, Huntingford C, Cox P, Williams M, et al. Multiple mechanisms of Amazonian forest biomass losses in three dynamic global vegetation models under climate change. Net Phytologist. 2010;187:647-665. DOI: 10.1111/j.1469-8137.2010.03350.x

[41] Exbrayat JF, Liu YY, Williams M. Impact of deforestation and climate on the Amazon Basin's above-ground biomass during 1993-2012. Scientific Reports. 2017;7(1):1-7. DOI: 10.1038/ s41598-017-15788-6 
Estimating Aboveground Biomass Loss from Deforestation in the Savanna and Semi-arid Biomes... DOI: http://dx.doi.org/10.5772/intechopen.85660

[42] Liang J, Crowther TW, Picard N, Wiser S, Zhou M, Alberti G, et al. Positive biodiversity-productivity relationship predominant in global forests. Science. 2016;354:aaf8957. DOI: 10.1126/science.aaf8957

[43] Lecina-Diaz J, Alvarez A, Regos A, Drapeau P, Paquette A, Messier C, et al. The positive carbon stocks-biodiversity relationship in forests: Co-occurrence and drivers across five subclimates. Ecological Applications. 2018:1-13. DOI: 10.1002/eap.1749

[44] Cardinale BJ. Biodiversity improves water quality through niche partitioning. Nature.

2011;472(7341):86-89. DOI: 10.1038/ nature09904 



\title{
Economic Impacts of the Anthropic Effects of the Deforestation on the Rural Populations of Mali
}

\author{
Amadou K. dit Amobo Waïgalo
}

\begin{abstract}
Deforestation in rural surroundings in Mali is the main problem determining the deterioration of the quality of the environment with consequent climate change (drought, erosion and decrease in rainfall). More than $70 \%$ of the Malian's population is predominantly rural, with a poverty line of $48.7 \%$ in 2017 . Their main source of energy comes from the consumption of firewood and charcoal. The Mali Sahelian country suffered for nearly two decades, from 1968 to 1985, a long cycle of drought that has weakened its ecosystem. Population pressure in the 1970s and 1980s increased demand for farmland. This has resulted in massive deforestation in favor of cereal and cash crops. Since rural agriculture is extensive and has low productivity, the populations find that wood is used as an alternative to offset the decline in their agricultural income. From the analysis of the results obtained, anthropogenic factors significantly impacting deforestation with negative and positive effects are pasture and firewood consumption. The variable associated with population growth is negative and significant at 5\%. Population growth positively affects forest cover regeneration.
\end{abstract}

Keywords: anthropic, deforestation, economic impacts, firewood, forest, population

\section{Introduction}

Mali is a vast country of West Africa with a surface of $1,241,238 \mathrm{~km}^{2}$. In 2018 , its total population rose to $18,338,322$ inhabitants ${ }^{1}$, that is to say, a low density of approximately 15 inhabitants per $\mathrm{km}^{2}$. The essence of its economy rests on agriculture and the breeding including more of the $2 / 3$ of its total population evolving in the sector. More than $70 \%$ of the Malian population is rural. The incidence of poverty $^{2}$ of the Malian population which accounted for $46.8 \%$ in 2016 knew a fall of $1.9 \%$ in 2017. However, this fall of the rate of incidence of poverty would be ascribable in the good crop year of 2017-2018 cereal productions. In 2017, poverty was accentuated in rural medium, with a threshold of $53.6 \%$. At the same period, the

\footnotetext{
${ }^{1}$ https://contrymeters.info

2 The INSTAT brings back this rate to the proportion of the population which does not manage to spend $178,000 \mathrm{~F}$ CFA to satisfy its basic needs per annum.
} 
real growth rate of the GDP was about 5.4\%. On the other hand between 2016 and 2017 , the rate of inflation passed from -1.8 to $1.8 \%$, that is to say, a clear increase of $2 \%$ [1]. The rate of inflation which results in the impact that the rise in the price of goods has on the purchasing power of the consumers is relatively low. It indicates that apart from the agricultural sector, few economic alternatives are offered to the rural medium in order to easily integrate the nonagricultural market.

Mali Sahelian country knew a long cycle of dryness between 1968 and 1985. For this period, the rains were done rare. It had as consequences the degradation of the grounds, the recurring dryness, a reduction in vegetable cover with a considerable reduction of spaces of grazing ground and a deceleration of the growth of the livestock. During years 1970 and 1980, the Sahelian countries made considerable great strides of the demographic growth which resulted thereafter in an expansion of the cultivated grounds, less grounds put in fallow and the exhaustion of the grounds. During nearly one century, the essence of the marketing policy of the colonizers rested on the cultures of revenue. The imposition of the cultures of revenue by the colonial capacities more contributed to deforestation with as a corollary the degradation of the not very fertile grounds. Thus, $60-93 \%$ of the energy needs of the Sahelians come from wood [2]. Between 1990 and 2005, deforestation passed from 84,000 to 144,000 hectares. It results primarily from the human intervention. During this interval of period, the total surface of artificial afforestation passed from 5000 to 65,000 hectares [3].

The economic activities of the rural populations of Mali are mainly dependent on the agriculture which constitutes their principal source of income. With that the exploitation of the forest resources is added (nonwoody forest products, woodcut, pharmacopeia, etc.) which come to them in complement from incomes for the periods of welding.

With the accentuated effects of the climatic change, these populations are more and more confronted with falls of their mean level of productivity, which impacts negatively on their level of incomes. Consequently, to compensate for the fall of their agricultural incomes and the abuse of the local forest resources, they are increasingly inclined with the expansion of cultivable surfaces with an aim of increasing the agricultural output per hectare. It has as a corollary the excessive firewood cut for the charcoal (domestic consumption and sale on the urban markets), with less afforestation with regard to the local trees. The excessive anthropic pressures on these resources limit their productivities and exacerbate local and community conflicts.

Indeed, in front of these factors impacting the standard of living of these populations, they find as alternative the migration, the rural migration, nonagricultural gold washing and other activities (small trade and seasonal work in the large cities). These various factors thus make it possible to compensate for those which would have positive and significant impacts on deforestation. For this study, except the above-mentioned factors, it is also a question of determining the socio-economic and anthropic effects which impact positively and negatively deforestation. It will make it possible to pose a real not very used econometric diagnosis by the engineering departments which primarily focus on the descriptive analysis of the data that they produce.

Considering these various factors, one would be brought to analyse and interpret the bond of dependence between the deforestation and the variation of the economic (macroeconomic indicator determined by the GDP per capita and the poverty line) and demographic (evolution of the size of the population and manpower of the pupils having the level of the second cycle) factors. And a thorough comprehension of the anthropic actions (pasture of the cattle, consumption of the firewood and charcoal, the breeding, the expansion of surfaces of food crops 
and production of food crops) in bond with deforestation will make it possible to corroborate the immediate and indirect causes as well as the consequences of deforestation.

For this study, we will use a suitable econometric model which will enable us to determine the explanatory variables which have impacts on deforestation. It will enable us to make recommendations as regards public policy for better apprehending the immediate and indirect causes of deforestation generated by the people.

Moreover, deforestation in Mali appears more and more as a phenomenon which mobilizes the government, local populations, the nongovernmental organizations and international organizations to limit these socio-economic impacts on the populations.

\section{Methodology}

\subsection{Medium of study and data acquisition}

From its surface, Mali is the $23^{\mathrm{e}}$ vastest country in the world. It is located between the $10^{\mathrm{e}}$ and $25^{\mathrm{e}}$ degrees of northern latitude and between the $4^{\mathrm{e}}$ degree of east longitude and the $12^{\mathrm{e}}$ degree of western longitude. The climate is at the same time very dry and very heat for the 3/4 of the country, except in the extreme South, being in part of the area of Sikasso. In the Far North, the Sahara, precipitations' ring average is lower than $250 \mathrm{~mm}$ and exceeds $100-150 \mathrm{~mm}$ with difficulty. On the other hand, in the extreme North, the rains are quasi non-existent. The Sahel sheltering the semi-desert central areas receives on average less than $500 \mathrm{~mm}$ of rain per annum. The South is subhumid with average precipitations lower than $750 \mathrm{~mm}$ per annum. The lowest value of the average annual temperature is of $28^{\circ} \mathrm{C}$ and highest is of $32^{\circ} \mathrm{C}^{3}$.

The whole of the data collected for this study is secondary data. They are time series and cover the periods going from 2003 to 2012. The data made up are carried mainly on deforestation and of the macroeconomic and sociodemographic variables. The collected data come from the sources of the National Institute of the Statistics-INSTAT of Mali, the World Bank, the reports/ratios of study and the sites: perspective.usherbrooke.ca and ps://donnees.banquemondiale.org.

\subsection{Specification of the model and processing of data}

Two models of regression will be used to analyse the direct and indirect bonds between deforestation and the variables from which it would result. The estimate of the first regression will relate to ordinary least squares (OLS) in order to identify the immediate causes of deforestation. The second stage will be specified with the model logarithmic curve in order to explain the relative variations (in \%) of deforestation following the variations (in \%) of the macroeconomic and sociodemographic variables. The data processing will be made by the Stata software.

First stage of the specification of the model

$$
\text { Def }=\beta_{0}+\beta_{1} \mathrm{ManLi}+\beta_{2} \mathrm{FWC}+\beta_{3} \mathrm{SFC}+\beta_{4} \mathrm{PFC}+\varepsilon
$$

Def: annual decline of forest cover $\left(\mathrm{km}^{2}\right)$.

ManLi: manpower of the livestock (number).

FWC: firewood overall consumption (tons).

\footnotetext{
${ }^{3}$ https://fr.m.wikipedia.org consulted the $14 / 02 / 2019$ at 15.32
} 
SFC: surface of food crops (hectare).

PFC: production of food crops (tons).

$\beta_{1,2,3,4}$ : coefficients.

$\beta_{0}$ : constant.

$\varepsilon$ : term of the error.

Second specification of the model

$$
\text { LnDef }=\beta_{0}+\beta_{1} \text { LnPop }+\beta_{2} \text { LnTEEFII }+\beta_{3} \text { LnGDPC }+\mathrm{U}
$$

Ln: neperian logarithm.

Def: annual decline of forest cover $\left(\mathrm{km}^{2}\right)$.

Population: population of the inhabitants (number).

ETPF II: total of the population having the level from Fundamental II (number).

GDPC: gross domestic product per capita (\$).

$\beta_{1,2,3,4}$ : coefficients.

U: constant.

\section{Econometric estimate, results and discussions}

\subsection{Anthropic actions}

The anthropic actions having impacts on deforestation are caused directly by human activities. Among those we have the pressures exerted by the animals on spaces of grazing ground, the woodcut for multiple uses, the extension of cultivable surfaces for cereals and the production of food crops.

In the model of estimate between the anthropic deforestation and actions, it arises that $\mathrm{R}^{2}=0.8789$, which would explain why $87.89 \%$ of the causes of deforestation are due to the explanatory variables of the model, that is, to the human activities. There is adequacy of the model. It arises that the model is overall significant since the value of Prob(F-statistic) is associated to be lower than 5\%. As a whole, variables ManLi, FWC, SFC and PFC have overall a significant impact on the degradation of forest cover. More specifically, only variables ManLi and FWC have a significant impact on the degradation of forest cover (Table 1).

\subsubsection{The pasture}

The value of the coefficient associated with the variable ManLi is negative and significant to $10 \%$. It indicates an opposite relation between the deforestation and the number of the cattle. It is obvious that the increase in the livestock in rural medium of Mali is one of the causes of the reduction of the level of deforestation. Therefore, the increase in livestock impacts negatively the degradation of vegetable cover (graminaceous grasses, fodder and Graminaceae). It allows a rapid restoration of the forest cover made up of woody species. It appears thus that it is the overgrazing which leads to the abuse of the forest resources.

Space pastorales in rural medium of Mali are sufficiently available, and their rational use allows the reduction of the deforestation which induces an increase in forest cover. The breeding thus appears as an essential factor which impacts deforestation negatively. The elasticity of reduction of the degradation of the forest surface being of $6.66 \%$, which implies that the increase of $1 \%$ of animals constitutes the livestock, would reduce the deforestation by $6.66 \%$. It implies that the increase of the livestock through the production of the organic manure enriching the ground improves the agricultural productivity and contributes to the increase of the forest cover of $6.66 \%$. 
Economic Impacts of the Anthropic Effects of the Deforestation on the Rural Populations of Mali DOI: http://dx.doi.org/10.5772/intechopen.87252

\begin{tabular}{lcccr}
\hline Variable & Coefficient & Std. error & t-Statistic & Elasticity \\
\hline C & -17802.08 & 6641.227 & -2.680541 & -277.5293 \\
\hline ManLi & -0.000171 & $6.67 \mathrm{E}-05$ & $-2.558930^{*}$ & -6.661940 \\
\hline FWC & 0.004886 & 0.001659 & $2.945847^{* *}$ & 26.29780 \\
\hline SFC & 0.000105 & 0.000185 & $0.566668^{\mathrm{NS}}$ & 0.255692 \\
\hline PFC & -0.000200 & 0.000217 & $-0.922393^{\mathrm{NS}}$ & -0.676106 \\
\hline R-squared & 0.878947 & & \\
\hline Adjusted R-squared & 0.757894 & & \\
\hline Akaike information criterion & 12.71521 & & \\
\hline Schwarz criterion & 12.82478 & & \\
\hline Hannan-Quinn criter. & 12.47876 & & \\
\hline Durbin-Watson stat & 1.879230 & & \\
\hline Prob(F-statistic) & 0.040414 & & \\
\hline Note: ${ }^{* * *}=$ significant 1\%, ${ }^{* *}=$ significant $5 \%,^{*}=$ significant 10\%, NS = not significant. & \\
\hline
\end{tabular}

Table 1.

Anthropic factors determining deforestation.

The large stockbreeders in rural medium being mainly wandering have a good perception of the traditional management of the natural resources. Most of the share of the livestock occupies spaces of grazing ground according to the variation of the seasons and the availability of fodder. It allows thus fast reconstitution of the vegetation after one period when space pastorales are almost unexploited [2].

\subsubsection{The firewood consumption}

The firewood overall consumption is positively correlated with deforestation. Its coefficient is positive and has a threshold of significativity of 5\%. The firewood consumption by the households is thus one of the principal reasons of the deforestation in rural medium of Mali. That is means that as the consumption of the firewood increases, the decline of forest cover also increases. Thus, the elasticity of the variation of the firewood consumption with regard to the increase in deforestation is $26.30 \%$. Any increase in the firewood consumption of $1 \%$ implies an increase of $26.30 \%$ of the forest degradation.

Indeed, that who corroborate with the idea according to which more the share of the countries of Africa Subsaharian use like principal energy wood. Nigeria does not make exception since the increase in its forest decline results mainly from the wood consumption due to a demand in increasing. This request results from an increasing population of need for sources of energy and building machineries for the houses [4]. In the Sahel and in Africa, the local wood energy consumption would be one of the principal causes of deforestation. With that the fall of the pluviometry characterized by dryness is added to the Sahel which decimates the population of the woody species [5].

In Mali, the proportion of the households which use the firewood or coal passed from $77 \%$ in 2001 to $77.6 \%$ in $2016^{4}$. Also in rural medium as in urban environment of Mali, the use of wood thus constitutes the first source of energy. It is thus used as charcoal for cooking and in the manufacture of boxes and is

\footnotetext{
${ }^{4}$ Data resulting from the investigation of the periods active from April 2017 to March 2018, into

Consumption, Poverty and Welfare of Households of the National Institute of Statistics-INSTAT of Mali.
} 
used to cover the roofs of the concessions. In rural and urban medium, there are many electric posts which are made containing wood. The mortars, the rammers, the hoe, cart, etc. are also designed containing wood. That who confers on wood multiples uses.

\subsubsection{The expansion of surfaces of the food crops}

The coefficient determining the expansion of surfaces of food crops is positive and nonsignificant. An increase of $1 \%$ of cultivable surfaces increases the deforestation of $0.25 \%$. It shows that compared to the other above-mentioned factors, the increase in surfaces of food crops impacts little on the deforestation in rural medium of Mali. The country has sufficient bottom funds, of arranged plains and irrigated perimeters where cereal culture is made. That is the case of the Office zone of Niger which counts with him only an agricultural potential of $2,458,506$ ha including $1,907,406$ ha suitable, $1,445,000$ ha irrigable by gravity and a surface of 131,000 ha exploited ${ }^{5}$. These great installations were conceived since the colonial period. It would limit the impact of the expansion of surfaces of food crops on deforestation. Another factor not less significant is that the farmers who extend their cultivable surfaces take more and more conscience of the risk which weighs on the environmental pollution through deforestation. The trees resulting from local species are thus protected by the farmers and certain regulations in force.

Many studies highlight the positive impact and the degree of significativity which the increase in cultivable surfaces has on the degradation of forest cover, but the bond established in the Malian context proves the opposite. The models of development of agriculture in Africa, Asia and Latin America, based on rice growing, tend to increase considerably agricultural surfaces which would be the principal cause of the deforestation of the tropical forests [6].

\subsubsection{Production of food crops}

The coefficient determining the production of food crops impacting deforestation in Mali is negative and nonsignificant. If the agricultural productivity increases by $1 \%$, deforestation decreases by $0.68 \%$. In other words the level of reduction of deforestation decreases less proportionally than the increase in the agricultural productivity. The most of the agricultural productivity, the more high will be the reduction of deforestation but in a less significant way. A high agricultural output ensures a sufficient income and puts the farmer safe from economic and food needs. These factors return to him less vulnerable.

A successful agriculture is that which gives better results in terms of increase in the agricultural productivity through an intensive culture and the safeguarding of the environmental quality leading to less of deforestation [7].

\subsection{Economic and socio-demographic determinants of the deforestation}

Economic and socio-demographic factors which determine deforestation are estimated by the function neperian logarithm. The model is well specified since $\mathrm{R}^{2}=0.9712$, which indicates that $97.12 \%$ of the variations of the variable dependent on the model are explained by the explanatory variables. Given that the value of Prob(F-statistic) is lower than 5\%, the model is overall significant. The model is thus adequate (Table 2 ).

\footnotetext{
${ }^{5}$ Consulted the 18/02/2019 on https://www.maliweb.net.
} 
Economic Impacts of the Anthropic Effects of the Deforestation on the Rural Populations of Mali DOI: http://dx.doi.org/10.5772/intechopen.87252

\begin{tabular}{lccc}
\hline Variable & Coefficient & Std. error & t-Statistic \\
\hline C & 124.4731 & 20.12615 & 6.184648 \\
\hline LETPF II & -0.161668 & 0.223772 & $-0.722465^{\mathrm{NS}}$ \\
\hline LPOP & -6.083446 & 0.892867 & $-6.813383^{* *}$ \\
\hline LGDPC & -2.036184 & 2.714014 & $-0.750248^{\mathrm{NS}}$ \\
\hline R-squared & 0.971229 & & \\
\hline Adjusted R-squared & 0.928074 & & \\
\hline Durbin-Watson stat & 2.951644 & & \\
\hline Prob(F-statistic) & 0.042844 & & \\
\hline Note: ${ }^{* *}=$ significant $5 \%$, NS $=$ not significant. & & & \\
\hline
\end{tabular}

Table 2.

Anthropic factors determining deforestation.

\subsubsection{The level of education}

The coefficient associated with education is negative and nonsignificant. An increase of $1 \%$ of the level of education reduces the deforestation of a rate of $0.16 \%$ in rural medium of Mali. It indicates that the rate of deforestation decreases with the increase in the level of education. This reduction of the level of deforestation in connection with that of education, secondary level, is done in a less significant way since the impact is not considerable. Nevertheless, the level of education is a very significant factor making it possible to understand the stakes related to quality and the environmental pollution. With regard to the secondary school between 2009 and 2014, the net rate of enrolment was $36 \%$ for men and $23 \%$ for women ${ }^{6}$. So that the impact of the reduction ratio of deforestation is more considerable in rural medium of Mali, it is necessary that the policies adopt a programme of elimination of illiteracy on a large scale. This policy must promote the access for the attack of a minimal level at the secondary school for the adults.

\subsubsection{The demographic factor}

The negative and significant sign of the demographic growth to the threshold of $5 \%$ indicates that it negatively impacts the degradation of forest cover in medium of rural of Mali. In other words, the demographic growth affects the regeneration of forest cover positively. Elasticity relating to the variation of the population is $-6.08 \%$. Any increase in the population of $1 \%$ reduced the degradation of the forest cover of $6.08 \%$. The rural migration and seasonal worker are the principal reasons of this fall of the destruction of forest cover. With the place that their principal source of income comes only from the wood sale, the rural ones prefer the rural migration towards the urban centres for other remunerative employment. Agriculture principal source of income for the rural young people is forsaken with the profit of gold washing. The migration of the rural young people is also one of the principal causes of fall of the anthropic pressure on the forests. With that the recurrence of the community conflicts between farmers and stockbreeders is added and even sometimes between sedentary farmers who are at the origin of internal displacements. From these factors, cultivable surfaces which shelter many forest resources are thus saved by the extensive agriculture and the extensive pasture.

\footnotetext{
${ }^{6}$ Base data of the UNICEF, consulted the 19/02/2019 at 12:01 PM on < https://www.unicef.org > infobycountry
} 
That who is explained by this effect regulator the pressure anthropic. The demographic factor, i.e. the number of inhabitants which accounts a country, is quoted in many scientific works as a factor which is positively correlated with deforestation. This assertion is the subject also of controversy on this subject.

Moreover, the rate of deforestation can increase because of the increase in population which induces significant anthropic needs. The growth of the population created enormous food needs, which impacts on the demand for arable lands which results in the deterioration of forest cover. The growth of a population is also accompanied by a keen demand out of firewood, structural timber and woody forest products. Of another share, the demographic growth can induce technological progress and institutional changes which will contribute to reduce devastating effects of the forest [8].

\subsubsection{The gross domestic product per capita}

Gross domestic product, that is, the income per capita, is negatively correlated with deforestation. But its coefficient is nonsignificant. For any increase of $1 \%$ of the annual income per capita, deforestation decreases by $2.03 \%$. The improvement of the living conditions of populations, through the increase in their incomes, is an essential factor of reduction of deforestation. The higher the income per capita, the more the degradation of forest cover is reduced, and the less is the rate of the environmental pollution in bond with deforestation.

Indeed, the gross domestic product per capita significantly affects various manners of restoration of forest cover. That is the Asian case of four countries of which the Philippines, Indonesia and Malaysia, and Brazil. By reducing poverty, the increase in gross domestic product per capita positively affects forest cover and the expansion of the roads. On the other hand, the increase in gross domestic product has a negative influence on forest cover through the expansion of cultivable surfaces. It is the case of the Asian countries where the principal causes of reduction of the forest surface are explained by the economic growth with an elasticity of $-0.76 \%$ and $-0.06 \%$ in Brazil [9].

\section{Conclusion}

With the instar of the other continents, Sub-Saharan Africa is confronted with enormous challenges and more particularly those concerning the climatic changes. The Mali Sahelian country faces the same stakes related to the climatic changes and the deterioration of the quality the environment. Because of the growth of its population, the request for the forest resources is large. This request results from an enormous requirement in consumption for wood which constitutes the first of energy for the households. The consequence is the loss of a woody potential due to anthropic actions which emanate several factors. The level of development of the country with its average income per capita offers few alternatives for the rural and urban populations to use other more accessible sources of energy.

Indeed, the results obtained show that the increase in population is accompanied by a significant level of reduction of deforestation. The principal reason of the negative effect that the increase in population has on deforestation is the rural migration and the migration. These two factors reduce the effects of the anthropic pressure on deforestation. While migrating and urbanizing the rural populations, find other alternatives to compensate for their sources of income primarily coming from agriculture and the wood sale. It has as a corollary the reduction in the exploitation of the cultivable surfaces and that of the woodcut for domestic uses. 
Indeed, the rural populations by changing life mode adopt other more suitable means of power consumption induced by institutional measurements. It causes the decrease in the demand out of firewood, structural timber and woody and nonwoody forest products. Political, lawful and legislative measurements quite suitable would encourage the rural and urban populations with a moderation in wood consumption.

However, the level of education affects deforestation negatively but in a nonsignificant way. Thus, significant challenges are to be raised in order to increase the rate of elimination of illiteracy in rural medium. Education is thus a powerful means making it possible for the populations to understand the consequences related to the environmental pollution.

The abundance of the cultivable ground and pastoral space availability makes Mali a country with potential strong agro-pastoral. The majority of nomads being large stockbreeders have ways of life very related to nature and the forest. It enables them to put methods and traditional techniques into practice favorable to the nature conservation, thus inducing a rational use of spaces of grazing ground. Therefore, the breeding appears as determining which impacts deforestation negatively. It wants to say that the mode of breeding as practised by the rural stockbreeders supports the restoration of forest cover.

However, the principal cause of deforestation in rural medium of Mali results from the wood consumption. It constitutes the principal source of energy for the rural and urban populations since the level of their average incomes offers few alternatives for the use of other sources of energy (solar, wind and thermal). Wood is also used for multiple uses, the coating of the roofs of house, construction of boxes and manufacture of farm equipments.

Deforestation in rural area of Mali is the result of several institutional and regulatory factors. The inadequacy of these measures makes their implementation difficult. Mali is weakened in a sociopolitical context marked by insecurity due to the presence of several armed groups in a large part of the country. The state is therefore unable to implement an effective strategy to combat deforestation and, moreover, mitigate the devastating effects of forest cover. Suddenly, rural populations become direct actors in the preservation of their forest resources. If the state wants to put in place long-term effective environmental policy measures, the involvement of rural people would be fundamental.

However, the implementation of certain institutional, that is, legislative and regulatory, measures is not followed by a policy of large-scale application. Stakeholders involved in the use of forest resources must be made aware of the strict application of these laws and regulations in order to minimize the excessive cutting of wood. As more than half of Mali's rural population is not literate, it is necessary to convey the message of the content of the laws governing forest resource management policy in the local language. Several communication channels, such as rural radio broadcasting and sensitization sessions on the importance of preserving forest resources with local people, should be explored as alternatives. As a result, environmental issues may be better understood by an uninformed population regarding the consequences of climate change. This will have a positive impact on the behaviour of rural populations in terms of wood consumption and reduced destruction of forest cover.

In addition, other more appropriate policy measures need to be taken to significantly reduce the use of wood for domestic purposes. These measures concern the limitation of exploitation rates of forest resources so that the rate of use or exploitation does not exceed the rate of recovery of forest resources. To limit the impact of deforestation, the public authorities, in particular the Malian State, must grant property rights to individuals in certain protected forest areas. The granting of marketable permits and negotiable access rights to forest resources to loggers would be an alternative to significantly reduce deforestation. 
In fact, to reduce the consumption of wood as a source of energy, the State must promote the use of substitutable energy. This is to convince rural households of the utility of improved stoves and solar cookers for more economic and environmental purposes. This would allow rural households and loggers to devote a good deal of their time to other more profitable income-generating activities.

\section{Author details}

Amadou K. dit Amobo Waïgalo ${ }^{1,2}$

1 Department of Agribusiness at the University Institute of Professional Training (Institut Universitaire de Formation Professionnelle IUFP), University of Ségou, Mali

2 ISFRA, Bamako, Mali

*Address all correspondence to: amobowaigalo@yahoo.fr

\section{IntechOpen}

(C) 2020 The Author(s). Licensee IntechOpen. This chapter is distributed under the terms of the Creative Commons Attribution License (http://creativecommons.org/licenses/ by/3.0), which permits unrestricted use, distribution, and reproduction in any medium, provided the original work is properly cited. (cc) BY 


\section{References}

[1] INSTAT. Report on the Modular and Permanent Survey of HouseholdsConsumption, Poverty and Welfare of Households. Bamako: 2018

[2] Enriquez-Sarano F. Les habitants du Sahel face à la deforestation-Activités quotidiennes et lutte des femmes. Courrier de l'environnement de l'INRA. 2000. pp. 91-96

[3] FAO. Evaluation des ressources forestières mondiales. Rome: Rapport National Mali; 2014

[4] Ibrahim A, Iheanacho A, Bila Y. Econometric analysis of causes and impact of deforestation one agriculture in Nigeria. Newspaper of Agricultural Economics, Environment and Social Sciences. 2015;1(1):143-150

[5] Benjaminsen TA. Bois-énergie, déboisement et sécheresse au Sahel: le cas du Gourma malien. Centre pour le Développement et l'Environnement. 1996;7(3):179-185

[6] Barbier EB. The economics of tropical deforestation and land uses: Special year introduction to the exit. Land Economics. 2001;77(2):155-171

[7] Angelsen A. Policies for reduced deforestation and to their agricultural impact one production. In: PNAS.

R. S. DeFries; 2009

[8] Angelsen A, Kaimowitz D.

Rethinking the causes of deforestation: Lessons from economic models. The World Bank Research Observer. 1999;14(1):73-98. Visited on https:// www.jstor.org/stable/3986539 the 20-01-2019 to 03:46 UTC

[9] López R, Galinato GI. Trade policies, economic growth, and the direct causes of deforestation. Land Economics.

2005;81(2):145-169 


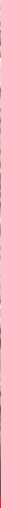

\section{Edited by Mohd Nazip Suratman, Zulkiflee Abd Latif, Gabriel De Oliveira, Nathaniel Brunsell, Yosio Shimabukuro and Carlos Antonio Costa Dos Santos}

The growth in the human population has forced mankind to convert forested land into other land uses such as agricultural land, residential, urban, road construction and mining activities. The degradation of forest due to anthropogenic activities is significantly reducing forests in the world. These practices result in significant impacts on the forest structure, species composition and ecology, which will consequently reduce forest productivity and ecosystem functions. Due to deforestation, half of the earth's vegetation surface has reduced to one-third, resulting in large degraded areas. The significant reduction of the forest areas requires appropriate planning

for sustainable management of the forests. This book reviews the extent and consequences of deforestation around the world. It highlights case studies of the causes of deforestation in Malaysia, Korea, India, Bangladesh, Columbia, Brazil and Mali. It is hoped that the book will provide insights on the importance of effective forest planning and management for the sustainable development of forest resources.

Published in London, UK

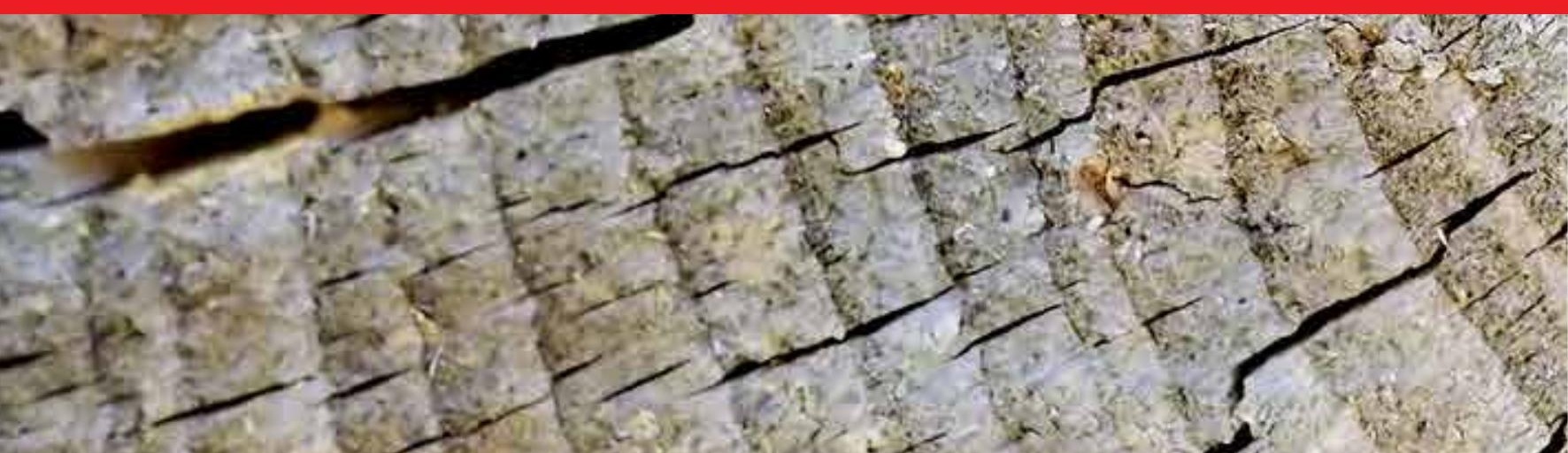

